Daniela Bulgarelli (Ed.)

Perspectives and research on play for children with disabilities

Collected papers 

Daniela Bulgarelli (Ed.)

Perspectives and research on play for children with disabilities

Collected papers

Managing Editor: Daniela Bulgarelli

DE GRUYTER \$ sciendo 
ISBN 978-83-956696-2-0

e-ISBN (PDF) 978-83-956696-1-3

e-ISBN (EPUB) 978-3-11-069569-4

\section{(c) BY-NC-ND}

This work is licensed under the Creative Commons Attribution-NonCommercial-NoDerivs 3.0 License. For details go to http://creativecommons.org/licenses/by-nc-nd/3.0/.

\section{Library of Congress Cataloging-in-Publication Data}

A CIP catalog record for this book has been applied for at the Library of Congress.

(C) 2020 Daniela Bulgarelli

Published by De Gruyter Poland Ltd, Warsaw/Berlin

Part of Walter de Gruyter GmbH, Berlin/Boston

The book is published with open access at www.degruyter.com.

Managing Editor: Daniela Bulgarelli

www.degruyter.com

www.sciendo.com

Cover illustration: Inclusive play at school (Camilla, 10 years, Italy). 


\section{Contents}

Daniela Bulgarelli and Serenella Besio

Preface - VII

Fostering play for the sake of play for children with disabilities through LUDI — VIII References - XI

Daniela Bulgarelli

Introduction - XII

Acknowledgements - XIII

References - XIV

Carol Barron, Helen Lynch, Annemie Desoete, Marieke Coussens and Karen De Maesschalck

1 Theoretical models for enabling play from a child-centred perspective - 1

1.1 Understanding Children's Worlds: Children's Voice and Rights-based Approach to Participation - 1

1.2 Research and children - 3

1.3 Theoretical models for enabling researchers: child-centred approaches for studying play - $\mathbf{5}$

$1.4 \quad$ Motivational enablers of play -8

1.5 Some useful resources -9

1.6 Acknowledgements -10

$1.7 \quad$ References -10

Christina Schulze, Hólmdís F. Methúsalemsdóttir, Helen Lynch, Nan Cannon Jones, Ursula Winklhofer and Carol Barron

2 Empowering and enabling play in differing settings -13

$2.1 \quad$ Home as a play setting - 13

2.1.1 Play in the home setting and why it is important -13

2.1.2 Known barriers to play in the home setting - 14

2.1.3 Enabling play in the home setting - 15

2.1.4 Conclusion - 17

$2.2 \quad$ Empowering play in the early years - 18

2.2.1 Conclusion -20

2.3 Enabling play in the school context -20

2.3.1 Play in the school setting and why it is important -21

2.3.2 Known barriers for play in the school setting - 21

2.3.3 Enabling play in the school setting - 22 
2.3.3.1 Organisational framework conditions at the school as an institution -23

2.3.3.2 Design of an inclusive play environment -23

2.3.3.3 Supportive attitudes and roles of adults -24

2.3.3.4 Participation of the children -24

2.3.4 Conclusion - 25

2.4 Play in Health Care Settings - 25

2.4.1 Enabling play in Health care settings - 26

2.4.1.1 Ordinary Play -26

2.4.1.2 Therapeutic Play — 27

2.4.1.3 Preparation -27

2.4.1.4 Distraction -27

2.4.1.5 Post-Procedural Play/Support -27

2.4.2 Conclusion -28

$2.5 \quad$ Recommended websites -29

2.6 Acknowledgements -29

$2.7 \quad$ References -29

Nicole Bianquin and Fabio Sacchi

3 Studies On Play For Children With Disabilities: Exploring The Interdisciplinary Approach — 33

3.1 Introduction - 33

3.2 Play: an interdisciplinary research area -34

3.3 Play and disabilities construct within the LUDI theoretical framework 35

3.4 Scientific subjects classification in the Scimago system - 37

$3.5 \quad$ Method -38

3.6 Results - 39

3.7 Discussion $-\mathbf{5 2}$

3.8 References -54

Mabel Giraldo

4 Children with and without disabilities in disasters. A narrative overview of play-based interventions into the humanitarian programmes and researches. - 61

$4.1 \quad$ Introduction -61

4.2 Emergencies and children (with and without disabilities): a neverending story - 63

4.2.1 Pedagogy of emergency: a framework for today's crisis situations - 64

4.2.2 Children and emergencies: geodemographic data -65

4.2.3 Children with disabilities in disasters: twice as vulnerable -66

4.3 Educating beyond the emergencies: the possible role of play - 69

4.3.1 The importance of play for all the children -69 
4.3.2 Play-based interventions in emergencies - 71

4.3.3 What kind of play is promoted in crisis situations? - 73

$4.4 \quad$ Conclusion -77

$4.5 \quad$ References -78

Rianne Jansens and Andrea Bonarini

5 Usability and accessibility of toys and technologies for play for children with disabilities: Scoping review of guidelines and tools. - 83

$5.1 \quad$ Introduction -83

$5.2 \quad$ Method -85

5.2.1 Data collection - 85

5.2.2 Reviewing process $-\mathbf{8 8}$

$5.3 \quad$ Results -89

5.4 Conclusion -99

5.5 Discussion - 99

5.6 Acknowledgements $-\mathbf{1 0 0}$

5.7 References - 101

Appendix I 103

Appendix II 104

Rianne Jansens and Andrea Bonarini

6 Guidelines for parents, professionals, designers, makers and researchers on toys and technologies for play for children with disabilities: How to take usability and accessibility aspects into consideration? - 106

$6.1 \quad$ Introduction -106

$6.2 \quad$ Method -110

6.3 Designing guidelines on usability and accessibility of toys and technologies for play for children with disabilities for different stakeholders — 110

6.3.1 Objectives of guidelines on usability and accessibility of toys and technologies — 110

6.3.2 Features of guidelines on usability and accessibility of toys and technologies — 112

6.3.3 Structure of the newly developed LUDI guidelines - 114

6.3.4 Evaluation of the first version of the guidelines on usability and accessibility of toys and technologies for play for children with disabilities — 115

6.4 Guidelines on usability and accessibility of toys and technology for play for children with disabilities for different stakeholders; parents, professionals, designer, makers and researchers — 116

6.5 Discussion -143 

6.6 Conclusion - 143
6.7 Acknowledgements - 144
6.8 References - 145

Mira Tzvetkova-Arsova, Anna Trosheva-Asenova

7 Parents' perspectives on the play of children with sensory disabilities: a comparative study -146

$7.1 \quad$ Introduction - 146

7.2 Method 149

7.2.1 Sample -149

7.2.2 Procedure -150

7.3 Results and discussion -150

7.3.1 Comparison between visually impaired and hearing impaired children - 162

7.4 Conclusion -163

$7.5 \quad$ References -164

Appendix $1-165$

Daniela Bulgarelli

8 Inclusive Play and Disability in Early Childhood Education and Care Services. The Experiences of Italian Practitioners — 167

8.1 Italian inclusive child care services: education for all -167

8.2 Organizational aspects of ECEC services in Italy - 169

8.2.1 The role of play in Italian ECEC services — 170

8.2.2 Ongoing training for the ECEC service staff -172

8.3 Play and disabilities in Italian early child care services: an explorative study -173

8.3.1 Participants - 173

8.3.2 The Questionnaire "The Child with Disability in ECEC Service" — 174

8.3.3 Data analyses - 175

8.4 Results and discussion -176

8.4.1 Strategies to support play in structured and spontaneous situations - 176

8.4.2 Toys: barriers or facilitators? - 180

8.4.3 Training on disabilities and toys - 181

$8.5 \quad$ Conclusion - 182

8.6 References -183

9 Contributors -185 


\section{Daniela Bulgarelli and Serenella Besio Preface}

This book is one of the outcomes of the work conducted by several scholars and professionals belonging to the COST Action TD1309 "LUDI-Play for Children with Disabilities"1. LUDI was established in 2014 and financed until 2018, thanks to COSTEuropean Cooperation in Science and Technology, an intergovernmental organisation that supports research and innovation networks. LUDI was characterised by the multidisciplinary contribution of more than 100 members living in 32 countries: they were researchers and practitioners in the fields of psycho-pedagogical sciences, health and rehabilitation sciences, humanities, assistive technologies and robotics, as well as representatives from end-users' organizations aimed at granting the right to play for every child, and specifically for children with disabilities.

In fact, LUDI started from the awareness that children with disabilities still need support to fully experience play as a crucial activity. At an international level, play has been recognised as a right for everyone: the Convention on the Rights of the Child declares that: "1. States Parties recognize the right of the child to rest and leisure, to engage in play and recreational activities appropriate to the age of the child and to participate freely in cultural life and the arts. 2. States Parties shall respect and promote the right of the child to participate fully in cultural and artistic life and shall encourage the provision of appropriate and equal opportunities for cultural, artistic, recreational and leisure activity" (Article 31; United Nations, 1989). The Convention on the Rights of Persons with Disabilities reinforced this concept even more, by stating that: "States Parties shall take appropriate measures [...] to ensure that children with disabilities have equal access with other children to participation in play, recreation and leisure and sporting activities, including those activities in the school system" (Article 30, clause 5d; United Nations, 2006). In 2013, pressure groups' activities in favour of the specific needs of children with disabilities lead to the release of the 'General Comment' on the Article 31 of the UNCRC by the United Nations Committee on the Rights of the Child. The comment highlighted the need to enhance the overall understanding of the importance of such article and to strengthen its application: children with disabilities are among those who require particular attention, given their difficulties in enjoying play on an equal basis with their peers.

1 Serenella Besio, Full Professor in Special Education at the Università degli Studi di Bergamo (I), has been the Chair of the COST Action TD1309 “LUDI-Play for Children with Disabilities”. Daniela Bulgarelli, Assistant Professor in Developmental Psychology at the Università degli Studi di Torino (I), has been Grant Holder Representative and Communication Manager of the Action. More information about LUDI are available at https://www.ludi-network.eu/ and https://www.cost.eu/actions/ TD1309/\#tabs|Name:overview 
Due to the peculiar characteristics of their functioning, children with disabilities might not be able to play: they might not want to play or not know how to do it; they might not recognize a situation as play or an object as a toy; they might isolate themselves from others or be scared by a ludic situation; they might feel uncomfortable in unusual conditions and prefer to repeat the same play in the same way, in the same place, over and over. This is likely to happen especially if the environment in which they play is not accessible for them: the right tools and instruments for play are not available, knowledge about inclusive contexts is not adequate, related practices are not effective. Barriers to play for children with disabilities may come both from the built environment (i.e., places and areas where play may take place are not accessible to their needs) and from people's attitudes and knowledge, that are not based on experience and that are not in-depth informed about play, in general, and about play for children with disabilities, in particular. Specifically, play can be considered a waste of time when children with disabilities' lives are dominated by medical and rehabilitative practices. In such situations, those children are more likely to lack the possibility to play for the sake of play (Besio, 2017), i.e. to participate in intrinsically motivated activities, during which the child can make his/her own decisions about what to do, how to do it and when. Given that the possibility to freely explore the dimension of play for the sake of play is crucial for the child's relational, cognitive, affective and social development, LUDI wants to spread the message that children with disabilities need to be supported in their ludic experiences (Besio et al., 2017).

\section{Fostering play for the sake of play for children with disabilities through LUDI}

LUDI aimed at fostering play for the sake of play for children with disabilities, addressing three main objectives: a) collecting and systematizing the existing competence and skills in this field; b) developing new knowledge related to settings, tools and methodologies associated with the play of children with disabilities; c) disseminating the best practices emerging from the joint effort of researchers, practitioners and users. Operationally, LUDI was organized into four Working Groups, each of them focused on specific topics related to the core theme of the Action: WG1 "Children's play in relation to the types of disabilities"; WG2 "Tools and technologies for the play of children with disabilities"; WG3 "Contexts for play of children with disabilities"; WG4 "Methods, tools and frameworks for the development of the child with disabilities' play”. The Working Groups were composed by a leader, a vice-leader and several other members of the Network, who took care of drafting deliverables and documents, each of them related to the LUDI's main goals.

With respect to the first aim, i.e. collecting and systematizing the existing competence and skills, LUDI invited both parents of children with disabilities and representatives from some of the most important associations of persons with 
disabilities in Europe to be part of the Advisory Board. Secondly, the Action brought on a scientific work that ended in the publication of four books. "Play development in children with disabilities" aimed to contribute to the creation of a common language on the topic, sharing the definition of types of play, reviewing the literature devoted to play and the use of toys in children with different disabilities (intellectual disabilities, hearing impairment, visual impairment, communication disorders, physical impairment, autism spectrum disorders and multiple disabilities) and reporting the contribution of occupational therapy, special education and early intervention on the ludic activities of children with impairments (Besio, Bulgarelli, \& StanchevaPopkostadinova, 2017). The book “Evaluation of children's play: Tools and methods" presented a review of instruments and procedures that were internationally available to assess play (Besio, Bulgarelli, \& Stancheva-Popkostadinova, 2018). The book "Barriers to Play and Recreation for Children and Young People with Disabilities: Exploring Environmental Factors" was meant to report about the literature dealing with barriers to play in everyday contexts (Barron et al., 2016). Finally, "Users' Needs Report on Play for Children with Disabilities: Parents' and children's views” was a report on the view of children with disabilities, their families and representatives of associations in the field about the play needs (Allodi Westling \& Zappaterra, 2019). Moreover, the special issue "Play and Children with Disabilities. Interdisciplinary Perspectives" was published in the journal “Today's Children Tomorrow's Parents” in 2018, reporting 11 studies conducted by members of the LUDI Network.

The second LUDI aim was developing new knowledge related to settings, tools and methodologies associated with the play of children with disabilities. To pursue such goal, the network supported 30 Short-Term Scientific Missions of LUDI members who had the possibility to run some research hosted in institutions belonging to the network. Also, LUDI financed the two Training Schools "Play and Toys for All" that took place in 2017 in Herleen (NL) and in 2018 in Bergamo (I). About 100 trainees coming from all over the world worked together with a group of trainers chasing two goals: the first was to deepen the LUDI theoretical approach to the play of children with disabilities and the second was to develop customized solutions (using both low and high technology) to a challenge in play of 12 different children with disabilities, who participated in the Schools together with their families. It is worth noting that those Schools enabled to establish a training model of the LUDI approach towards play (Besio, Bulgarelli, Iacono, Jansens, Mizzi \& Perino, 2018). More recently, a new tool to evaluate the usability of toys by children with hearing, visual and upperlimb motor impairment was delivered, the "Toys and game Usability Evaluation Tool” (Costa, Périno, \& Ray-Kaeser, 2018); it is available in English, French and Spanish (Costa et al., 2018), in Italian (Besio, Bianquin, \& Bulgarelli, 2019) and in Portuguese (Encarnação, 2020). Finally, in the current book, Chapter 6 is devoted to new "Guidelines for parents, professionals, designers, makers and researchers on toys and technologies for play for children with disabilities: How to take usability and accessibility aspects into consideration?” by Jansens and Bonarini. 
The third aim was disseminating the best practices emerging from the joint effort of researchers, practitioners and users. Over the project period, LUDI members participated in 20 international conferences to present the Network and its work. Moreover, LUDI created connections with other stakeholders: on one hand, toy companies that produce mainstream ludic materials and objects; on the other, the Chair and other representatives of LUDI had the possibility to access twice the European Parliament, to come into contact with politicians involved in the promotion of the rights of persons with disabilities. To address the third aim, LUDI members also wrote some documents. The Position Statement was delivered in 2017 and was one of means of the Network to interact with European organizations and institutions. It stated that topics related to play and childhood, to the children's needs, especially in case of disability, should be taken into account more deeply in the future at a European level. Finally, the book "Guidelines for supporting children with disabilities' play: Methodologies, tools, and contexts" was specifically meant for parents and professionals wishing for a theoretical-based yet easy-to-read introduction to the theme of play of children with disabilities (Encarnação, Ray-Kaeser, \& Bianquin, 2018). The last chapter of this book was also delivered in 2018 as the LUDI Manifesto: a list of key ideas and statements about play for children with disabilities that the Network would like to underline and to share with those interested in dealing with our issue.

The strengths and contributions of the Network to the field of play of children with disabilities were acknowledged in three different occasions. In 2017, LUDI participated in the International Play Association Triennial World Conference in Calgary and received the "IPA Right to Play Award". In 2018, at the end of the fouryear funding period, LUDI's outcomes, impacts and successes were evaluated by an independent Rapporteur (i.e., dr. Ute Navidi), addressed by COST to judge the quality of the work done. Navidi commented: "The Action has clearly met and exceeded its main objective of raising awareness of the importance of giving children with disabilities the opportunity to play on an equal basis with their peers. This has been achieved by tackling long-standing attitudes and physical barriers that mitigated against such participation, and creating a valuable evidence base for future changes. The international, interdisciplinary collaborative efforts benefited from the active and varied engagement of a range of professional disciplines which supports wider buy-in and appropriate further dissemination activities. The Action's tangible results are inspirational and practical. Impact at the policy and decision making entities at EU level has benefited from a position statement and a manifesto. It is now up to the LUDI members in the Action's extensive networks to contribute to the pursuit of practical implementation in their respective countries." Finally, in 2019, LUDI received the "Premio Inclusione 3.0" [Inclusion 3.0 Award] by the Università di Macerata (Italy) and the SIPeS (Italian Society of Special Education) as it "represents one of the most important networks of researchers and professionals from 32 different European countries. LUDI supports the right to play of children with disabilities, fostering the possibility to experience play for the sake of play”. 


\section{References}

Barron, C., Beckett, A., Coussens, M., Desoete, A., Cannon Jones, N., Lynch, H., Prellwitz, M., \& Fenney Salkeld, D. (2016). Barriers to Play and Recreation for Children and Young People with Disabilities: Exploring Environmental Factors. Warsaw, PL: De Gruyter Open.

Besio, S. (2017). The need for play for the sake of play. In: S. Besio, D. Bulgarelli \& V. StanchevaPopkostadinova (Eds.), Play development in children with disabilities (9-52). Warsaw, PL: De Gruyter Open.

Besio, S., Bianquin, N., \& Bulgarelli, D. (2019). TUET - Toys \& games Usability Evaluation Tool. Manuale \& Questionario. Traduzione italiana. Alicante, E: AlJU.

Besio, S., Bulgarelli, D., lacono, I., Jansens, R., Mizzi, M., \& Perino, O. (2018). Becoming Expert in Playing with Children with Disabilities. The LUDI Training School "Play and Toys for All”. Today's Children Tomorrow's Parents, 47-48, 62-73.

Besio, S., Bulgarelli, D., \& Stancheva-Popkostadinova, V. (2017, Eds). Play development in children with disabilities. Warsaw, PL: De Gruyter Open.

Besio, S., Bulgarelli, D., \& Stancheva-Popkostadinova, V. (2018, Eds.). Evaluation of children's play: Tools and methods. Warsaw, PL: De Gruyter Open.

Costa, M., Périno, O., \& Ray-Kaeser, S. (2018). TUET - Toys and games Usability Evaluation Tool. Manual, Questionnaire and Development Process. Alicante, E: AlJU.

Encarnação, P. (2020). TUET - Toys \& games Usability Evaluation Tool. Manual \& Questionário. Versão portuguesa. Alicante, E: AlJU.

Encarnação, P., Ray-Kaeser, S., \& Bianquin, N. (2018, Eds.). Guidelines for supporting children with disabilities' play: Methodologies, tools, and contexts. Warsaw, PL: De Gruyter Open.

Allodi Westling, M., \& Zappaterra, T. (2019, Eds.). Users' Needs Report on Play for Children with Disabilities: Parents' and children's views. Warsaw, PL: De Gruyter and Sciendo. 


\section{Daniela Bulgarelli Introduction}

This book includes eight chapters reflecting various approaches towards the theme of play for children with disabilities that characterised the work done by the members of the COST Action TD1309 "LUDI-Play for Children with Disabilities".

Chapter "1. Theoretical models for enabling play from a child-centred perspective" by Carol Barron, Helen Lynch, Annemie Desoete, Marieke Coussens and Karen De Maesschalck focuses on Article 31 and Article 12 of the United Nations Convention on the Rights of the Child (1989), to address the theme of the children's right to play and to have their voice given due weigh in any matter which concerns them. The paper also presents a sample of theoretical models which may support practitioners or parents to look at play of children with disabilities.

Chapter "2. Empowering and enabling play in differing settings" by Christina Schulze, Hólmdís F. Methúsalemsdóttir, Helen Lynch, Nan Cannon Jones, Ursula Winklhofer and Carol Barron examines the barriers and the enablers to play in different contexts: the home, the early years setting, the school setting and the healthcare setting.

Chapter "3. Studies on play for children with disabilities: exploring the interdisciplinary approach" by Nicole Bianquin and Fabio Sacchi presents a systematic review to show the interdisciplinary complexity around the topic of play for children with disabilities, that is studied in different fields, from medicine to human-computer interaction, to education and psychology.

Chapter "4. Children with and without disabilities in disasters. A narrative overview of play-based interventions into the humanitarian programmes and researches" by Mabel Giraldo deepens the psycho-pedagogical literature on the use of play in emergency situations (natural, humanitarian, social, political): this contribution is a preliminary overview of the different play-based interventions promoted worldwide in such emergencies.

Chapter "5. Usability and accessibility of toys and technologies for play for children with disabilities: Scoping review of guidelines and tools” by Rianne Jansens and Andrea Bonarini describes a scoping review carried out to investigate: which guidelines and tools about usability and accessibility of toys and technologies for play for children with disabilities exist; what is their possible use by different stakeholders; what are the strengths and the weaknesses of such guidelines and tools. The study selected 10 guidelines on usability or accessibility of toys and technologies; five of them had a specific focus on play.

Chapter "6. Guidelines for parents, professionals, designers, makers and researchers on toys and technologies for play for children with disabilities: How to take usability and accessibility aspects into consideration?” by Rianne Jansens and Andrea Bonarini is based on Chapter 5 and shows guidelines for usability and 
accessibility of toys and technologies for play for children with disabilities, that were developed by the LUDI Working Group 2. The guidelines have a pragmatic aim at supporting reflections and decision-making processes for choosing, adapting, designing or studying a toy or technology.

Chapter "7. Parents' perspectives on the play of children with sensory disabilities: a comparative study" by Mira Tzvetkova-Arsova and Anna Trosheva-Asenova presents a study that involved 20 families of children with sensory disabilities (visual impairments and hearing impairments) to compare their perspectives, understanding and involvement in play, and to establish whether families of different groups of children with sensory disabilities show different attitudes.

Chapter "8. Inclusive Play and Disability in Early Childhood Education and Care Services. The Experiences of Italian Practitioners" by Daniela Bulgarelli reports a study that describes the strategies practitioners used to foster inclusive play and the difficulties they faced in preventing or overthrowing the barriers to participation in play in some Italian nursey schools.

Alongside these multifaceted points of view in play, some theoretical aspects emerged as being their common background. First, coherently with the ICF-CY theoretical perspective, play is mainly seen as an activity children can participate in, thanks to a good interaction between their body functions and structures and the contextual factors (WHO, 2007). Second, as highlighted in the Preface, LUDI promoted the vision of "play for the sake of play" for children with disabilities. This means that adults in their different roles-parents, teachers, educators, rehabilitators, toy designers, researchers-should look at play and should support it as an everyday activity that is important per se, not only as a means to reach some improvements in child's communicative, affective, social, cognitive or motor competencies (Besio, 2017). Third, play is conceptualised as a fundamental right of every child, accordingly both to the Convention on the Rights of the Child (United Nations, 1989) and the Convention on the Rights of Persons with Disabilities (United Nations, 2006). Play for children with disabilities still needs to be supported at different levels: this book aims at contributing to the dissemination of the research in the field, that can mainly impact on adults' awareness about the importance of play for the sake of play as a strong engine of child development.

\section{Acknowledgements}

Special thanks go to the following scholars and professionals who performed a review of the chapters, together with the editor of the book, Daniela Bulgarelli: Prof. Serenella Besio, Università degli Studi di Bergamo (Italy); Dr. Francesca Caprino, INDIRE (National institute of educational documentation innovation and research) (Italy); Dr. Iolanda Iacono, Glitch Factory and QuestIT (Italy); Prof. Agnieszka Landowska, Gdańsk University of Technology (Poland); Prof. Paola Molina, Università degli Studi 
di Torino (Italy); Prof. Ana Muntean, West University of Timişoara (Romania); Prof. Sylvie Ray-Kaeser, University of Applied Sciences and Arts of Lausanne (Switzerland); Prof. Tamara Zappaterra, Università degli Studi di Firenze and Università degli Studi di Ferrara (Italy).

\section{References}

Besio, S. (2017). The need for play for the sake of play. In: S. Besio, D. Bulgarelli \& V. StanchevaPopkostadinova (Eds.), Play development in children with disabilities (9-52). Warsaw, PL: De Gruyter Open

World Health Organization (2009). International Classification of Functioning, Disability and Health-Children and Youth (ICF-CY). Geneva, CH: WHO. 


\title{
1 Theoretical models for enabling play from a child- centred perspective
}

\begin{abstract}
This chapter focuses on the importance of the child's and young person's right to have a voice to ensure their play and recreational needs are identified, addressed and included in research, policy and practice in related to play and recreation. We examine both Article 31 of the UNCRC - the child's right to play and Article 12 - the child's right to have their voice heard and given due weigh in any matter which concerns them. This is followed by a discussion of a sample of theoretical models which may help us as practitioners or parents to look at play and children with disabilities.
\end{abstract}

\subsection{Understanding Children's Worlds: Children's Voice and Rights- based Approach to Participation}

The United Nations Convention on the Rights of the Child (UNCRC) back in 1989 may be regarded as a milestone in how we view children and childhood, in both the development of national and international policies related to children and how the views and active participation of children and young people can be incorporated into these policies which affect them (UN, 1989). Given that all European states have ratified this convention, it is important that we understand its implications and know what is recommended to ensure children's rights are met. In other reviews of play and the rights of the child by our LUDI colleagues, we introduced some key conventions, some key articles within them, and some general comments that give a fuller overview (see Barron et al., 2017, and Lynch \& Moore, 2018 for a more detailed overview). However, for the purposes of this chapter, we are focusing on two articles in particular that are of interest for those of us who want to promote a child-centred, child's participation approach to working with children with disabilities, and enabling play: Article 12 and Article 31.

Article 12 of the UNCRC focuses on the child's right to express their opinion and have it taken into account in any matter or procedure affecting them. For the first time we have an international agreement that states that children have the right to express their views and have them taken into account (Morrow \& Richards, 1996). Article 12 considers children for the first time as rights holders and states that:

States Parties shall assure to the child who is capable of forming his or her own views the right to express those views freely in all matters affecting the child, the views of the child being given due weight in accordance with the age and maturity of the child (UNCRC, 1989). 
This article is frequently considered to be an article about participation, whereby a child has a fundamental right to participate in decision-making. Article 12 is cited repeatedly in differing Government publications over the last two decades as enabling the "voice" of the child to be heard or "giving voice" to the child; e.g. EU Guidelines for the Promotion and Protection of the Rights of the Child (2017), Leave no child behind. The importance of consultation with and participation of young people in issues that affect them such as a play and recreation mirrors the views articulated in the more recent General Comment 17, which was drafted and adopted in 2013 (United Nations, 2013). General Comment 17 on the Convention of the Rights of the Child specifically focuses on play and recreation as identified below.

Children are entitled to exercise choice and autonomy in their play and recreational activities. [...] The Committee underlines the importance of providing opportunities for children to contribute to the development of legislation, policies, strategies and design of services to ensure the implementation of Article 31 rights. This might include their involvement, for example, in consultations on policies related to play and recreation [...] the development of parks and other local facilities, urban planning and design for child friendly communities and environments, feedback on opportunities for play, or recreation (2013; p. 8) [our emphasis].

Yet surprisingly, few adults have included children's perspectives in researching play. What we know about play has come more frequently from an adult perspective, from adults who have observed children and made assumptions about the meaning of the child's actions and moreover, the meaning of their experiences.

One of the first people to collect material about children's play, games, lore and language directly from children themselves, as opposed to adult's recollections of their play as children, was the British folklorists Iona and Peter Opie. As they stated in "The Lore and Language of Schoolchildren" (1959), their collection from the 1950s and 1960s was "made up of what will be the childhood recollections of the older generation after AD 2000" (Opie \& Opie 1959, p. 9). More recently, projects such as National and county wide Play Policies in Ireland and the United Kingdom have been developed, where children are included in planning for their own play and recreational needs, resources and facilities e.g. Barron $(2017,2018)$,

International policies are increasingly constructing children as rights bearing citizens rather than immature beings. However, there is no universal agreement on this view and Jean La Fontaine (1997) argues that whatever the rhetoric, at a legislative level, many in the West still reject the idea of children as persons. The UNCRC also has at its core a universalized view of "the child" based on Western assumptions about children's best interests (Bluebond-Langer \& Korbin, 2007) and a single standard of age which is 18 years and under. This universal definition of children is problematic as it assumes that all children and childhoods are the same globally irrespective of ability, culture, ethnicity and history despite evidence to the contrary in anthropological research with children and childhoods (LeVine, 2007). Nor does the universal definition take into account developmental age as opposed 
to chronological age. The UNCRC attempted to address this by ensuring that the key consideration was that people take into account both the child's age and ability.

\subsection{Research and children}

Article 12 is used to support the shift in conducting research with children as opposed to on children and that the child's voice has a right to be heard rather than the adults. The acknowledgement of children's agency and a move away from children as passive recipients of action has occurred with a parallel move away from relying on adult voices about children's worlds and experiences. There has been a shift in the positioning of children's voices to the forefront of policy and research which concerns children's experiences. Yet, in many cases, younger children are not included in these new opportunities as the challenge of communicating with some children is difficult to overcome. These challenges extend to children with disabilities also: parents and carers are still considered to be the preferred choice of participant due significantly to the prevalence of language and communication difficulties among children with disabilities. So how do we operationalize Article 12 for children with disabilities?

Lundy has proposed a model for supporting a child-centred approach in enabling participation (Lundy, 2007; see Figure 1.1).
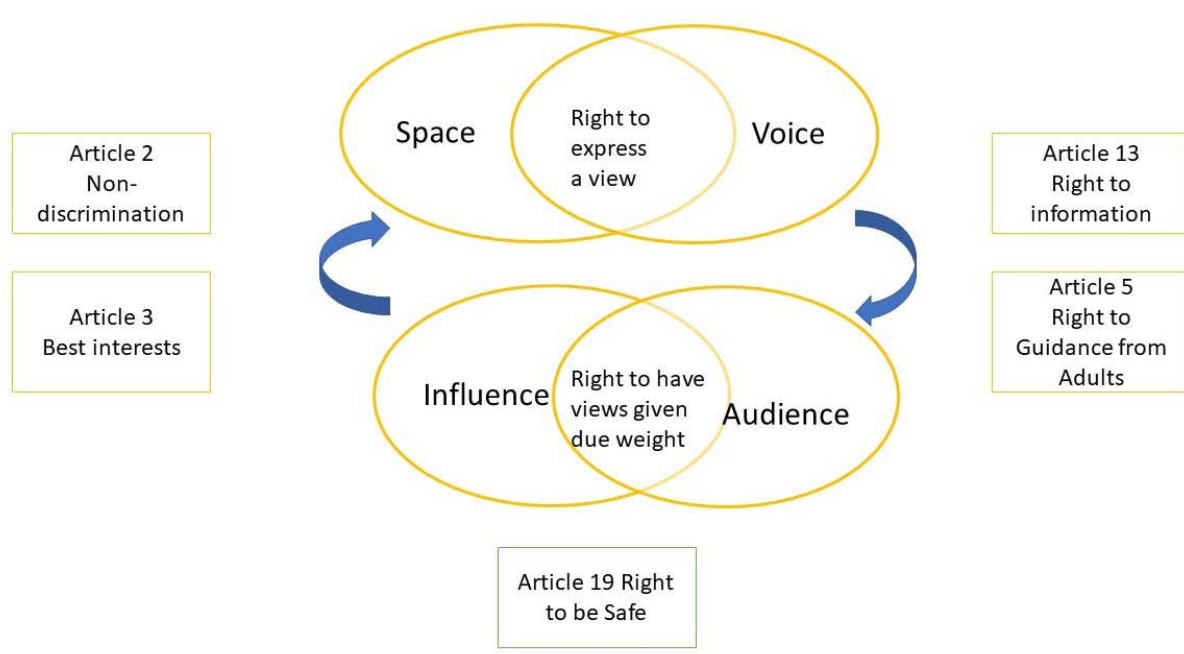

Figure 1.1: Conceptualising Article 12, adapted from Lundy, 2007. 
She proposes that we consider four main elements, that have a chronological order (see Figure 1.2 for a more in-depth examination of Lundy's elements):

1. Space: children must be given safe and inclusive opportunities to form and express their views

2. Voice: children must be facilitated to express their views

3. Audience: children must be listened to, they must be heard

4. Influence: their views must be acted on as appropriate

\section{Space}

How: Provide a safe and inclusive space for children to express their views.

Have children's views been actively sought?

Was there a safe space in which children can express themselves freely?

Have steps been taken to ensure that all children can take part?

\section{Voice}

How: Provide appropriate information and facilitate the expression of children's views.

Have children been given the information to form a view?

Do children know that they do not have to take part?

Have children been given a range of options as to how they might choose to express themselves?

\section{Audience}

How: ensure that children's views are communicated to someone with the responsibility to listen.

Is there a process for communicating children's views?

Do children know who their communications are being communicated to?

Does that person/organization have the power to make decisions?

\section{Influence}

How: ensure that children's views are taken seriously and are acted upon, where appropriate.

Were the children's views considered by those with the power to effect change?

Are there procedures in place that ensure that the children's views have been taken seriously?

Figure 1.2: Lundy's Space, Voice, Audience, Influence Model. 
For children with disabilities, this model can help us develop new ways of designing child-centred research projects. Importantly, for children with disabilities, who may not be able to speak, 'voice' is considered to be about communication. Methods to communicate can be expanded to include pictures, sign-language, map making, and other techniques that maximise understanding (Lynch \& Stanley, 2018). In other studies, researchers have also explored using social stories to explain research to children with disabilities (Pyle \& Danniels, 2016), and to use emojis to help them communicate (Fane, MacDougall, Javanovic, Redmond \& Gibbs, 2018). Whatever approach used, the underlying need to engage and advocate for a child-centred approach is essential and integrating Lundy's model can help us do this most effectively. Some suggestions could be:

- Spending time with a child to begin to know how they communicate; this may not be verbal but communication through doing

- Through trial and error, exploring different ways of helping the child express their views; using pictures, photographs, drawings, web-based media, play activity

- Involving children in designing your methodology and consider including children as analysts to strengthen your research

- Consideration of how you will disseminate your research in a child-oriented way.

The next section of the chapter will look more specifically at some examples of models that enable adults take on a child-centred approach in advocating for children.

\subsection{Theoretical models for enabling researchers: child-centred approaches for studying play}

The world is complex with a lot of components interacting with each other. Researchers created models to simplify and try to explain and predict parts of this world. When looking at play and disabilities there are several possible models we could consider to enable us to adopt a child-centred, holistic approach.

For example, in the International Classification of Functioning, Disability and Health (ICF; WHO, 2001), functioning and disability are multi-dimensional concepts. The ICF conceptualises a person's level of functioning as a dynamic interaction between their health conditions, environmental factors, and personal factors. The context of play is evident in the ICF when we look at the activity and participation opportunities afforded by each child, in the context of their physical, social, cultural and political environment. In this model, there is an attempt to consider the multifaceted elements that contribute to enabling play and participation. See figure 1.3 for a representation of the ICF. 


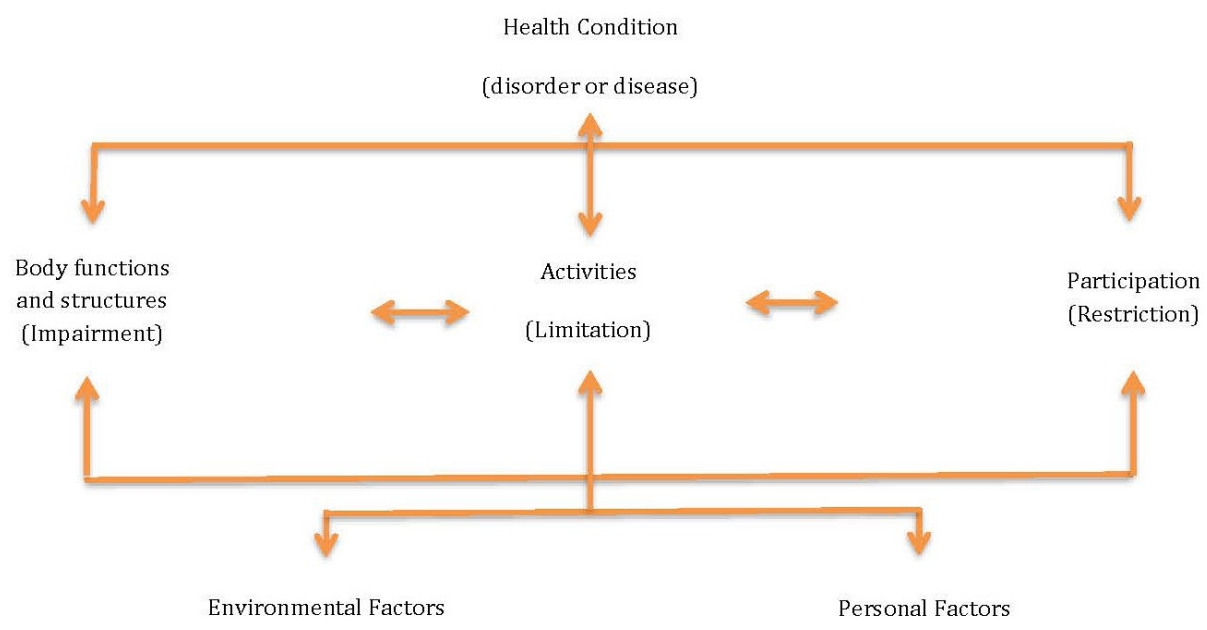

Figure 1.3: The International Classification of Function, Disability and Health (ICF), adapted from Simeonsson (2009) and WHO (2007).

In contrast, other models focus on individual differences among children, in order to understand their reasons for play and participation: in other words their motivation. An example is the Opportunity (O)-Propensity (P) model. Byrnes and Miller (2007) developed this framework, to differentiate between opportunity and propensity factors in an effort to explain variance and individual differences. Applied to playfulness, Propensity factors (P) are variables that make children able (e.g., intelligence) and/ or willing (e.g., motivation) to play. Opportunity factors $(0)$ include contexts and variables that expose children to learning content (e.g., home environment, classroom, playgrounds). Antecedent (A) or distal variables, for example SES, are present early in a child's life and explain why some people are exposed to richer opportunity contexts and have stronger propensities for learning than others (Byrnes \& Miller, 2007, 2016; Wang \& Byrnes, 2013).

Some other models sometimes cluster subtypes/groups of children with the same profile/needs. An example of such a model is the Process Communication Model (PCM) (Gilbert, 2014; Kahler, 1982, 2008) identifying, based on a cluster analysis, six 'needs' (types) in children, giving some suggestions on specific barriers and enablers to motivate those children, and make them play. PCM is a model that is created to understand, motivate and communicate with others by looking at within and betweengroup differences (Ampaw, Gilbert, \& Donlan, 2013). The model has been used in education (Pauley, Bradly, \& Pauley, 2002) and in hospital settings (Pauley \& Pauley, 2012). There have been some dissertations and master studies on the model (Appold, 2005; Donlan, 2009; Eyers, 2009; Francisco, 2005; Hall, 1995; Hawking, 1995; Martin, 
2001; Mlinarcik, 1990; Nash, 1984; Shcolnik, 1987; Wallin, 1992; Weisenbach, 2004). According to the model, we can differentiate the following types:

- Empathic children (or harmonizers/reactors) have, according to the model, pleasantness, compliance to others' wishes and generosity as assets. These children (30\% of the population) are, according to the model, attentive to others and sensitive. They are motivated by a well-willing style, play in groups with a lot of sensory stimulation and appreciate getting recognized and acknowledged as a person.

- Thinkers ( $25 \%$ of the population) are children that are responsible, logical and organized, performing best in a democratic style where they can work/play alone or with one other child. They are motivated by recognition of their work and time structure in plays.

- Persisters (10\% of the population) are devoted, good observers and conscientious children. These children are motivated by a democratic management style where they can work/play alone or with one other child with recognition of work done and respect for opinions.

- Dreamers (10\% of the population) are imaginative, reflective and calm. These children are motivated when adults and peers respect their need of solitude and invite them to act after a period of reflection. These children need plays that they can play by their own.

- Promoters ( $5 \%$ of the population) are convincing, adaptive and capable to realize things. These children need strong sensations and actions to be motivated to play.

- Rebels have passionate commitment, sympathy for the underdog and persistence as assets. These children ( $20 \%$ of the population) are spontaneous, creative and playful and enjoy the here and now. They are motivated by playful 'contact' with teachers with a 'laissez faire' style inviting them to work in a group-to-group environment. Playfulness is especially important for rebels.

It is important to note that each of the six types have different strengths and all types are needed in our society. In addition, every child has characteristics of all six types. The model is bidirectional with communication, interaction style and the motivational needs differing with subsequent implications for playfulness. Models like this are useful for us in that they help to understand how children make sense of their worlds. We however have to keep in mind that they simplify this world and that several models might be needed to explain and help us look at play and children with disabilities. It certainly is important to look at individual and social characteristics and to look at between and within group differences when looking for barriers and enablers of play. 


\subsection{Motivational enablers of play}

In children in the United Kingdom, motivation in terms of ability self-perceptions and intrinsic values predicted the achievement above general intelligence (Spinath, Spinath, Harlaar, \& Plomin, 2006). Motivation also moves children, brings them into action and keeps them playing. The language used to introduce, to monitor and guide during play and to deliver feedback impact upon intrinsic motivation (Mabbe, Soenens, De Muynck, \& Vansteenkiste, 2018; Reeve \& Tseng, 2011). A study revealed that elementary school children who were instructed through autonomy-supportive language when playing with puzzles reported elevated interest and persevered more at the difficult puzzles during a free-choice period compared to those received controlling instructions (Mabbe et al., 2018). In addition, in a meta-analysis, Taylor and colleagues (2014) highlighted a positive relationship between autonomous motivation (where the force to play is internal, e.g., passion) and achievement, in addition to a negative relationship between controlled motivation (where the force to play is external, e.g., reward-related) and achievement.

The Self-Determination Theory or SDT (Chen et al., 2015; Deci \& Ryan, 1985; Vansteenkiste \& Ryan, 2013; Vansteenkiste, Sierens, Soenens, Luyckx, \& Lens, 2009) is one of the leading theories in motivational psychology. SDT claims that the more autonomous (vs. controlled) the motivation is, the better (Vansteenkiste et al. 2009). The force that drives people to play can be external or internal. When its external, this is called controlled motivation. In contrast, autonomous motivation is used when the force to fulfil a task is internal. For instance, playing for feelings of pleasure and passion.

In addition, the SDT states this motivation is achieved by fulfilling three important needs: autonomy, competenceand relatedness. Autonomy is the psychological concept of feeling free to make your own choices (Van Petegem, Soenens, Vansteenkiste, \& Beyers, 2015). Competence is achieved when you attribute successful performance to own capacities and Relatedness is described as the experience of feeling loved by significant others. Including these needs in our approach to play seems indicated. Barriers and enablers for play can be looked at based on the SDT and opportunitypropensity (see par. 1.3) model.

In summary, the SDT model give parents and adults/professionals an evidencebased framework to understand and adapt play in different settings remembering the need of Autonomy (A), Belonging (B) and Competence (C) in mind. Satisfaction of these $\mathrm{ABC}$-needs was found to result in positive outcomes such as psychological growth (Vansteenkiste \& Ryan, 2013) and wellbeing in terms of self-esteem, whereas frustration of these needs resulted in stress and ill-being such as depressive symptoms or externalizing problems (Vansteenkiste \& Ryan, 2013). In addition, reflecting on motivation makes us aware of the fact that toys may not motivate everyone else to play. This is an argument to take into account the voices of children and to be aware of diversity in preferred interpersonal interaction. A closer look at the communication 
might help to broaden the picture and the needs to be motivated for play of boys and girls.

Getting a better insight in motivation and wellbeing can enhance playfulness in children with disabilities. This results in the following recommendations:

- Playfulness should be looked at in an autonomy-supportive way

- The language used to introduce, to monitor and guide during play and to deliver feedback should enhance the autonomous motivation to play

- Satisfaction of the Autonomy, Competence and Relatedness needs result in positive outcomes such as psychological growth and wellbeing in terms of selfesteem. Taking these components into account when looking at playfulness is important.

- In addition, when analysing the opportunities for play in different settings, it is important to investigate: 1 . the warmth and sensory stimulation of the setting, 2. the structure and the recognition of the work of the setting, 3. the fun and creativity/freedom of the setting, 4. the possibility of respect (values) of the setting, 5 . being able to play alone and 6 . the action, excitement and novelty of the setting.

These recommendations can reduce barriers and enhance enablers increasing playfulness and performance and realize more quality of life and participation in play activities in different settings (Deci, \& Ryan, 1985; Vansteenkiste \& Ryan 2013; Vansteenkiste, Sierens, Soenens, Luyckx, \& Lens 2009).

To conclude, children's voice and children's participation in expressing their views extend beyond simply giving choice in what to eat for dinner or in what clothes to wear. Children are rights holders and warrant our support to help them find ways to communicate what it is important to them in their lives. This includes play choices and preferences, play motivators and barriers. It also involves understanding children's play preferences, communication styles and sense of autonomy. To help us consider ways to understand children's world better, we explored some sample models that take into account such characteristics.

\subsection{Some useful resources}

Research with Children with Disabilities, for guidelines on good practice: http://nda. ie/Policy-and-research/Research/Research-Publications/Research-with-Childrenwith-Disabilities.html

Researching with children: understanding wellbeing project for an exemplar on including children as researchers: http://www.nuigalway.ie/hbsc/documents/ childrenunderstandingofwellbeing.pdf

Eurochild, for European work on children's voice and participation: http://www. eurochild.org/projects/childrens-voices/ 


\subsection{Acknowledgements}

Paragraphs 1.1 and 1.2 are written by Carol Barron and Helen Lynch; paragraphs 1.3 and 1.4 are written by Annemie Desoete, Marieke Coussens and Karen De Maesschalck.

\section{References}

Ampaw, F. D., Gilbert, M. B., \& Donlan, R. A. (2013). Verifying the validity and reliability of the Personality Pattern Inventory: Preliminary Results. The Journal of Process Communication, 1(1), 27-46.

Appold, B. E. (2005). A case study of the impact teachers with awareness of the Process Communication Model on student achievement (Doctoral dissertation). Mount Pleasant, MI: Central Michigan University.

Barron, C. (2017). Development of a play and recreation policy for children growing up in Kildare. Dublin, IE: Campus Print Dublin City University.

Barron, C. (2018). Development of a play policy for Limerick. Phase 1. Dublin, IE: Campus Print Dublin City University.

Barron, C., Beckett, A., Coussens, M., Desoete, A., Cannon Jones, N., Lynch, H., Prellwitz, M., \& Fenney Salkeld, D. (2017). Barriers to play and recreation for children and young people with disabilities. Warsaw, PL: De Gruyter Open.

Berne, E. (1964). Games people play. New York, NY: Grove Press.

Bluebond-Langer, M. \& Korbin, J. E. (2007). Challenges and opportunities in the anthropology of childhoods: An introduction to "Children, Childhoods, and Childhood Studies". American Anthropologist, 109(2), 241-246.

Chen, B., Vansteenkiste, M., Beyers, W., Boone, L., Deci, E. L., Van der Kaap-Deeder, J., ... Verstuyf, J. (2015). Basic psychological need satisfaction, need frustration, and need strength across four cultures. Motivation and Emotion, 39, 216-236.

Deci, E. L., \& Ryan, R. M. (1985). Intrinsic motivation and self-determination in human behavior. New York, NY: Plenum.

Donlan, R. (2009). An investigation of the relationship between Michigan charter school leaders' personality strengths and the schools' Performance Indicators Under Education Yes (Master thesis). Mount Pleasant, MI: Central Michigan University.

European Union (2017). EU guidelines for the promotion and protection of the rights of the child (2017) leave no child behind. Luxembourg, LU: Publications Office of the European Union.

Eyers, C. (2009). Personality Patterns of NCAA Wrestlers and their Relationship to Disordered Eating: Implication for Educational Leaders (Master thesis). Mount Pleasant, MI: Central Michigan University.

Fane, J., MacDougall, C., Jovanovic, J., Redmond, G., \& Gibbs, L. (2018). Exploring the use of emojis as a visual research method for eliciting young children's voices in childhood research. Early Child Development and Care, 188, 359-374.

Francisco, M. (2005). An investigation of the relationship between administrator personality and teacher job satisfaction from a sample of Michigan k-12 public schools [Master thesis]. Mount Pleasant, MI: Central Michigan University.

Gilbert, M. B. (2014). Effective communication evolving from listening to processing. The Journal of Process Communication, 2(1), 1-31.

Hall, G. R. (1995). The Process Communication Model of humanistic psychology as a rehearsal aid in the creation of character and character interaction (Master thesis). Leeds, UK: Leeds University. 
Hantson, E., Van de Velde, C., De Bie, L., De Jaeger, T., De Coster, N., \& Desoete, A. (2015). How to keep more children motivated. The Learning Teacher Magazine, 6(4), 3.

Hawking, N. (1995). A Study of the impact on student achievement by teachers. Training in Process Communication (Master thesis). Little Rock, AR: University of Arkansas at Little Rock.

Kahler, T. (1982). Process Communication Model: A contemporary model for organizational development. Little Rock, AR: Kahler Communications, Inc.

Kahler, T. (2008). The process therapy model: the six personality types with adaptations. Little Rock, AR: Taibi Kahler Associates, Inc.

La Fontaine, J. (1997) Are Children People? Paper presented at The Invisibility of Children Conference, Linkoping University, Sweden.

LeVine, R. (2007). Ethnographic studies of childhood: a historical overview. American Anthropologist, 109(2), 247-260.

Lundy, L. (2007). "Voice" is not enough: Conceptualising Article 12 of the United Nations Convention on the Rights of the Child. British Educational Research Journal, 33(6), 927-942.

Lynch, H., \& Stanley, M. (2017). Beyond Words: Using qualitative video methods for researching occupation with young children. OTJR: Occupation, Participation and Health, 38(1), 56-66.

Mabbe, E., Soenens, B., De Muynck, G.-J., \& Vansteenkiste, M. (2018). The impact of feedback valence and communication style on intrinsic motivation in middle childhood: Experimental evidence and generalization across individual differences. Journal of Experimental Child Psychology, 170, 134-160.

Martin, S. (2001). A study of the behavior causes of miscommunication in Arkansas elementary public school students (Master thesis). Little Rock, AR: University of Arkansas at Little Rock.

Mlinarcik, J. (1990). Alcoholic personality types revisited a la Kahler's Process Communication (Master thesis). Santa Barbara, CA: The Fielding Institute.

Moore, A., \& Lynch, H. (2015). Accessibility and Usability of playground environments for children under 12: a scoping review. Scandinavian Journal of Occupational Therapy, 22(5), 331-344.

Morrow, V., \& Richards, M. (1996). The ethics of social research with children: an overview. Children and Society, 10, 28-40

Nash, B. (1984). Process Therapy: A reliability and validity study (Master thesis). Kalamazoo, MI: Western Michigan University.

Opie, I., \& Opie, P. (1959). The lore and language of school children. Oxford, UK: Oxford University Press.

Pauley, L. A., Bradly, D. F. \& Pauley, J. F. (2002). How to reach me. Matching instruction to personality types in your classroom. Baltimore, MD: Brookes Publishing.

Pauley, J. A., \& Pauley, J. F. (2012). Establishing a culture of patient safety. Improving communication, building relationships, and using quality tools. Milwaukee, WI: ASQ Quality Press.

Pyle, A., \& Daniels, E. (2016). Using a picture book to gain assent in research with young children. Early Child Development and Care, 186, 1438-1452.

Reeve, J., \& Tseng, C.-M. (2011). Cortisol reactivity to a teacher's motivating style: the biology of being controlled versus supporting autonomy. Motivation and Emotion, 35, 63-74.

Shcolnik, B. (1987). The Process Communication Model concept of developmental processes: The effects of phase development in husbands on marital satisfaction of wives (Master thesis). Santa Barbara, CA: The Fielding Institute.

Spinath, B., Spinath, F.M., Harlaar, N., \& Plomin, R. (2006). Predicting school achievement from general cognitive ability, self-perceived ability, and intrinsic value. Intelligence, 34, 363-74.

Stiffman, A. R., Pescosolido, B., \& Cabassa, L. J. (2004). Building a model to understand youth Service access: the gateway provider model. Mental Health Services Research, 6, 189-198.

Taylor, G., Jungert, T., Mageau, G. A., Schattke, K., Dedic, H., Rosenfield, S., \& Koestner, R. (2014). A self-determination theory approach to predicting school achievement over time: The unique role of intrinsic motivation. Contemporary Educational Psychology, 39, 342-358. 
United Nations High Commissioner for Human Rights (1989). UN Convention on the Rights of the Child (UNCRC). Geneva, CH: Office of the United Nations High Commissioner for Human Rights.

UN Committee on the Rights of the Child [CRC] (2013). General Comment No. 17 on the right of the child to rest, leisure, play, recreational activities, cultural life and the arts.

Van Petegem, S., Soenens, B., Vansteenkiste, M., \& Beyers, W. (2015). Rebels with a Cause? Adolescent Defiance from the Perspective of Reactance Theory and Self-Determination Theory. Child Development, 86, 903-918.

Vansteenkiste, M., \& Ryan, R. M. (2013). On psychological growth and vulnerability: Basic psychological need satisfaction and need frustration as a unifying principle. Journal of Psychotherapy Integration, 23, 263-280.

Vansteenkiste, M., Sierens, E., Soenens, B., Luyckx, K., \& Lens, W. (2009). Motivational profiles from a self-determination perspective: The quality of motivation matters. Journal of Educational Psychology, 101, 671-688.

Wallin, M. (1992). Making the grade. The effects of teacher personality types on student grading practices (Master thesis). San Francisco, AZ: Northern Arizona University

Wang, A. H., Shen, F., \& Byrnes, J. P. (2013). Does the Opportunity-Propensity Framework predict the early mathematics skills of low-income pre-kindergarten children? Contemporary Educational Psychology, 38, 259-270.

Weisenbach, J. (2004). An investigation of the relationship between principal's personality and a School's organizational climate in Lutheran elementary schools in Michigan (Master thesis). Mount Pleasant, MI: Central Michigan University.

World Health Organization (2001). International Classification of Functioning, Disability and Health (ICF). Geneva, CH: WHO. 
Christina Schulze, Hólmdís F. Methúsalemsdóttir, Helen Lynch, Nan Cannon Jones, Ursula Winklhofer and Carol Barron

\title{
2 Empowering and enabling play in differing settings
}

\begin{abstract}
Children play in a variety of differing spaces and places. This chapter examines play in settings in which children live their lives; the home, the early years setting, the school setting and finally the health-care setting, which can be a frequently visited site for children with disabilities. We examine the unique barriers and more importantly the enablers for play within these differing physical spaces.
\end{abstract}

\subsection{Home as a play setting}

Home means having a place for rest and safety, privacy and freedom, comfort and order. It includes the indoor and outdoor areas linked to the home, including yards and back gardens. Home can be described as a place that allows individuals to meet their customary needs (Empson \& Nabuzoka, 2004) and provides a place to carry out daily activities, such as play. Home is a place rather than a building: a place for safety and belonging, and most significantly a core setting for developing primary relationships (Prellwitz \& Skär, 2006). At the most basic level, each form of home needs to consist of a safe and secure environment: without it children are not likely to play (Bundy, 1993; Cermak, 2009).

\subsubsection{Play in the home setting and why it is important}

It has been identified that children with disabilities spend more time in their homes than children without disabilities (Mundhenke, Hermansson, \& Nätterlund, 2010). The home setting is therefore of particular importance in relation to how homes support play and enable children's participation. Yet to date, it has been noted that few studies have researched children's participation in the home setting specifically. However, studies have shown that children with disabilities have less time for play as other children, due to extra time spent on self-care and/or therapy activities. Therefore, the physical, social and emotional environments including issues related to physical context (spaces and objects) family members, cultural values, attitudes and routines needs to be taken into account. 


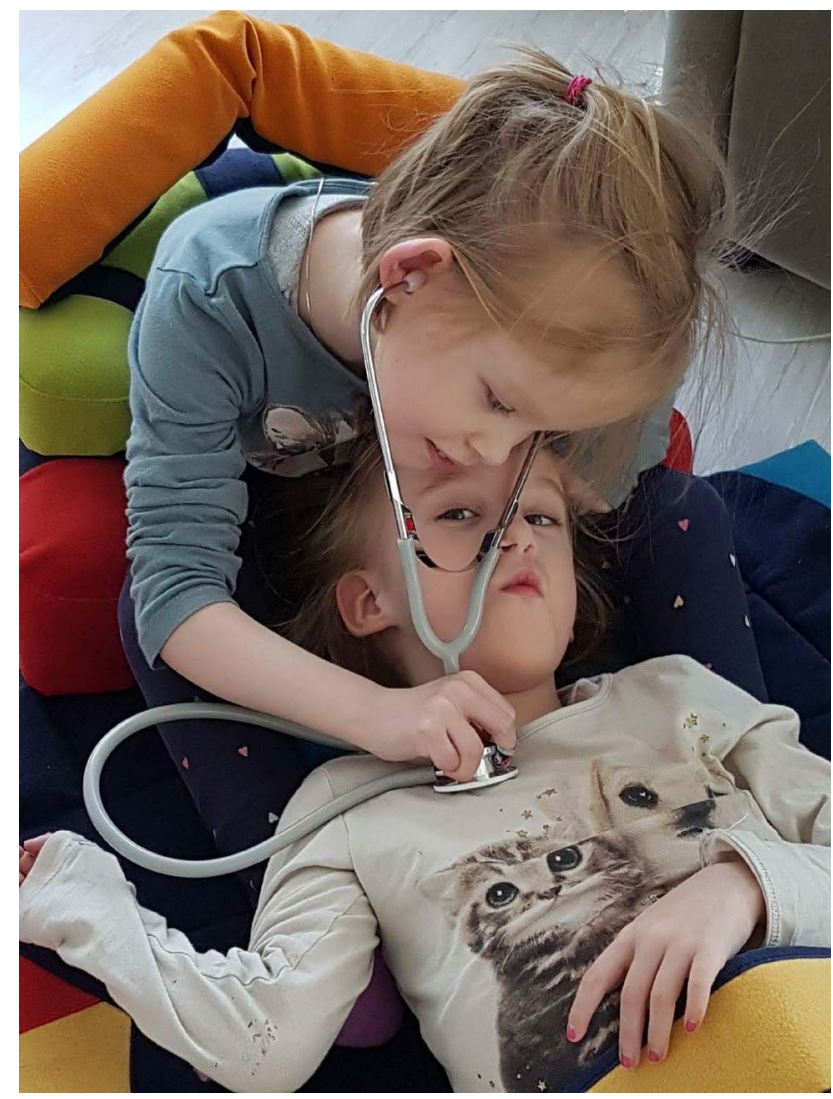

Figure 2.1: Twin sisters playing doctor (reprinted with kind permission of Sara Birgisdóttir).

\subsubsection{Known barriers to play in the home setting}

Barriers to play in the home environment have been identified and vary according to different forms of disability. Environmental barriers have been identified associated with the physical, social and political environment. For example, there is a lack of consideration of usability of home spaces for play indoors and out in many countries, alongside a lack of information on specific intervention strategies to address barriers to participation in home activities. Barriers in the physical environment consist for example in a limited accessibility to and on play settings because of constructional obstacles (Law, Haight, Milroy, Willms, Stewart, \& Rosenbaum, 1999; Moore \& Lynch, 2015). Furthermore, caregivers mention how their families can miss play experiences because of accessibility problems or safety concerns (Moore \& Lynch, 2015). In some studies, parents expressed that the social barriers and attitudes of other persons are the most significant barriers (Law et al., 1999; Piškur et al., 2012). 
However, barriers also exist at another level: the political context. Here, it is noted that there is a lack of clear legislation and policy in many countries in relation to build home environments and accessible and usable spaces for play. Furthermore, there is frequently no consultation with stakeholders, and lack of disability equality training in key professionals who lead on planning design and policy. In the political environment, not enough attention is given to adequately designed play settings for children with all abilities due to limited knowledge about disabilities, restricted financing options, and limited responsibility (Moore \& Lynch, 2015). Together with barriers in the social environment, parents named institutional barriers as the most important hindering factors in changing physical barriers (Law et al., 1999).

Due to these barriers, children with disabilities in many communities, rarely experience social inclusion, in contrast to children without disabilities (Prellwitz \& Skär, 2007). Findings from different studies reflect how children with disabilities experience these barriers: Tamm and Skär (2000) identified that children with restricted mobility often play alone, with adults or as "onlookers" in games where their mobility limitations do not allow them to be actively involved in the game. Furthermore, children with disabilities do less often participate in active recreation activities and activities involving social interactions (Law et al., 1999). If children do participate in active recreational activities, the participation is mainly possible because of the engagement of the parents (Law et al., 1999; Piškur et al., 2012). Prellwitz and Tamm (1999) found that children with restricted mobility do not experience play settings as a place for them. Tamm and Skär (2000) confirm this finding and assume that children with restricted mobility do not feel welcome and often experience negative feelings, because they are excluded from playing together with other children. The environment in general, especially in a community setting, is determining for enabling or preventing children with disabilities from participation and social inclusion. One possibility to address the need for inclusive and accessible play environments is by design.

\subsubsection{Enabling play in the home setting}

One way to enable play in homes is to implement Universal Design. General guidelines for buildings using a Universal Design approach exist in many countries. These guidelines include physical accessibility for housing. However, they focus primarily on physical access issues such as entrances, ramps, stairways, related to mobility issues rather than other forms of impairment that may also affect how the home accommodates individual needs. Prellwitz and Skär (2006) found that eighty-two children with restricted mobility perceived their home environments as being relatively accessible compared to places outside the home. This was because their homes had been tailored for the needs in many ways. Thus, specific policies 
on accessible built environments appear to be providing effective results. However, these children also identified that accessible rooms did not result in usable places e.g. not being able to perform cooking activities in the kitchen. Research needs to explore the different needs of children with disabilities in relation to the accessibility and usability of the home environment, and specifically play in the home. In addition, it has also been noted that achieving such adapted, usable spaces requires funding that is not always available (Lewis, 1987).

Play in the home involves friends as much as family, through for example the organisation of playdates and facilitation of community play in the neighbourhood's communities. Solitary play has been found to be the most common play type in the home, even though children with disabilities have identified peer relationships / friendship to be of significant importance to them (Mundhenke et al., 2010; Sandberg, Björck-Åkesson, \& Granlund, 2004). Play can be enabled in environments in which the opportunities and play resources made available to children are matched with their interests and abilities (Rigby \& Huggings, 2003). It is therefore very important that parents are well informed and aware of how to make home environment accessible for play, not only from the physical point of view but also the social one. Access to suitable technical aids and assistive devices in addition to an accessible home area (indoors and outdoors) are basic elements for some children with disabilities, to enable play along with motivated attitudes of families that are willing to make opportunities for friends to come into the home to play. Recommended websites to enable play in the home setting are included in par. 2.5 at the end of this chapter.

Children with disabilities rely on the home social environment for much of their play opportunities since they tend to have fewer friends and spend more time with adults than other children (Mundhenke et al., 2010). Hence social support from family is a significant factor in enabling participation in play. Social support includes instrumental support, emotional support and informative support (House, Kahn, McLeod, \& Williams, 1985). In studies with parents of children with Autism Spectrum Disorder (ASD), parents reported that their families participated in fewer family occupations together compared to other families. They felt very little shared meaning of these occupations and spent more time preparing and planning for their children (Bagby, Dickie \& Baranek, 2012). Schaaf, TothCohen, Johnson, Outten and Benevides (2011) examined everyday routines of families of children with ASD. Analysis from this qualitative study identified core themes linked to barriers to participation including lack of flexibility in daily routines, difficulty completing family activities, the need for constant monitoring of the child's activities, and the importance of developing strategies to improve participation for the family as a whole. In addition, studies have shown that children with ASD, who have fewer playdates organised for them in the home, have more difficulties in negotiating play with peers in the school playground (Frankel, Gorospe, Chang \& Sugar, 2011). Across these studies, it appears that parents work hard to organise and orchestrate play partners for their children to prevent this barrier to play in their children's lives. However, this was also identified as an extra challenge in these families' lives. 


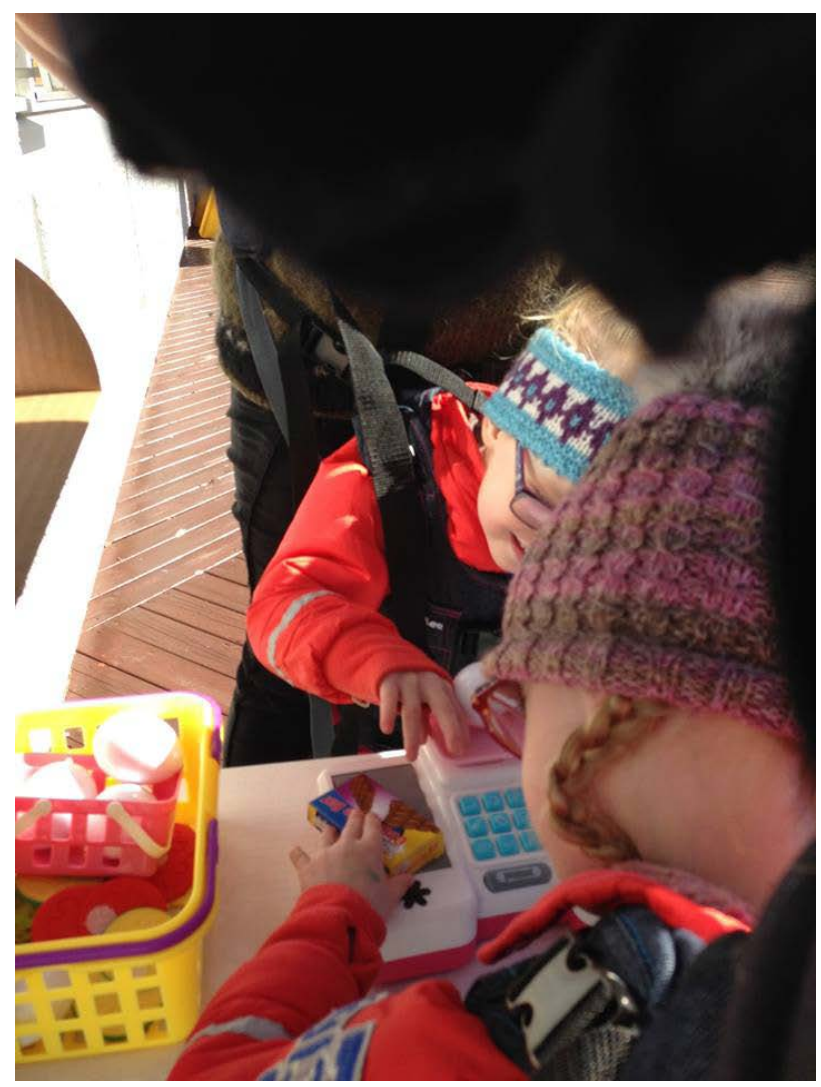

Figure. 2.2: Twin sisters in shopping game (reprinted with kind permission of Sara Birgisdóttir).

\subsubsection{Conclusion}

Every child is entitled to quality play experiences in their own home and it is a child's right to be included. The family plays a big role in child's play experience in relation to optimise their play opportunities. To maximize successful play opportunities in the home setting, it is important that families are provided with the "right tools" and knowledge to identify strategies that can help children to bypass known barriers with that in mind that play is active and should be directed by the child. These strategies can for example be related to designing safe and enabling play environment at home, select motivating toys and invite friends over for playdates. 


\subsection{Empowering play in the early years}

Early years education can trace its history from Rousseau and Kant in the 18th century; Froebel, Montessori and Steiner in the 19th century; Piaget, Vygotsky and Bruner in the 20th century. In the 21st century, the knowledge base is being added to by the work of Howard Gardner, Ferre Laevers, Loris Malaguzzi, Chris Athey amongst many others. From the conception of early- years education, the importance of play in the lives and education of all children is forefronted and promoted.

Young children begin to make sense of the world through active engagement in freely chosen, personally directed, intrinsically motivated play (Hughes, 2015). Opportunities arise for them to use their imagination, to communicate meaning to themselves and to others, to transform their thinking and to solve problems within the Early Years setting. The difficulty for adults is to understand and give meaning to children's freely chosen play, often leading them to take control of children's play themselves (Bae 2010). Delome, Rousselet, Mace and Fabre Thorpe (2004) consider play as an opportunity to practice new skills, to understand how and why things work. Carefully selected toys motivate children to explore, to discover and to share with others, freely chosen play acts to emphasize what the child can do and what he likes. Miller and Almon (2009) advocate that by promoting play we promote self-choice, self-direction, self-esteem and an independent spirit. Murray (as cited in Moyles, 2014) advocates that children who are given the time, freedom and space to lead their own play may develop their knowledge and understanding to a greater extent than they would through adult directed activities. Empowering play for young children with disabilities requires sensitive adults with the ability to respond appropriately to the needs of individual children (Wood, 2004) in relation to their present play activity.

Julia Moor (2008) a special educator whose own son was diagnosed with ASD, discovered that a direct approach did not work with her child and developed a 'back door' approach, capturing her son's attention through play with his favourite objects. Miller and Almon (2009) describe the adult role as being 'creative and inspirational'. The physical, cognitive, emotional and social environment should provide opportunities for children to feel secure, to develop a sense of their own worth and that of others, with opportunities to have the freedom to explore independently.

Jane Murray (as cited in Moyles 2014) in her study 'Young Children as Researchers' explains that whilst working as an Early Years teacher she observed that young children often use the same strategies as adult researchers. She identifies occasions, during child led self initiated play. where she observed children questioning, problem solving, exploring and commenting on new ideas. With other colleagues she identified four specific behaviours that are important to all research whether it is carried out by adults or children. They are exploration, finding a solution, conceptualising, and basing decisions on evidence discovered during their work or play.

Before engaging a child in play, practitioners in the Early Years setting must first consider the child's diagnosis and the effect that it might have on the child's access to 
play through discussion with parents and/or carers (Vakil, Welton, O’Connor, \& Kline, 2009). Sensory preferences, visual, auditory and communicative skills, physical ability including best play positions and the need for specialist seating or supportive positioning must be identified and understood. Practitioners then need to consider the different aspects of play.

The COST Action TD1309 "LUDI - Play for children with disabilities” classification of play considers play as either having a cognitive or a social value. Cognitive play encompasses practice play, where children learn about cause and effect using simple body movements along with their senses to explore objects that interest them. Symbolic play involves using objects in ways other than their intended use and eventually leads to pretend play. In constructive play children' gather, combine and arrange' objects, fitting them together to build simple structures. Play with games that have specific rules usually involves children playing together with others and understanding that they must all follow the rules of the game. These games generally involve aspects of practice, symbolic, and constructive play as described above.

Social play encompasses solitary play, parallel play, associative play and cooperative play. Solitary play involves playing purposefully alone, often showing lack of awareness of others. In parallel play the child shows awareness of others at the same activity but plays independently. In associative play the children may be engaged in separate activities sharing equipment, taking turns and acknowledging their playmates. In cooperative play children engage in play where each has a role to play and all have a shared purpose (Besio, Bulgarelli \& Stancheva-Popkostadinova, 2017).

Practitioners who consider the child as a whole person, emotionally, intellectually, socially, physically, morally, culturally and spiritually are better able to provide opportunities for children to confidently and independently explore ideas, feelings and relationships that they have experienced. The approach to empowering play must be both heuristic and holistic (Hughes, 2015) suggests that children's investigation stimulated in a safe and caring environment, with the provision of time and space, along with appropriate play materials set the stage for play to ensue. Moor (2008) discusses how through sensitivity to her son's needs, she was able to capture his attention rather than experiencing 'fight and flight' in her interactions with him. She structured play times with him, breaking down each play activity into small manageable parts, playing alongside with a duplicate set of equipment, either copying his play or introducing new actions.

Practitioners facilitating playfulness, in response to the child's interests through child-led play, (Wood, 2004) need to organize resources to enable successful and meaningful play. The National Scientific Council on the Developing Child (2005) suggests that opportunities for children to extend or change their play are readily available. Equipment needs to be presented in a way that meets individual need and makes for easy access. Supporting adults, through actions and/or dialogue can encourage children to build on their ideas, elaborate their play schemes and make 
connections between one discovery and another. Practitioners can best support children's play by recognizing its quality, rather than the children's performance, and by sharing success with parents and colleagues. The Kate Greenaway Nursery School and Children's Centre London England (2009) provides a theoretical guide to support the planning of a broad, balanced and rich nursery education for every child, whilst involving all participants in the process. Working together as a team, listening to parents, carers and the children themselves, discussing practice and sometimes changing beliefs, enables practitioners to improve the quality of their practice. With enhanced knowledge and understanding they become advocates of playful environments.

\subsubsection{Conclusion}

Play acts to emphasize what children can do and what they like. With a knowledge of the child, their abilities and the areas and types of play they most enjoy, adults can provide suitable developmentally appropriate playful activities where children can have fun with toys and people. By discovering personal characteristics through the understanding of individual reactions, strengths and abilities can be identified and as suggested by Evans and Dubrowski (2001) and Moor (2008), the environment can be tailored to meet individual needs. Time spent in purposeful interaction increases and children begin to give meaning to experiences and to make sense of the world around them.

\subsection{Enabling play in the school context}

Today children and young people stay at school for a great part of their day. As a result, school is more than a centre of learning: it is a centre of living, where children spend a proportion of their leisure time, meet their friends and build vital experience of peer interaction. "Public school playgrounds are important spaces in children's daily geographies in terms of the amount of time spent and the activities that occur within them" (Yantzi, Young, \& Mckeever, 2010, p. 65). Given this, it is not surprising that school is highly important as a context for play, including from the perspective of the children themselves. A survey conducted in various European cities showed that while six to eight year-olds like to play at home (83\%), in the home environment (garden/backyard, 80\%) or at the playground (79\%), school is also an important play location for almost three quarters of the children surveyed (71\%). When asked where they play most frequently, older children ranked school in equal first place $(51 \%)$ with playing at home (Winklhofer et al., 2013). For children with disabilities, school offers the opportunity to experience not only inclusive education, but also inclusive play. Jeanes and Magee (2012) point out that access to inclusive leisure opportunities 
increases feelings of self-confidence and allows disabled children to socially interact, develop new skills and gain some independence.

\subsubsection{Play in the school setting and why it is important}

Analysis of existing studies shows that school-based play in general for children with disabilities has been largely ignored (Burke, 2013; Yantzi et al., 2010; Woolley, Armitage, Bishop, Curtis, Ginsborg, 2006). For the United Kingdom, Woolley et al. state that "[...] there has been a dearth of research directly investigating the use that disabled children make of school playgrounds" (Woolley et al., 2006, p. 304). A general analysis of studies on inclusiveness at schools in Germany shows that the studies primarily address development of children's performance at school, social integration in the classroom and issues of general school development, organisation and equipment, yet fail to explicitly examine the topic of play (Preuss-Lausitz, 2014).

The subjects of school-based play and physical activity exercise attract interest within the context of health policy objectives such as the prevention of obesity and chronic diseases including type 2 diabetes. "An emerging public health priority is to enhance children's opportunities for active play. Children spend a large proportion of weekdays in schools, making schools an influential and suitable setting to promote children's active play” (Hyndman, 2015, p. 56). The study “Active by Design: Promoting physical activity through school ground greening" was able to show that "through greening, school grounds diversify the play repertoire, creating opportunities for boys and girls of all ages, interests and abilities to be more physically active" (Dyment \& Bell, 2007, p. 463). Indoor play may be catered for with play corners in the classroom, play offerings in communal recreation rooms or in different rooms or spaces dedicated to specific activities, such as painting and crafts in one room or space, and physical activity and letting off steam in another.

Last but not least, school is an attractive play location for precisely the reason that it offers the opportunity to be with peers and make friends and playmates. "Existing research suggests that for disabled children in particular, participating in play is an important way in which they make friends” (Jeanes \& Magee, 2012, p. 196).

\subsubsection{Known barriers for play in the school setting}

The quality of play opportunities at school is essentially dependent on the space available. However, despite the dedication shown in some projects concerning design of school grounds, many school grounds still offer no more than an asphalt surface and a climbing frame, and are viewed by the children as boring environments that ignore their interests (Titman, 1994; Willenberg et al., 2010). At the same time, school grounds are hugely important for children and provide many children with their main 
opportunity to be outside on a regular basis (Burke, 2013). This applies all the more to children with disabilities, who often have only limited access to public playgrounds and frequently play at home alone (Mundhenke, Hermansson \& Sjöqvist Nätterlund, 2010). Attractive and inclusive design of school grounds offers to these children in particular the opportunity to experience play outdoors.

A further aspect of fundamental importance are the time structures provided for play and leisure. Play at school generally takes place during breaks, in lunch breaks or in the afternoon. However, the school timetable often relies on rigid, closely scheduled time structures for lessons, lunch and organised activities, leaving little time for free play. In their study "Inclusion of disabled children in primary school playgrounds", Woolley et al. (2006) found that not all schools scheduled time for outdoor play in the afternoons. While the lack of playtime was a restriction for all children, an added problem for children with disabilities was that in some cases they were scheduled for additional support or therapy services with different timetables. Arriving with a delay made it harder for them to join in the play (Woolley et al., 2006). Also Yantzi et al. (2010) point out, that barriers for inclusive play in the school setting include school organisational arrangements such as scheduling therapy sessions during breaks.

Another barrier is the lack of staff with appropriate training to enable students with play activities and deterring peers' negative behaviours such as bullying. Studies of school playgrounds show that the experiences of disabled children can be extremely isolating due to both their physical restrictions and the views of non-disabled children towards them (Jeanes \& Magee, 2012; Prellwitz \& Tamm, 1999). There are many ways that children with disabilities are excluded from playgrounds; even if they can physically move through the playground, they may not actually be able to play in the space. An accessible playground which lacks suitable play opportunities is not necessarily playable for all children (Yantzi et al., 2010).

It is essential to acknowledge that perceptions of what makes spaces excluding, can vary across children with disabilities. While design was particularly important to children with sensory and physical disabilities, young people with mild physical or learning disabilities experienced attitudinal discrimination more frequently (Jeanes \& Magee, 2012). For example, a lack of quiet places for withdrawal or observation could be a barrier for children with autism spectrum disorder, while children with hearing difficulties may experience problems with the acoustics of a room.

\subsubsection{Enabling play in the school setting}

Various aspects and strategies play key roles in fostering opportunities for play in a school context and maximising their quality for children with disabilities. From our perspective the most important aspects are: 
1. Organisational framework conditions at the school as an institution

2. Design of an inclusivity-based play environment

3. Supportive attitudes and role of adults

4. Participation of the children

\subsubsection{Organisational framework conditions at the school as an institution}

Taking the current organisational culture in schools as a starting point, it is vital to note that both the allocated space and the time structures provide insufficient support for play, particularly autonomous free and active play. Improvement of the situation would necessitate not only organisational changes - such as providing adequate time for joint play for all children - but also a shift in the perspective of school directors, staff and education professionals, and thus a change in the status and significance accorded to inclusive play in a school context. Such a reappraisal would be reflected in the allocation of funding for the design of inclusive school environments and for qualifying staff to support and accompany inclusive play processes.

\subsubsection{Design of an inclusive play environment}

In the design of a physical play environment, the accepted objective is to create an environment that is inviting and attractive for the children while catering to their differing abilities and needs (Casey, 2005). There are five significant characteristics of a play environment which support this objective: flexibility, shelter, centres of interest, natural features and atmosphere (Casey, 2005). Further important features are sensory elements, accessibility, risk and challenge, and continuity between indoors and outdoors. Flexibility requires the play environment to contain elements which the children can use in any way they choose. The availability of sheltered space provides the feeling of privacy, of a safer and more intimate space. Some children experience difficulty when confronted by particular sensory experiences, and the option of being in a smaller, more enclosed space rather than a very open or busy play space is very welcome. 'Centres of interest' can be temporary or flexible features such as a sensory garden, a paddling pool full of balls or a tepee. This allows inclusion around a focus, where becoming involved does not rely on having high social and communication skills. Natural features in a play environment like trees, long grass, water, stones and logs can offer a softer and more reassuring environment. As well as developing the physical environment, a supportive and accepting atmosphere developed between the children, between the adults, and between the adults and children is crucial (Casey, 2005). 


\subsubsection{Supportive attitudes and roles of adults}

Most studies on this topic conclude that appropriate support from adults plays an important role in encouraging play in children with disabilities (Jeanes \& Magee 2012; Casey, 2005; Woolley et al., 2006; Heimlich, 2017). Jeanes and Magee (2012), for example, point out that fully trained and supportive staff are critical elements when developing more inclusive play facilities. "The importance of skilled play workers, capable of connecting young people and their families and supporting their participation, cannot be understated" (Jeanes \& Magee, 2012, p. 206). For Casey, a crucial factor is that "the adult's role in supporting inclusive play requires a sensitive balance between allowing the children control over their own play and providing appropriate support to those children who need it" (Casey, 2005, p. 56). Important issues include overcoming fears, effective scaffolding of play between children of diverse abilities and needs, and appropriate ways of addressing risk and challenge. As examples of good practice, Woolley et al. (2006) describe situations where staff have encouraged confidence and ability in children. Heimlich (2017) defines inclusive encouragement to play as an area of core competence which takes in attentive observation and identification of the children's topics of play, provision of appropriate play equipment, space and times, and scaffolding of play processes. Training and studies need to be adjusted to reflect this, providing more effective preparation for the complex requirements involved and their blend of personal, social and professional factors.

\subsubsection{Participation of the children}

The widely diverse positive effects gained from active participation by children and young people in the design of their school grounds and play areas has been confirmed by a number of participatory projects (Tsevreni \& Bentenidi, 2013; Jeanes \& Magee, 2012; Jansson, Mårtensson \& Gunnarsson, 2018). A review of case studies by Titman (1994) concludes that significant changes are revealed in children's attitude and behaviour, including heightened self-esteem and reduction in aggression, accidents and incidents of damage and vandalism, as well as a general change in the atmosphere throughout the school when children had been involved in a meaningful way in the design of their school grounds and play areas. Participation in play space design helps to develop a sense of ownership and belonging (Titman, 1994). Young people with disabilities reported that by "being consulted and having the opportunity to significantly influence the design of the facility, play provision was developed that they genuinely wanted and that met their needs" (Jeanes \& Magee, 2012, p. 201). Furthermore, an open and creative planning process offers the opportunity to identify the specific abilities and needs of the individual children and allows them to develop understanding and empathy for each other during their involvement together in the process. 


\subsubsection{Conclusion}

The foremost barriers for children with disabilities include lack of accessibility of play areas and the heightened difficulties these children experience in coming into contact with other children and playing together. Schools have enormous potential to overcome this lack of play opportunities for children with disabilities by offering appropriate play provision. In addition to numerous practical approaches described here in detail, a further key issue is certainly the need for policymakers and practice to develop greater awareness of the important role of inclusive play opportunities within the school context.

\subsection{Play in Health Care Settings}

According to the Association for the Wellbeing of Children in Healthcare (AWCH, 2005) the acceptance of play as a right for children in hospital, now underpins the work of play therapists worldwide and influences the planning of hospital policy and practice. Before we can look at play in health care settings today, it is helpful to identify when specialist children's health care settings were established. Prior to the mid19th Century, children, when hospitalised, were placed in existing adult health care settings and the history of child health care in Europe is linked with the development of hospital establishments. The first generally accepted children's hospital is the "Hôpital des Enfants Malades", which opened in Paris in June 1802. Over the next 70 years, Europe saw the establishment of numerous children's hospitals and children's services (Stevens \& Meyer 2002), although many of these were children's departments integrated into general hospitals (Ballabriga \& Schmidt, 1987).

By the 1870s onwards, the dominant view was that sick children were better off in hospital, removed from their 'unsanitary homes' and mothers who could not provide the specialist care and treatment needed (Davies, 2010). Up to the early and mid-20th century, health care professionals subscribed to the belief that, if a child became upset when a parent left them in hospital, they were experiencing psychological trauma (Robertson, 1970). It was therefore thought it was better for the child if the parents did not visit and the child was left to 'settle in' (Alsop-Shields \& Mohay, 2001). The combination of these beliefs about cross-infection and the adverse effects of parental visits meant that some children did not see their parents for months at a time. Jolley's research (2004) tells us whilst children's physical needs were met in children's hospitals at this time, their emotional and psychological needs were not. In America, René Spitz (1945) identified the negative effects of hospitalisation on children. In the U.K., John Bowlby was publishing his findings on the early and traumatic separation from their mother and how they continued to be deprived of their parent's presence because of restrictions on hospital visiting. During the time Bowlby and his colleague Robertson were conducting their research, the British government 
set up a parliamentary select committee to investigate conditions in children's wards and hospitals. The resulting document became known as the Platt Report (National Association of Hospital Play Staff Milestones, NAHPS, 1959). It contained 55 recommendations, including allowing parents to stay in hospital with their children and providing recreational play for hospitalised children. This report formed the basis for dramatic changes in the British health system and subsequently in many other countries. However, these reforms were not accepted without opposition across the international field of child health care.

\subsubsection{Enabling play in Health care settings}

In 1959, The Welfare of Children in Hospital (Platt Report) recognised the importance of play opportunities and play provision for children in hospitals. Several years later in 1963, Susan Harvey, Save the Children Fund advisor, was credited as the Founder of Play in Hospital. A decade later (1973), the first training programme for Hospital Play specialists was established and since then, the hospital play specialists play a principle role in both enabling play in hospital settings and using differing forms of play with children and young people to minimise traumatic effects of hospitalisation. Their primary focus is on the following types of play:

1. Ordinary / Normal Play

2. Therapeutic Play

3. Preparatory Play

4. Distraction Technique / Play

5. Post Procedural Play

\subsubsection{Ordinary Play}

Ordinary play is child-directed, enjoyable and spontaneous. Play is a normal part of childhood and needs to be provided within a hospital environment. Ordinary play can reduce stress and anxiety and can encourage parental involvement in the child's care. Play gives the children an opportunity to explore their hospital experiences and it can give a daily routine or structure to their day that can otherwise be busy with medical tests and procedures. The inclusion of familiar, preferred toys in a hospital environment may enhance the motivation to play for children with disabilities (Desha et al., 2003). 


\subsubsection{Therapeutic Play}

Therapeutic play is purposeful play led by the hospital play specialist and its main aim is to improve the emotional and physical wellbeing of the child ${ }^{2}$. This is accomplished with playful activities that directly relate to the child's medical condition. It can be used by the play specialist to help build rapport with children and young people. Therapeutic Play is also used when children and young people need to express some of their anger/frustration or anxieties while being in hospital. Children may have an intravenous cannula, wound dressing, naso-gastric tube, limb cast etc. or may have special needs, but through therapeutic play they can enjoy a wide range of activities using textures, art work, messy play, water-play and food play. Health care professionals in both community and hospital settings play a pivotal role by becoming aware of the unique play and recreation needs of children with disabilities and their families (Hoogsteen \& Woodgate, 2010). Children with intellectual disabilities specifically have been shown to benefit from the use of therapeutic play strategies during their hospitalisations (Li \& Lopez, 2008).

\subsubsection{Preparation}

Preparatory play is used to support children, young people and their families in understanding and coping with the hospital treatments and procedures. The form of the preparatory play will differ widely and is normally guided by the child's engagement and influenced by their specific disability, e.g. the use of preparatory books in braille for children who are visually impaired.

\subsubsection{Distraction}

Invasive procedures such as injections can cause considerable pain to children. Distraction techniques involving play, such as blowing bubbles, use of lights, sounds, listening to music and so forth are one of a repertoire of strategies employed within hospital setting to decrease children's pain, however, it is not yet clear which specific distraction techniques using play work best for children of various ages and disabilities (Barron \& Cocoman, 2008).

\subsubsection{Post-Procedural Play/Support}

Post-Procedural Play is carried out with children when they appear anxious following a procedure/treatment and can help reduce possible distress and benefit the child with future hospital admissions. Some children's hospitals across Europe now have

2 Therapeutic, preparation, distraction and post procedural play are proposed in LUDI as "play-like activities" (Besio, 2018). 
sensory rooms (Glasper, 2017), which provide a multi-sensory experience for children and help meet their play needs throughout their hospitalisation.

In recent years, there has been international recognition of the importance of play and recreation for hospitalised children and young people. The European Association for Children in Hospital (EACH) in 2016 published a Charter for children in hospital, which takes a children's rights approach to their experiences in health care settings whilst being cognisant of the themes expressed in the United Nations Convention on the Rights of the Child (1989). Article 7 of the EACH charter states that:

"Children shall have full opportunity for play, recreation and education suited to their age and condition and shall be in an environment designed, furnished, staffed and equipped to meet their needs."

Children have the right to an environment, which meets the needs of children of all ages and situations wherever they are being cared for. This applies to hospitals, day care facilities or other healthcare facilities where children are being treated or examined. The Charter for children in hospital (EACH, 2016) reports:

- The architecture and interior design of such an environment must incorporate appropriate features for all age groups and types of illnesses treated in the facility. The environment should be adaptable to the needs of different age groups.

- Sufficient suitably qualified staff should be available to meet the needs of children for play, recreation and education, regardless of the state of health and age of the children.

- All staff, both clinical and non-clinical, who come in contact with children should have an understanding of the needs of children for play and recreation.

- Extensive opportunities for play, recreation and education, supported by appropriate play materials, resources and equipment, should be provided for all the age groups that are being cared for in the facility and include:

- $\quad$ sufficient periods of time for play, seven days a week;

- creative activities by all children, including those who are in isolation should be encouraged.

\subsubsection{Conclusion}

The importance of play for hospitalised children was not always recognised but its significance cannot be overstated. Play in hospital provides an ordinary daily experience in a stressful environment and, guided by a Hospital Play Specialist, can help to increase each child's ability to cope with illness and hospitalisation and to understand treatment. The need for play facilities arises not only in acute hospital settings, but also in other locations where children attend or access health and related services including health centres and child and adolescent psychiatric units. The central role of play in children's health care settings is being recognised by provision of specialist play therapists (Glasper, 2017), amongst many other health 
care professionals and is supported from a children's rights perspective by European organisations, specifically, The European Association for Children in Hospital (EACH).

\subsection{Recommended Websites}

- A Professionals' Guide to Assisting Families in Creating Play Environments for Children with Disabilities: http://letsplay.buffalo.edu/products/PlayManual.pdf

- Guidelines to Promote Play Opportunities for Children with Disabilities: http:// letsplay.buffalo.edu/play/play-guidelines2.pdf

- International Play Association: http://ipaworld.org

- $\quad$ Let the Children Play: http://www.letthechildrenplay.net/

- LUDI Guidelines for Supporting Children with Disabilities' Play: https://www. degruyter.com/view/product/507228

- Right to Play: http://www.righttoplay.com/Pages/default.aspx

- The Whole Child - Creativity and Play: http://www.pbs.org/wholechild/parents/ play.html

- UNICEF: https://www.unicef.org/sowc2013/universal_design.html

\subsection{Acknowledgements}

Paragraph 2.1 is written by Christina Schulze, Hólmdís F. Methúsalemsdóttir and Helen Lynch; paragraph 2.2 is written by Nan Cannon Jones; paragraph 2.3 is written by Ursula Winklhofer, who thanks Karen de Maesschalck for her support with the research for this paragraph; and paragraph 2.4 is written by Carol Barron.

\subsection{References}

Alsop-Shields, L., \& Mohay, H. (2001). John Bowlby and James Robertson: theorists, scientists and crusaders for improvements in the care of children in hospital. Journal of Advanced Nursing, 35(1), 50-58.

Association for the Welfare of Child Health (AWCH) (2005). The Psychosocial Care of Children and their Families in Hospital. AWCH 2005 National Survey Report. Gladesville, NSW: Association for the Welfare of Child Health.

Ballabriga, A., \& Schmidt, E. (1987). Actual trends of the diversification of infant feeding in industrialized countries in Europe. In: A. Ballabriga \& J. Rey (Eds.), Weaning, why, what and when? (pp. 129-51). New York, NY: Raven Press.

Bae, B. (2009). Children's right to participate-challenges in everyday interactions. European Early Childhood Education Research Journal, 17(3), 391-406.

Bagby, M. S., Dickie, V. A., \& Baranek, G. T. (2012). How sensory experiences of children with and without autism affect family occupations. American Journal of Occupational Therapy, 66(1), $78-86$. 
Barron, C., \& A. Cocoman. (2007). Administering intramuscular injections to children: what does the evidence say? Journal of Children's and Young People's Nursing, 2(3), 138-144.

Besio, S. (2018). What is play?. In: P. Encarnação, S. Ray-Kaeser \& N. Bianquin

(Eds.), Guidelines for supporting children with disabilities' play: Methodologies, tools, and contexts (pp. 1-12). Warsaw, PL: De Gruyter Open.

Besio, S., Bulgarelli, D., \& Stancheva-Popkostadinova, V. (2017). Play development in children with disabilities. Warsaw, PL: De Gruyter Open.

Brown, M., \& Gordon, W. A. (1987). Impact of impairment on activity patterns of children. Archives of Physical Medicine and Rehabilitation, 68(12), 828-832.

Bundy, A. C. (1993). Assessment of play and leisure: Delineation of the problem. American Journal of Occupational Therapy, 47(3), 217-222.

Burke, J. (2013). Just for the fun of it: making playgrounds accessible to all children. World Leisure Journal, 55(1), 83-95.

Casey, T. (2005). Inclusive play. Practical strategies for working children aged 3 to 8 . Thousand Oaks, CA: Sage Publications.

Cermak, S. (2009). Deprivation and sensory processing in institutionalized and postinstitutionalized children: Part I. Sensory integration. Special Interest Section Quarterly / American Occupational Therapy Association, 32(2), 1-3.

Davies, R. (2010). Marking the 50th anniversary of the Platt Report: from exclusion, to toleration and parental participation in the care of the hospitalized child. Journal of Child Health Care, 14(1), 6-23.

Delome, A., Rousselet, G. A., Macé, M. J. M., \& Fabre-Thorpe, M. (2004). Interaction of top-down and bottom-up processing in the fast visual analysis of natural scenes. Cognitive Brain Research, 19(2), 103-113.

Desha, L., Ziviani, J., \& S. Rodger (2003). Play preferences and behavior of preschool children with autistic spectrum disorder in the clinical environment. Physical \& Occupational Therapy in Pediatrics, 23(1), 21-42.

Dyment, J. E., \& Bell, A. C. (2007). Active by design: Promoting physical activity through school ground greening, Children's Geographies, 5(4), 463-477.

Empson, J. M., \& Nabuzoka, D. (2004). Atypical child development in context. New York, NY: Houndmills.

European Association for Children in Hospital (2016). The EACH Charter with Annotations. EACH European Association for Children in Hospital. Retrieved from https://www.each-for-sickchildren.org/each-charter

Evans, K., \& Dubowski, J. (2001). Art therapy with children on the autistic spectrum, beyond words. London, UK: Jessica Kingsley Publishers.

Frankel, F. D., Gorospe, C. M., Chang, Y., \& Sugar, C. A. (2011). Mothers' reports of play dates and observation of school playground behavior of children having high-functioning autism spectrum disorders. Journal of Child Psychology and Psychiatry, 52(5), 571-579.

Glasper, A. (2017). Optimising the care of children with intellectual disabilities in hospital. Comprehensive Child and Adolescent Nursing, 40, 63-67.

Heimlich, U. (2017). Das Spiel mit Gleichaltrigen in Kindertageseinrichtungen. Teilhabechancen für Kinder mit Behinderung [Peer play in ECEC facilities. Opportunities for participation by children with disabilities]. WiFF Expertisen, 49, 1-59.

Hoogsteen, L., \& Woodgate, R. L. (2010). Can I play? A concept analysis of participation in children with disabilities. Physical \& Occupational Therapy in Pediatrics, 30(4), 325-339.

House, J. S., Kahn, R. L., McLeod, J. D., \& Williams, D. (1985). Measures and concepts of social support. In: S. Cohen \& S. L. Syme (Eds.). Social support and health (pp. 83-108). San Diego, CA: Academic Press.

Hughes, A. M. (2015). Developing play for the under 3's. London, UK: Routledge. 
Hyndman, B. (2015). Where to next for school playground interventions to encourage active play? An exploration of structured and unstructured school playground strategies. Journal of Occupational Therapy, School \& Early Intervention, 8, 56-67.

Jansson, M., Mårtensson, F., \& Gunnarsson, A. (2018). The meaning of participation in school ground greening: a study from project to everyday setting. Landscape Research, 43(1), 163-179.

Jeanes, R., \& Magee, J. (2012). 'Can we play on the swings and roundabouts?': creating inclusive play spaces for disabled young people and their families. Leisure Studies, 31(2), 193-210.

Jolley, J. (2004). A Social History of Paediatric Nursing: 1920-1970 (unpublished PhD thesis). Hull, UK: The University of Hull.

Kate Greenaway Nursery School and Children's Centre (2009). Core experiences for the Early Years Foundation Stage. London, UK: Kate Greenaway Nursery School and Children's Centre

Law, M., Anaby, D., Teplicky, R., Khetani, M.A., Coster, W., \& Bedell, G. (2013). Participation in the home environment among children and youth with and without disabilities. The British Journal of Occupational Therapy, 76(2), 58-66.

Lewis, B. (1987). “How are families managing at home?” Architectural barriers in households of children with special needs - an issue ignored by health professionals. Children's Environments Quarterly,4(3), 36-41.

Li, H. C. W., \& Lopez, V. (2008). Effectiveness and appropriateness of therapeutic play intervention in preparing children for surgery: A randomized controlled trial study. Journal for Specialists in Pediatric Nursing, 13, 63-73.

Law, M., Haight, M., Milroy, B., Willms, D., Stewart, D., \& Rosenbaum, P. (1999). Environmental factors affecting the occupations of children with physical disabilities. Journal of Occupational Science, 6(3), 102-110.

Miller, E., \& Almon, J. (2009). Crisis in the kindergarten: Why children need to play in school. College Park, MD: Alliance for Childhood.

Moor, J. (2008). Playing, laughing and learning with children on the autistic spectrum. London, UK: Jessica Kingsley.

Moore, A., \& Lynch, H. (2015). Accessibility and usability of playground environments for children under 12: A scoping review. Scandinavian Journal of Occupational Therapy, 22(5), 331-344.

Moyles, J. (2014). The excellence of play. London, UK: McGraw-Hill Education.

Mundhenke, L., Hermansson, L., \& Sjöqvist Nätterlund, B. (2010). Experiences of Swedish children with disabilities: activities and social support in daily life. Scandinavian journal of occupational therapy, 17(2), 130-139.

Nelson, C., Nelson, A. R., McDonnell, A. P., Johnston, S. S., \& Crompton, A. (2007). Keys to play: A strategy to increase the social interactions of young children with autism and their typically developing peers. Education and Training in Developmental Disabilities, 42(2), 165-181.

Parham, L.D., \& Fazio, L., S. (2008). Play in occupational therapy for children. Maryland Heights, MO: Mosby.

Piškur, B., Beurskens, A. J. H. M., Jongmans, M. J., Ketelaar, M., Norton, M., Frings, C. A., ... Smeets, R. J. E. M. (2012). Parents' actions, challenges, and needs while enabling participation of children with a physical disability: A scoping review. BMC Pediatrics, 12(1), 177.

Prellwitz, M., \& Tamm, M. (1999). Attitudes of key persons to accessibility problems for children with restricted mobility: A study in a medium-sized municipality in northern Sweden. Scandinavian Journal of Occupational Therapy, 6, 166-173.

Prellwitz, M., \& Skär, L. (2006). How children with restricted mobility perceive the accessibility and usability of their home environment. Occupational Therapy International, 13(4), 193-206.

Prellwitz, M., \& Skär, L. (2007). Usability of playgrounds for children with different abilities. Occupational Therapy International, 14(3), 144-155.

Preuss-Lausitz, U. (2014). Wissenschaftliche Begleitungen der Wege zur inklusiven Schulentwicklung in den Bundesländern. Versuch einer Übersicht. [An overview of scientific 
studies along the way to developing inclusive schools in Germany]. Retrieved from https:// www.ewi.tu-berlin.de/fileadmin/i49/dokumente/Preuss-Lausitz/Wiss._Begleitung_Inklusion. pdf

Rigby, P., \& Huggings, L. (2003). Enabling young children to play by creating supportive play environments. In L. Letts, P. Rigby \& D. Stewart (Eds.), Using environments to enable occupational performance (pp. 155-176). Thorofare, NJ: Slack Incorporated.

Robertson, J. (1970). Young children in hospital. 2nd Ed. London, UK: Tavistock Publications. Sandberg, A., Björck-Åkesson, E., \& Granlund, M. (2004). Play in retrospection. Scandinavian Journal of Disability Research, 6(2), 111-130.

Schaaf, R. C., Toth-Cohen, S., Johnson, S. L., Outten, G., \& Benevides, T. W. (2011). The everyday routines of families of children with autism: Examining the impact of sensory processing difficulties on the family. Autism, 13(3), 373-389.

Spitz, R. A. (1945). Hospitalism-An inquiry into the genesis of psychiatric conditions in early childhood. Psychoanalytic Study of the Child, 1, 53-74.

Stevens, R., \& Meyer. (2002). Fanconi and Glanzmann: the men and their works. British Journal of Haematology, 119, 901-904

Tamm, M., \& Skär, L. (2000). How I Play : Roles and relations in the play situations of children with restricted mobility, Scandinavian Journal of Occupational Therapy 7(4), 174-183.

Titman, W. (1994). Special Places; Special People: The Hidden Curriculum of School Grounds. Surrey, UK: World Wide Fund for Nature.

Tsevreni, I., \& Bentenidi, K. (2013). Space as a pedagogical tool for children with additional educational needs participation and empowerment. Education in the North, 20, 39-54.

Vakil, S., Welton, E., O'Connor, B., \& Kline, L. S. (2009). Inclusion means everyone! The role of the early childhood educator when including young children with autism in the classroom. Early Childhood Education Journal, 36(4), 321-326.

Willenberg, L. J., Ashbolt, R., Holland, D., Gibbs, L., MacDougall, C., Garrard, J., ... \& Waters, E. (2010). Increasing school playground physical activity: a mixed methods study combining environmental measures and children's perspectives. Journal of Science and Medicine in Sport, 13(2), 210-216.

Winklhofer, U., Barbovschi, M., Rus, C., Sandu, O. N., Domagala, I., Hayes, N., Westwood, M., O'Connor, K., Sopinska, A. (2013). Results of the Re-play Survey in eight european cities. Munich, DE: Pröll.

Wood, E. (2004). Early childhood education: Society and culture. London, UK: Sage Publications.

Woolley, H., Armitage, M., Bishop, J., Curtis, M., \& Ginsborg, J. (2006). Going outside together: Good practice with respect to the inclusion of disabled children in primary school playgrounds. Children's Geographies, 4(3), 303-318.

Yang, T. R., Wolfberg, P. J., Wu, S. C., \& Hwu, P. Y. (2003). Supporting children on the autism spectrum in peer play at home and school piloting the integrated play groups model in Taiwan. Autism, 7(4), 437-453.

Yantzi, N. M., Young, N. L., \& Mckeever, P. (2010). The suitability of school playgrounds for physically disabled children. Children's Geographies, 8(1), 65-78. 


\title{
3 Studies On Play For Children With Disabilities: Exploring The Interdisciplinary Approach
}

\begin{abstract}
Play is considered one of the main activities carried out by children. It is characterized by several aspects, interconnected and investigated by researchers belonging to heterogeneous disciplinary fields. With the aim of grasping the interdisciplinary complexity around the topic of play for children with disabilities, the present systematic review was conducted. Scientific studies about play for children with disabilities were searched on three databases using key words and then the included papers were analysed through a specific reading form. The scientific fields of the journal containing the article included in the review, were retrieved using the classification system proposed by the SCImago (Science Citation Index) Journal \& Country Rank (o SJR indicator), a public available portal that includes national scientific journals and indicators developed by the information contained in the Scopus database. Results highlight that the theme of play of children with disabilities is covered in a variety of scientific fields, belonging from medicine to human-computer interaction, and that the most represented scientific field of the studies where education and psychology. The scientific fields seem to reconfigure their percentages in relation to the characteristics ascribable to the different investigated disabilities.
\end{abstract}

\subsection{Introduction}

Play is one of the main activities carried out by every child; it is fundamental for the development of cognitive, social and communicative abilities (Vygotsky, 1967; Piaget, 1981; Sutton-Smith, 1997), and is internationally recognized as a right of infancy (United Nations, 1989) also for children with disabilities (UN, 2013; International Play Association, 2015).

It is characterized by different aspects (Besio, 2017) investigated by researchers belonging to heterogeneous disciplinary fields. The consistent presence of studies related to play for children with disabilities, identified in the last years, highlights an increasing interest in the scientific community (Bulgarelli \& Bianquin, 2018). Over the years, pedagogy, engineering, law, medicine, psychology, sociology, design, rehabilitation have investigated the same object, namely play, including that of the child with disabilities, stressing different aspects, such as the analysis of play development in children with disabilities (Meyers \& Vipond, 2005, Besio 2010), educational robotics (Besio, Caprino, \& Laudanna, 2009, Cook, Encarnação, \& Adam, 2010; Robins, Dautenhahn, Ferrari, Kronreif, PrazaK-Aram, Marti, Iacono, Gelderblom, Berned, \& Caprino, 2012), adapted toys (Brodin, 1999) or accessibility of play area (Ashley, 1999; Prellwitz, Tamm \& Lindqvist, 2009; Ripat \& Becker, 2012). 
Moreover, in the international literature, the definitions and classifications of the types of play are multiple (Sutton-Smith, 1997; Besio, 2017): this diversity brings to a variety of tools, procedures, interventions in order to implement and evaluate play (Bulgarelli \& Bianquin, 2018).

This plurality of researches has been published in journals belonging to specific disciplinary fields (Nagpaul, 1995). The examination of papers published in such journals provides a picture of the complexity through which the topic of 'play' is investigated, giving at the same time information about their quantity, the categories of play investigated, and the disabilities considered.

The aim of this paper is to provide a systematic review of the recent studies that analysed the theme of play for children with disabilities in order to seize the complexity of the interdisciplinary approach highlighted above. The specific research questions are:

1. In which scientific journals have been articles about play for children with disabilities published in the period from 2006 to 2017 ?

2. To which disciplinary fields such researches do they belong?

3. Which types of disabilities have been investigated by these researches?

4. Which categories of play have been investigated by these researches?

\subsection{Play: an interdisciplinary research area}

There are few subjects that have been studied by many disciplines as play (Gordon, 2009): biology, psychology, education, anthropology, sociology, history, engineering, design have all focused on play.

Play has many irreducible features, some of which have been highlighted by different theorists (Huizinga, 1950; Bateson, 1955; Vygotskij, 1967; Piaget, 1981; SuttonSmith, 1997). Providing a comprehensive definition of play remains a theoretical challenge because there are different forms of play, which have several functions and characteristics, multiple players, play contexts, perspectives and languages through which to analyse and to describeit. Furthermore, there is alack of an effective coordination of the different scientific fields within a single speculative framework, which can bring to a clear systematization, to the identification of further research questions and to the creation of new studies, tools and methodological proposals (Besio, Carnesecchi, \& Encarnação, 2015; Besio, Bulgarelli, \& Stancheva-Popkostadinova, 2017).

For these reasons, the COST Action TD1309 "LUDI - Play for Children with Disabilities" was born; it was an international and interdisciplinary network of researchers and professionals funded by the European COST Program ${ }^{3}$ (COoperation in

3 The title of the COST Action initiating the project is: LUDI-Play for Children with Disabilities. For more information https://www.ludi-network.eu/ 
Science and Technology). This action aimed at creating an innovative and autonomous field of research and intervention on play for children with disabilities (Besio et al., 2017). The network involved over 100 researchers, professionals and practitioners from 32 European and non-European countries, belonging to the most diverse disciplines focusing on the topic of play for children with disabilities - clinic (paediatricians, physiatrists, child neuropsychiatrists), rehabilitation (physiotherapists, speech therapists, rehabilitation therapists, neuropsychomotricists), psychology (developmental and educational psychologists), education (teachers, pedagogists, educators, recreation and education centre operators, sociology), engineering, design, industrial sector, legal and policy - establishing a constructive dialogue between them, in order to reach shared definitions and knowledge (Bianquin, 2017). In addition to the vastness and variety of the areas involved, the LUDI network has also another constitutive characteristic: the confluence between theoretical studies and studies related to intervention practices from clinical to industrial contexts. LUDI has therefore carried out a systematization of the new multidisciplinary study area, building the effective basis for future developments.

\subsection{Play and disabilities construct within the LUDI theoretical framework}

Among the several definitions and classifications of play (Bulgarelli \& Bianquin, 2017), LUDI decided to adopt the one proposed by Garvey, the broadest and at the same time flexible one, for the purposes of the project: «play is a series of voluntary and intrinsically motivated activities, normally associated with entertainment and recreational pleasure» (1990:4).

The concept of play is strongly connected to the distinction between ludic activities - play for the sake of play - and play-like activities (Visalberghi, 1958). ${ }^{4}$ The first are started and implemented by the player (alone, with peers, with adults) with the sole purpose of play itself (fun, joy, interest, challenge, competition, etc.). These activities clearly have consequences on growth and development, but these outcomes are not intentionally pursued. Instead, play-like activities are initiated and conducted

\footnotetext{
4 The Italian pedagogist Aldo Visalberghi systematized these concepts in 1958. According to the scholar, play has the following characteristics: it is demanding, requires a complete commitment of the player; it is continuous, it develops throughout a child's life; it is progressive, since it can gradually become more complex; foresees the end of the activity and does not require any kind of continuation once finished. Many activities carried out in schools or in educational contexts that have learning objectives can have the appearance and even the structure of the play activities and can, of course, have fun features. For these activities Visalberghi proposes the expression of 'ludiform'. They have the same first three characteristics of play activities but not the last one, since they do not end in themselves but have educational objectives and a final scope, that of learning.
} 
by adults, in educational, clinical or social contexts; they appear playful and pleasant, but their main objective is other than play: cognitive and social learning, functional rehabilitation, observation and evaluation, psychological support, psychotherapy, etc. (Besio, 2017).

Moreover, LUDI has chosen to adopt the definition of disability proposed by the International Classification of Functioning, Disability and Health (WHO, 2001) as suitable for the purposes of the project (Bianquin \& Bulgarelli, 2017). In the ICF, disability is conceived as the result of a complex relationship between the individual (its functioning characteristics) and the environment and emphasizes how the latter can represent an obstacle or a facilitation element to the functioning individual. This definition also closely interacts with that given by the Convention on the Rights of Persons with Disabilities (UN, 2006), ${ }^{5}$ which underlines the importance of the participation dimension for everyone, and for people with disabilities.

To share a common language and classification, LUDI also identified the categories of disability, starting from the ones ${ }^{6}$ developed by the OECD's (Organization for Economic Cooperation and Development) Center for Educational Research and Innovation (CERI; see Table 3.1, Bianquin \& Bulgarelli, 2017). The categories adopted are functional and meaningful for the purposes of the project, and they are related to impairments that could prevent or reduce children's playing possibilities.

Table 3.1: The LUDI classification of disabilities.

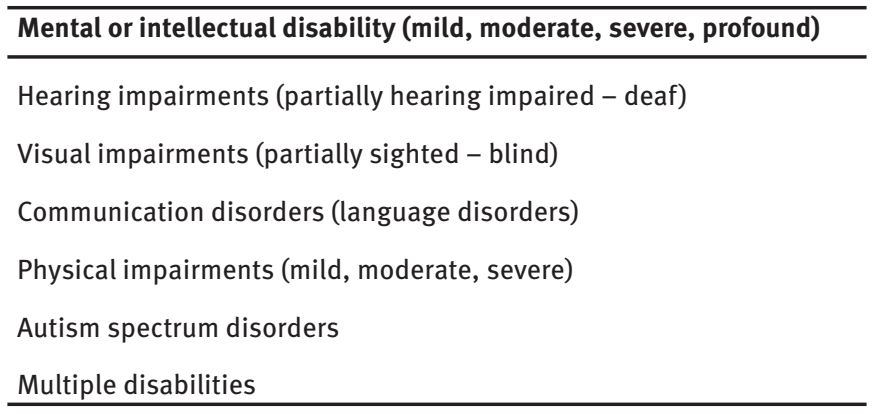

5 «[Recognizing that] disability is an evolving concept [...] [that] results from the interaction between persons with impairments and attitudinal and environmental barriers that hinders their full and effective participation in society on an equal basis with others» (Convention on the Rights of Persons with Disabilities, Preamble, Art. e).

6 The document 'Students with Disabilities, Learning Difficulties and Disadvantages: Policies, Statistics and Indicators' (2007, an updated version of a previous document published in 2005) contains a collection of data from many countries and present a comparison of data concerning the access to educational provisions by students with special needs in a number of OECD countries. 


\subsection{Scientific subjects classification in the Scimago system}

Most scientific publications are tracked by electronic databases that can be considered the greatest repositories of scientific knowledge (Gómez-Núñez, VargasQuesada, de Moya-Anegón, \& Glänzel, 2011). Among the different databases, some contain only works related to a specific subject area (for example, ERIC for the educational sciences, INSPEC for physics and engineering, PsycINFO for psychology or MEDLINE for medical literature); others, as Web of Science (WOS) and Scopus, are interdisciplinary and include research from different scientific fields. These databases collecting publications from different disciplinary areas and require systems of classification and organization of scientific knowledge (Gómez-Núñez et al., 2011). Among the different classifications, one of the most important is that proposed by Scopus (Falagas, Kouranos, Arencibia-Jorge, \& Karageorgopoulos, 2008) which is based on a two-level hierarchical classification system: the areas (first level) and the categories of subjects (second level). All publications collected from this database are placed first in one or more areas and then categorized based on criteria such as title, scope or citation models. Starting from the classification system and the data contained in Scopus, a group of scientists led by the Consejo Superior de Investigaciones Científicas (CSIC) in Spain created the SCImago (Science Citation Index) Journal \& Country Rank (o SJR indicator), a public available portal that includes national scientific journals and indicators developed by the information contained in the Scopus database. The publications available in the SCImago public portal are organized in levels, according to a progressive classification system in which four Super Groups are located at the top level: Life Sciences, Social Sciences, Physical Sciences and Health Sciences. These Super Groups are further divided in 27 Major Thematic Areas indicated with a numerical code from 1000 to 3600 and 313 Specific Subject Categories. ${ }^{7}$ This information can be used to evaluate and analyse scientific domains and journals by making comparison or single analysis (GómezNúñez et al., 2011).

The title of a paper is inserted in the search engine to identify the scientific fields of classification: if the journal is registered, the system provides automatically information about its classification, with the reference to the Major Thematic Areas and the Specific Subject Categories. From them is possible to date back to the 4 Super Groups. The identification could not be always univocal because a journal might have been classified into different Major Thematic Areas that, in turn, could refer to a different Super Groups.

For example, the Major Thematic Areas Psychology identified by the numerical code 3200, belongs to the Super Groups Social Sciences and is divided into 8 Specific Subject Categories (see Figure 3.2).

7 https://www.scimagojr.com/aboutus.php 


\section{Super groups

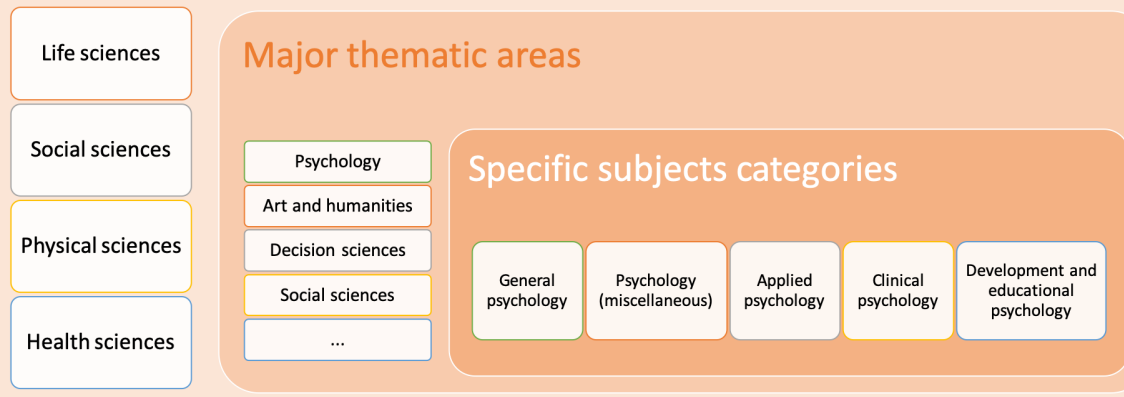

Figure 3.1: SJR levels: example of the thematic area and specific subject "Psychology".

The journals ${ }^{8}$ Education \& Training in Developmental Disabilities and Education and Training in Autism and Developmental Disabilities belong to the Super Group Social Sciences, to Major Thematic Area Psychology and Social Sciences and to the Specific Subject Categories related to Developmental and Educational Psychology and Education.

\subsection{Method}

In order to select the articles to be included in the systematic review, a multi-phase procedure based on guidelines was followed (Kitchenham, 2004). First, a thorough discussions between the researchers about the goals of the systematic review and the inclusion and exclusion criteria aimed at building a shared understanding and a common framework for the selection phases. Then, the following steps were taken.

The words characterizing the LUDI project, i.e. "play" "children" and "disabilities" (using the logical operator AND) were used to query the databases and to identify the papers. In order to cover different scientific fields, three databases were chosen: Education Resources Information Center (ERIC), an authoritative database of indexed and full text education literature and resources; Institute of Electrical and Electronic Engineers Xplore Digital Library (IEEE Xplore Digital Library), a research database for discovery and access to journal articles, conference proceedings and related materials on computer science, electrical engineering and electronics, and allied fields; and

8 These three journals were founded in the present review. 
Public/Publisher MEDLINE (PUBMED) PubMed, a free search engine based on the MEDLINE database, of biomedical scientific literature.

The results from all databases were registered, merged and duplicates were removed. Two independent raters examined the titles and abstracts and applied the inclusion and exclusion criteria.

The review included studies that:

1. Addressed play;

2. Addressed children with disabilities ( 0 to 18 years old);

3. Were published in the period from 2006 to 2017 in peer reviewed journal or peer reviewed conference proceedings;

4. Were published in English or there is an English translation available;

The search took place from 27 June 2018 to 6 July 2018. The two raters then compared their decisions and settled all differences through discussion. In cases where it was not clear from the abstract if the study should be included or not, the full paper was retrieved and analysed from both raters to better support the decision. Subsequently, the articles corresponding to the eligibility criteria were analysed using a reading form to obtain information relevant to the research questions identified: title, authors, journal, year, Super Groups, Major Areas and Categories (according to the SJR classification), disability diagnosis (see Table 3.1) and play type (play vs. play-like activities).

\subsection{Results}

The databases search identified 584 documents. After removing duplicates, 579 studies remained and 80 were included in this review. The inter-rater reliability score was $89 \%$ (good) and the Cohen's kappa coefficient of 0.75 (good) was obtained. The selected papers are reported in the Table 3.3.

As regards the years, 30 of them were distributed equally in the years 2009, 2010 and 2011, when the major number of papers was published (graph. 3.1). The year with the least number of publications $(\mathrm{N}=3)$ was 2006.

The Table 3.3 shows the disabilities considered in the selected papers. The diagnostic labels used by the researchers were exactly reported. 46 studies took into consideration only one disability, the remaining ones (34) focused on more. Regarding the different diagnoses, the most represented was the Autism Spectrum Disorder (31/80 - ST 4, 6, 7, 8, 11, 13, 17, 19, 22, 26, 27, 28, 33, 34, 40, 50, 51, 52, 56, 59, 62, 64, 68, 72, 73, 74, 75, 76, 78, 79, 80)), followed by Down Syndrome (12 - ST 4, 11 , 14, 16, 25, 28, 32, 44, 54, 64, 67, 73 ) and Cerebral Palsy (7 - ST 16, 20, 42, 47, 49, 63, 71) and Intellectual Disability (7 - ST 17, 18, 22, 24, 26, 43, 53). It must be noted that 10 studies did not provided a specific diagnosis but referred generically to a wide range of disabilities or special needs (ST 2, 3, 21, 30, 35, 36, 38, 41, 46, 60). 
Table 3.2: Selected papers.

\begin{tabular}{|c|c|c|c|}
\hline Code & Author/s & Title & Year \\
\hline ST1 & Celeste M & $\begin{array}{l}\text { Play Behaviors and Social Interactions of a } \\
\text { Child Who Is Blind: In Theory and Practice }\end{array}$ & 2006 \\
\hline $\mathrm{ST} 2$ & DiCarlo CF, Stricklin SB, Reid DH & $\begin{array}{l}\text { Increasing Toy Play among Toddlers with and } \\
\text { without Disabilities by Modifying the Structural } \\
\text { Quality of the Classroom Environment }\end{array}$ & 2006 \\
\hline ST3 & Pang Y & $\begin{array}{l}\text { Assist Parents to Facilitate Social Skills in } \\
\text { Young Children with Disabilities through Play }\end{array}$ & 2006 \\
\hline ST4 & $\begin{array}{l}\text { Rutherford MD, Young GS, } \\
\text { Hepburn S, Rogers SJ }\end{array}$ & A Longitudinal Study of Pretend Play in Autism & 2007 \\
\hline ST5 & Cress CJ, Arens, KB, Zajicek, AK & $\begin{array}{l}\text { Comparison of Engagement Patterns of Young } \\
\text { Children with Developmental Disabilities } \\
\text { between Structured and Free Play }\end{array}$ & 2007 \\
\hline ST6 & $\begin{array}{l}\text { Robins B, Otero N, Ferrari E, } \\
\text { Dautenhahn K }\end{array}$ & $\begin{array}{l}\text { Eliciting Requirements for a Robotic Toy for } \\
\text { Children with Autism - Results from User } \\
\text { Panels }\end{array}$ & 2007 \\
\hline ST7 & $\begin{array}{l}\text { Nelson C, McDonnell AP, Johnston } \\
\text { SS, Crompton A, Nelson AR }\end{array}$ & $\begin{array}{l}\text { Keys to Play: A Strategy to Increase the Social } \\
\text { Interactions of Young Children with Autism and } \\
\text { their Typically Developing Peers }\end{array}$ & 2007 \\
\hline ST8 & $\begin{array}{l}\text { Wong CS, Kasari C, Freeman S, } \\
\text { Paparella T }\end{array}$ & $\begin{array}{l}\text { The Acquisition and Generalization of Joint } \\
\text { Attention and Symbolic Play Skills in Young } \\
\text { Children with Autism }\end{array}$ & 2007 \\
\hline ST9 & Johnson KA, Klaas SJ & $\begin{array}{l}\text { The changing nature of play: implications for } \\
\text { pediatric spinal cord injury }\end{array}$ & 2007 \\
\hline ST10 & $\begin{array}{l}\text { Raisamo R, Patomäki S, Hasu, M, } \\
\text { \& Pasto V }\end{array}$ & $\begin{array}{l}\text { Design and evaluation of a tactile memory } \\
\text { game for visually impaired children }\end{array}$ & 2007 \\
\hline ST11 & Colozzi GA, Ward, LW, Crotty, KE & $\begin{array}{l}\text { Comparison of Simultaneous Prompting } \\
\text { Procedure in 1:1 and Small Group Instruction } \\
\text { to Teach Play Skills to Preschool Students } \\
\text { with Pervasive Developmental Disorder and } \\
\text { Developmental Disabilities }\end{array}$ & 2008 \\
\hline ST12 & Hsieh HC & $\begin{array}{l}\text { Effects of ordinary and adaptive toys on } \\
\text { pre-school children with developmental } \\
\text { disabilities }\end{array}$ & 2008 \\
\hline ST13 & Ganz JB, Flores MM & $\begin{array}{l}\text { Effects of the Use of Visual Strategies in Play } \\
\text { Groups for Children with Autism Spectrum } \\
\text { Disorders and Their Peers }\end{array}$ & 2008 \\
\hline ST14 & $\begin{array}{l}\text { De Falco S, Esposito G, Venuti P, } \\
\text { Bornstein MH }\end{array}$ & $\begin{array}{l}\text { Fathers' Play with Their Down Syndrome } \\
\text { Children }\end{array}$ & 2008 \\
\hline
\end{tabular}


Continued Table 3.2: Selected papers.

\begin{tabular}{lllr}
\hline Code & Author/s & Title & Year \\
\hline ST15 & Cress CJ, Moskal L, Hoffmann A & $\begin{array}{l}\text { Parent Directiveness in Free Play with Young } \\
\text { Children with Physical Impairments }\end{array}$ & 2008 \\
ST16 & Buchanan M, Johnson Giovacco T & $\begin{array}{l}\text { A Second Look at the Play of Young Children } \\
\text { with Disabilities }\end{array}$ & 2009 \\
ST17 & Marti P, Moderini C, Giusti L, & A robotic toy for children with special needs: & 2009 \\
& Pollini A & From requirements to design & 2009 \\
ST18 & Malone M & Patterns of Home- and Classroom-Based & Toy Play of Preschoolers with and without \\
& & Intellectual Disabilities
\end{tabular}

ST19 Lang R, Machalicek W, O’Reilly M, Review of Interventions to Increase Functional

2009 Sigafoos J, Rispoli M, Shogren K, and Symbolic Play in Children with Autism Regester A

ST20 Odle BM, Irving A, Foulds R Usability of an adaptable video game platform 2009 for children with cerebral palsy

ST21 Di Carlo CF, Schepis MM, Flynn L Embedding Sensory Preference into Toys to 2009 Enhance Toy Play in Toddlers with Disabilities

ST22 Di Carlo CF, Schepis, MM, Flynn, L Exploring play styles with a robot companion collaborative play in children with learning disabilities

ST24 Handen BL, Sagady AE, McAuliffe- Methylphenidate and Play Skills in Children Bellin S with Intellectual Disability and ADHD

ST25 Venuti P, de Falco S, Esposito G, Bornstein $\mathrm{MH}$

Mother-Child Play: Children with Down Syndrome and Typical Development

ST26 Marti P, Giusti L A robot companion for inclusive games: A user2010 centred design perspective

ST27 Walberg, Loncola J, Craig-Unkefer LA

An Examination of the Effects of a Social Communication Intervention on the Play Behaviors of Children with Autism Spectrum Disorder

ST28 Barton EE Development of a Taxonomy of Pretend Play for 2010 Children with Disabilities 
Table 3.2: Selected papers.

\begin{tabular}{llll}
\hline Code & Author/s & Title & Year \\
\hline ST30 & Myck-Wayne J & $\begin{array}{l}\text { In Defense of Play: Beginning the Dialog about } \\
\text { the Power of Play }\end{array}$ & 2010
\end{tabular}

ST31 Pizzo L, Bruce SM

Language and Play in Students with Multiple

Disabilities and Visual Impairments or Deaf-

Blindness

ST32 De Falco S, Esposito, G,Venuti P, Bornstein MH

Mothers and Fathers at Play with Their Children

2010

with Down Syndrome: Influence on Child

Exploratory and Symbolic Activity

ST33 Tsao LL, McCabe H

Why Won't He Play with Me?: Facilitating

Sibling Interactions

ST34 Ganz JB, Flores MM

Supporting the Play of Preschoolers with

Autism Spectrum Disorders: Implementation of Visual Scripts

ST35 Clark MK, Nwokah, EE

Play and Learning in Summer Camps for

Children with Special Needs

ST36 Lifter K, Mason, EJ, Barton, EE

Children's Play: Where We Have Been and

ST37 Elmore SR, Vail CO

Effects of Isolate and Social Toys on the Social Interactions of Preschoolers in an Inclusive Head Start Classroom

ST38 Stanton-Chapman TL, Hadden DS

Encouraging Peer Interactions in Preschool

Classrooms: The Role of the Teacher

ST39 Klein T, Gelderblom GJ, de Witte L, Evaluation of short term effects of the IROMEC Vanstipelen S robotic toy for children with developmental disabilities

ST40 Jull, S,; Mirenda, P, Parents as Play Date Facilitators for

ST42 Pfeifer LI, Pacciulio AM, dos

Pretend Play of Children with Cerebral Palsy

Santos CA, dos Santos JL, Stagnitti KE

ST43 Wasterfors D 
Continued Table 3.2: Selected papers.

\begin{tabular}{|c|c|c|c|}
\hline Code & Author/s & Title & Year \\
\hline ST44 & Frey JR, Kaiser AP & $\begin{array}{l}\text { The Use of Play Expansions to Increase the } \\
\text { Diversity and Complexity of Object Play in } \\
\text { Young Children with Disabilities }\end{array}$ & 2011 \\
\hline ST45 & Vail CO, Elmore SR & $\begin{array}{l}\text { Tips for Teachers Selecting Toys to Facilitate } \\
\text { Social Interaction }\end{array}$ & 2011 \\
\hline ST46 & Burke J. & $\begin{array}{l}\text { "Some Kids Climb up; Some Kids Climb down”: } \\
\text { Culturally Constructed Play-Worlds of Children } \\
\text { with Impairments }\end{array}$ & 2012 \\
\hline ST47 & $\begin{array}{l}\text { Chiarello LA, Palisano RJ, Bartlett } \\
\text { DJ, McCoy Westcott S }\end{array}$ & $\begin{array}{l}\text { A Multivariate Model of Determinants } \\
\text { of Change in Gross-Motor Abilities and } \\
\text { Engagement in Self-Care and Play of Young } \\
\text { Children with Cerebral Palsy }\end{array}$ & 2012 \\
\hline ST48 & $\begin{array}{l}\text { Bartolomé NA, Zorrilla AM, } \\
\text { Zapirain Bg }\end{array}$ & $\begin{array}{l}\text { A serious game to improve human } \\
\text { relationships in patients with neuro- } \\
\text { psychological disorders }\end{array}$ & 2012 \\
\hline ST49 & Hsieh HC & $\begin{array}{l}\text { Effectiveness of Adaptive Pretend Play on } \\
\text { Affective Expression and Imagination of } \\
\text { Children with Cerebral Palsy }\end{array}$ & 2012 \\
\hline ST50 & Wong C, Kasari C & $\begin{array}{l}\text { Play and Joint Attention of Children with } \\
\text { Autism in the Preschool Special Education } \\
\text { Classroom }\end{array}$ & 2012 \\
\hline ST51 & Ganz JB, Flores MM & $\begin{array}{l}\text { Teaching Play Skills to Children with Autism } \\
\text { through Video Modeling: Small Group } \\
\text { Arrangement and Observational Learning }\end{array}$ & 2012 \\
\hline ST52 & $\begin{array}{l}\text { Scheflen Clifford S, Freeman, SFN, } \\
\text { Paparella T }\end{array}$ & $\begin{array}{l}\text { Using Video Modeling to Teach Young Children } \\
\text { with Autism Developmentally Appropriate Play } \\
\text { and Connected Speech }\end{array}$ & 2012 \\
\hline ST53 & Nader-Grosbois N, Vieillevoye S & $\begin{array}{l}\text { Variability of Self-Regulatory Strategies in } \\
\text { Children with Intellectual Disability and } \\
\text { Typically Developing Children in Pretend Play } \\
\text { Situations }\end{array}$ & 2012 \\
\hline ST54 & Matthews A, Rix, J & $\begin{array}{l}\text { Early Intervention: Parental Involvement, Child } \\
\text { Agency and Participation in Creative Play }\end{array}$ & 2013 \\
\hline ST55 & Stockall N, Dennis L & $\begin{array}{l}\text { Fathers' Role in Play: Enhancing Early } \\
\text { Language and Literacy of Children with } \\
\text { Developmental Delays }\end{array}$ & 2013 \\
\hline
\end{tabular}


Table 3.2: Selected papers.

\begin{tabular}{lllc}
\hline Code & Author/s & Title & Year \\
\hline ST56 & Jung S, Sainato DM & $\begin{array}{l}\text { Teaching Play Skills to Young Children with } \\
\text { Autism }\end{array}$ & 2013
\end{tabular}

ST57 Hughett K, Kohler FW, Raschke D The Effects of a Buddy Skills Package on Play

ST58 Guerette P, Furumasu, Jan; Tefft, The Positive Effects of Early Powered Mobility Donita on Children's Psychosocial and Play Skills

ST59 Hobson JA, Hobson RP., Malik S, The Relation between Social Engagement and Bargiota K, Calo S

Pretend Play in Autism

ST60 Crawford SK, Stafford KN, Phillips SM, Scott KJ, Tucker P.

Strategies for inclusion in play among children with physical disabilities in childcare centers: an integrative review

ST61 Mills PE, Beecher CC, Dale PS, Language of Children with Disabilities to Peers Cole KN, Jenkins JR at Play: Impact of Ecology

ST62 Stockall N, Dennis LR, Rueter JA Play-Based Interventions for Children with PDD

ST63 Oliveira E, Sousa G, Aires Tavares $\mathrm{T}$, Tanner $\mathrm{P}$

Sensory stimuli in gaming interaction: The potential of games in the intervention for children with cerebral palsy

ST64 Barton EE Teaching Generalized Pretend Play and Related Behaviors to Young Children with Disabilities

ST65 Suhonen E, Nislin MA, Alijoki A, Children's Play Behaviour and Social Sajaniemi NK Communication in Integrated Special Day-Care Groups

ST66 Murphy FE, Donovan M, i4Toys: Video technology in toys for improved Cunningham J, Jezequel T, García access to play, entertainment, and education E, Jaeger A, McCarthy J, Popovici EM

ST67 Macedo I, Trevisan DG, Vasconcelos CN, Clua E

Observed Interaction in Games for Down Syndrome Children

ST68 Finke EH, Hickerson B, McLaughlin E

Parental Intention to Support Video Game Play by Children with Autism Spectrum Disorder: An Application of the Theory of Planned Behavior 
Continued Table 3.2: Selected papers.

\begin{tabular}{|c|c|c|c|}
\hline Code & Author/s & Title & Year \\
\hline ST70 & Chuang TY, Kuo MS & $\begin{array}{l}\text { A Motion-Sensing Game-Based Therapy to } \\
\text { Foster the Learning of Children with Sensory } \\
\text { Integration Dysfunction }\end{array}$ & 2016 \\
\hline ST71 & $\begin{array}{l}\text { Ryalls BO, Harbourne R, Kelly- } \\
\text { Vance L, Wickstrom J, Stergiou N, } \\
\text { Kyvelidou A }\end{array}$ & $\begin{array}{l}\text { A Perceptual Motor Intervention Improves Play } \\
\text { Behavior in Children with Moderate to Severe } \\
\text { Cerebral Palsy }\end{array}$ & 2016 \\
\hline ST72 & Kossyvaki L, Papoudi D. & $\begin{array}{l}\text { A Review of Play Interventions for Children with } \\
\text { Autism at School }\end{array}$ & 2016 \\
\hline ST73 & Karaaslan 0 & $\begin{array}{l}\text { Comparison of Social Engagement of Children } \\
\text { Having Disabilities with Their Mothers and } \\
\text { Fathers }\end{array}$ & 2016 \\
\hline ST74 & Mahoney G, Solomon R & $\begin{array}{l}\text { Mechanism of Developmental Change in the } \\
\text { PLAY Project Home Consultation Program: } \\
\text { Evidence from a Randomized Control Trial }\end{array}$ & 2016 \\
\hline ST75 & $\begin{array}{l}\text { Shireman ML, Lerman, DC, } \\
\text { Hillman CB }\end{array}$ & $\begin{array}{l}\text { Teaching Social Play Skills to Adults and } \\
\text { Children with Autism as an Approach to } \\
\text { Building Rapport }\end{array}$ & 2016 \\
\hline ST76 & Kim S & $\begin{array}{l}\text { Use of Video Modeling to Teach } \\
\text { Developmentally Appropriate Play with Korean } \\
\text { American Children with Autism }\end{array}$ & 2016 \\
\hline ST77 & Eilertsen LJ & $\begin{array}{l}\text { Constructing Conditions of Participation } \\
\text { through Play Formats: Children with Hearing } \\
\text { Impairment and Complex Needs }\end{array}$ & 2017 \\
\hline ST78 & $\begin{array}{l}\text { Mizumura Y, Ishibashi K, Yamada } \\
\text { S, Takanishi A, } \\
\text { Ishii H }\end{array}$ & $\begin{array}{l}\text { Mechanical design of a jumping and } \\
\text { rolling spherical robot for children with } \\
\text { developmental disorders }\end{array}$ & 2017 \\
\hline ST79 & $\begin{array}{l}\text { Miller LJ, Schoen SA, Camarata } \\
\text { SM, McConkey J. Kanics IM, } \\
\text { Valdez A, Hampton S }\end{array}$ & $\begin{array}{l}\text { Play in Natural Environments: A Pilot Study } \\
\text { Quantifying the Behavior of Children on } \\
\text { Playground Equipment }\end{array}$ & 2017 \\
\hline ST80 & $\begin{array}{l}\text { Nelson C, Paul K, Johnston, SS, } \\
\text { Kidder JE }\end{array}$ & $\begin{array}{l}\text { Use of a Creative Dance Intervention Package } \\
\text { to Increase Social Engagement and Play } \\
\text { Complexity of Young Children with Autism } \\
\text { Spectrum Disorder }\end{array}$ & 2017 \\
\hline
\end{tabular}




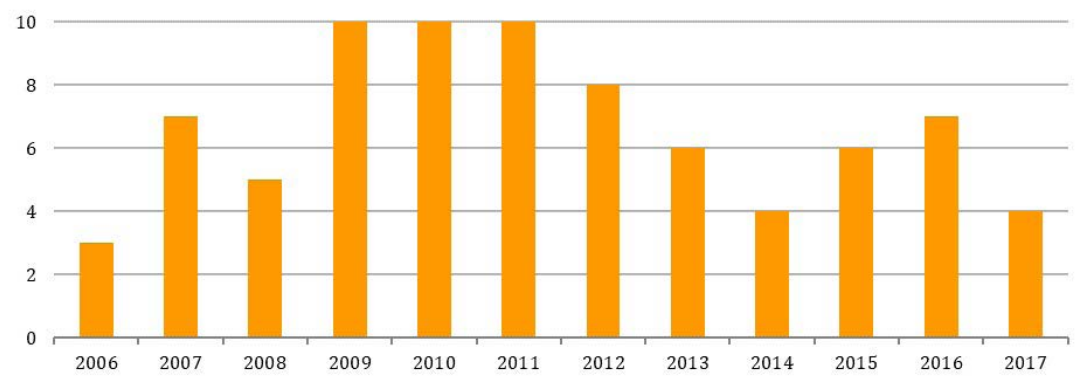

Graph 3.1: Years distribution of the selected paper.

Subsequently, the disabilities were re-classified according to the seven typologies identified by the LUDI network and considered significant in relation with the topic of play. Most of the studies focused on children with autism ( $\mathrm{N}=31$ - ST 4, 6, 7, 8, 11, 13, 17, 19, 22, 26, 27, 28, 33, 34, 40, 50, 51, 52, 56, 59, 62, 64, 68, 72, 73, 74, 75, 76, 78, 79, 80). Followed by Mental or Intellectual Disability ( $=25$; ST 4, 5, 11, 14, 16, 17, 18, 22 , $25,26,28,32,37,39,42,44,45,53,54,55,59,61,64,67,73)$ including studies about Down Syndrome $(\mathrm{N}=12)$, Intellectual Disabilities $(\mathrm{N}=7)$ and Developmental Delays $(\mathrm{N}=6)$. According to the LUDI Conceptual Review of Disabilities in the category of Physical Impairments were included papers $(\mathrm{N}=15$; ST 9, 15, 16, 17, 20, 22, 26, 42, 43, $47,49,58,63,69,71)$ related to motor impairments $(\mathrm{N}=3)$, physical disabilities $(\mathrm{N}=$ 4), cerebral palsy $(\mathrm{N}=7)$ and spinal cord injury $(\mathrm{N}=1)$. Hearing Impairments were the less investigated disability $(\mathrm{N}=1$; ST 77).

The information about the two categories of play was then retrieved. Sixty-two papers were included in the category of play for the sake of play (ST 1, 3, 4, 5, 7, 8, 9, $10,11,12,13,14,15,16,17,18,19,21,22,23,24,25,26,27,28,31,32,33,34,35,37,38$, 39, 42, 44, 45, 46, 47, 49, 50, 51, 52, 53, 54, 57, 58, 59, 60, 63, 64, 65, 66, 67, 68, 69, 71, 72, $73,74,76,79,80$ ), 14 into the one of play like activity (ST 20, 29, 30, 40, 43, 48, 55, 56, $61,62,70,75,77,78)$ and 4 in both categories (ST 2, 6, 36, 41). Most of the articles that feature both play as play for the sake of play and play like activity belong to the Super Group of Social Sciences.

For each paper the journal was identified: totally 51 different titles of journals were founded. The journals with the major number of retrieved articles were:

- 'Young Exceptional Children' ( $\mathrm{N}=$ 5; ST 33, 34, 30, 38, 44, 62);

- 'Education \& Training in Developmental Disabilities' ( $\mathrm{N}=4$; ST 5, 7, 11, 19);

- 'Education and Training in Autism and Developmental Disabilities' ( $N=4$; ST 27, $51,52,80)$;

- 'Journal of Autism and Developmental Disorders' ( $\mathrm{N}=4$; ST 4, 13, 50, 74). 
Table 3.3: Disabilities considered in the selected papers reorganized according to the LUDI classification.

\begin{tabular}{|c|c|c|c|}
\hline LUDI classification of disabilities & Label reported in the papers & $\mathbf{N}$ & $\mathrm{N}$ (tot) \\
\hline Autism Spectrum Disorder & Autism & 31 & 31 \\
\hline \multirow[t]{3}{*}{ Mental or Intellectual disabilities } & Down Syndrome & 12 & 25 \\
\hline & Intellectual disability & 7 & \\
\hline & Developmental disabilities & 6 & \\
\hline \multirow[t]{4}{*}{ Physical impairments } & Physical Disabilities & 4 & 15 \\
\hline & Cerebral Palsy & 7 & \\
\hline & Motor impairments & 3 & \\
\hline & Spinal cord injury & 1 & \\
\hline \multirow[t]{3}{*}{ Visual impairments } & Visual impairment & 3 & 5 \\
\hline & Blindness & 1 & \\
\hline & Blindness with deafness & 1 & \\
\hline Hearing impairments & Hearing Impairment & 1 & 1 \\
\hline \multirow[t]{2}{*}{ Communication disorders } & Language delays & 2 & 3 \\
\hline & Social and communication Delays & 1 & \\
\hline Multiple disabilities & Multiple disabilities & 3 & 3 \\
\hline \multirow{11}{*}{$\begin{array}{l}\text { Other disabilities not included in the } \\
\text { LUDI classification of disabilities }\end{array}$} & Label reported in the papers & $\mathbf{N}$ & $N$ (tot) \\
\hline & ADHD & 3 & 31 \\
\hline & Learning disabilities & 5 & \\
\hline & Regulatory disorder & 2 & \\
\hline & Developmental delays & 6 & \\
\hline & Neuro-psychological disorders & 1 & \\
\hline & Pervasive developmental disorder & 1 & \\
\hline & Sensory disorder & 1 & \\
\hline & Sensory Integration Dysfunction & 1 & \\
\hline & Severe disabilities & 1 & \\
\hline & Not specified & 10 & \\
\hline
\end{tabular}

Only two journals, 'Journal of Play' and 'American Journal of Play', were not present on the SJR portal. In Table 3.4, the list of all journal titles retrieved is reported.

According to the SJR classification 54 studies were included in the Super Groups of the Social Science and 33 in the one of Health Sciences, whereas 16 entered the Physical Sciences Super Group. No studies were founded in the Super Group Life Sciences. The three studies published in the two journals not classified by SJR were not considered. 
Table 3.4: List of the journals selected in the current paper.

\begin{tabular}{|c|c|}
\hline Journal & Article (ID) \\
\hline American journal of play & 16 \\
\hline American Journal on Intellectual and Developmental Disabilities & 25 \\
\hline Assistive Technology & 58 \\
\hline British Journal of Developmental Psychology & 59 \\
\hline Communication Disorders Quarterly & 15 \\
\hline Deafness \& Education International & 77 \\
\hline Disability \& Society & 43,46 \\
\hline Early Childhood Education Journal & 55 \\
\hline Early years & 54 \\
\hline Education \& Training in Developmental Disabilities & $5,7,11,19$ \\
\hline Education and Training in Autism and Developmental Disabilities & $27,51,52,80$ \\
\hline Educational Sciences: Theory and Practice & 73 \\
\hline European Journal of Special Needs Education & 65 \\
\hline Exceptional Children & 64 \\
\hline Frontiers in psychology & 71 \\
\hline Infants and young children & 21,28 \\
\hline $\begin{array}{l}\text { Intelligent Technologies for Interactive Entertainment (INTETAIN), } 2015 \text { 7th } \\
\text { International Conference on IEEE }\end{array}$ & 69 \\
\hline Interacting with Computers & 10 \\
\hline International Journal of Disability, Development and Education & 18,72 \\
\hline International Journal of Special Education & 3 \\
\hline Journal of applied behavior analysis & 75 \\
\hline Journal of Applied Research in Intellectual Disabilities & 32 \\
\hline Journal of Autism and Developmental Disorders & $4,13,50,74$ \\
\hline Journal of early intervention & 36,61 \\
\hline Journal of Educational Technology \& Society & 70 \\
\hline Journal of Intellectual \& Developmental Disability & 56 \\
\hline Journal of Intellectual Disability Research & 14,53 \\
\hline Journal of Mental Health Research in Intellectual Disabilities & 24 \\
\hline Journal of Occupational Therapy, Schools, \& Early Intervention & 79 \\
\hline
\end{tabular}


Continued Table 3.4: List of the journals selected in the current paper.

\begin{tabular}{|c|c|}
\hline Journal & Article (ID) \\
\hline Journal of play & 35 \\
\hline Journal of Positive Behavior Interventions & 40 \\
\hline Journal of Visual Impairment \& Blindness & 1,31 \\
\hline Language, speech, and hearing services in schools & 68 \\
\hline NHSA Dialog A Research-to-Practice Journal for the Early Childhood Field & $2,37,45$ \\
\hline Physical \& Occupational Therapy in Pediatrics & $42,47,60$ \\
\hline Proceedings - IEEE International Conference on Robotics and Automation & 26 \\
\hline Research and Practice for Persons with Severe Disabilities & 8,76 \\
\hline Research in Developmental Disabilities: A Multidisciplinary Journal & 12,49 \\
\hline $\begin{array}{l}\text { Robotics and Biomimetics (ROBIO), } 2017 \text { IEEE International Conference on } \\
\text { IEEE }\end{array}$ & 78 \\
\hline $\begin{array}{l}\text { RO-MAN } 2007 \text { - The 16th IEEE International Symposium on Robot and } \\
\text { Human Interactive Communication }\end{array}$ & 6 \\
\hline $\begin{array}{l}\text { The 18th IEEE International Symposium on Robot and Human Interactive } \\
\text { Communication }\end{array}$ & 22 \\
\hline The Journal of Spinal Cord Medicine & 9 \\
\hline Topics in Early Childhood Special Education & 41,57 \\
\hline Young Exceptional Children & $33,34,30,38,44,62$ \\
\hline 2009 IEEE 35th Annual Northeast Bioengineering Conference & 20 \\
\hline 2009 IEEE International Conference on Rehabilitation Robotics & 17,23 \\
\hline $\begin{array}{l}2010 \text { 2nd International IEEE Consumer Electronics Society’s Games } \\
\text { Innovations Conference }\end{array}$ & 48 \\
\hline 2010 International Symposium on Information Technology & 29,39 \\
\hline 2014 IEEE Games Media Entertainment & 63 \\
\hline 2015 48th Hawaii International Conference & 67 \\
\hline 2015 IEEE International Symposium on Technology and Society (ISTAS) & 66 \\
\hline
\end{tabular}

The journals containing the articles included in this review were ascribable to different Major Thematic Areas. As shown in the Table 3.5, in the Super Group Social Sciences (54) most articles were included in the Major Thematic Areas of Psychology (42), Social Sciences (37) and Arts and Humanities (6). Within the area of Psychology, the great prevalence of articles referred to Specific Subject Categories Developmental and 
Educational Psychology (36); regarding the area Social Sciences the most relevant Specific Subject Category identified was Education (31).

The second Super Group for representativeness was that of the Health Sciences ( $\mathrm{N}=33$ studies). Analysing the overall internal architecture, the most representative Major Thematic Areas were Medicine ( $\mathrm{N}=21$ studies), Health Professions $(\mathrm{N}=14)$ and Neurosciences $(\mathrm{N}=3)$. With reference to the categories - micro level of the SJR classification - 13 dimensions had a value of articles greater than three: for Medicine, Paediatrics, Perinatology, and Child Health $(\mathrm{N}=9)$, Rehabilitation $(\mathrm{N}=9)$, Psychiatry and Mental health $(\mathrm{N}=8)$, Medicine (miscellaneous, $\mathrm{N}=5)$ Clinical Neurology $(\mathrm{N}=$ 4); for the Health Professions, Health Professions (miscellaneous, $N=7$ ), Physical Therapy, Sports Therapy and Rehabilitation $(\mathrm{N}=4)$ and Occupational Therapy $(\mathrm{N}=4)$.

The last Super Group detected was that of the Physical Sciences (16 articles) whose architecture was, compared to the two previously illustrated, less articulated as constituted only by two Major Thematic Areas: Computer Sciences with 15 articles and Engineering with 9 articles. The two areas were respectively divided into five and four categories (Computer Graphics and Computer-Aided Design, Computer Vision and Pattern Recognition, Human-Computer Interaction, Software) with an article value of more than three and in two categories of which only Electrical and Electronic Engineering includes more than three researches.

This concentration of articles in two categories (31 in Education and 36 in Developmental and Educational Psychology) determines an inhomogeneous distribution with an average value of 5.82 and a standard deviation of 9.53. The Super Group of Health Sciences, instead, is characterized by a more homogeneous distribution of studies within the different categories, such as Clinical Neurology, Ophthalmology, Physical Therapy, Sports Therapy and Rehabilitation, and in which the average value settles around 3.82 with a standard deviation of 1.89 . The trend in the number of studies, in the Super Group of Physical Sciences, presents an average value of 5.25 and a standard deviation of 4.89. This Super Group could be considered in an intermediate position compared to the two previously analysed.

As previously reported the most presented diagnosis was Autism Spectrum Disorder ( $\mathrm{N}=31)$. Concerning the SJR classification, the largest number of studies is within the Super Group Social Sciences $(\mathrm{N}=25)$, followed by Health Sciences $(\mathrm{N}=9)$ and Physical Sciences $(\mathrm{N}=5)$; the Major Thematic Areas most involved are Psychology $(\mathrm{N}=24)$ and Social Sciences $(\mathrm{N}=17)$.

Studies related to the intellectual disability were 25 and according to the Super Groups SJR classification, most of the studies concerning this disability were included in publications belonging to the Social Sciences $(\mathrm{N}=20)$, then the Health Sciences $(\mathrm{N}=10)$ and Physical Sciences $(\mathrm{N}=5)$. The most representative Major Thematic Areas was represented by Psychology $(\mathrm{N}=16)$ and Social sciences $(\mathrm{N}=13)$. 
Table 3.5: Major Thematic Areas and Specific Subject Categories in the selected papers.

\begin{tabular}{|c|c|c|c|}
\hline $\begin{array}{l}\text { Super } \\
\text { Groups }\end{array}$ & $\begin{array}{l}\text { Major Thematic } \\
\text { Areas }\end{array}$ & $\begin{array}{l}\text { Specific } \\
\text { Subject Categories }\end{array}$ & \\
\hline \multirow{13}{*}{$\begin{array}{l}\text { Health } \\
\text { sciences (33) }\end{array}$} & \multirow[t]{7}{*}{ Medicine (21) } & Ophthalmology & 2 \\
\hline & & Rehabilitation & 9 \\
\hline & & Medicine (miscellaneous) & 5 \\
\hline & & Paediatrics, Perinatology, and Child Health & 9 \\
\hline & & Psychiatry and Mental health & 8 \\
\hline & & Clinical Neurology & 4 \\
\hline & & Public Health, Environmental and Occupational Health & 3 \\
\hline & \multirow{4}{*}{$\begin{array}{l}\text { Health professions } \\
\text { (14) }\end{array}$} & Occupational Therapy & 4 \\
\hline & & Physical Therapy, Sports Therapy and Rehabilitation & 4 \\
\hline & & Health Professions (miscellaneous) & 7 \\
\hline & & Speech and Hearing & 2 \\
\hline & \multirow[t]{2}{*}{ Neuroscience (3) } & Developmental Neuroscience & 1 \\
\hline & & Neurology & 2 \\
\hline \multirow{14}{*}{$\begin{array}{l}\text { Social Sciences } \\
(54)\end{array}$} & \multirow{5}{*}{$\begin{array}{l}\text { Social Sciences } \\
\text { (37) }\end{array}$} & Education & 31 \\
\hline & & Social Sciences (miscellaneous) & 2 \\
\hline & & Linguistics and Language & 2 \\
\hline & & Health (social sciences) & 2 \\
\hline & & Sociology and Political Sciences & 2 \\
\hline & \multirow[t]{6}{*}{ Psychology (42) } & Social psychology & 3 \\
\hline & & Developmental and educational psychology & 36 \\
\hline & & Neuropsychology and Physiological Psychology & 1 \\
\hline & & Applied Psychology & 2 \\
\hline & & Psychology (miscellaneous) & 2 \\
\hline & & Clinical Psychology & 2 \\
\hline & \multirow{3}{*}{$\begin{array}{l}\text { Arts and } \\
\text { Humanities (6) }\end{array}$} & Arts and Humanities (miscellaneous) & 4 \\
\hline & & Language and Linguistics & 1 \\
\hline & & Philosophy & 1 \\
\hline
\end{tabular}


Table 3.5: Major Thematic Areas and Specific Subject Categories in the selected papers.

\begin{tabular}{llll}
\hline $\begin{array}{l}\text { Super } \\
\text { Groups }\end{array}$ & $\begin{array}{l}\text { Major Thematic } \\
\text { Areas }\end{array}$ & $\begin{array}{l}\text { Specific } \\
\text { Subject Categories }\end{array}$ \\
\hline Physical & $\begin{array}{l}\text { Computer Science } \\
\text { Sciences (16) }\end{array}$ & Artificial Intelligence & 1 \\
& & $\begin{array}{l}\text { Computer Graphics and Computer-Aided Design } \\
\text { Computer Vision and Pattern Recognition }\end{array}$ & 4 \\
& & Human-Computer Interaction & 14 \\
& Software & 5 \\
& Engineering (9) & Electrical and Electronic Engineering & 8 \\
& & Engineering (miscellaneous) & 1 \\
\hline
\end{tabular}

15 studies out of 80 included were attributable to physical impairments: 6 of them were found in publications belonging to the Super Group of Health Sciences, followed by the one of Physical Sciences $(\mathrm{N}=5)$ and Social Sciences $(\mathrm{N}=4)$. The most representative Major Subject Areas were Health Profession $(\mathrm{N}=5)$ in Health Sciences and Computer Science $(\mathrm{N}=5)$ in Physical Sciences.

Autism, the most studied disability, includes papers referring to 8 different Major Thematic Areas, with a clear prevalence (25/31) of researches falling within the Social Sciences Super Group. The most populated area (24) is the one of Psychology with the specific subject category of Developmental and Educational Psychology. A substantial similarity characterizes the distribution of the studies also included in the second most representative disability, namely the intellectual one, in which the Social Sciences area although always preeminent is slightly smaller (7\% less) to the benefit of the Health Sciences. The latter that in autism included $23 \%$ of the studies, in this disability come to include $29 \%$. The distribution in terms of areas and categories reflects the one already highlighted in autism. On the other hand, the situation of the third most studied disability, motor impairments, appears different, since the relationships between the three Super Groups change substantially. The most representative Super Group (40\%), in fact, is that of the Health Sciences with two areas, Health Professions and Medicine, while the Social Sciences are the least involved (only $27 \%$ of the studies). Finally, it should also be noted that the Super Group of Physical Sciences has major importance including 33\% of the researches.

\subsection{Discussion}

This systematic review identified 80 articles that in the last 10 years (since 2006) focused on the research topic of play for children with disabilities. The papers were 
presented continuously in the period considered, highlighting a continuative interest on this issue. It should also be noted that, since the Convention of the Rights of the Child (United Nations, 1989), also at international level there has been an important movement, consolidated in the last 10 years, aiming at sanctioning the right to play also for children with disabilities (Bianquin, 2017; Towler, 2018) as evidenced by authoritative documents: the Convention on the Rights of Persons with Disabilities, Article 30 (UN, 2006); the General Comment No 17 (UN, 2013), the Position Statement on the Play Rights of Disabled Children (IPA, 2015). References to this authoritative documentation, however, were reported in the theoretical framework of two papers only (Buchanan, Johnson \& Giovacco, 2009; Barton, 2015) out of the 80 investigated.

The high number of scientific journals containing the articles included in the present review, 51 journals for a total of 80 articles, confirms the existence of a multiperspectival approach to the theme of play (Bulgarelli \& Bianquin, 2017; Bulgarelli, Bianquin, Caprino, Molina, \& Ray-Kaeser, 2018). This variety is also supported by the linguistic analysis of the titles of scientific publications belonging to the group of journals. There is a clear connection with specific scientific areas of study directly in the title of the journal itself: to psychology (British Journal of Developmental Psychology, Frontiers in Psychology), education (Early Childhood Education Journal, International Journal of Special Education), technologies (Assistive technology, Interacting with Computers) and medicine (Journal of Mental Health Research in Intellectual Disability, The Journal of Spinal Cord Medicine). The same type of analysis conducted on the titles of the proceedings, the other component of the scientific publications considered, highlights that 11 titles out of the 12 retrieved made a direct reference to the technologies (2014 IEEE Games Media Entertainment, 2009 IEEE International Conference on Rehabilitation Robotics). Finally, it should be noted that there are only two journals stating that play is the focus of their interest: American journal of play and Journal of play.

This multi-perspectival approach also emerges from the analysis carried out through the classification proposed by SCImago. Regarding the Super Groups, Social Sciences appears to be the most represented, including the highest number of studies (54 out of 80), followed by the Health Sciences (33 studies included). The comparison between these two Super Groups underlines a similar architecture regarding the number of areas and categories that constitute them, but it must be noted that the one of Social Sciences is monopolized by studies falling in the categories of Education and Developmental and Educational Psychology, which are traditionally interested in the topic of play.

The investigation of the categories containing the largest number of studies in each Super Group identifies how some of these have a major role compared to the study of play for children with disabilities: apart from the aforementioned Education and Psychology, these are the Paediatrics and Rehabilitation (for the Health Sciences) and the Computer Vision and Pattern Recognition (for the Physical Sciences). The analysis carried out on the classifying architectures of the SJR levels give a further 
evidence on the multidisciplinary nature characterizing the researches focusing on the topic of play.

Moreover, the disciplinary variety outlined above emerged from the examination of the studies referring to the different types of disability, to the three most represented (highest number of researches). The multidisciplinary perspective that accompanies the theme of play seems to be reflected also in the distribution of studies related to the different disabilities as proposed by SCImago, even if showing a differentiation as regards the scientific fields involved. A further qualitative analysis of the present survey could gather more detailed information on the studies with regards to the methodologies, aims and results in order to relate them to the categories of the SCImago classification system.

Despite the complexity of the results obtained, this work presents some important limits with reference to the number of databases investigated and the choice of a specific classification system. Future research could implement the number of databases and perform analyses and subsequent comparisons with different classifications to find further disciplinary and interdisciplinary perspectives.

\subsection{References}

Ahmad, W. F. W., Akhir, E. A. P., \& Azmee, S. (2010). Game-based learning courseware for children with learning disabilities. 2010 International Symposium on Information Technology (ITSim), 1, 1-4.

Ashley, B. (1999). Park playgrounds can meet many needs. Play Rights, 22, 12-21.

Banerji, S., \& Heng, J. (2009). A unified, neuro-physio platform to facilitate collaborative play in children with learning disabilities. 2009 IEEE International Conference on Rehabilitation Robotics, 912-917.

Bartolomé, N. A., Zorrilla, A. M., \& Zapirain, B. G. (2010). A serious game to improve human relationships in patients with neuro-psychological disorders. Games Innovations Conference (ICE-GIC), 2010 International IEEE Consumer Electronics Society's, 1-5.

Barton, E. E. (2010). Development of a taxonomy of pretend play for children with disabilities. Infants \& young children, 23(4), 247-261.

Barton, E. E. (2015). Teaching generalized pretend play and related behaviors to young children with disabilities. Exceptional Children, 81(4), 489-506.

Bateson, G. (1955). A theory of play and fantasy. Psychiatric Research Report, 239-251.

Besio, S. (Ed.) (2010). Gioco e giocattoli per il bambino con disabilità motoria [Play and toys for children with motor impairments]. Milano, I: Edizioni Unicopli.

Besio, S. (2017). The need for play for the sake of play. In S. Besio, D. Bulgarelli, \& V. StanchevaPopkostadinova (Eds.), Play Development in Children with Disabilities. Warsaw, P: De Gruyter Open.

Besio, S., Bulgarelli, D., \& Stancheva-Popkostadinova, V. (2017). Introduction. In S. Besio, D. Bulgarelli, V. Stancheva-Popkostadinova (Eds.), Play Development in Children with Disabilities. Warsaw, P: De Gruyter Open.

Besio S., Caprino F., \& Laudanna E. (2009). Methodological Framework to set up educational and therapy sessions with IROMEC. Trento, I: Uniservice. 
Besio, S., Carnesecchi, M., \& Encarnação, P. (2015). Introducing LUDI: a research network on play for children with disabilities. Studies in Health Technologies and informatics, 217, 689-95.

Bianquin, N. (2017). Ludi - Play for children with disabilities: l'interdisciplinarietà a supporto di un nuovo modello di intervento per il gioco del bambino con disabilità, [Ludi - Play for children with disabilities: interdisciplinarity to support a new model of intervention for play for children with disabilities]. Italian Journal of Special Education for Inclusion, V(5), 15-31.

Bianquin, N., \& Bulgarelli D. (2017). Conceptual review of disability. In S. Besio, D. Bulgarelli, \& V. Stancheva-Popkostadinova (Eds.). Play Development in Children with Disabilities. Warsaw, P: De Gruyter Open.

Brodin, J. (1999). Play in children with severe multiple disabilities: play with toys-a review. International Journal of Disability, Development and Education, 46(1), 25-34.

Buchanan, M., \& Johnson, T. G. (2009). A Second Look at the Play of Young Children with Disabilities. American Journal of Play, 2(1), 41-59.

Bulgarelli, D., \& Bianquin, N. (2017). Conceptual review of play. In: Besio, S., Bulgarelli, D., \& V. Stancheva-Popkostadinova (Eds.). Play Development in Children with Disabilities. Warsaw, P: De Gruyter Open.

Bulgarelli, D., \& Bianquin, N. (2018). La valutazione del gioco nella ricerca psico-pedagogica italiana, Una sintesi di ricerca. [Play evaluation in Italian psycho-pedagogical research, A synthesis of research] L'Integrazione Scolastica e Sociale, 17 (4), 26-36.

Burke, J. (2012). 'Some kids climb up; some kids climb down': culturally constructed play-worlds of children with impairments. Disability \& Society, 27(7), 965-981.

Celeste, M. (2006). Play Behaviors and Social Interactions of a Child Who Is Blind: In Theory and Practice. Journal of visual impairment \& Blindness, 100(2), 75-90.

Chiarello, L. A., Palisano, R. J., Bartlett, D. J., \& McCoy, S. W. (2011). A multivariate model of determinants of change in gross-motor abilities and engagement in self-care and play of young children with cerebral palsy. Physical \& occupational therapy in pediatrics, 31(2), 150-168.

Childress, D. C. (2011). Play behaviors of parents and their young children with disabilities. Topics in Early Childhood Special Education, 31(2), 112-120.

Chuang, T. Y., \& Kuo, M. S. (2016). A motion-sensing game-based therapy to foster the learning of children with sensory integration dysfunction. Journal of Educational Technology \& Society, 19(1).

Clark, M. K., \& Nwokah, E. E. (2010). Play and Learning in Summer Camps for Children with Special Needs. American Journal of Play, 3(2), 238-261.

Colozzi, G. A., Ward, L. W., \& Crotty, K. E. (2008). Comparison of simultaneous prompting procedure in 1: 1 and small group instruction to teach play skills to preschool students with pervasive developmental disorder and developmental disabilities. Education and Training in Developmental Disabilities, 226-248.

Cress, C. J., Arens, K. B., \& Zajicek, A. K. (2007). Comparison of engagement patterns of young children with developmental disabilities between structured and free play. Education and Training in Developmental Disabilities, 152-164.

Cress, C. J., Moskal, L., \& Hoffmann, A. (2008). Parent directiveness in free play with young children with physical impairments. Communication Disorders Quarterly, 29(2), 99-108.

Crawford, S. K., Stafford, K. N., Phillips, S. M., Scott, K. J., \& Tucker, P. (2014). Strategies for inclusion in play among children with physical disabilities in childcare centers: An integrative review. Physical \& occupational therapy in pediatrics, 34(4), 404-423.

Cook A., Encarnação P., \& Adams K. (2010). Robots: assistive technologies for play, learning and cognitive development. Technology and Disability, 22(3), 127-145.

De Falco, S., Esposito, G., Venuti, P., \& Bornstein, M. H. (2008). Fathers' play with their Down syndrome children. Journal of Intellectual Disability Research, 52(6), 490-502. 
De Falco, S., Esposito, G., Venuti, P., \& Bornstein, M. H. (2010). Mothers and fathers at play with their children with Down syndrome: influence on child exploratory and symbolic activity. Journal of Applied Research in Intellectual Disabilities, 23(6), 597-605.

DiCarlo, C. F., Schepis, M. M., \& Flynn, L. (2009). Embedding sensory preference into toys to enhance toy play in toddlers with disabilities. Infants \& Young Children, 22(3), 188-200.

DiCarlo, C. F., Stricklin, S. B., \& Reid, D. H. (2006). Increasing toy play among toddlers with and without disabilities by modifying the structural quality of the classroom environment. NHSA Dialog: A Research-to-Practice Journal for the Early Intervention Field, 9(1), 49-62.

Eilertsen, L. J. (2017). Constructing conditions of participation through play formats: children with hearing impairment and complex needs. Deafness \& Education International, 19(2), 95-106.

Elmore, S. R., \& Vail, C. O. (2011). Effects of isolate and social toys on the social interactions of preschoolers in an inclusive Head Start classroom. NHSA Dialog, 14(1), 1-15.

Falagas, M. E., Kouranos, V. D., Arencibia-Jorge, R., \& Karageorgopoulos, D. E. (2008). Comparison of SCImago journal rank indicator with journal impact factor. The FASEB journal, 22(8), 26232628.

Finke, E. H., Hickerson, B., \& McLaughlin, E. (2015). Parental intention to support video game play by children with autism spectrum disorder: An application of the theory of planned behavior. Language, speech, and hearing services in schools, 46(2), 154-165.

Frey, J. R., \& Kaiser, A. P. (2011). The use of play expansions to increase the diversity and complexity of object play in young children with disabilities. Topics in Early Childhood Special Education, 31(2), 99-111.

Ganz, J. B., \& Flores, M. M. (2008). Effects of the use of visual strategies in play groups for children with autism spectrum disorders and their peers. Journal of Autism and Developmental Disorders, 38(5), 926-940.

Ganz, J. B., \& Flores, M. M. (2010). Supporting the play of preschoolers with autism spectrum disorders: Implementation of visual scripts. Young Exceptional Children, 13(2), 58-70.

Garvey C. (1990). Play. Cambridge, UK: Harvard University Press.

Gómez-Núñez, A. J., Vargas-Quesada, B., de Moya-Anegón, F., \& Glänzel, W. (2011). Improving SCImago Journal \& Country Rank (SJR) subject classification through reference analysis. Scientometrics, 89(3), 741-750.

Gordon, G. (2009). What is Play? In Search of a Definition. In D. Kuschner (Ed.), From Children to Red Hatters. Diverse Images and Issues of Paly. Play and Culture Studies, Volume 8, Lanham, MA: University Press of America.

Guerette, P., Furumasu, J., \& Tefft, D. (2013). The positive effects of early powered mobility on children's psychosocial and play skills. Assistive Technology, (1), 39-48.

Handen, B. L., Sagady, A. E., \& McAuliffe-Bellin, S. (2008). Methylphenidate and Play Skills in Children with Intellectual Disability and ADHD. Journal of Mental Health Research in Intellectual Disabilities, 2(1), 1-10.

Hsieh, H. C. (2008). Effects of ordinary and adaptive toys on pre-school children with developmental disabilities. Research in Developmental Disabilities, 29(5), 459-466.

Hsieh, H. C. (2012). Effectiveness of adaptive pretend play on affective expression and imagination of children with cerebral palsy. Research in developmental disabilities, 33(6), 1975-1983.

Hobson, J. A., Hobson, R. P., Malik, S., Bargiota, K., \& Caló, S. (2013). The relation between social engagement and pretend play in autism. British Journal of Developmental Psychology, 31(1), 114-127.

Huinziga, J. (1950). Homo Ludens: A study of the play-element in culture. Boston, MA: Beacon Press. Hughett, K., Kohler, F. W., \& Raschke, D. (2013). The effects of a buddy skills package on preschool children's social interactions and play. Topics in Early Childhood Special Education, 32(4), 246-254. 
International Play Association (IPA), (2014). Declaration on the importance of play. Retrieved October 26, 2018 from http://ipaworld. org/wp-content/uploads/2015/05/IPA_Declaration-FINAL.pdf

Johnson, K. A., \& Klaas, S. J. (2007). The changing nature of play: Implications for pediatric spinal cord injury. The journal of spinal cord medicine, 30(1), 71-75.

Jull, S., \& Mirenda, P. (2011). Parents as play date facilitators for preschoolers with autism. Journal of Positive Behavior Interventions, 13(1), 17-30.

Jung, S., \& Sainato, D. M. (2013). Teaching play skills to young children with autism. Journal of Intellectual and Developmental Disability, 38(1), 74-90.

Karaaslan, O. (2016). Comparison of Social Engagement of Children Having Disabilities with Their Mothers and Fathers. Educational Sciences: Theory and Practice, 16(5), 1649-1670.

Kim, S. (2016). Use of Video Modeling to Teach Developmentally Appropriate Play With Korean American Children With Autism. Research and Practice for Persons with Severe Disabilities, 41(3), 158-172.

Kitchenham, B. (2004). Procedures for performing systematic reviews. Keele, UK: Keele University.

Kossyvaki, L., \& Papoudi, D. (2016). A review of play interventions for children with autism at school. International Journal of Disability. Development and Education, 63(1), 45-63.

Lang, R., O'Reilly, M., Rispoli, M., Shogren, K., Machalicek, W., Sigafoos, J., \& Regester, A. (2009). Review of interventions to increase functional and symbolic play in children with autism. Education and Training in Developmental Disabilities, 481-492.

Lifter, K., Mason, E. J., \& Barton, E. E. (2011). Children's play: Where we have been and where we could go. Journal of Early Intervention, 33(4), 281-297.

López, S. A., Corno, F., \& De Russis, L. (2015). Playable one-switch video games for children with severe motor disabilities based on GNomon. 2015 7th International Conference on Intelligent Technologies for Interactive Entertainment (INTETAIN), 176-185.

Macedo, I., Trevisan, D. G., Vasconcelos, C. N., \& Clua, E. (2015). Observed interaction in games for Down syndrome children. 2015 48th Hawaii International Conference on System Sciences (HICSS), 662-671.

Mahoney, G., \& Solomon, R. (2016). Mechanism of developmental change in the PLAY project home consultation program: Evidence from a randomized control trial. Journal of autism and developmental disorders, 46(5), 1860-1871.

Malone, M. (2009). Patterns of Home-and Classroom-based Toy Play of Preschoolers With and Without Intellectual Disabilities. International Journal of Disability, Development and Education, 56(4), 333-347.

Marti, P., \& Giusti, L. (2010, May). A robot companion for inclusive games: A user-centred design perspective. 2010 IEEE International Conference on Robotics and Automation (ICRA), 43484353.

Marti, P., Giusti, L., \& Pollini, A. (2009). Exploring play styles with a robot companion. The 18th IEEE International Symposium on Robot and Human Interactive Communication, 2009. ROMAN 2009. 717-722.

Marti, P., Moderini C., Giusti L., \& Pollini, A. (2009). A robotic toy for children with special needs: From requirements to design. IEEE International Conference on Rehabilitation Robotics, 2009. 918-923.

Matthews, A., \& Rix, J. (2013). Early intervention: parental involvement, child agency and participation in creative play. Early Years, 33(3), 239-251.

Meyers, C., \& Vipond, J. (2005). Play and Social Interactions Between Children with Developmental Disabilities and Their Siblings A Systematic Literature Review. Physical \& Occupational Therapy in Pediatrics, 25(1-2), 81-103.

Miller, L. J., Schoen, S. A., Camarata, S. M., McConkey, J., Kanics, I. M., Valdez, A., \& Hampton, S. (2017). Play in natural environments: A pilot study quantifying the behavior of children on 
playground equipment. Journal of Occupational Therapy, Schools, \& Early Intervention, 10(3), 213-231.

Mizumura, Y., Ishibashi, K., Yamada, S., Takanishi, A., \& Ishii, H. (2017). Mechanical design of a jumping and rolling spherical robot for children with developmental disorders. IEEE International Conference on Robotics and Biomimetics (ROBIO), 2017, 1062-1067.

Muñoz-Leiva, F., Viedma-del-Jesús, M. I., Sánchez-Fernández, J., \& López-Herrera, A. G. (2012). An application of co-word analysis and bibliometric maps for detecting the most highlighting themes in the consumer behaviour research from a longitudinal perspective. Quality \& Quantity, 46(4), 1077-1095.

Murphy, F. E., Donovan, M., Cunningham, J., Jezequel, T., García, E., Jaeger, A., McCarthy, J., \& Popovici, E.M. (2015). i4Toys: Video technology in toys for improved access to play, entertainment, and education. IEEE International Symposium on Technology and Society (ISTAS), 2015, 1-6.

Myck-Wayne, J. (2010). In defense of play: Beginning the dialog about the power of play. Young Exceptional Children, 13(4), 14-23.

Nagpaul, P. S. (1995). Quasi-quantitative measures of research performance: an assessment of construct validity and reliability. Scientometrics, 33(2), 169-185.

Nader-Grosbois, N., \& Vieillevoye, S. (2012). Variability of self-regulatory strategies in children with intellectual disability and typically developing children in pretend play situations. Journal of Intellectual Disability Research, 56(2), 140-156.

Nelson, C., Nelson, A.R., McDonnell, A.P., Johnston, S.S., \& Crompton, A. (2007). Keys to play: A strategy to increase the social interactions of young children with autism and their typically developing peers. Education and Training in Developmental Disabilities, 165-181.

Nelson, C., Paul, K., Johnston, S.S., \& Kidder, J.E. (2017). Use of a creative dance intervention package to increase social engagement and play complexity of young children with autism spectrum disorder. Education and Training in Autism and Developmental Disabilities, 52(2), 170.

Odle, B. M., Irving, A., \& Foulds, R. (2009, April). Usability of an adaptable video game platform for children with cerebral palsy. 2009 IEEE 35th Annual Northeast on Bioengineering Conference, $1-2$.

Organization for Economic Cooperation and Development - Centre for Educational Research and Innovation (2007). Students with Disabilities, Learning Difficulties and Disadvantages: Policies, Statistics and Indicators. Retrieved October 03, 2018 from: http://www.oecd.org/edu/school/ studentswithdisabilitieslearningdifficultiesanddisadvantagespoliciesstatisticsandindicators2007edition.htm

Ozen, A., Batu, S., \& Birkan, B. (2012). Teaching play skills to children with autism through video modeling: Small group arrangement and observational learning. Education and Training in Autism and Developmental Disabilities, 84-96.

Pang, Y. (2006). Assist Parents to Facilitate Social Skills in Young Children with Disabilities through Play. International Journal of Special Education, 21(2), 74-79.

Pfeifer, L. I., Pacciulio, A. M., Santos, C. A. D., Santos, J. L. D., \& Stagnitti, K. E. (2011). Pretend play of children with cerebral palsy. Physical \& occupational therapy in pediatrics, 31(4), 390-402.

Piaget J. (1981). L'equilibrazione delle strutture cognitive: problema centrale dello sviluppo [The balancing of cognitive structures: central problem of development]. Torino, I: Boringhieri.

Pizzo, L., \& Bruce, S. M. (2010). Language and play in students with multiple disabilities and visual impairments or deaf-blindness. Journal of visual impairment \& blindness, 104(5), 287-297.

Prellwitz M., Tamm M., \& Lindqvist R. (2009). Are playgrounds in Norrland (Northern Sweden) accessible to children with restricted mobility? Scandinavian Journal of Disability Research, 3(1), 56-68. 
Raisamo, R., Patomäki, S., Hasu, M., \& Pasto, V. (2007). Design and evaluation of a tactile memory game for visually impaired children. Interacting with Computers, 19(2), 196-205.

Ripat J., \& Becker P. (2012). Playground usability: what do playground users say?. Occupational Therapy International, 3, 144-153.

Robins B., Dautenhahn K., Ferrari E., Kronreif G., Prazak-Aram B., Marti P., Iacono I., Gelderblom G. J., Bernd T., \& Caprino F. (2012). Scenarios of robot-assisted play for children with cognitive and physical disabilities. Interaction Studies, 13(2), 189-234.

Robins, B., Otero, N., Ferrari, E., \& Dautenhahn, K. (2007). Eliciting requirements for a robotic toy for children with autism-results from user panels. The 16th IEEE International Symposium on Robot and Human interactive Communication, 2007. ROMAN 2007,101-106.

Rutherford, M. D., Young, G. S., Hepburn, S., \& Rogers, S. J. (2007). A longitudinal study of pretend play in autism. Journal of Autism and Developmental Disorders, 37(6), 1024-1039.

Ryalls, B. O., Harbourne, R., Kelly-Vance, L., Wickstrom, J., Stergiou, N., \& Kyvelidou, A. (2016). A perceptual motor intervention improves play behavior in children with moderate to severe cerebral palsy. Frontiers in psychology, 7, 643.

Scheflen, S. C., Freeman, S. F., \& Paparella, T. (2012). Using video modeling to teach young children with autism developmentally appropriate play and connected speech. Education and Training in Autism and Developmental Disabilities, 302-318.

Shireman, M. L., Lerman, D. C., \& Hillman, C. B. (2016). Teaching social play skills to adults and children with autism as an approach to building rapport. Journal of applied behavior analysis, 49(3), 512-531.

Stanton-Chapman, T. L., \& Hadden, D. S. (2011). Encouraging peer interactions in preschool classrooms: The role of the teacher. Young Exceptional Children, 14(1), 17-28.

Stockall, N., \& Dennis, L. (2013). Fathers' role in play: Enhancing early language and literacy of children with developmental delays. Early Childhood Education Journal, 41(4), 299-306.

Suhonen, E., Nislin, M. A., Alijoki, A., \& Sajaniemi, N. K. (2015). Children's play behaviour and social communication in integrated special day-care groups. European Journal of Special Needs Education, 30(3), 287-303.

Sutton-Smith B. (1997). The ambiguity of play. Cambridge, MA: Harvard University Press.

Tsao, L. L., \& McCabe, H. (2010). Why won't he play with me? Facilitating sibling interactions. Young Exceptional Children, 13(4), 24-35.

UN General Assembly, (1989). Convention on the Rights of the Child. United Nations. Retrieved October 03, 2018 from http://www.ohchr.org/EN/Professionallnterest/Pages/CRC.aspx.

UN General Assembly (2006). Convention on the Rights of Persons with Disabilities. United Nations. Retrieved October 22, 2018 from https://www.un.org/development/desa/disabilities/ convention-on-the-rights-of-per-sons-with-disabilities.html.

UN Committee on the Rights of the Child (2013). United Nations Convention on the Rights of the Child - General comment No. 17 on Article 31. Retrieved October 3, 2018 from http://www.ohchr.org/ EN/HR- Bodies/CRC/Pages/CRCIndex.aspx.

Vail, C. O., \& Elmore, S. R. (2011). Tips for teachers selecting toys to facilitate social interaction. NHSA Dialog, 14(1), 37-40.

Venuti, P., De Falco, S., Esposito, G., \& Bornstein, M. H. (2009). Mother-child play: children with Down syndrome and typical development. American journal on intellectual and developmental disabilities, 114(4), 274-288.

Visalberghi, A. (1958). Esperienza e valutazione [Experience and evaluation]. Torino, I: Taylor.

Vygotskij, L. S. (1967). Play and its role in the mental development of the child. Soviet Psychology, 5(3), 6-18 (or. ed., 1966).

Walberg, J. L., \& Craig-Unkefer, L. A. (2010). An examination of the effects of a social communication intervention on the play behaviors of children with autism spectrum disorder. Education and Training in Autism and developmental Disabilities, 69-80. 
Wästerfors, D. (2011). Stretching capabilities: children with disabilities playing TV and computer games. Disability \& Society, 26(3), 337-349.

Wong, C., \& Kasari, C. (2012). Play and joint attention of children with autism in the preschool special education classroom. Journal of autism and developmental disorders, 42(10), 21522161.

Wong, C. S., Kasari, C., Freeman, S., \& Paparella, T. (2007). The acquisition and generalization of joint attention and symbolic play skills in young children with autism. Research and Practice for Persons with Severe Disabilities, 32(2), 101-109.

World Health Organization (2001). International Classification of Functioning, Disability, and Health. Geneva, CH: World Health Organization.

World Health Organization (2007). International Classification of Functioning, Disability, and Health: Children \& Youth Version: ICF-CY. Geneva, CH: World Health Organization. 


\title{
4 Children with and without disabilities in disasters. A narrative overview of play-based interventions into the humanitarian programmes and researches. ${ }^{9}$
}

\begin{abstract}
The scientific literature (mainly psycho-pedagogical) on the child's play is immense and epistemologically recognized, but the same cannot be said about the use of play in emergency situations (natural, humanitarian, social, political). Few researches exist on this subject, especially focused on children with disabilities.

The paper analyses the situation of children (with and without disabilities) in natural and man-made disasters and of the attention given to this vulnerable population within academic researches and humanitarian programmes. Then, this article reflects on the pedagogical value of the role and the use of play in crisis situations for all the children. In particular, starting from a narrative review of the academic literature and research in area, it aims at proposing a preliminary overview of the different play-based interventions promoted worldwide in such emergencies.
\end{abstract}

Keywords: Play, crisis situations, education in emergency, children with disabilities, play for the sake of play, disaster.

\subsection{Introduction}

Crisis situations have always been a sworn enemy of childhood. For centuries they mainly concerned wars in the form of clashes between soldiers, with civilians in the role of spectators and casual victims. From the Second World War onwards, the extent of the emergencies has been massively amplified. Firstly, the theaters of modern conflicts were no more battle fields, but cities, villages, schools and hospitals, as over $90 \%$ of the fallen in the wars were civilians, in half of the cases children (UNICEF, 2007). Secondly, new men-made (such as industrial accidents, chemical disasters, terrorism, etc.) and natural (such as tzunamis, earthquakes, floods) disasters have opened up.

Today, all these emergencies do not affect all people evenly: often they supervene to pre-existing vulnerable conditions of some groups, such as for example disability

9 This article is an update and in-depth revision of a previous paper entitled Educating Beyond the Emergency. A Preliminary Overview on the Use of Play in Situations of Crisis published in the journal "Today's children - Tomorrow's parents (TCTP)", within the special issue "Play and children with disabilities - interdisciplinary perspectives” (2018, pp. 48-61). 
and age. Thus, children and, especially, children with disabilities are widely recognised as particularly vulnerable and in need of specific interventions in crisis situations (Bizzarri, 2012).

Conservative estimates suggest that 7 million children with disabilities are impacted by disasters each year (Peek \& Stough, 2010). Millions more acquire disabilities during childhood as a consequence of disasters. Historically, children with disabilities have been overlooked by disaster researchers and professionals and, for this reason, are effectively deprived of the humanitarian aid they need due to a lack of identification and referral procedures, poorly adapted services and poor access (Battle, 2015: 238). This is even more surprising since children with disabilities are among the least prepared and most poorly supplied, ultimately experiencing amplified physical, psychological and educational vulnerability (Alexander, 2011).

Although the recent Resolution 2475 (UN, 2019), adopted by UN Security Council, calls upon Member States and parties to armed conflict to protect specifically persons with disabilities in conflict situations and to ensure they have access to justice, basic services and unimpeded humanitarian assistance ${ }^{10}$, a small body of research (mainly on war or post-conflict emergencies within the legal, political and sociological framework) focused on this topic (Alexander, 2011). Therefore, further investigations, especially from an educational perspective and also including all the actual forms of disasters, are needed, with respect to the historical-social and cultural conditions: What are the crisis situations (including all humanitarian, natural and men-made disasters) today? What consequences do they have on the children (with and without disabilities), their life and their educational process? How can it be possible for them to live their infancy in spite of drama, fear, bereavement? Is it possible to imagine that they preserve their spontaneous urge and desire to play as the most vital expression of their childhood? Can play become a source of well-being, renaissance and even resilience?

In order to answer to these questions, this article reflects on the pedagogical value of the role and the use of play in crisis situations for all the children. In particular, starting from a narrative review of the academic literature and research in area, it aims at proposing a preliminary overview of the different play-based interventions promoted worldwide in such emergencies.

10 This first-ever resolution of its kind, adopted by UN Security Council in June 2019, encourages Member States to ensure to persons with disabilities enjoy equal access to basic services, including education, health care, transportation and information and communications technology (ICT) and systems, and that States undertake measures to enable the meaningful participation and representation of persons with disabilities, including their representative organizations, in humanitarian action and in conflict prevention, resolution, reconciliation, reconstruction and peacebuilding. It also urges proactive steps to eliminate discrimination and marginalization on the basis of disability in situations of armed conflict and compliance with the UN Convention on the Rights of Persons with Disabilities (UNCRPD) (2006). 


\subsection{Emergencies and children (with and without disabilities): a neverending story}

In 1900, the Swedish designer, reformer and social theorist Ellen Key published a manifesto with an evocative title: The Century of the Child (1900), a declaration for social, political, aesthetic and psychological change that presented universal rights and the well-being of children as a mission for the future. Her thought inaugurates the reconsideration of the value of childhood in the human life. This topic, as a constitutive traits of contemporary Western culture from the end of the Nineteenth Century onwards, has been at the center of theoretical research in the psycho-pedagogical and medical field, as well as a series of legislative, educational and cultural proposals aimed at the protection and development of the child internationally (Gecchele, Polenghi \& Dal Toso, 2017: 9) ${ }^{11}$. Among them, the Convention on the Rights of the Child (UNCRC) (UN, 1989) was an important reminder of the civil, political, economic, social, health and cultural rights of children, including, not secondarily, the right to rest, leisure, play, recreational activities, cultural life and the arts.

Neverthelss, today's reality of childhood is not progressive as hoped. Around the world children are exposed to violence in multiple forms getting them caught in the crossfire; these events involve particularly children with disabilities. In fact, emerging research suggests that disasters have differential and most often negative consequences for individuals with disabilities (Parr, 1987; Rockhold \& McDonald, 2009; Kett \& Twigg, 2007). Epidemiological studies also indicate higher exposure and mortality rates for persons with disabilities in such crisis situations (Chou et al., 2004). Thus, although the UN Convention on the Rights of the Persons with Disabilities (UNCRPD, 2006) outlines the obligation of State Members to protect and ensure the safety of persons with disabilities in situations of risk (art. 11) - including natural disaster and armed conflicts - and today, as mentioned, the same mission is specifically recalled by UN Resolution 2475 (2019), in practice disability is still rarely considered in humanitarian programmes (Kett \& van Ommeren, 2009).

What are these emergency situations? What scenarios (pedagogical, political, cultural, social, humanitarian) do current crisis situations open? What consequences do these emergencies have for children (with and without disabilities)?

11 This perspective is questioned, from the Eighties, by Neil Postman who affirms that in the twentieth century, because of its progressive mass-medialization, it has been passed from the discovery of childhood to its demise (Postman, 1982: 10). 


\subsubsection{Pedagogy of emergency: a framework for today's crisis situations}

The history, past or more recent, offers numerous examples of "crisis", especially since the Twentieth Century when the changed complexity of the historical, political and social reality brought out new forms of "catastrophes" (men-made and natural) as well as transformed the nature of war conflicts (up to becoming global). In such disasters, today a significant role is played worldwide - not without ambiguity (Hemment, 1998; Smith \& Vaux, 2002) - by Governamental organisations as well as by the international cooperative movement and many NGOs: in managing emergencies, ensuring first aids and protection and, in general, supporting the global development of the most socially and economically backward countries as well as helping to set the international agenda, mediating political bargaining, providing place for political initiatives and acting as catalysts for coalition-formation.

The scientific community, for its part, tries to give its meaningful contribution from many areas: among them, natural, educational, psychological, anthropological sciences.

In particular, new fields of study and intervention are born: for example, the psychology of emergencies (whose main exponents are Mitchell, Lebigot, Crocq, DeClercq) and the sociology of castrophes (Barton, Dynes, Drabek, V.A. Taylor), together with a new discipline called pedagogy of emergency or emergency pedagogy (Kagawa, 2005). This last, in particular, started within the broader discourse on educational policy (Sinclair, 2002), a branch still little known in the scenario of pedagogical disciplines with a specialized epistemology (e.g.: social pedagogy, special pedagogy, etc.) (Isidori \& Vaccarelli, 2015). It concerns a theoretical and practical proposal at the crossroads between pedagogical reflection and educational interventions to face the issues that the current emergencies (cultural, humanitarian, political, social, economics) open up in the distablished and destroyed educational systems (UNESCO, 1999; Pigozzi, 1999; Sinclair, 2002).

Within the international literature (mainly French and English) starting from the Nineties ${ }^{12}$ (Sinclair, 2001), pedagogy of emergency deals with education during and after complex humanitarian hazards, rapid responses during crisis and postcrisis educational reconstruction, referring to those timely actions able to restore the essential and basic conditions to allow the education of children, young people and adults (Sinclair, 2001).

12 This research field has become especially important from the "Education for All Summit" at Jomtien (1990) and the "World Education Forum" held at Dakar in 2000 which emphasized the role of education in addressing and preventing problems arising from conflicts and natural disasters (Chand et al., 2004). 


\subsubsection{Children and emergencies: geodemographic data}

"Crisis or emergency situations" are characterized as non-places where entire generations lead their existence in conditions of stable precariousness (refugee camps, post-conflict cities or entire nations devastated by the forces of nature) in which "the provisional is lived as definitive" and "the definitive is lived as provisional” (Augé, 1995: 172). In these non-places, children are the invisible majority. Not only are their lives at risk, but they risk becoming child soldiers, being forced into child labour, early marriage or trafficked for exploitation. These children need protection.

A report by UNICEF (2016a) refers that children are being used in war zones in at least 20 countries around the world. They are being forced into child labour to earn money for their refugee or displaced families, for instance; Syrian girls are being married off early as families seek to protect and secure the future of their daughters, and children fleeing war are easy targets for trafficking into slavery. Because of the complexity of this kind of phenomenos, the reality is much more complicated than the traditional dicotomy portraited in the related literature, between children and young people as "passive victims" and "active treats" (Sommers, 2006: 6; Wessels, 1998).

In another document, UNICEF reveals that an estimated 535 million children (nearly one in four) live in countries affected by conflict or disaster, often without access to medical care, quality education, proper nutrition and protection (2016b), whether for reasons of physical location, psychological difficulties, administrative and social barriers or other causes (Save the Children, 2006).

The geopolitics of these emergencies concerns particularly 3 areas: Sub-Saharan Africa is home to nearly three-quarters (393 million) of the global number of children living in countries affected by emergencies, followed by the Middle East and North Africa where 12 per cent of these children reside (Poulatova, 2013). The impact of conflicts, natural disasters and climate changes is forcing children to flee their homes, trapping them behind conflict lines, and putting them at risk of disease, violence and exploitation. Nearly 50 million children have been uprooted, more than half of them driven from their homes by conflicts (Poulatova, 2013). As violence continues to escalate across Syria, the number of children living under siege has doubled in less than one year. Nearly 500,000 children now live in 16 besieged areas across the country, almost completely cut off from sustained humanitarian aid and basic services. In northeastern Nigeria, nearly 1.8 million people are displaced, almost 1 million of them are children. In Afghanistan, nearly half of primary-aged children are out of school. In Yemen, nearly 10 million children are affected by the conflict. In South Sudan, 59 per cent of primary-aged children are out of school and 1 in 3 schools is closed in conflict affected areas. More than two months after Hurricane Matthew hit Haiti, more than 90,000 children under five remain in need of assistance.

Despite significant progress and The Dakar Framework for Action commitment to «meet the needs of education system affected by conflict, natural calamities and 
instability» (UNESCO, 2000), too many children are being left behind because of their gender, race, religion, ethnic group or (pre-exsisting or acquired) disability; because they live in poverty or in hard-to-reach communities. Or simply because they are children.

\subsubsection{Children with disabilities in disasters: twice as vulnerable ${ }^{13}$}

The impact of war, conflicts and disasters on children with disabilities is even more severe. These children may have a pre-existing disability prior to emergencies or they may have reported an impaiment due to the conflict or the disaster. Vulnerability in their cases is exacerbated by facing natural and man-made hazards and their indipendence reduced (Miles, 2013), by factors that include mobility difficulties, preexisting medical conditions, and existing social and physical structures and policies (Peek \& Stough, 2010; Boon et al., 2011). Physical disabilities can limit children's effective responses to disaster; in Haiti, hundreds of children lost their limbs from crashes during the 2010 earthquake, while others under-went amputation as a result of secondary infections (Alexander et al., 2012). Moreover, pre-existing disabilities may be due to medical conditions related to illness, malnutrition, and abuse when disaster strikes (Boon et al., 2011). Additional impairments may be acquired and further health issues might be faced as a result of inadequately staffed shelters that are not prepared to meet their medical needs (Lemyre et al., 2009). Children with autism spectrum disorders may suffer from sensory integration problems related to their high sensitivity to light, sounds, odors, tastes, and touch that make them particularly vulnerable during disasters (Boon et al., 2011). Children with hearing difficulties are disadvantaged in recognising an (impending) disaster or in accessing to emergency information when oral directions are given unaccompanied by sign language or visual hints (Boon et al., 2011). Children with intellectual disabilities and mental health problems face severe disadvantages and confusion, for example in recognising signs of environmental danger or understanding impending threats

13 The concept of "vulnerability" has been the subject of intense debate and interpretation among scholars. The term is often used in divergent ways, for different purposes (Bankoff et al., 2004), and sometimes out of its original theoretical framework. In this paper, in line with the studies on disaster and humanitarian programmes (Alexander et al., 2012), the concept is used according to the philosophical and political paradigm of "social vulnerability" (O’Keefe et al., 1976) and, consequently, viewed as a social construct associated with fragility in the face of natural hazard (Cutter et al., 2000; Gaillard \& Pangilinan, 2010; Phillip et al., 2010; Singh et al., 2014). According to Ranci (2002), a state of vulnerability can be synthetically defined as a life situation in which the subjects' autonomy and self-determination ability is permanently threatened by an unstable integration into the main systems of social integration and resource distribution. 
(Kailes \& Enders, 2007) or they may become anxious and confused in response to emergency signals (Scotti et al., 2007).

While the disaster literature highlights the overall effects of emergencies on children as a vulnerable group in society (UNICEF, 2007; Peek, 2008; Gaillard \& Pangilinan, 2010), researchers rarely examine the experiences of children with disabilities during disasters, regardless of their type of disability (Peek \& Stough, 2010; Boon et al., 2011). In addition, the more pressing needs of living arrangements, food and basic healthcare in countries affected by conflicts and other disasters are understandly prioritised over disability. As a result, children with disabilities are overlooked in Disaster Risk Reduction (DRR) planning or emergency training (Ronoh et al., 2015). This lack of research and emergency programmes reinforces the perception of their inherent vulnerability and risks to increase their invisibility as well as the level of discrimination (Alexander, 2011).

The existing literature is concordant on some common problems that can increase the probability of negative effects of disasters particularly in the case of children with disablities. First, as recognised by the UN High Commissioner for Refugees (UNHCR) (2014), their specific needs are often overlooked, especially in the early phases of humanitarian emergencies. There is plenty of evidence on the widespread failure to recognize the specific needs of children with disabilities during disasters, and, when these needs are indentified, a tailored response is not available (Alexander, 2011). Oversights and omissions appear almost inevitable in such circumstances.

Secondly, most of the problems experienced by children with disabilites in emergencies are directly attributable to limitation in staffing and management (Twigg et al., 2011). According to Clive and colleagues (2010), these issues concern poor DDR planning, confusion about the roles and responsibilities and misplaced assumptions among emergency managers that disability service providers can meet all needs of the persons with disabilities in a crisis. As a result, persons with disabilities (especially children) remain largely invisible to emergency officials (Twigg et al., 2011) and disregarded in most disaster response systems (Kailes, 2008).

A third set of problems refers to some local and pre-exisiting social, political, cultural and educational barriers. Social distancing or stigma on disability may further limit access to primary resources, social networks, and other sources of psychological support during a disaster, or make it difficult for a child with a disability to adjust emotionally to a new neighborhood or community (Tierney et al., 1988). As disabilities are strongly associated with social, structural and financial disadvantages, families caring for children with disabilities become even more vulnerable in facing a crisis situation. In addition, these barriers may include non-flexible government policies and service funding constraints.

Although these problems and the small body of research on children with disabilities involved in disasters (Alexander, 2011), several UN and non-governmental organization initiatives have started to consolidate a "disability focus" within the humanitarian sector (Kett \& van Ommeren, 2009) leading to the recent Resolution 
2475 (UN, 2019). At the beginning, in 2012 new guidelines, entitled Including everyone: INEE pocket guide to inclusive education in emergencies $(2009)^{14}$, were drafted by the Inter-agency Network on Education in Emergency (INEE) ensuring the inclusion of children with disabilities in the work of the education cluster, through specific measures: by making school buildings physically accessible, providing training to teachers, and raising both awareness and perceptions of disability amongst teachers, parents, other children, communities, humanitarian actors and policy-makers. Similarly, Sphere Handbook ${ }^{15}$, translated into more than 30 languages, include "persons with disabilities" as a cross-cutting problem in disasters recognizing them as a "vulnerable group", along with women, children and elderly. More recently, UNICEF has developed guidance to help make sure that children and adolescents with disabilities are included in all stages of humanitarian actions, from preparing for emergencies to recovering from them. Including Children with Disabilities in Humanitarian Action guideline ${ }^{16}$ consists of six booklets - respectively dedicated to general guidance; nutrition; health and HIV/AIDS; water, sanitation and hygiene (WASH); child protection; and education - full of practical actions and tips.

In addition, Alexander (2011) suggests some useful initiatives such as Verona Charter on the Rescue of Persons with Disabilities in Case of Disaster (2007) ${ }^{17}$, the nongovernmental organization (NGO) Handicap International (2006; 2008) ${ }^{18}$ or again some manuals of best practice by the US Federal Emergency Management Agency $(\text { FEMA })^{19}$.

Despite these efforts, education for children with disabilities in emergencies remains marginalised, and it is particularly difficult to hold donors accountable for including disability issues in humanitarian relief efforts. Especially, most programmes and manuals focus on disability as a crosscutting issue or on protecting persons with disabilities as a vulnerable group, rather than indicate specific actions for realizing inclusion and overcoming barriers. As suggested by Kett and van Ommeren (2009), «there is little evidence that these guidelines are used to any effect with people with disabilities, in part because of a lack of standards and indicators to monitor inclusion; but also because of the lack of awareness and training at the field level» (p. 1801). It is a vicious circle within which the children with disabilities usually risk being considered as mere passive recipients of aid (Twigg et al., 2011: 252). Consequently, the problems with the potential vulnerabilities of children with disabilities during disasters are poorly understood (Ronoh et al., 2015), as well as their psychological impact (Joshi \&

14 See: https://inee.org/system/files/resources/INEE_Pocket_Guide_Inclusive_Education_EN.pdf (retrieved: July, 2019)

15 See: https://www.spherestandards.org/handbook-2018/ (retrieved: July, 2019)

16 See: http://training.unicef.org/disability/emergencies/index.html (retrieved: July, 2019)

17 See: www.eena.org/ressource/static/files/Verona\%20Charter\%20approved.pdf (retrieved: July, 2019)

18 See: https://hi.org (retrieved: July, 2019)

19 See: https://www.fema.gov (retrieved: July, 2019) 
O'Donnell, 2003). Thus, the children are largely portrayed as "helpless" in the face of disaster (Smith et al., 2012).

\subsection{Educating beyond the emergencies: the possible role of play}

Play is recognized as a constituent tract of childhood and one of the child's rights: «every child should be able to enjoy these rights regardless of where he or she lives, his or her cultural background or his or her parental status ${ }^{20}$. However, there are children who can not or do not want to play for a variety of reasons. Often these reasons concern emergency and crisis situations, where «play is often given lower priority than provision of food, shelter and medicines» (UN, Commettee on the Right of the Child, 2013).

Thus, why and how might the universal right to play to all the children (with and without disabilities) be guaranteed even in crisis situations? What forms can it take? What supports can be made available?

\subsubsection{The importance of play for all the children}

The significance and importance of play and its educative and psycho-pedagogical value are more widely acknowledged. As it is known, the interest of pedagogy and psychology towards child's play dates since the very beginning of these disciplines and many perspectives over the centuries have followed one another, offering multiple interpretative models (Besio, 2007; Staccioli, 2004). It is now unquestionable that play represents for each child a rewarding and vital experience linked both to the connected conditions of pleasure and enjoyment, beyond his/her social, biophisiological, cultural, economic, politic, etc. situations; it is also universally known for its crucial importance for the overall development of the child's cognitive, sociorelational and psychological skills (Winnicott, 1971). In line with this, the wise pedagogical research (from Froebel to Dewey, from Montessori to Agazzi sisters) accredits play not as one of the countless occupations of the human being, but as the engine of his/her most important activities, as a permanent formative device and ontologically embodied in the same idea of humankind and culture (Huizinga, 1938). Especially after the Second World War, the interest in play as a field of intervention against disasters gradually begins to grow in a dual way. First, it has been used by interdisciplinary groups of professionals who, among the ruins of many European cities, implemented psycho-educational interventions addressed to children, aimed

20 See: UN, General Comment No. 17 (2013) on the Right of the Child to Rest, Leisure, Play, Recreational Activities, Cultural Life and the Arts (art. 31). 
at alleviating the inevitable wounds of the war (one example is Klein's "therapeutic play”; Klein, 1929). This pioneering experience was then replicated and disseminated, along the second part of the Twentieth Century, where psychological intervention has variously been adopted in the forms of «processing of trauma, resilience, resistance, prevention, training and learning in crisis situations, educational care» (Isidori \& Vaccarelli, 2015: 17). Second, active cultural and political shifts in the population's attitudes at large have been actively provoked by artists and contemporary designers by intervening in the toy industry, promoting the idea a new toy: well designed, safe and non-violent ${ }^{21}$.

Furthermore, play is a right proclaimed and recognized by the 1959 UN Declaration of the Right of the Child and reiterated by its edition of 1989, in particular in the Article 31: «1) States Parties recognize the right of the child to rest and leisure, to engage in play and recreational activities appropriate to the age of the child and to participate freely in cultural life and the arts. 2) States Parties shall respect and promote the right of the child to participate fully in cultural and artistic life and shall encourage the provision of appropriate and equal opportunities for cultural, artistic, recreational and leisure activity». It is the first, but necessary attempt to establish a link between the material rights and the immaterial aspects of the child's life as the right to play presupposes that the child, as well as the adult, participates into the social life (Besio, 2010).

This epochal change had enormous consequences in child pedagogy as well as in infancy politics and it led to the birth of various associations in the field, including International Play Association (IPA) which in occasion of the International Year of the Child (1977) issued its Declaration of the Child's Right to Play, updated then in 2014 with the title Declaration on the Importance of Play. In particular, IPA, with the document The Play Rights of Disabled Children IPA Position Statement published in 2015, affirms that children with disabilities have the same right as other children to sufficient time and space to play freely, in the ways they choose, without being unduly overprotected.

In this regard, the General Comment $\mathrm{N}^{\circ}$ 17, related to the UNCRC Article 31, mentions the problems associated with the even more dramatic lack of attention on play in the case of emergencies and vulnerable groups, such as children with disabilities and children in situations of conflict, natural disaster or humanitarian crisis, among others (art. 31). They need specific attentions and the right to play must be ensured to all children in order not to limit their developmental opportunities. As suggested by Bianquin (2018), this is underlined also by the Convention of the Rights

21 In this regard, it is noteworthy the exhibition held at the MoMa in New York dedicated to play and toys, entitled The Century of the Child: Growing by Design, 1900-2000 (2012), an ambitious survey on the design of the 20th century, an overview through 500 objects to tell how design, artists and architects - many of whom are not by chance women - have designed the world of childhood. 
of Persons with Disabilities (2006), which devotes its Art. No. 7 to the expression and the protection of the rights of children with disabilities, giving then emphasis to the need to guarantee them an adequate educational process in an inclusive system throughout life (Article 24) and to ensure their participation in all recreational activities, entertainment and sport, including education (Article 30).

Multiple physical and social barriers prevent children with disabilities from exercising their rights under Article 31 and reduce the naturalness of their play. For example, children with physical disabilities' playing skills are generally affected by the severity of motor functional limitations and the possible association with other types of disability (Besio, 2010). Children with intellectual disabilities, especially medium-severe, are not eager to playful interactions with peers preferring to play with the younger companions, and usually prefer to repeat the play activities they already know; they usually do not like to explore new activities or try to transfer their games to other contexts (Meyers \& Vipond, 2005). Due to their impairment in comprehension, they rarely have the opportunity to reach the more complex types of play. Children with autism spectrum disorders tend to hinder their participation in play activities and they do not disclose a natural inclination towards what happens around them; they are used to be attracted by some particular objects intensely and in an exasperated way (Jordan, 2003). The visual impairment causes a serious decrease in the quantity and quality of usable games, which eventually converge on board games, based on preformed materials.

But beyond these barriers, play for all the children is an intrinsic and necessary element as human beings and is configured as one of the most significant indicators of their bio-psycho-social health (Besio, 2010). It represents a decisive factor for the development of cognitive, motor and emotional abilities: play is discovery, exploration, and stimulation (Besio et al., 2017).

\subsubsection{Play-based interventions in emergencies}

Within the interventions that every day are set off by pedagogists, educational professionals, operators and international organizations (such as NGOs and IGOs) to manage the enormous educational problems related to the major emergencies hit on a global scale, some of them adopt activities based on play or that in some way include it. Over the years, these experiences have produced a certain amount of materials, documents, operational and methodological proposals (mostly accessible online) aimed at ensuring to all children involved in crisis situations to fully enjoy the aforementioned "right to play".

What happens to children when they can not play? Then, how do they replace war, sufferings by playing? Do they usually play, even in dramatic contexts and conditions? How do they play in these situations? 
As reported by IPA, «Play deprivation is highly detrimental to affected children, communities and society as a whole. Not playing deprives children of experiences that are regarded as developmentally essential and results in those affected being emotionally, physically, cognitively and socially disabled. If normal play experiences are absent the child is more likely to become violent and antisocial. Although data on the impact of not playing for humans is scarce, the findings of the studies that do exist give cause for concern. If children are kept in and not allowed out to play, they are likely to manifest symptoms ranging from aggression and repressed emotions and reduced social skills, to inactivity and an increased risk of obesity. Adults reporting environmental restrictions on play (e.g. having less time to play) are more likely to be overweight and have less healthy lifestyles» (IPA, 2014) ${ }^{22}$. To face these conditions, in 2015 IPA launched a new project Access to play in crisis (APC) composed by two parts: a training project (tool kit) and an international research project aimed at filling the lack in studies by conducting empirical researches in six countries (India, Japan, Lebanon, Nepal, Thailand, Turkey). In its related Handbook (IPA Handbook, 2017), fully endorsing UNCRC and UNCRPD, IPA states that every child, included those with disabilities, should have equal opportunities to enjoy his/her right to play in their everyday lives.

So, although in crisis situations, play has to be recognised as a fundamental educational tools for all the children (UNESCO, 1999), helping them not only to cope with stress, anxiety, depression and trauma due to the emergency, but also to keep them anchored to their own childhood, that was dramatically interrupted by the crisis itself (Euli, 2007).

Unfortunately, as reported in the following paraghaph, few researches focus on children's play in crisis situations, especially related to children with disabilities.

22 The first results were presented at the IPA Triennial World Conference host in Calgary last September 2017. For further information, see: http://ipaworld.org/what-we-do/access-to-play-incrisis/ (retrieved: August, 2019). After the world conference, it was also published The Access to Play in Crisis Handbook (IPA Handbook, 2017) to support people and agencies working in crisis situations in understanding and supporting children's everyday and community-based play opportunities at two levels: 1. the practical application of children's right to play within programmes for children in crisis situations; and 2. a raised awareness of this right at a strategic level so that the resources and networks will support sustainable impact. The Playshop introduces the new Handbook using a practical interactive and fun style so that participants gain an insight into ways in which we can support the play rights of children in very challenging situations and, in doing so, support their physical, social, cognitive, emotional and spiritual development. The Playshop focuses on the practical elements of facilitating play including: the role of adults, supporting play, features of the environment, balancing risk and benefit and reflective practice. Participants reflect on the implications for a range of different circumstances in which children face barriers in exercising their play rights. They be in invited to contribute their own experience and observations so that together we can further develop our understanding of play in the context of crisis. 


\subsubsection{What kind of play is promoted in crisis situations?}

In what follows, a first overview on the role and the use of play in crisis situations within the humanitarian programmes and researches is presented ${ }^{23}$.

As it is easily imaginable, most of the educational interventions implemented within emergency settings are principally school-based. As Baxter (2009) underlines, they concern «three different types of alternative access programmes: accelerated learning, home-based or community-based schools and education programmes that are partly literacy/numeracy and part skills training» (p. 45). In this kind of experiences, a central role is played by teachers as change-agents (Shepler, 2011) and play is replaced by teaching and learning activities. In fact, the so-called educational kits $^{24}$ generally contain, in one easily transportable container, the basic materials (e.g. exercize book, pencil, erasers, scissors, chalkboard, chalk) that teachers need to teach a group of children in an emergency (Penson \& Tomlinson, 2009: 46). Moreover, these programmes can carry "alternative" topics (e.g. hygiene, peace education, etc.), and can be used in post-conflict situations as well as for educational access for otherwise marginalized children, such as children labourers, children living in remote geographical areas and very poor children. In advocating also for the importance of education in emergencies, literature focuses especially on the development of more inclusive education systems and schools (Miles, 2013).

Furthermore, these educational interventions are sometimes included in schoolfeeding programmes (Penson \& Tomlinson, 2009) starting from Barnard's statement that «in many cases food is more essential to the boys and girls than education» (Barnard, 1987). Aiming at removing the obstacles to learning caused by malnutrition,

23 The data presented in this paragraph have been selected starting from a narrative overview, also known as an unsystematic narrative review (Oxman \& Guyatt, 1993; Collins \& Fauser, 2005), of the primary sources related to the use of play-based interventions for children (with and without disabilities) in crisis situations. All the documents (n. 10) included (papers, proceedings, chapters in book and reports) in the review have been selected by surfing the website of the organisations and associations of the area as well as using the EBSCO host and ERIC databases. Aiming at analysing the use of play in emergencies, the review follows these steps: 1 . exploring the humanitarian educational programmes proposed by the main NGOs, associations or international organisations; 2 . selecting those programmes or researches that provide specifically play-based startegies; 3. analyzing and discussing the play-based strategies used starting from the distinction between "play for the sake of play" (Besio et al., 2017) and "play-like activities". This narrative overview does not pretend to be exhaustive, as representative of a certain way to decline play in the current context of crisis and emergency.

24 They are called "school-in-a-box" by UNICEF and "Teacher Emercency Package" by UNESCO. This idea of "one-size-fits-all" solution is developed in response to the breakdown of formal provision of education. They have been used for the first time in Somalia in 1991, emplemented in 1993 and subsequently used mostly in conflict zones (Abrioux, 2006). 
they contribute to children's more general cognitive development (Levinger, 1986) ${ }^{25}$, the improvement of school enrollment and attendance and learning capacities (IRC, 2002: 29).

Alongside these experiences, there are also alternative curriculum programmes developed because the mainstream curriculum is not attempting to respond to the perceived needs and are, therefore, filling tha gap (Baxter, 2009: 91). They are generally composed by "preventive programme" (such as HIV and AIDS education) as well as "psychosocial programme" designed in order to «help overcome negative consequences of conflict or disaster and associated trauma» (Baxter, 2009: 33) and to change behaviours according to modern behaviour change approach (Glanz, Lewis \& Rimers, 1990; Grizzell, 2007) ${ }^{26}$.

A different role could be played by Child-Friendly Spaces (CFS) which, by definition, «are community programmes to create larger protective environment [as they] are developed with communities to protect children during emergencies through structured learning, play, psychosocial and access to basic services» (Save the Children, 2007: 4). The related Handbooks, edited by UNICEF and Save the Children, generally mention children with a disability as a vulnerable group, proving some (general and common) tips for realizing inclusion: in terms of space accessibility («for example, by providing ramps for wheelchair access in addition to or instead of steps») or social inclusion and partecipation. They suggest some proactive measures pointed out also by the UNCRPD.

Although these CFS are not schools and usually do not seek to provide formal schooling, the main goal of children's protection is often linked with the provision of psychosocial support. In this way, even if CFSs have been created as «spaces to give children the space to be children» (Penson \& Tomlinson, 2009: 30) - areas for children to come to express themselves through sport, recreational activities, drama, drawing, games, theater (UN, 2013) -, their play-based interventions are generally subjected to rehabilitation and therapeutic purposes. And though few organizations or agencies adopt this psychosocial approach, the general label of "psychosocial" is often used for characterizing these humanitarian projects as they rapidly become attractive and fashionable for Western donors (Summerfield, 1996: 12).

This also seems to be validated by some reports presented at the aforementioned IPA Triennial World Conference of $2017^{27}$ : whilst they confirm the positive impact that

25 In reality, very little research has been done on the effectiveness of school-feeding programmes (Levinger, 1986) and there was no empirical evidence to demonstrate a causal link between school feeding and educational results (Sack, 1986; Loewald, 1986; WFP, 2007).

26 Modern behaviour change models are a combination of behaviourist perspectives (mainly Skinner), social-learning theory and social cognitive model (see: Bandura \& Walters, 1963; 1977; Bandura, 1986; Perry, Barnowski \& Parcel, 1990).

27 All the abstracts of the conference presentations are available online: http://canada2017.ipaworld. org/wp-content/uploads/2017/05/Concurrent-Session-Descriptions.pdf. Retrieved: August, 2019. 
play has on children's developmental outcomes in various settings, including children affected by crisis situations, and on creating inclusive contexts, they generally promote integration, feeling of belonging and resilience through play activities based on programmatically clear educational goals.

It is, for instance, the case of Equitas Play it Fair! Approach (Sighomnou \& Morrison, IPA Calgary, 2017), a play-based project grounded in human rights values (e.g. respect, inclusion, equality) that is being used internationally to build children's resilience and participation in post-crisis contexts (e.g. Syrian Refugees in Canada, children in Sri Lanka, children in Haiti). In particular, it reinforces the important role of play (grounded in a human rights-based approach) in fighting disconnection and social isolation experienced by refugee children (and families), by supporting children in two ways. First, it re-builds their socio-emotional competences, communication skills thus promoting healthy mental development, through regular physically active play-based activities. Secondly, it disseminates the knowledge and supports the skills of community-based organizations so that they can lead activities including children who experienced crisis to the goal of supporting them to take on leadership roles and exploit their full potential in their communities.

A similar approach is also presented by Kinoshita and collegues (IPA Calgary, 2017) related to the Great East Japan Earthquake of March 11, 2011 that damaged a wide area in the Northern part of Japan, together with the subsequent tsunami and nuclear power station accident. Children who experienced these terrible disasters and the post-disaster situation have suffered in mental, physical and social ways for their development and affected by PTSD (Post-Traumatic Stress Disorder). The authors address the role of play, adventure playgrounds and other play interventions for healthy development (mental, physical and social issues of children after the disasters).

Diaz (IPA Calgary, 2017), instead, presents how play was used in disasters as an avenue for Psychological Debriefing through Instruction (PDI) which was offered to children who experienced the devastating effects of a series of natural disasters. The processes undertaken included creation of developmentally appropriate activities for young children that focused on sharing interactive stories and play, as well as on actual implementation of these learning opportunities to children-at-risk. Planning of content and delivery of the PDI took into account knowledge of developmentally appropriate practice from story selection and thematic play-oriented activities.

Another example could be offered by the experiences of "clowns nudging" and "hospital clowning" in emergencies (Anes, IPA Calgary, 2017) in which, by engaging children in a playful interaction and pushing their natural instinct to play, the clowndoctors performances and workshops could successfully convey non-formal learning and support the teaching of important life-skills to the target groups, thus contributing to decrease the level of stress and fear of crisis-affected persons - from insecurity, hopelessness and disillusionment to a more optimistic prospective in life including happiness and positive solution finding. 
The experiences presented show that play is often included in the humanitarian programmes, but what idea of play emerges from them? What features and purposes does it assume?

In order to answer these questions, we adopt the useful distinction between "play-like activities" (Visalberghi, 1958) and "play for the sake of play" (Besio et al., 2017). The first ones are initiated and conducted by the adult, in educational, clinical or social contexts; they appear playful and pleasant, but their main objective is other than play (that of cognitive or social learning, functional rehabilitation, psychological support, etc.). The second ones are instead started and carried out by the player (alone, with peers, with adults) with the sole purpose of play itself (fun, joy, interest, challenge, competition, etc.).

According to this distinguishing feature, within the humanitarian programmes and researches for children in crisis situations play is often subordinated to therapeutic-rehabilitation goals (Boyd Webb, 2015). Also in the case of programmes and guidelines developed specifically for children with disabilities, play is then used as a means to obtain scopes other than fun, or as a context of improvement of compromised developmental areas of the children; thus, it is not surprising to read in this literature the frequent use of the expression "play therapy". Serious games are possible examples of these activities: they might be devoted to improveing community resilience and preparedness, to teach disaster risk management skills, or to recover from trauma (such as abuse, parents' loss, armed attacks, etc.).

This tendency is nourished by that liminal border, not yet clearly addressed until now between education and rehabilitation, since both «aim for the same goal: give the child an opportunity to make positive and useful experiences, for training new effective abilities, so positively influencing the structure of the brain and consolidating new learning» (Besio, 2017, p. 37). According to Visalberghi's definition, these kinds of interventions adopt play as a fun and motivating mode for inducing children to take active part to rehabilitative and educational activities, thus orieìnting them towards specific educational objectives. In this sense, these "play-like activities" become important factors of "educational care" rather than education and aim at satisfying needs rather than desires.

This "ludomatics" perspective (Besio, 2010, p. 86), based on learning methods intentionally proposed by the adult in an extrinsic way, certainly finds its theoretical justification in the positive effects (widely recognized in the related sciences) that play and playing have in the different dimensions of the person's life (biophysiological, cognitive, recreational, emotional, psychodynamic, etc.).

This initial review on the field literature seems to highlight that, when it comes to play, it is generally the case of "play-like activities", even if this choice involves a loss of value for play itself. Quoting Besio (2017): «while play has extraordinary educational value and can be used as an incomparable educational 'hook', it undoubtedly loses some of its play features: for example, freedom, pure ludic spirit, transgression, autonomous initiative, and autotelism» (p. 38). 
This use of play in crisis situations has contributed to overshadow its genuinely ludic, fun and recreational dimension and to implement the risk of its negative intellectualization that Vygotskij more than fifty years ago already feared (1967).

Although such play-like activities are certainly driven by advanced goals, opting mainly for them implies the risk of losing that idea of play that some authors of the past (amoung the others Fink, Claparède, Parlebas, Aucouturier) indicated as «an oasis of joy» (Fink, 1957).

In the particular case considered in this study - crisis situations - the pure and ludic play, instead of being neglected, should be steadily supported and fed. In these contexts, in fact, children's play might lose its characheristics of vital force, spontaneity, and recovering this ricreative, fascinnating, revitalizing instinct of play as pure realization of the free expressiveness of oneself, may reveal salvific for the child, innovative as a message of freedom, peace and hope. This understanding would inaugurate a new way of looking at play and being in play, as adults aware of its natural life-giving dimension even in the case of very serious situations. That adult, however, may carve out an unprecedented role, which is not that of the educator, or psychologist, but is that of the experienced player, who is inside play, but knows which play he/she wants to play and why.

\subsection{Conclusion}

The present narrative overview underlines the importance that play (especially in the form of "play-like activities") could assume even in crisis situations. At the same time, the study confirms the overall lack of data on the use of play-based activities in emergencies areas (especially related to children with disabilities) and the consequent need for future in-depth analysis and researches at two levels.

First, from the empirical point of view, in order to give greater systematicity to humanitarian programmes and related researches, more experimental studies are needed, aiming at assessing the impact and effectiveness that these playbased interventions have or may have on all the children in crisis situation, their infancy, their well-being, and their educational process. Second, from a theoretical perspective, more comprehensive frameworks are welcomed as to give a scientific and methodological coherence to the different experiences and as to indicate the way for further possible play-orientered approaches. These considerations are even more valid for children with disabilities who represent a variable almost completely unexplored by scholars, policy makers and international organisations.

In this way, not only the pedagogy of emergency as discipline would be implemented and enriched (especially by a proper "disability focus"), but such renewed researches would also allow scholars, policy makers, educational professionals, operators and international organisations to support childhood and its spontaneous urge to play even during and after disasters. As resulting here, for 
all the children (with and without disabilities) living such extraordinary situations as hazards, conflicts and natural or men-made disasters play is more important than ordinary. According to Hyder (2004), play is fundamental not only as necessary feature to childhood and essential component of his/her development, but especially as a means to regain "lost childhood" restoring that positive meaning included in the Greek etimology of word "crisi" as "moment of decision", "resolved moment"28 according to which the "possibility of change" becomes the necessary prerequisite for a general improvement, a rebirth.

\subsection{References}

Abrioux, E. (2006). The use of Emergency Education and Recreational Kits in Aceh: A Review.

Bangkok, TH: UNICEF, EAPRO. Retrieved August, 2019 from: www.unicef.org/eapro/Emergency_ Education_Kits.pdf

Alexander, D.E. (2011). Disability and Disaster. In: B. Wisner, J.C. Gaillard, I. Kelman (Eds.). Handbook of Hazards and Disaster Risk Reduction (pp. 384-394). London, UK: Routledge.

Alexander, D.E., \& Davis, I. (2012). Disaster Risk Reduction: An Alternative Viewpoint. International Journal of Disaster Risk Reduction, 2, 1-5

Augé, M. (1995). Non-places: Introduction to an Anthropology of Supermodernity. London, UK: Verso. Bandura, A. (1986). Social Foundations of Thought and Action. Englewood Cliffs, N): Prentice-Hall.

Bandura, A., \& Walters, R.H. (1963). Social Learning and Personality Development. New York, NJ: Holt, Rinehart\&Winston.

Bankoff, G., Frerks, G., \& Hilhorst, D. (Eds.) (2004). Mapping Vulnerability: Disasters, Development \& People. London, UK: Earthscan.

Barnard, T. (1987). Annual Report. In: J.W. Burgees. Reminiscences of an American scholar (pp. 179180). Boston, MA: Houghton-Mifflin Company (1931).

Battle, D.E. (2015). Persons with Communication Disabilities in Natural Disasters, War, and/or Conflict. Communication Disorders Quarterly, 36(4), 231-240.

Baxter, P., \& Bethke, L. (2009). Alternative Education. Filling the Gap in Emergency and Post-conflict Situations. Paris, F: International Institute for Education Planning.

Besio, S. (2010). Gioco e giocattoli per il bambino con disabilità motoria [Play and toys for the child with physical disability]. Milano, IT: Unicopli.

Besio, S., Bulgarelli, D., \& Stancheva-Popkostadinova, V. (Eds.) (2017). Play Development in Children with Disabilities. Berlin, D: De Gruyter Open.

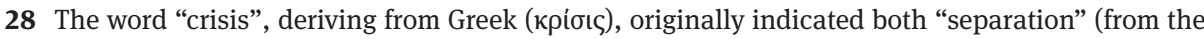

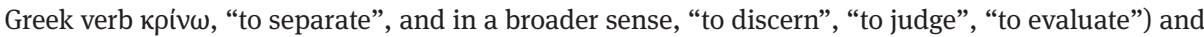
a series of secondary interpretations including its meaning, born in the medical field, as "critical period", "critical phase". This etymological sense of change, transformation over time - originally declined in terms of the course of a disease - during the centuries has taken on a negative meaning overshadowing the positive one as "possibility of change", "resolved phase" - and is now mostly used to indicate a worsening of a situation, the perturbation or sudden change in the life of an individual or of a community, with more or less serious and lasting effects (e.g.: spiritual, religious, conscience, social, etc.). 
Bianquin, N. (2018). The Right to Play: A Powerful Promise Made Also to Children with Disability. TCTP Today's children, tomorrow's parents, 47-48, 18-27.

Bizzarri, M. (2012). Protection of Vulnerable Groups in Natural and Man-Made Disasters. In: G. Turchetti, S. Cannizzo, \& L. Trieste (Eds.). Natural and Man-Made Disasters: Challenges and International Perspectives for Insurance (pp. 381-414). Switzerland, CH: Springer T.M.C. Asser Press.

Boon, H.J., Brown, L.H., Tsey, K., Speare, R., Pagliano, P., Usher, K., \& Clark, B. (2001). School Disaster Planning for Children with Disabilities: A Critical Review of the Literature. International Journal of Special Education, 26(3), 223-37.

Boyd Webb, N. (2015). Play-therapy with Children and Adolescents in Crisis. London, UK: The Guilford Press.

Chand, V.S., Joshi, S., \& Dabhi, R. (2004). 'Emergency Education': The Missing Dimension in Education Policy. Educational Research for Policy and Practice. 2, 223-235.

Chou, Y., Huang, N., Lee, C., Tsai, S., Chen, L., \& Chang, H. (2004). Who is at Risk of Death in an Earthquake?. Am J Epidemiol, 160(7), 688-695.

Clive. A., Davis, E.A., Hansen, R., \& Mincin, J. (2010). Disability. In: B.D., Phillips, D.S.K., Thomas, A., Fothergill, \& L., Blinn-Pike (Eds.). Social Vulnerability to Disasters (pp. 187-216). Boca Raton, FL: CRC Press.

Collins, J.A., \& Fauser, B.C. (2005). Balancing the Strengths of Systematic and Narrative Reviews. Hum Reprod Update, 11(2),103-104.

Cutter, S.L., Mitchell, J.T., \& Scott, M.S. (2000). Revealing the Vulnerability of People and Places: A Case Study of Georgetown County, South Carolina. Annals of the AAG, 90(4), 713-737.

Euli, E. (2007). Casca il mondo! Giocare con la catastrofe. Una nuova pedagogia del cambiamento [Drop the world! Playing with catastrophe. A new pedagogy of change]. Molfetta, IT: La Meridiana.

Fink, E. (1957). Oase Des Glücks; Gedanken Zu Einer Ontologie Des Spiels. Freiburg, D: Karl Alber.

Gaillard, J.C., \& Pangilinan, M.L.C. (2010). Participatory Mapping for Raising Disaster Risk Awareness Among the Youth. Journal of Contingencies \& Crisis Management, 18(3), 175-179.

Gecchele, M., Polenghi, S., \& Dal Toso, P. (Eds.). (2017). Il Novecento: il secolo del bambino? [Twentieth Century: is it the Century of the Child?]. Parma, IT: Edizioni Junior.

Glanz, K., Lewis, F.M., \& Rimers, B.K. (Eds.). (1990). Health Behavior and Health Education: Theory, Research, and Practice. San Francisco, CA: Jossey-Bass.

Grizzell, J. (2007). Behavior Change Theories and Models. Retrieved August, 2019 from http://www. csupomona.edu/ jvgrizzell/best_practices/bctheory.html.

Hemment, J. (1998). Colonization or Liberation: the Paradox of NGOs in Postsocialist States. Newsletter of the Eastern European Anthropology Group, 16(1). Retrieved August, 2019 from: www.depaul.edu/ rrotenbe/aeer/aeer16_1.html

Huizinga, J. (1938). Homo Ludens: A Study of the Play-Element in Culture. London, UK: Routledge \& Kegan Paul (1949).

Hyder, T. (2004). War, Conflict and Play. Maidenhead, Berkshire: Open University Press.

International Play Association (IPA). (1977). Declaration of the Child's Right to Play 1977. Retrieved August, 2019 from: http://ipaworld.org/about-us/declaration/ipa-declaration-of-the-childsright-to-play/

International Play Association (IPA). (2014). Declaration on the Importance of Play. Retrieved August, 2019 from: http://ipaworld.org/wp-content/uploads/2015/05/IPA_Declaration-FINAL.pdf

International Play Association (IPA). (2017). The Access to Play in Crisis Handbook. Retrieved August, 2019 from: http://ipaworld.org/wp-content/uploads/2017/07/IPA-A4-ACCESS-TO-PLAY-INSITUATIONS-OF-CRISIS-TOOLKIT-LR.pdf

International Rescue Committee (IRC). (2002). Emergency Education and Psychosocial Support Programming for Eritrean Refugees in Ethiopia. New York: IRC. Retrieved August, 2019 from: 
www.theirc.org/resources/IRC-Lessons-Learned_Emergency-Education-Psychosocial-SupportProgramming-for-Eritrean-Refugees-in-Ethiopia-」July-2002.pdf

Isidori, M.V., \& Vaccarelli, A. (2015). Pedagogia dell'emergenza. Didattica dell'emergenza. I processi formativi nelle situazioni di criticità individuali e collettive [Pedagogy of the emergencies. The training processes in individual and collective critical situations]. Milano, IT: FrancoAngeli.

Jordan, K. (2003). A Trauma and Recovery Model for Victims and Their Families after a Catastrophic School Shooting: Focusing on Behavioral, Cognitive, and Psychological Effects and Needs. Brief Treatment \& Crisis Intervention, 3(4), 397-411.

Joshi, P.T, \& O’Donnell, D.A. (2003). Consequences of Child Exposure to War and Terrorism. Clinical Child and Family Psychology Review, 6(4), 275-292.

Kagawa, F. (2005). Emergency Education: A Critical Review of the Field. Comparative Education, 41(4) 487-503.

Kailes, J.I., \& Enders, A. (2007). Moving Beyond "Special Needs": A Function-Based Framework for Emergency Management and Planning. Journal of Disability Policy Studies, 17(4), 230-237.

Kailes, J.I. (2008). Southern California Wildfires Report. Prepared in partnership with the Access to Readiness Coalition, the California Foundation for Independent Living Centers, and the Center for Disability Issues and the Health Professions at Western University of Health Sciences. Retrieved August, 2019 from: www.jik.com/CaliforniaWildfires.pdf

Key, E. (1900). The Century of the Child. London, UK: G.P. Putman's Son.

Kett, M., \& Twigg, J. (2007). Disability and Disasters: Towards an Inclusive Approach. In: IFRC, World Disasters Report. Focus on Discrimination (pp. 86-111). Geneva, CH: IFRC. Retrieved August, 2019 from: http://www.ifrc.org/Global/Publications/disasters/WDR/WDR2007English.pdf

Kett, M., \& van Ommeren, M. (2009). Disability, Conflict, and Emergencies. The Lancet, 374(9704), 1801-1803.

Klein, M. (1929). Personification in the Play of Children. The International Journal of Psychoanalysis, 10, 193-204.

Lemyre, L., Gibson, S., Zlepnig, J., Meyer-Macleod, R., \& Boutette, P. (2009). Emergency Preparedness for Higher Risk Populations: Psychosocial Considerations. Radiation Protection Dosimetry, 134(3-4), 207-214.

Levinger, B. (1986). School Feeding Programs in Developing Countries: An Analysis of Actual and Potencial Impact. Washington, DC: USAID.

Meyers, C., \& Vipond, J. (2005). Play and Social Interactions Between Children with Developmental Disabilities and Their Sibings. A Systematic Literature Review. Physical \& Occupational Therapy in Pediatrics, 25(1-2), 81-103.

Miles, S. (2013). Education in Times of Conflict and the Invisibility of Disability: a Focus on Iraq?. Disability \& Society, 28(6), 798-811.

O’Keefe, P., Westgate, K. and Wisner, B. (1976). Taking the Natural Out of Natural Disaster. Nature, 260, 566-567.

Oxman, A.D, \& Guyatt, G.H. (1993). The Science of Reviewing Research. Ann NY Acad Sci, 31(703), $125-33$.

Parr, A.R. (1987). Disasters and Disabled Persons: An Examination of the Safety Needs of a Neglected Minority. Disasters, 11(2), 148-159.

Peek, L., \& Stough, L. (2010). Children with Disabilities in the Context of Disaster: A Social Vulnerability Perspective. Society for Research in Child Development, 18, 1260-1270.

Penson, J., \& Tomlinson, K. (2009). Rapid Response. Programming for Education Needs in Emergency. Paris, F: IIEP.

Perry, C. L., Barnowski, T., \& Parcel, G.S. (1990). How Individuals, Environments, and Health Behavior Interact: Social Learning Theory. In: K. Glanz, F.M. Lewis, B.K. Rimer (Eds.), Health Behavior and Health Educaiton: Theory Research and Practice. San Francisco, CA: Jossey-Bass. 
Phillips, B.D., Thomas, D.S.K., Fothergill, A. \& Blinn-Pike, L. (2010). Social Vulnerability to Disasters. Boca Raton, FL: CRC Press.

Pigozzi, M. J. (1999). Education in Emergencies and for Reconstruction: A Developmental Approach. New York: UNICEF. Retrieved August, 2019 from: www.unicef.org/girlseducation/EducEmerg.

Postman, N. (1982). The Disappearance of Childhood. New York, NJ: Delacorte Press.

Poulatova, C. (2013). Children and Armed conflict. Cambridge, UK: Cambridge Scholar Publishing.

Ranci, C. (2002). Fenomenologia della vulnerabilità sociale [Phenomenology of social vulnerability]. Rassegna Italiana di Sociologia, XLIII(4), 521-551.

Rockhold, P., \& McDonald, L. (2009). The Hidden Issue in International Development Aid: Health and Disability in Conflict-affected Settings in Sub-Saharan Africa. Journal for Disability and International Development, 1, 4-11.

Ronoh, S., Gaillard, J.C., Marlowe, J. (2015). Children with Disabilities and Disaster Risk Reduction: A Review. International Journal of Disaster Risk Science, 6(1), 38-48.

Save the Children. (2006). Rewrite the Future Campaign Report. London, UK: International Save the Children Alliance. Retrieved August, 2019 from: www.savethechildren.org.uk/scuk_cache/ scuk/cache/cmsattach/4271_rtf_campaignreport.pdf

Save the Children. (2007). Child Protection in Emergency. Retrived August, 2019: http://www. refworld.org/docid/47fb94fe2.html

Scotti, J.R., Stevens, S., Cavender, A., Morford, M., Jacoby, V., \& Freed, R. (2007). Response of Persons with Mental Retardation / Developmental Disabilities to Emergency Situation: Implications for Disaster Preparedness. Paper presented at the annual meeting of the International Society for Traumatic Stress Studies, Baltimore.

Singh, S.R., Eghdami, M.R., \& Singh, S. (2014). The Concept of Social Vulnerability: A Review from Disasters Perspectives. International Journal of Interdisciplinary and Multidisciplinary Studies, 1(6), 71-82.

Shepler, S. (2011). Helping Our Children Will Help in the Reconstruction of Our Country. In: K. Mundy, \& S. Dryden-Peterson. Educating Children in Conflict Zone: Research, Policy and Practice for Systemic Change (pp. 199-207). New York, NJ: Teachers College Press.

Sinclair, M. (2001). Educating in Emergencies. In: J. Crisp, C. Talbot, \& D. Cipollone (Eds.). Learning for a Future: Refugee Education in Developing Countries, pp. 1-83. Geneva, CH: UNHCR. Retrieved August, 2019 from: www.unhcr.org/research/RESEARCH/3b8a1ba94.pdf

Sinclair, M. (2002). Planning Education in and after Emergencies. Fundamentals of Educational Planning - 73. Paris, F: UNESCO, International Institute for Educational Planning.

Smith, A., \& Vaux, T. (2002). Education, Conflict and International Development. London, UK: Department for International Development.

Smith, J., Levy, M.J., Hsu, E.B., \& Levy, J.L. (2012). Disaster Curricula in Medical Education: Pilot Survey. Prehospital and disaster medicine, 27(5), 492-494.

Sommers, M. (2006). Touth and Conflict. A brief Review of Available Literature. Washington, DC: USAID. Retrieved August, 2019 from: http://pdf.usaid.gov/pdf_docs/Pnadt380.pdf

Staccioli, G. (2004). Il gioco e il giocare [Play and playing]. Roma, IT: Carocci.

Summerfield, D. (1996). The Impact of War and Atrocity on Civilian Populations: Basic Principles for NGO Interventions and a Critique of Psychosocial Trauma Projects. London, UK: Relief and Rehabilitation Network.

Tierney, K.J., Petak, W.J., \& Hahn, H. (1988). Doubled Persons and Earthquake Hazards. Colorado, CO: University of Colorado Boulder, Institute of Behavioral Science.

Twigg, J., Kett, M., Bottomley, H., Tan, L.T., \& Nasreddin, H. (2011). Disability and Public Shelter in Emergencies. Environmental Hazards, 10(3-4), 248-261.

United Nations (UN). (1959). Declaration of the Right of the Child. Retrieved August, 2019 from: http://www.ohchr.org/EN/Issues/Education/Training/Compilation/Pages/1DeclarationoftheRi ghtsoftheChild(1959).aspx 
United Nations (UN). (1989). Declaration of the Right of the Child. Retrieved August, 2019 from: http://www.ohchr.org/en/professionalinterest/pages/crc.aspx

United Nations (UN). (2006). Convention on the Right of the Persons with Disabilities. Retrieved August, 2019 from: https://www.un.org/development/desa/disabilities/convention-on-therights-of-persons-with-disabilities.html

United Nations (UN). (2013). General Comment No. 17 on the Right of the Child to Rest, Leisure, Play, Recreational Activities, Cultural Life and the Arts. Retrieved August, 2019 from: http://www.iccpplay.org/documents/news/UNGC17.pdf

United Nations High Commissioner for Refugees. (UN). (2014). Needs Assessment of Syrian Refugees with Disabilities in Central and West Bekaa, Lebanon. Retrieved August, 2019 from: www.data. unhcr.org/syrianrefugees/download.php?id=956

United Nations (UN). (2019). Resolution 2475. Protection of Civilians in Armed Conflict. Retrieved August, 2019 from: http://unscr.com/en/resolutions/2475

UNESCO (2000). The Dakar Framework for Action. Retrieved August, 2019 from: http://unesdoc. unesco.org/images/0012/001211/121147e.pdf

UNESCO (1999). World Communication and Information. Retrieved August, 2019 from: http:// unesdoc.unesco.org/images/0011/001190/119077e.pdf

UNICEF (2007). Bambini e guerra: speciale sul rapporto ONU/UNICEF 2007 [Children and war: special issue on 2007 UN/UNESCO Report]. Retrieved on August August, 2019 from: http://www.unicef. it/flex/cm/pages/ServeBLOB.php/L/IT/IDPagina/3755

UNICEF (2016a). The State of the World's Children. Retrieved August, 2019 from: https://www.unicef. org/publications/files/UNICEF_SOWC_2016.pdf

UNICEF Office of Research (2016). 'Fairness for Children: A league table of inequality in child well-being in rich countries'. Innocenti Report Card 13. UNICEF Office of Research. Florence, I: Innocenti. Retrieved August, 2019 from: https://www.unicef-irc.org/publications/pdf/RC13_ eng.pdf

Visalberghi, A. (1958). Esperienza e valutazione [Experience and evaluation]. Torino, IT: Taylor.

Vygotskij, L.S. (1967). Play and Its Role in the Mental Development of the Child. Soviet Psychology, 5(3), 6-18 (or. ed., 1966).

Wessells, M. (1998). Children, Armed Conflict, and Peace. Journal of Peace Research, 35(5): 635-646. Retrieved August, 2019 from: http://www.jstor.org/stable/425703

WFP (2007). Full report of the Thematic Evaluation of WFP School Feeding in Emergency Situations. Rome, IT: WFP. Retrieved August, 2019 from: https://www.wfp.org/content/thematicevaluation-wfp-school-feeding-emergency-situations

Winnicott, D.W. (1971). Playing and Reality. London; New York, NJ: Tavistock Publications. 


\title{
5 Usability and accessibility of toys and technologies for play for children with disabilities: Scoping review of guidelines and tools.
}

\begin{abstract}
For creating play opportunities for children with disabilities toys, games, apps, robots, and other technological products are as important as for typically developing children. Above all the products have great potential for inclusive play. However, many anecdotes from clinical practice and data from research show the challenges in finding and choosing a suitable toy or technology, in evaluating these play objects on their usability and accessibility for given children, in designing and producing a toy usable for all children. This paper describes the scoping review carried out to investigate: (1) which guidelines and tools regarding usability and accessibility of toys and technologies for play for children with disabilities exist, (2) what is their possible use for different stakeholders involved in play for children with disabilities, (3) what are the strengths and the weaknesses of the guidelines and tools. For this review, sources identified by experts, different databases, and hand-made search results were considered, which yielded to a final set of 15 guidelines on usability and accessibility of toys and technologies for play for children with disabilities that was explored in detail. Each guideline was reviewed by two reviewers using the adapted AGREE II instrument. The review resulted in the selection of 10 guidelines on usability or accessibility of toys and technologies, only 5 had a specific focus on play. For most of the guidelines the rigour of the development and the supporting evidence were not described. Further research and development is needed, as adults involved in play for children with disabilities need support in handling or creating the appropriate toys and technologies.
\end{abstract}

\subsection{Introduction}

The importance of play for children's development, well-being, and quality of life is extensively explored and described (Besio, Bulgarelli, \& Stancheva-Popkostadinova, 2017). Technological innovations are affecting many aspects of modern life, including play and play environments of children with and without disabilities. However, the impact on the use of toys made of non-standard materials, or including technological devices, is less discussed and researched in text books for diverse stakeholders involved on toys and technologies for play for children with disabilities (e.g., CaseSmith \& Clifford O’Brien, 2015; Nathan \& Pellegrini, 2010; Pullin, 2009). Bergen and colleagues (2016) mentioned that research on effects of technology-augmented play is still relatively small (Bergen, Davis, \& Abbitt, 2016). 
Still, important bodies like World Health Organization and UNICEF, emphasize the importance of access to assistive technology for children with disabilities to improve their participation (Borg, Berman-Bieler, Khasnabis, Mitra, Myhill, \& Samant Raja, 2015). One of the strategies to facilitate inclusion in play among children with physical disabilities in childcare centres concerns environmental factors, i.e. using a physical setting to enable the child to be included, using different types of toys to facilitate play behaviour and engagement in play, and using the specific play activity to encourage participation in play (Crawford, Stafford, Philips, Scott, \& Tucker, 2014). In this perspective, "play [for the sake of play, for the purpose and objective of the play itself and not as a mean for educational or rehabilitative objectives] becomes the privileged mean for creating inclusive contexts and adopting inclusive styles, with respect to any kind of differences, including those related to the possible impairment and to human functioning” (Besio, 2017, pp. 45,47).

Technology has great potential for play of children with disabilities. However, different questions are emerging about toys and technologies for this purpose. Are children, parents, teachers, and therapists supporting these children, aware of different kinds of toys and technologies? Do they know, how to get them and how to use them? How can they evaluate the impact of the play object? What is the evidence supporting the use of a specific toy or technology to enable play? To what extent are designers and engineers developing toys and technologies suitable for all children, including children in the age of 0-18 years with any kind of disability? How can the design and production of an object for play be made accessible and usable? How are scholars investigating the use of toys and technologies for play? What kind of measurements do they use? The list of questions remains open.

In this paper, we focus on usability and accessibility of toys and technologies for play for children with disabilities and above questions upon these topics will be addressed. Usability is defined as "the extent to which a product can be used by specified users to achieve specified goals with effectiveness, efficiency and satisfaction in a specified context of use” (ISO 9241-11:2018).

The aspects of the concept include:

- $\quad$ a user, i.e. an individual who accesses or interacts with a system;

- effectiveness, i.e. accuracy and completeness of achieving user-specific goals;

- efficiency, i.e. the resources expended in relation to effectiveness;

- $\quad$ satisfaction, i.e. freedom from discomfort, and positive attitudes towards to use of the product;

- context, i.e. physical and social environment of a system use, including users, tasks, equipment and materials.

The concept of accessibility is inevitably related to usability. For toys and technological play objects accessibility is so important that both concepts should be used along. Accessibility is defined as "the extent to which products, systems, services, environments and facilities can be used by people from a population with 
the widest range of characteristics and capabilities to achieve a specified goal in a specified context of use" (ISO 9241-11:2018, p. 3) Accessibility involves both ease of use and success of use (ISO/IEC Guide 71:2014) .

In this paper the following questions are investigated:

- Which guidelines and tools regarding usability and accessibility of toys and technologies for play for children with disabilities exist?

- What is their possible use for different stakeholders involved in play for children with disabilities?

- What are the strengths and the weaknesses of the identified guidelines and tools?

To answer these questions, we have considered the following definition for guideline: "information intended to advise people on how something should have been done or what something should be", whereas tool is defined as "something that helps you to do a particular activity" as described in the Cambridge English Dictionary. In this case the activity concerns usability and accessibility of toys and technologies for play for children with disabilities the concept of children with disabilities should be interpreted as persons in the age of 0 to 18 years with all kind of disabilities, as stated on in the Convention on the Rights of the Child by UNICEF (1989). The stakeholders we have considered are parents, professional caregivers, designers, and people interested in developing this kind of toys as hobbyists ("makers"). They have different purposes, and may profit of each guideline in different ways, if any.

\subsection{Method}

The current paper is one of the outcomes of the COST Action TD1309 "LUDI - Play for Children with Disabilities" (2014-2018) ${ }^{29}$, a network of more than 100 researchers and practitioners coming from 32 European countries and devoted to the theme of play and toys, technologies for children with disabilities.

\subsubsection{Data collection}

Having defined the adopted terminology, the methodology for this review is discussed in this section. A scoping study was chosen as an exploratory one in order to include all sources and data that can be used to identify gaps in the existing research (Arksey \& O'Malley, 2005). The study started by identifying four sources of information: the LUDI database, documents about the topic shared by LUDI members, results from extensive search on selected databases, and hand search.

29 For more detailed information about the COST Action LUDI, please refer to: https://www.cost.eu/ actions/TD1309/\#tabs|Name:overview and to: https://www.ludi-network.eu/ 
LUDI database was expected to provide information on tools and guidelines used in interventions and research projects. A working group of researchers and practitioners within LUDI project have created a database of assistive technologies to support play for children with disabilities (stored at: http://ludi.utad.pt/). Devices, services and contexts for play for children with disabilities were collected. Table 5.1. reports the set of attributes recorded in the database. The elements marked in bold with $\left(^{\star}\right)$ are explicitly aimed at collecting sources to evaluate usability, accessibility and effectiveness of devices, services and context for play for children with disabilities.

Table 5.1: Structure of the LUDI database records.

\begin{tabular}{|c|c|}
\hline Items of the database & Example of contents \\
\hline \multicolumn{2}{|l|}{ Name of play experience } \\
\hline Type of project & Intervention, finished or ongoing research \\
\hline Summary & $\begin{array}{l}\text { Target group, aims, kind of activities, Play Experience by AT } \\
\text { used (devices, services and contexts), play experiences and } \\
\text { results }\end{array}$ \\
\hline $\begin{array}{l}\text { Description of the play } \\
\text { experience }\end{array}$ & $\begin{array}{l}\text { Low-tech, high-tech products, services and contexts for play. } \\
\text { Intended user(s), intended target group(s), manufacturer/ } \\
\text { developer, reference }\end{array}$ \\
\hline The context of use & Home, school, rehab centre or other environments \\
\hline Type of play & $\begin{array}{l}\text { According to LUDI classification of types of play (Bulgarelli \& } \\
\text { Bianquin, 2017) }\end{array}$ \\
\hline $\begin{array}{l}\text { Objectives on play according } \\
\text { to ICF-CY }\end{array}$ & $\begin{array}{l}\text { Play for the sake of play with different objectives/codes } \\
\text { Play like activities with different objectives/code }\end{array}$ \\
\hline Participants & $\begin{array}{l}\text { Number, chronological and developmental age, type of } \\
\text { disabilities according to the LUDI classification }\end{array}$ \\
\hline Explanation & $\begin{array}{l}\text { Explanation of the adult about the use of low-tech, high-tech } \\
\text { devices, services or contexts } \\
\text { Involvement of adult(s) and his/her role }\end{array}$ \\
\hline Evaluation & $\begin{array}{l}\text { Evaluation of objectives and the outcome measures }\left(^{*}\right) \text { used } \\
\text { for this, including availability of outcome measure, publisher, } \\
\text { website, contact person were collected as shown in Figure } 5.1\end{array}$ \\
\hline Summary of achievements & Achieved effects \\
\hline $\begin{array}{l}\text { References to the intervention } \\
\text { or research project }\end{array}$ & $\begin{array}{l}\text { List of published materials referring to the specific entry of the } \\
\text { database }\end{array}$ \\
\hline Keywords & $\begin{array}{l}\text { Keywords of the described intervention or research. As well } \\
\text { reference of play system with similar keywords }\end{array}$ \\
\hline Additional information & $\begin{array}{l}\text { Information on guidelines/tool for usability and accessibility of } \\
\text { toys and technologies can be posted (*). }\end{array}$ \\
\hline
\end{tabular}




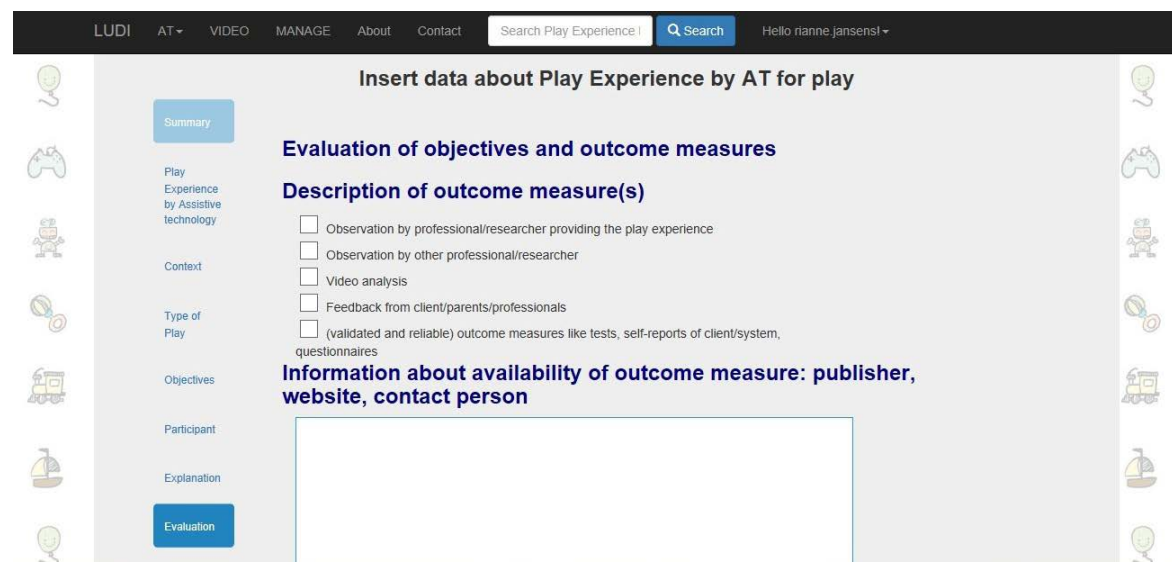

Figure 5.1: Evaluation of objectives and the outcome measures as reported in the LUDI database.

Secondly, members of LUDI were sharing the documents and resources that they created or worked with. These resources were about evaluating toys and technologies for play for children with disabilities, in particular about usability and accessibility.

Besides the so far mentioned resources, it was necessary to search at different databases and key journals to make the systematic review process sound.

In February 2018, searches were made on two online databases: DiZ and PubMed. $\mathrm{DiZ}^{30}$ is an online database of Zuyd University, which consists of 34 different databases. The search strategy was based on a PICO question (Schardt, Adams, Owens, Keitz, Fontelo, 2007), namely: 'Which guideline(s) exists on usability and accessibility of toys and technology for play for children with disabilities?'. The search strategy was first used on PubMed and then converted for the DiZ. For the search on PubMed, the patient, intervention and outcome categories were filled with MESH-terms and alternative terms, considering spelling variations and synonyms, to cover the complete scope of published articles. MESH-terms were also used as free terms, to make sure the most recently published articles were included as well. For patient, this included the MESH-term "Disabled Children" and the free terms "handicapped child*”, "children with disabilities", "child with disability", "disabled child ${ }^{\star}$; for intervention, the MESH-term "Play and Playthings" and the free terms "toys for play", "technologies for play", "technology for play”, "play technologies”, “play technology”, "APP”, "application" and "robot*" were used and for outcome this included the MESH-term "Architectural Accessibility" and the free terms "accessib»" and "usab»". The search was restricted to articles written in English or Dutch, published from November 2007, with full text availability. The date November 2007 was chosen as the start

30 Please, check: https://bibliotheek.zuyd.nl/en/home 
date due to the WHO publication at 24 October 2007 of a new internationally agreed standard for documenting the health of children and youth: ICF-CY, a commonly used framework in international research where toys and technologies are incorporated in the environmental factors. The search was carried out in February 2018 (Van der Hoef, 2018).

To be as comprehensive as possible, key journals, GoogleScholar and reference lists of relevant articles were hand-searched. Among these, the reference list of the $\mathrm{PhD}$ thesis "Empowering Interactive Technologies for Children with NeuroDevelopmental Disorders and their Caregivers” by Dr Mirko Gelsomini (2018), as he collected hundreds of references on the topic.

\subsubsection{Reviewing process}

Relevant studies, documents, website information were selected on three levels by three or more reviewers. The first selection was made on title level, the second selection on abstract/summary level, the third selection on full text level, based on the in- and exclusion criteria.

Regarding inclusion criteria, sources (documents, scientific articles, websites) were included when they concerned all of the following aspects:

1. children in the age of 0-18 years old;

2. children with any kind of disability/handicap or a combination of disabilities/ handicaps;

3. toys or technologies for play in its broadest sense, like APPs, videogames, robots, self-made or self-adapted toys.

Exclusion criteria: sources (documents, scientific articles, website information) were excluded when:

1. focused on the evaluation of the accessibility or the usability of one example of a toy or technology for play. This criterion was used because this is a search for guidelines, standards, tools or recommendations for guidelines on usability and/ or accessibility in general, not just for a single item.

2. the toys and/or technologies mentioned in the sources were used to improve physical or academic skills, since the guidelines and tools should concern play for the sake of play, and not on play-like activities (Besio, 2017).

More than 30 reviewers were involved to evaluate full texts of the retrieved documents. The process was divided into three stages: (1) a quick scan based on title and abstract, (2) full-text scan, (3) formal evaluation with AGREE II instrument. For stage 1 and 2, a quick scan taxonomy was developed, discussed and accompanied with clear instructions shown in Appendix 1. Sources were allocated to reviewers randomly, however bearing in mind the professional background assuring each document was 
reviewed by at least one person with product-oriented background and one with child-oriented background.

After selection at title, abstract, and full text level, the results were subject to an in-depth reviewing process. For this aim, different methodologies were considered. The AGREE II instrument (Brouwers et al., 2013 updated version), a tool for reviewing clinical guidelines, was chosen, adapted for the objectives of this review and piloted, presented in Appendix 2.

If the reviewers disagreed about the document meeting the criteria, more reviewers were involved.

\subsection{Results}

The records of LUDI database $(\mathrm{N}=54)$ were describing mostly qualitative, not validated evaluations of toys and technologies like observations and interviews by researcher/ therapist or members of the team. The evaluation focus, as stated in the record, was often on user experiences, observing his/her behaviour and asking feedback from the user, either directly, when possible, or to intermediaries or caregivers. As no record had detailed information about their research methodology e.g. any observation guide, interview guide or detailed information about video analysis was given, it was not possible to draw any conclusion regarding the rigour.

Only the following three records from the LUDI database were qualified for the in-depth review:

- "Juego, juguetes y discapacidad. La importancia del diseño universal”: there is an English version available of this guideline/tool (Costa et al., 2007).

- "Does it work?" A framework to evaluate the effectiveness of a robotic toy for children with special needs. (Ferrari, Robins, \& Dautenhahn, 2010).

- cTowards a New Measure of Playfulness: The Capacity to Fully and Freely Engage in Play" (Sandersons, 2010).

The second source, i.e., the LUDI project participants' collection of guidelines and tools on usability and accessibility of toys and technology for play for children with disabilities, yielded 59 documents or references to websites. In the first selection duplicates were removed. Secondly, 45 documents were reviewed with the quick scan taxonomy by 3 or more reviewers with technology-product oriented or child-oriented background. This process revealed 20 potentially interesting documents. Reasons for excluding the other 25 sources were diverse: measurement of a child abilities only, not referring technologies for play, focus on assistive technologies not referring to play support, list of toys without usability or accessibility aspects or sources explaining general principles of interaction design. The third source, the research databases, generated a total of 89 articles. The fourth source, i.e. hand-searching in key journals, reference lists of key journals and the 622 references of the $\mathrm{PhD}$ thesis of Gelsomini 


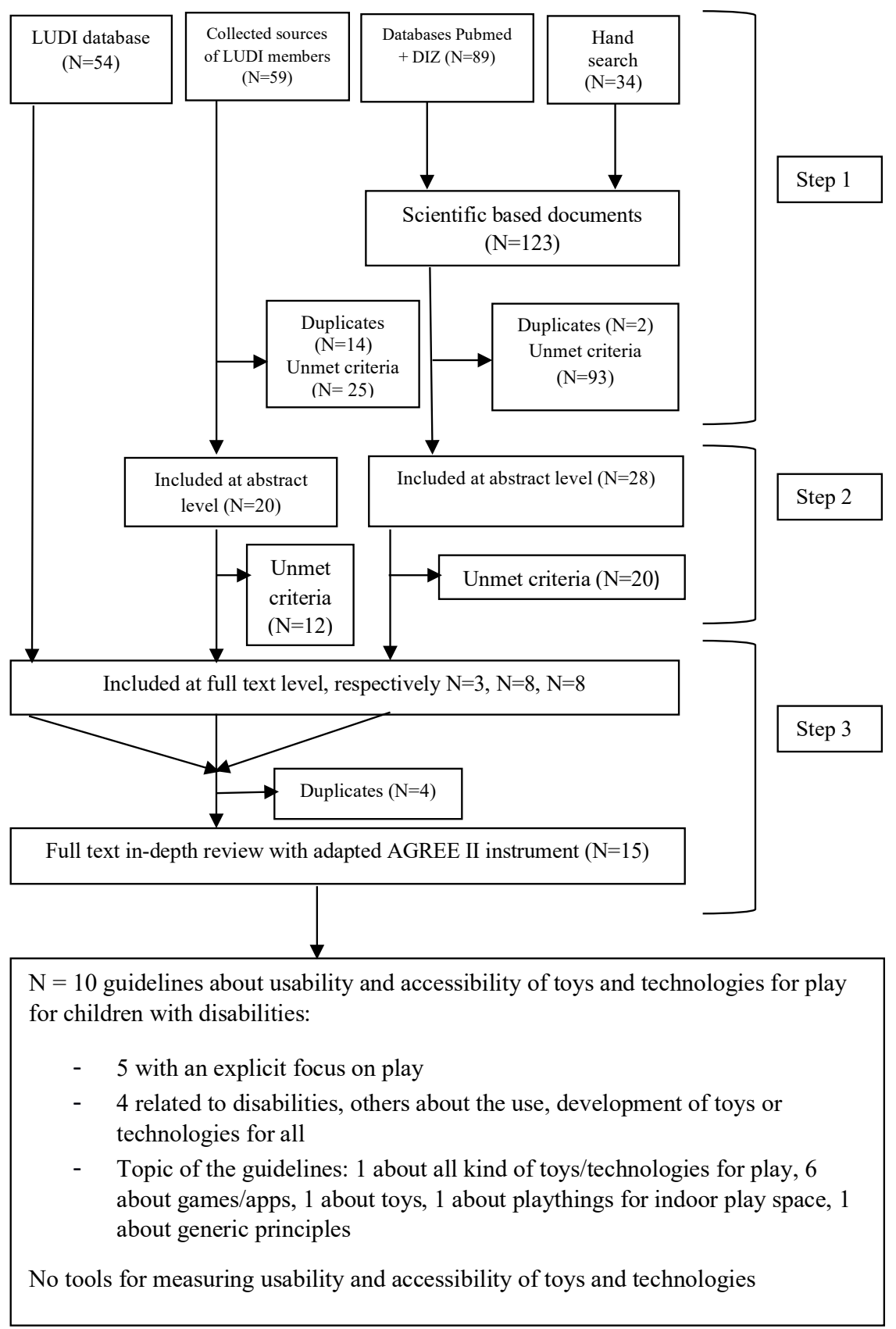

Figure 5.2: Reviewing process. 
(Gelsomini, 2018), added 34 more articles to the next review stage. The output from databased and hand search was combined and yielded in total 123 items. At title/abstract level of the study selection process, 2 documents were excluded due to duplication, 93 documents due to the criteria that the mentioned toy/technology was not for play or was used to improve physical or academic skills in a play-like activity or had a focus on the accessibility of healthcare or of a public building. Applying in- and exclusion criteria at abstract level limited the articles found to the final 8 included documents.

The four different sources of data collection revealed a total of 15 guidelines/ tools on usability and accessibility of toys and technologies for play for children with disabilities, after expelling 4 duplicates. These 15 documents were evaluated in-depth with the adapted AGREE II instrument. These data can be consulted at https://www. dropbox.com/sh/iafjr1mj01zgesf/AAAbw5KBEv6jKAZ543TSV9tHa?dl=0

Table 5.2 presents a summary of the review data with a justification for exclusion and whether the guideline/tool is a suitable guideline for this review aim or can be part of a guideline on usability and accessibility of toys and technologies for play for children with disabilities as described in the research questions in the introduction section.

As a result of the AGREE II evaluation phase, the following guidelines are recommended by LUDI as guidelines to support usability and accessibility of toys, games indoor play things or for all kind of play objects for play for children with disabilities:

- Toys, games and disabilities. The importance of a universal design ( ${ }^{\star}$ ) (Costa et al., 2007)

- Inclusive indoor play: An approach to developing inclusive design guidelines (Mullick, 2013)

- Designing universally accessible games (Grammenos, Savidis, \& Stephanidis, 2009)

- Guidelines to promote play opportunities for children with disabilities. Let's play projects.

- Game accessibility - A survey $\left(^{\star}\right)$ (Yuan, Folmer \& Harris, 2011)

Five other guidelines are not focusing explicitly on play but can be used for creating play opportunities as well, and therefore recommended by LUDI:

- Game accessibility guidelines (http://gameaccessibilityguidelines.com/)

- Highlights of Inclusive Design for App Development (https://tech.beitissie.org.il/ en/highlights-of-inclusive-design-for-app-development/)

- APPlication guidebook: 7 easy steps to making your app accessible $\left(^{\star}\right)$

- http://en.beitissie.org.il/kb/item/7-easy-steps-to-making-your-app-accessible/

- The Principles of Universal Design (https://projects.ncsu.edu/design/cud/about_ ud/udprinciplestext.htm)

- Includification. A practical guide to game accessibility $\left(^{\star}\right)$ (https://accessible. games/includification/) 


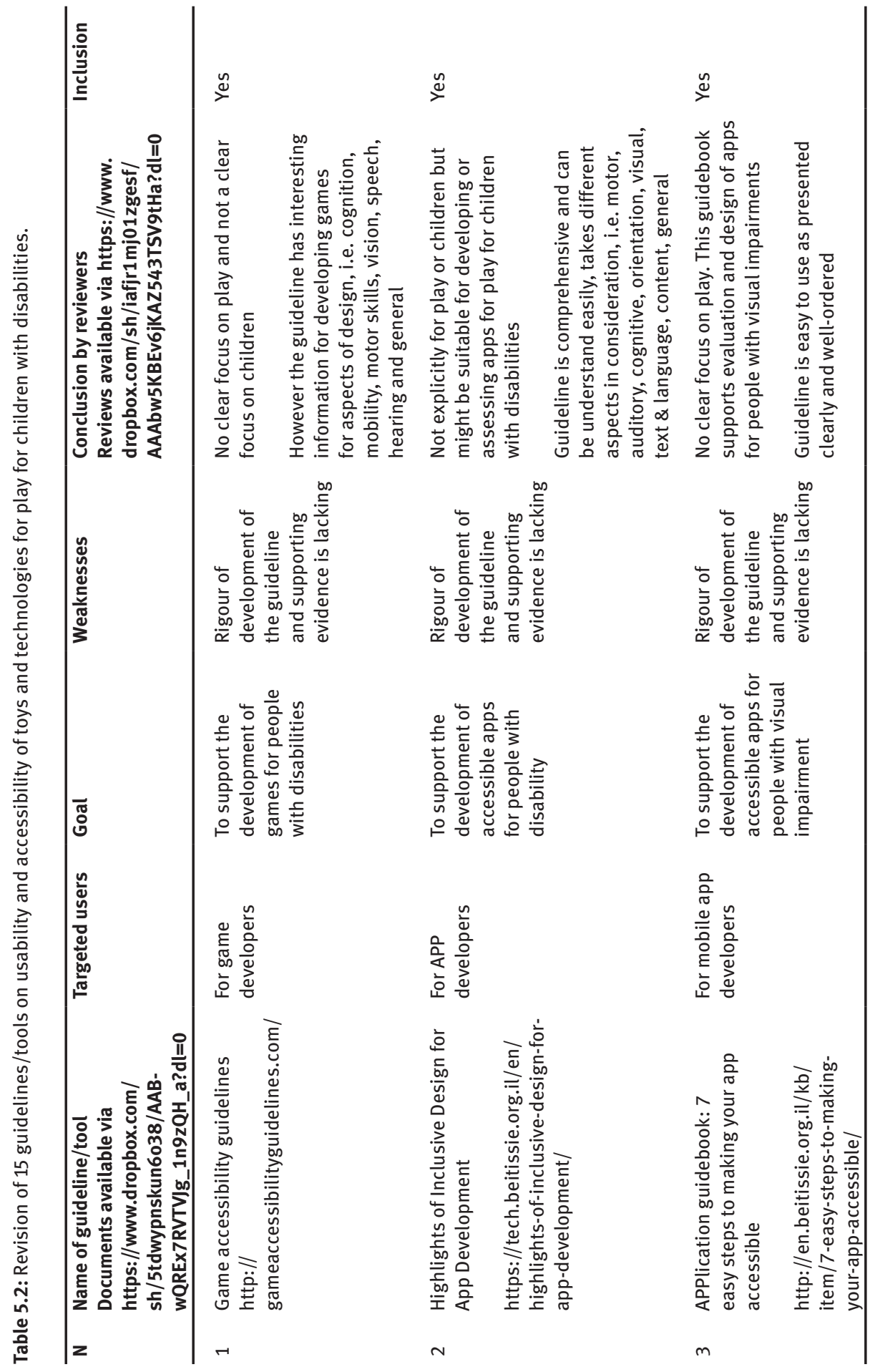




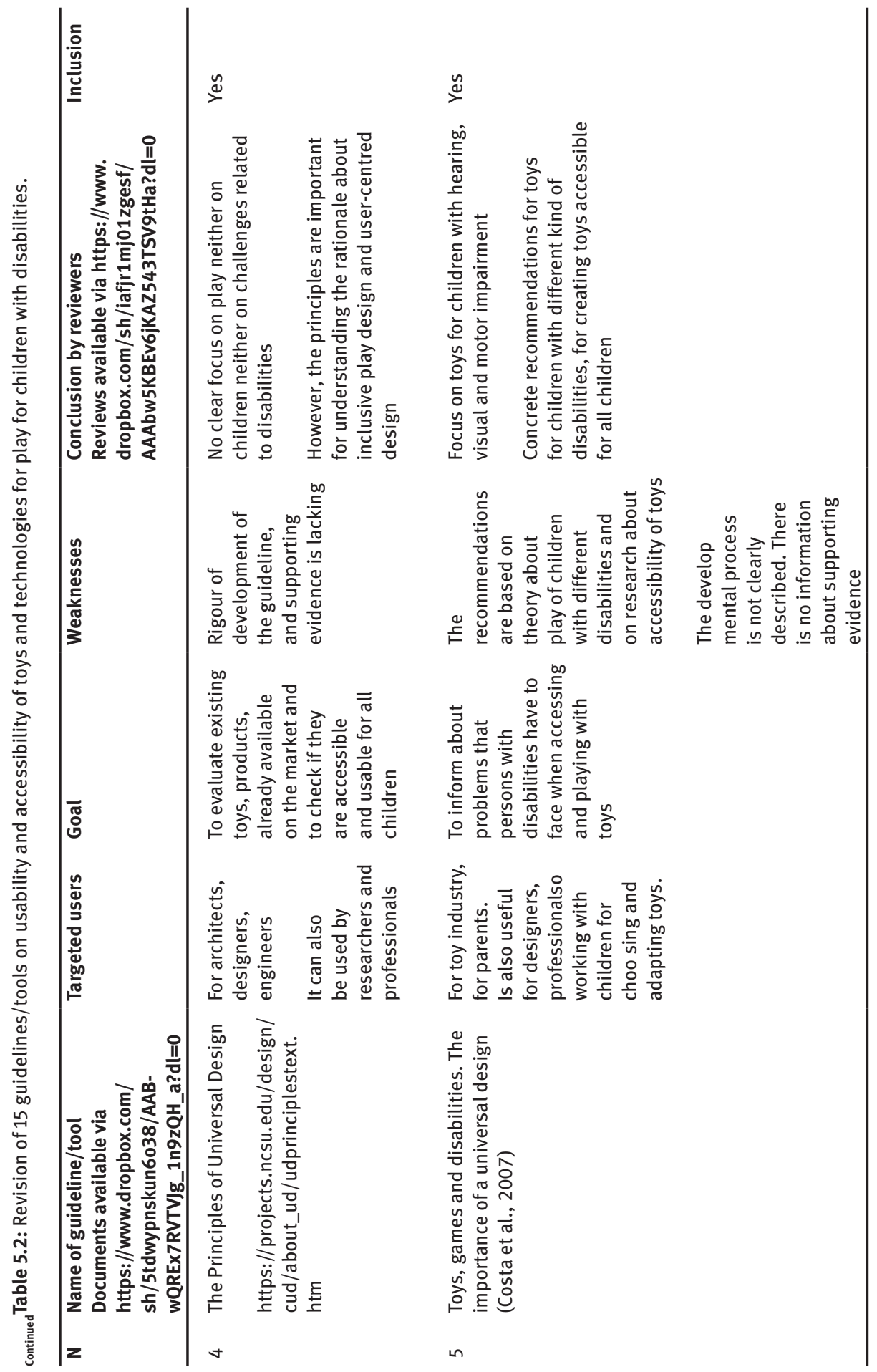




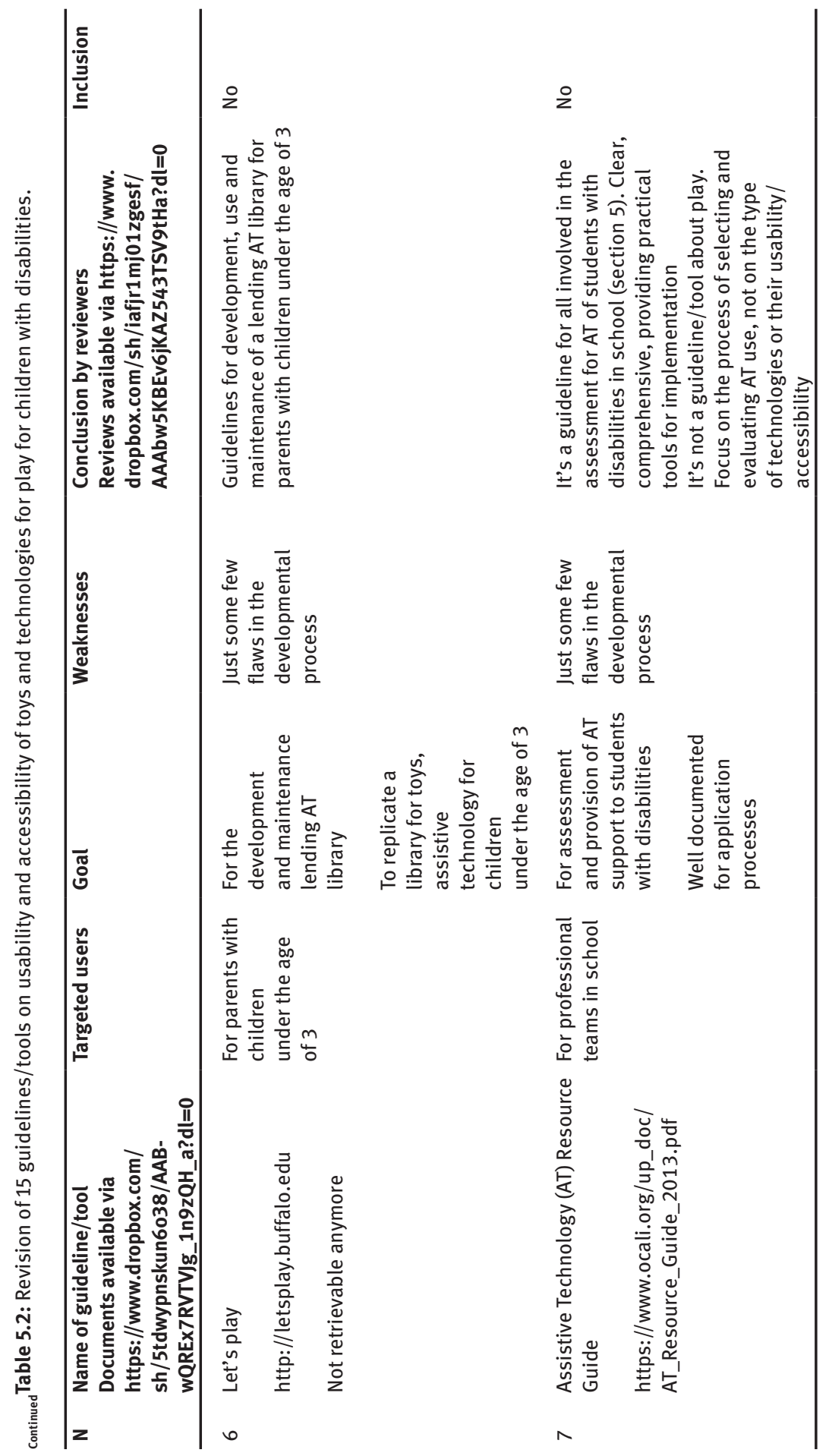




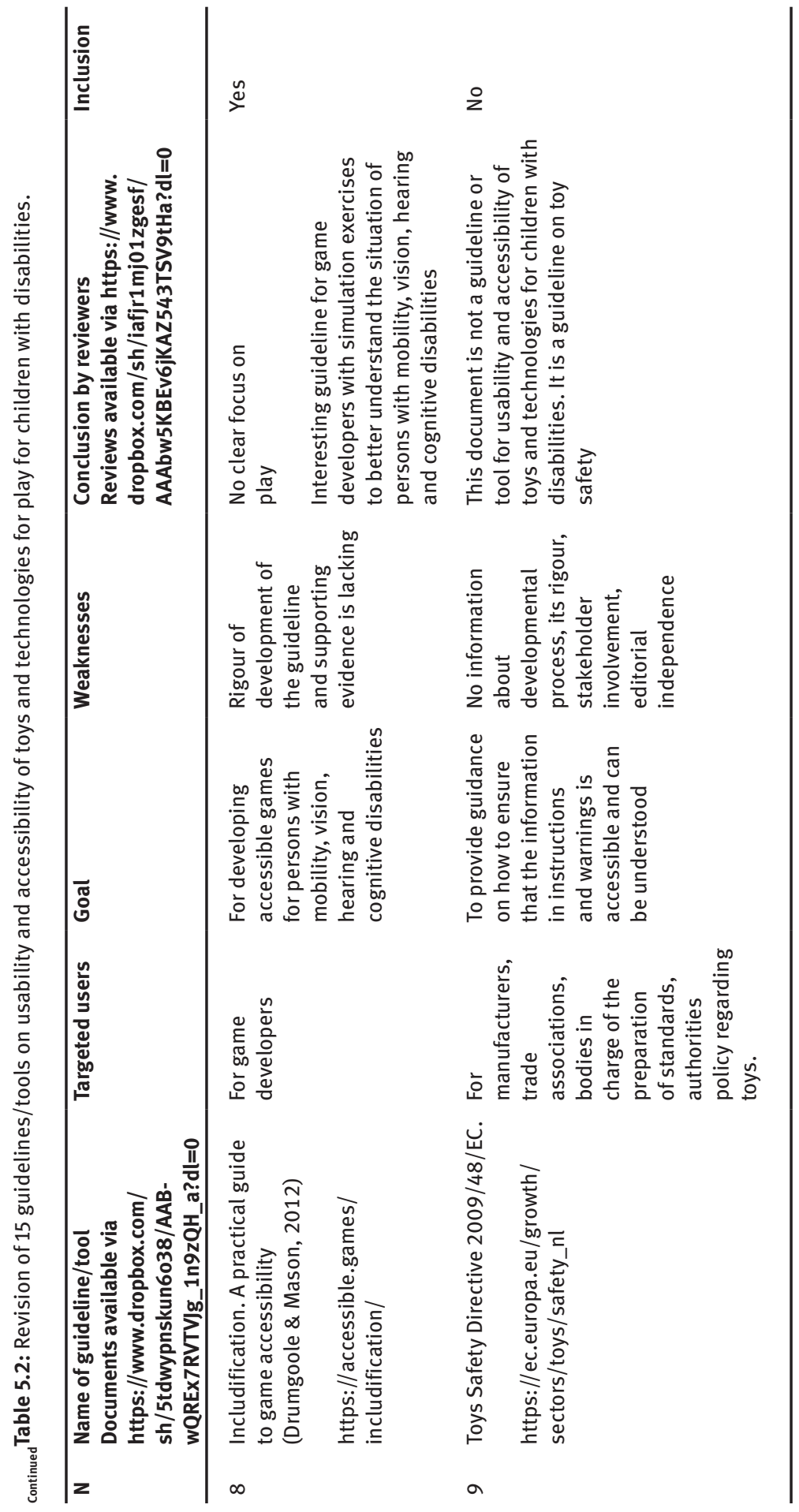




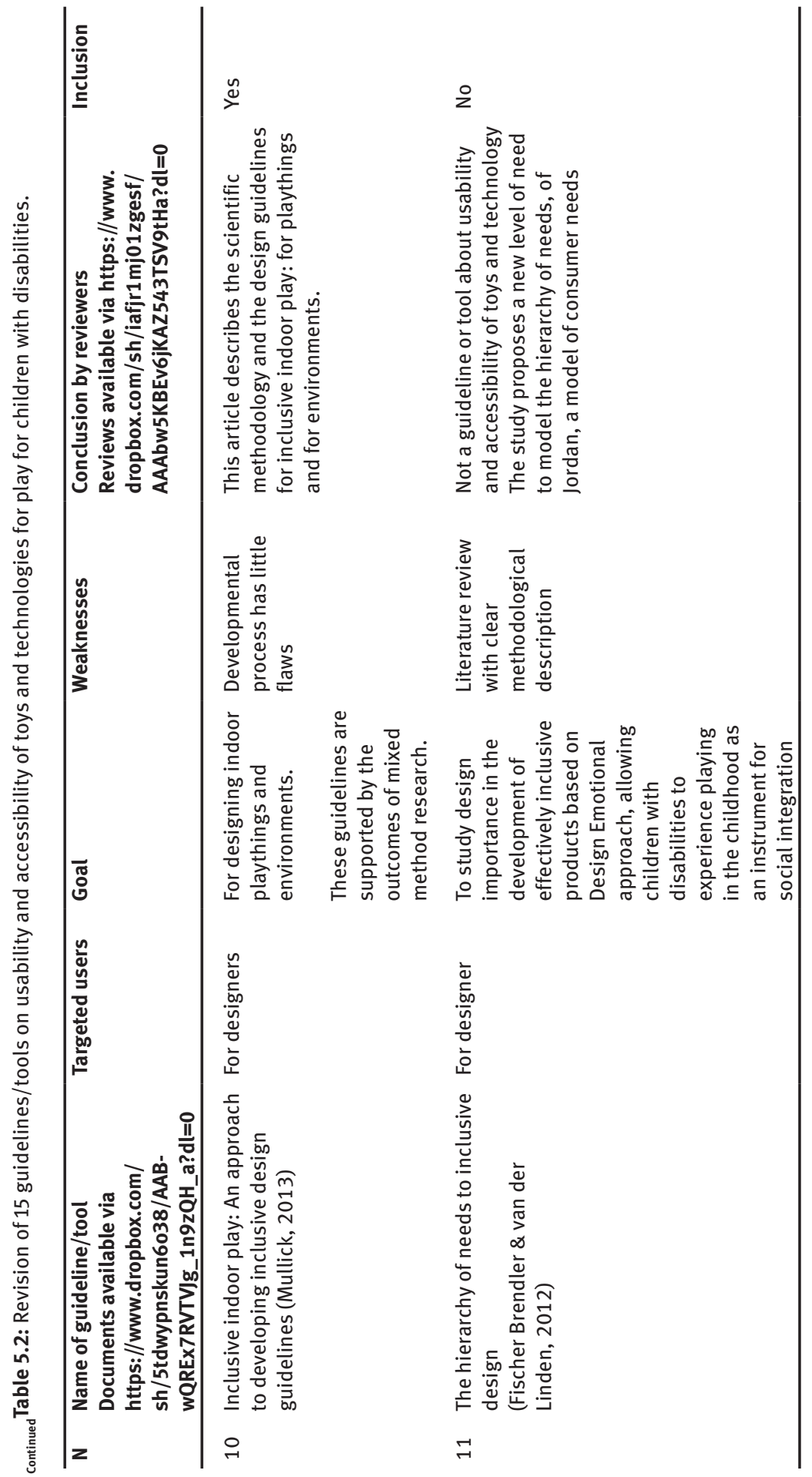




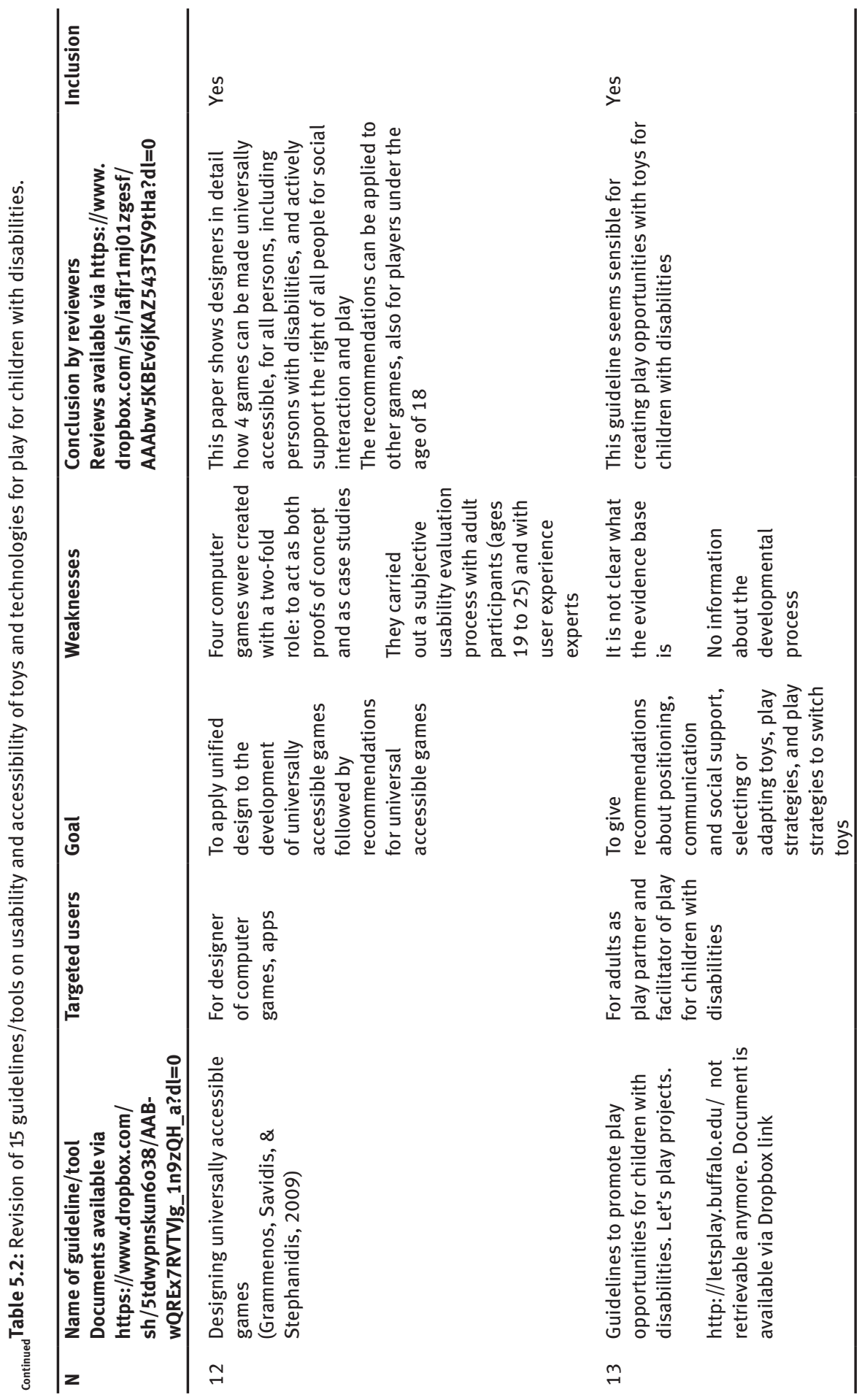




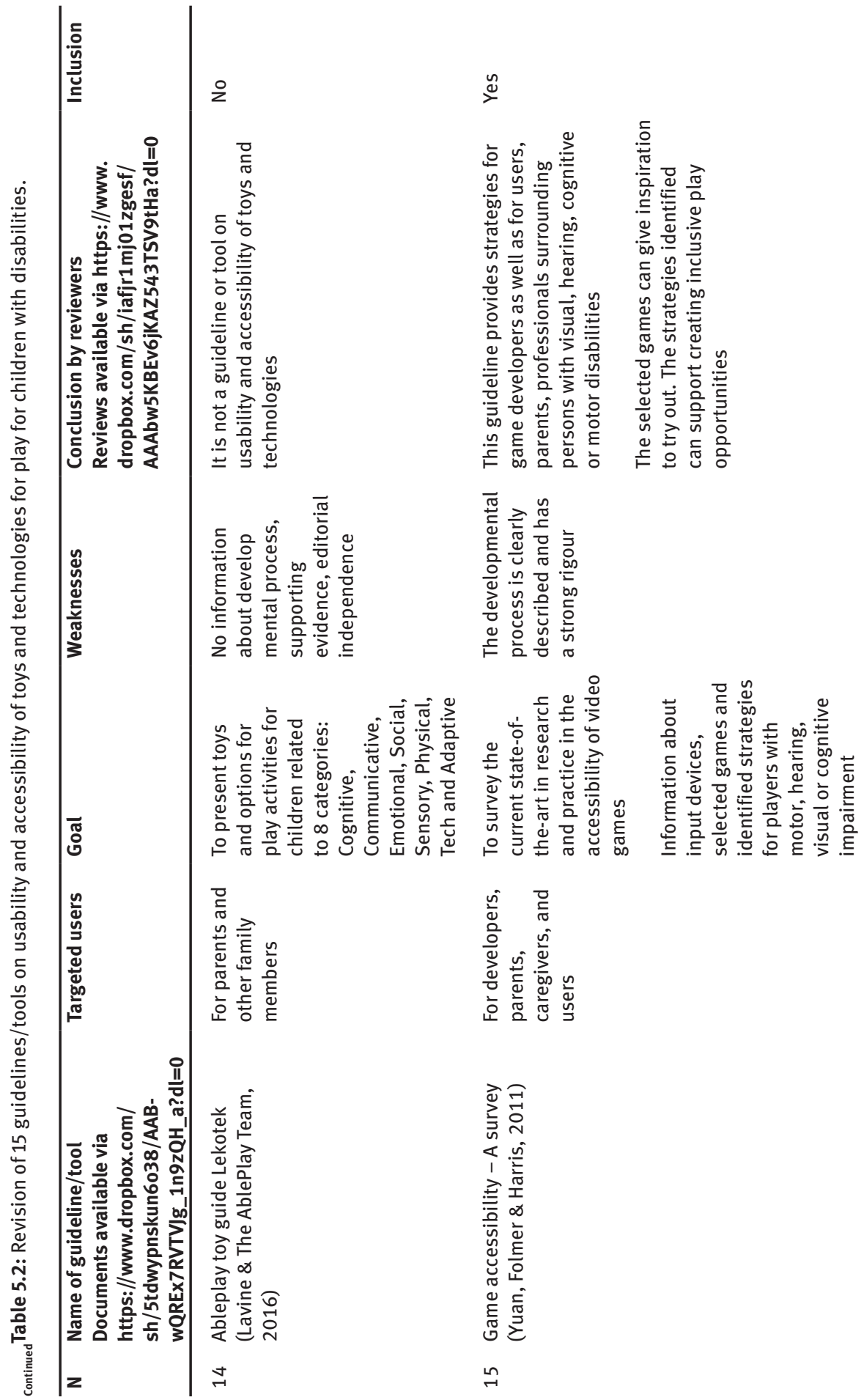


From these 10 guidelines, 4 (marked with *) are specifically addressing disabilities like hearing, visual, cognitive, motor or mobility impairments.

\subsection{Conclusion}

This scoping review resulted in recommendation of 10 guidelines on usability and accessibility of toys and technologies for play of children with disabilities. From the 15 guidelines/tools five were excluded as they did not focus on usability and accessibility of toys and technologies for play but on toys safety or setting up a library to lent assistive technology. In this review, no tools for usability and accessibility measurement were found. Most guidelines are focusing on games and apps. No source emerged about usability and accessibility of robots. The majority of the guidelines and tools developed for persons with disabilities are not in particular for children. Play is the focus of five guidelines emerged in this review. One guideline takes play things in an indoor play environment into consideration. In this perspective it is worth mentioning that play environment or contextual factors were not considered as criteria in this study. For most of the guidelines the rigour of the development, the supporting evidence, the process for updating and editorial independence were hardly described.

\subsection{Discussion}

Although efforts were made to have a transparent and scientifically sound process, this research was challenged in different ways. Cooperation with experts from different countries, with different languages and cultures, with expertise in different professional and scientific fields demands time for understanding, a common mindset and a methodological thorough work. On the opposite, the interdisciplinary and inter-cultural composition of the LUDI Network showed its merits: learning more about each other's profession, background and role in creating inclusive play opportunities for children with disabilities was beneficial for the scientific discussions and work.

Different sources were consulted to find guidelines and tools on usability and accessibility for play for children with disabilities. However, the choice of sources, the keywords and strategies applied cannot guarantee completeness.

Trustworthiness was aimed by using all occasions available to discuss the process, search, review criteria and outcomes with different LUDI members. The composition of the work group was not the same at all meetings and this challenged the process and preconceived outcomes. Each step of the review process was carried out by at least two reviewers, one with expertise in technology and products and one with expertise in supporting children with disabilities in order to increase the interdisciplinary character of research. 
The outcomes of this search and review process show the limited resources for assessing usability and accessibility either guiding the developmental process of toys and technologies for play for children with disabilities, and their application. The lack of methodological transparency and therefore accountability of the 10 included guidelines is a concern as well.

Fast technological developments and challenges bringing to the implementation of innovations indicate that further research in this field is required to support designers and engineers in making inclusive toys and technologies as well as to support parents and professionals in applying these toys and technologies to strengthen transparent professional reasoning and, if possible, evidence based practice. There is still work to be done by researchers, innovation managers and policy makers to support play processes in children with disabilities, to cooperate and to exchange expertise. Designing and producing accessible and useable toys and technologies for children with disabilities is often not reality, neither creating inclusive play opportunities for play for the sake of play so that children are in control, can direct the play situation, and, above all, have fun (Westling Allodi \& Zappaterra, 2019). Guidelines on usability and accessibility of toys and technologies for play for children, aged 0-18 years with all kind of disabilities might support different stakeholders in creating inclusive toys and technologies and in enabling children in play for the sake of play. However, this scoping review yielded 10 guidelines only, with a limited focus and lacking transparency in the methodological process, and no tools at all.

\subsection{Acknowledgements}

We would like to thank LUDI Working Group 2 members for their support in different phases of the development of the guidelines (in alphabetic order): Ms Natalia Amelina, UNESCO Institute for Information Technologies in Education in Russia; Ms Nan Cannon Jones, Independent Consultant in UK; Ms Dana Cappel, Beit Issie Shapiro in Israel; Ms Maria Costa, AIJU - Technological Institute for Children's Products and Leisure Alicante in Spain; Ms Tânia de Jesus Vilela da Rocha, University of Trásos-Montes and Alto Douro and INESCT/ UTAD in Portugal; Mr Pedro Encarnação, Católica Lisbon School of Business and Economics Universidade Católica Portuguesa in Portugal; Mr Raymond Holt, University of Leeds in United Kingdom; Ms Iolanda Iacono, Glitch Factory in Italy; Mr Antoni Jaume-i-Capó, Universitat de les Illes Balears in Spain; Ms Malgorzata Jedrzejewska-Szczerska, Gdansk University of Technology in Poland; Mr Jari Jessen, Due Jessen Digiplay in Denmark; Mr Vygaudas Juozaitis, Lithuanian College of Democracy in Lithuania; Ms Hatice Kose, Istanbul Technical University in Turkey; Ms Agnieszka Landowska, Gdansk University of Technology, ETI Faculty in Poland; Ms Patrizia Marti, University of Siena in Italy; Ms Veronica Montanaro, University of Malta \& TAASC in Malta; Ms Lourdes Moreno, Universidad Carlos III de Madrid in Spain; Mr Mati Mõttus, Tallinn University in Estonia; Ms Noa 
Nitzan, Beit Issie Shapiro in Israel; Ms Selda Ozdemir Gazi, University in Turkey; Mr Suat Ozdemir Gazi University in Turkey; Ms Lucía Pérez-Castilla Alvarez Ceapat (Imserso), National Reference Centre for Personal Autonomy and Assistive Technology in Spain; Ms Odile Perino, FM2J, Play Training Centre, Lyon in France; Ms Noemí Rando, AIJU, Technological Institute for Children's Products and Leisure Alicante in Spain; Mr Ben Robins, University of Hertfordshire in United Kingdom; Ms Evelyne Thommen, University of Applied Sciences and Arts in Switzerland; Mr Tim Vanden Hende, Arteveldehogeschool in Belgium; Ms Renée van den Heuvel, Zuyd University of Applied Sciences in the Netherlands; Mr Robin van Kampen, NYOYN International in the Netherlands.

Special thanks to Mirko Gelsomini, former Ph.D student at Politecnico di Milano in Italy and to Manon van der Hoef, former BSc. occupational therapy student at Zuyd University of Applied Sciences in the Netherlands for their significant contribution.

\subsection{References}

Arksey, H., \& O’Malley, L. (2005). Scoping studies: Towards a methodological framework. International Journal of Social Research Methodology, 8(1), 19-32.

Bergen, D., Davis, D. R., \& Abbitt, J. T. (2016). Technology play and brain development. Infancy to adolescence and future implications. New York, NY: Routledge.

Besio, S., (2017). The need for play for the sake of play. In S. Besio, D. Bulgarelli, \& V. StanchevaPopkostadinova (Eds.). Play development in children with disabilities (pp. 9-52). Warsaw, PL: De Gruyter Poland.

Besio, S., Bulgarelli, D., \& Stancheva-Popkostadinova, V. (Eds.). (2017). Play development in children with disabilities. Warsaw, PL: De Gruyter Poland.

Borg, J., Berman-Bieler, R., Khasnabis, C., Mitra, G., Myhill, W. N., \& Samant Raja, D. (2015). Assistive Technology for Children with Disabilities: Creating Opportunities for Education, Inclusion and Participation. A discussion paper. Geneva, CH: WHO. Retrieved from https://www.unicef.org/ disabilities/files/Assistive-Tech-Web.pdf

Brouwers, M., Kho, M., Browman, G., Burgers, J., Cluzeau, F., Feder, G., ... Zitzelsberger, L. (2013, updated version). AGREE II: Advancing guideline development, reporting and evaluation in healthcare. Retrieved from https://www.agreetrust.org/resource-centre/agree-reportingchecklist/

Case-Smith, J., \& Clifford O'Brien, J. (Eds.). (2015). Occupational therapy for children and adolescents (6 ed.). St. Louis, MO: Elsevier Mosby.

Costa, M., Romero, M., Mallebrera, C., Fabregat, M., Torres, E., Martínez, M., ... Martínez, P. (2007). Juego, juguetes y discapacidad. La importancia del diseño universal. Alicante, E: AlJU. Retrieved from http://www.guiaaiju.com/2015/docs/juego-juguete-y-discapacidad.pdf

Costa, M., Romero, M., Mallebrera, C., Fabregat, M., Torres, E., Martinez, M., ... Martinez, P. (2007). Toys, games, disabilities and integration. Received from the $1^{\text {st }}$ author.

Crawford, S. K., Stafford, K. N., Philips, S. M., Scott, K. J., \& Tucker, P. (2014). Strategies for inclusion in play among children with physical disabilities in childcare centers: An integrative review. Physical \& Occupational Therapy in Pediatrics, 34(4), 404-423.

Drumgoole, A., \& Mason, T. J. (2012). Includification. A practical guide to game accessibility. Retrieved from https://accessible.games/includification/ 
Ferrari, E., Robins, B., \& Dautenhahn, K. (2010). “Does it work?” A framework to evaluate the effectiveness of a robotic toy for children with special needs. Paper presented at the IEEE ROMAN 2010, 19th International Symposium in Robot and Human Interactive Communication Viareggio, Italy.

Fischer Brendler, C., \& van der Linden, J. C. S. (2012). The hierarchy of needs to inclusive design. Work, 41, 1357-1361.

Gelsomini, M. (2018). Empowering Interactive Technologies for Children with Neuro-Developmental Disorders and their Caregivers (Doctoral thesis). Milan, I: Politecnico di Milano.

Grammenos, D., Savidis, A., \& Stephanidis, C. (2009). Designing universally accessible games. ACM Computers in Entertainment, 7(1), 8:3-8:27.

ISO - International Organization of Standardization (2018). Ergonomics of human-system interaction - Part 11: Usability: Definitions and concepts. Retrieved from https://www.iso.org/ standard/63500.html

ISO - International Organization of Standardization / IEC (2014). Guide 71 - Guide for addressing accessibility in standards. Retrieved from https://isotc.iso.org/livelink/livelink/ fetch/2000/2122/4230450/8389141/ISO_IEC_Guide_71_2014\%28E\%29_Guide_for_ addressing_accessibility_in_standards.pdf?nodeid=8387461\&vernum $=-2$

Lavine, K. H. \& The AblePlay Team (2016). AblePlay toy guide. Lekotek. Retrieved from: https://www. lekotek.org/images/stories/files/pdf/ableplay_toyguide_FINAL_web.pdf

Mullick, A. (2013). Inclusive indoor play: An approach to developing inclusive design guidelines. Work, 44(2013), S5-S17.

Nathan, P., \& Pellegrini, A. D. (Eds.). (2010). The Oxford Handbook of the Development of Play. Oxford, UK: Oxford University Press.

Pullin, G. (2009). Design meets disability. Cambridge, MA: MIT Press.

Sandersons, R. C. (2010). Towards a new measure of playfulness: The capacity to fully and freely engage in play (Doctoral thesis). Chicago, MI: Loyola University. Retrieved from https:// ecommons.luc.edu/luc_diss/232/

Schardt, C., Adams, M. B., Owens, T., Keitz, S., \& Fontelo, P. (2007). Utilization of the PICO framework to improve searching PubMed for clinical questions. BMC Medical Informatics and Decision Making, 7(16), 1-6.

Van der Hoef, M. (2018). Reviewing guidelines on usability and accessibility of toys and technologies for play for children with disabilities and possible implication for OT services (Bachelor thesis). Heerlen, NL: Zuyd University of Applied Sciences.

Yuan, B., Folmer, E., \& Harris, F. C. J. (2011). Game accessibility: A survey. Universal Acces in the Information Society, 10(2011), 1-20.

Westling Allodi, M., \& Zappaterra, T. (Eds.). (2019). Users' needs report on play for children with disabilities. Parents' and children's views. Warsaw, PL: De Gruyter Poland. 


\section{Appendix I}

Review of guidelines and tools on usability and accessibility of toys and technologies for children with disabilities: quick scan taxonomy.

Each record requested the following information:

Document full name + source

Information of original file:

- person who has proposed this document

- what kind of source is it

- what is the aim

- for whom is it developed

- additional comments

\section{Quick scan of document:}

- Reviewers' information: name reviewer 1 + background, name reviewer $2+$ background, name reviewer 3 + background

- Dimension 1 Type of document: guideline, standard, assessment, research paper, website, other

- Dimension 2 Evaluated features: usability, accessibility, playfulness, enjoyment, user experience, other

- Comments

\section{Decision of each reviewer}

- In- or ex-clusion

- Comments

\section{Final decision}

- In- or ex-clusion 


\section{Appendix II}

Adapted version of AGREE II instrument (2013) for LUDI purpose: Reviewing guidelines on usability and accessibility for toys and technologies for play for children with disabilities.

Adaptations made for purposes of this review are marked as follows: $\mathbf{x x x}$ : information in bold is added information, $\mathrm{xxx}$ : this criterion is deleted

\section{DOMAIN 1: SCOPE AND PURPOSE}

1. The overall objective(s) of the guideline is (are) specifically described.

2. The health question(s) covered by the guideline is (are) specifically described. Health question: about accessibility and usability, what kind of disability is treated. It is really about a question which will be answered.

3. The population (patients, public, etc.) to whom the guideline is meant to apply is specifically described.

\section{DOMAIN 2: STAKEHOLDER INVOLVEMENT}

4. The guideline development group includes individuals from all relevant professional groups

5. The views and preferences of the target population (patients, public, etc.) have been sought. For the final users: children, aged 0-18 years with all kind of disabilities

6. The target users of the guideline are clearly defined. About the users of the guidelines, e.g. industry, therapist, teachers, parents, designers, engineers

\section{DOMAIN 3: RIGOUR OF DEVELOPMNENT}

7. Systematic methods were used to search for evidence.

8. The criteria for selecting the evidence are clearly described.

9. The strengths and limitations of the body of evidence are clearly described. Quality of the validation, possible limitations.

10. The methods for formulating the recommendations are clearly described.

11. The health benefits, side effects, and risks have been considered in formulating the recommendations.

12. There is an explicit link between the recommendations and the supporting evidence. Recommendations $=$ guidelines/evaluation methods

13. The guideline has been externally reviewed by experts prior to its publication. Experts are experts in clinical area, methodological experts, target population's representatives

14. A procedure for updating the guideline is provided. 


\section{DOMAIN 4: CLARITY OF PRESENTATION}

15. The recommendations are specific and unambiguous.

16. The different options for management of the condition or health issue are clearly presented.

17. Key recommendations are easily identifiable. Structure of document.

18. The guideline describes facilitators and barriers to its application.

19. The guideline provides advice and/or tools on how the recommendations can be put into practice.

20. The potential resource implications of applying the recommendations

21. The guideline presents monitoring and/or auditing criteria.

22. The views of the funding body have not influenced the content of the guideline. E.g. If developer might have had influence on content of guideline (funding/ company). There should be an explicit statement that the views of interest of the funding body have not influenced the final recommendations (e.g. conflict of interest).

23. Interests of guideline development group members have been recorded and addressed. Personal conflicts of interest

\section{OVERALL GUIDELINE ASSESSMENT}

For each question, please choose the response which best characterizes the guideline assessed:
a) Rate the overall quality of this guideline. (strongly disagree 1- strongly agree 10)
b) I would recommend this guideline for use. (yes, yes with modifications, no)
c) Notes 
Rianne Jansens and Andrea Bonarini

\title{
6 Guidelines for parents, professionals, designers, makers and researchers on toys and technologies for play for children with disabilities: How to take usability and accessibility aspects into consideration?
}

\begin{abstract}
Many toys, board or videogames, apps and even robots are nowadays available in many countries for play for children. However, a lot of these are not appropriate for children with disabilities. Instead of enabling play opportunities, frustration and withdrawal can be the case. Parents, siblings, therapists, teachers are often searching quite some time for the most suitable play object. Designers and engineers are interested in creating play objects with a universal design. Nevertheless, daily practices show challenges for these different persons involved in supporting children with disabilities' play. As the review of scientific and grey literature presented in Chapter 5 gained only 10 guidelines on usability and accessibility of toys and technologies for play for children with disabilities and no tools for measuring usability or accessibility. Working Group 2 of the COST Action TD1309 "LUDI - Play for Children with Disabilities" has developed guidelines for taking usability and accessibility of toys and technologies for play for children with disabilities into consideration. The guidelines for parents, professionals, designers, makers and researchers have a pragmatic character and aim to support reflections and decisionmaking processes for choosing, adapting, designing or studying a toy or technology. The guidelines have references to the new gained knowledge about creating play for the sake of play opportunities and evaluating usability and accessibility of play tools. Further evaluation of the presented guidelines is needed to support the adults in their efforts creating play opportunities for children with disabilities.
\end{abstract}

\subsection{Introduction}

Toys and technology have great potential to elicit play for all children. However, different questions regarding usability and accessibility are emerging about toys and technologies for play for children with disabilities. In Chapter 5 of this publication we have described the review process and outcomes about guidelines and tools about usability and accessibility of toys and technologies for play for children with disabilities. The results of this review showed 10 guidelines on usability and accessibility of different play objects with and without technology from which 4 especially developed for children with disabilities. Some of these guidelines, listed 
below, are entirely, usable for a specific group of stakeholders, some just partly. Most of the included guidelines concern apps or games for developers and designers. The 10 included guidelines are not always developed with a focus on play or children.

Table 6.1: Guidelines on usability and accessibility of toys and technologies for play of children with disabilities.

\begin{tabular}{|c|c|c|c|}
\hline $\mathrm{Nr}$ & $\begin{array}{l}\text { Name of guideline } \\
\text { Documents available via https://www. } \\
\text { dropbox.com/sh/8gtyowaokfbzeo3/ } \\
\text { AABm6TwGBOLoczDjU6VWZqsYa?dl=0 }\end{array}$ & Targeted users & Goal \\
\hline 1 & $\begin{array}{l}\text { Game accessibility guidelines } \\
\text { http://gameaccessibilityguidelines.com/ }\end{array}$ & Game developers & $\begin{array}{l}\text { To support the } \\
\text { development of } \\
\text { games for people with } \\
\text { disabilities }\end{array}$ \\
\hline 2 & $\begin{array}{l}\text { Highlights of Inclusive Design for App } \\
\text { Development } \\
\text { https://tech.beitissie.org.il/en/ } \\
\text { highlights-of-inclusive-design-for-app- } \\
\text { development/ }\end{array}$ & APP developers & $\begin{array}{l}\text { To support the } \\
\text { development of } \\
\text { accessible apps for } \\
\text { people with disability }\end{array}$ \\
\hline 3 & $\begin{array}{l}\text { APPlication guidebook: } 7 \text { easy steps to } \\
\text { making your app accessible } \\
\text { http://en.beitissie.org.il/kb/item/7-easy- } \\
\text { steps-to-making-your-app-accessible/ }\end{array}$ & $\begin{array}{l}\text { Mobile app } \\
\text { developers }\end{array}$ & $\begin{array}{l}\text { To support the } \\
\text { development of } \\
\text { accessible apps for } \\
\text { people with visual } \\
\text { impairment }\end{array}$ \\
\hline 4 & $\begin{array}{l}\text { The Principles of Universal Design } \\
\text { https://projects.ncsu.edu/design/cud/ } \\
\text { about_ud/udprinciplestext.htm }\end{array}$ & $\begin{array}{l}\text { Architects, } \\
\text { designers, } \\
\text { engineers. } \\
\text { It can also be used } \\
\text { by researchers and } \\
\text { professionals. }\end{array}$ & $\begin{array}{l}\text { To evaluate existing } \\
\text { toys, products, already } \\
\text { available on the market } \\
\text { and to check if they are } \\
\text { accessible and usable } \\
\text { for all children }\end{array}$ \\
\hline 5 & $\begin{array}{l}\text { Toys, games and disabilities. The } \\
\text { importance of a universal design. } \\
\text { Costa et al. (2007) } \\
\text { See Dropbox link }\end{array}$ & $\begin{array}{l}\text { Toy industry, for } \\
\text { parents. Is also } \\
\text { useful for designers, } \\
\text { professionals } \\
\text { working with } \\
\text { children for choosing } \\
\text { and adapting toys. }\end{array}$ & $\begin{array}{l}\text { To inform about } \\
\text { problems that persons } \\
\text { with disabilities have } \\
\text { to face when accessing } \\
\text { and playing with toys }\end{array}$ \\
\hline 6 & $\begin{array}{l}\text { Includification. A practical guide to game } \\
\text { accessibility } \\
\text { Drumgoole \& Mason (2012) Retrieved } \\
\text { from https://accessible.games/ } \\
\text { includification/ }\end{array}$ & Game developers & $\begin{array}{l}\text { For developing } \\
\text { accessible games for } \\
\text { persons with mobility, } \\
\text { vision, hearing and } \\
\text { cognitive disabilities }\end{array}$ \\
\hline
\end{tabular}


Table 6.1: Guidelines on usability and accessibility of toys and technologies for play of children with disabilities.

\begin{tabular}{|c|c|c|c|}
\hline $\mathrm{Nr}$ & $\begin{array}{l}\text { Name of guideline } \\
\text { Documents available via https://www. } \\
\text { dropbox.com/sh/8gtyowaokfbzeo3/ } \\
\text { AABm6TwGBOLoczDjU6VWZqsYa?dl=0 }\end{array}$ & Targeted users & Goal \\
\hline 7 & $\begin{array}{l}\text { Inclusive } \\
\text { indoor play: An approach to } \\
\text { developing inclusive design } \\
\text { guidelines. } \\
\text { Mullick (2013) }\end{array}$ & Designers & $\begin{array}{l}\text { For designing indoor } \\
\text { playthings and } \\
\text { environments }\end{array}$ \\
\hline 8 & $\begin{array}{l}\text { Designing universally } \\
\text { accessible games } \\
\text { Grammenos et al. (2009) }\end{array}$ & $\begin{array}{l}\text { Designer of } \\
\text { computer games, } \\
\text { apps }\end{array}$ & $\begin{array}{l}\text { To apply unified design } \\
\text { to the development of } \\
\text { universally accessible } \\
\text { games followed by } \\
\text { recommendations for } \\
\text { universal accessible } \\
\text { games }\end{array}$ \\
\hline 9 & $\begin{array}{l}\text { Guidelines to promote play opportunities } \\
\text { for children with disabilities (n.d.). Let's } \\
\text { play projects. } \\
\text { http://letsplay.buffalo.edu/ not available } \\
\text { but see Dropbox link }\end{array}$ & $\begin{array}{l}\text { Adults as play } \\
\text { partner and } \\
\text { facilitator of play } \\
\text { for children with } \\
\text { disabilities. }\end{array}$ & $\begin{array}{l}\text { To give } \\
\text { recommendations } \\
\text { about positioning, } \\
\text { communication } \\
\text { and social support, } \\
\text { selecting or adapting } \\
\text { toys, play strategies, } \\
\text { and play strategies to } \\
\text { switch toys }\end{array}$ \\
\hline 10 & $\begin{array}{l}\text { Game accessibility: A survey. } \\
\text { Yuan et al. (2011) }\end{array}$ & $\begin{array}{l}\text { Developers, parents, } \\
\text { caregivers, and users }\end{array}$ & $\begin{array}{l}\text { To survey the current } \\
\text { state-of-the-art in } \\
\text { research and practice } \\
\text { in the accessibility } \\
\text { of video games and } \\
\text { providing information } \\
\text { about input devices, } \\
\text { selected games and } \\
\text { identified strategies } \\
\text { for players with motor, } \\
\text { hearing, visual or } \\
\text { cognitive impairment }\end{array}$ \\
\hline
\end{tabular}


Scrutinizing the outcomes from the perspective of an adult involved in creating play opportunities for children with disabilities, the potential of each guideline can be described as follows in Table 6.2.

Table 6.2: Overview of potential of the included guidelines regarding creating play opportunities for children with disabilities with toys and technologies by different stakeholders.

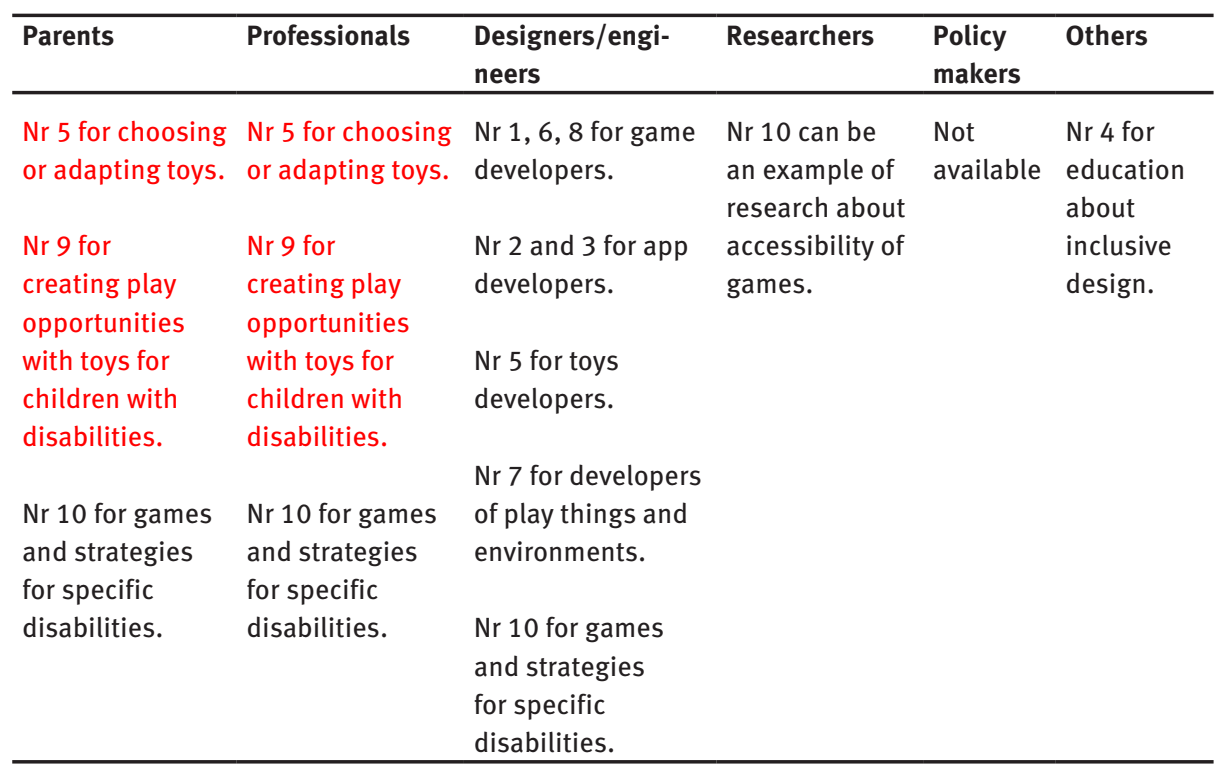

Red lines explicitly related PLAY with toys and technologies; balck lines not explicitly related to PLAY with toys and technologies

All outcomes were guidelines, no tools for evaluating usability or accessibility emerged from this review. Most of the guidelines aimed at analysing or developing games and apps, some of them toys, none of them robots. The guidelines were mostly addressing persons with disabilities and not specifically children or youngsters. Guidelines developed for a specific health condition or impairment were mentioning motor, hearing, visual or, in just one case (nr 3), cognitive impairments. One of the guidelines (nr 10) takes play objects as well as the play environment into consideration.

In conclusion, there is not much information or support available for adults designing, making, choosing, adapting, evaluating toys and technologies for play for children with disabilities. Reviewed guidelines have a rather strict focus, either on specific objects for play or on particular groups of children with disabilities.

Studies and experiences from participants of the COST Action TD1309 "LUDI Play for Children with Disabilities" (2014-2018) showed the need for more attention on usability and accessibility aspects of toys and technologies as these are important 
elements for creating inclusive play. Therefore, LUDI Working Group 2 decided to develop guidelines for different stakeholders in the sense of supporting a particular group when facing questions and issues to make choices regarding the development, adaptation or application of toys and technologies. The intended guidelines are a source of information to advice a specific group of stakeholders, not a protocol of standardized way of working. The results of the scoping review have been incorporated in these guidelines as they can be of important use for a particular stakeholder at a precise phase of his involvement in creating play opportunities.

\subsection{Method}

The development of the guidelines on usability and accessibility of toys and technologies for play for children with disabilities took part in two different phases. First, the objectives and features of the guidelines for a specific stakeholder group was discussed in a LUDI meeting in September 2017 that took place in Gdansk in the presence of more than 20 participants of Working Group 2. Secondly, the structure of the guidelines was discussed related to the intended overall objectives regardless the characteristics of the stakeholder. One of the elements of this discussion was how to make optimal use of the outcomes of the scoping review on guidelines and tools on usability and accessibility of toys and technologies for play for children with disabilities (Jansens \& Bonarini, 2019). Secondly, LUDI wanted to get feedback on the first version of the guidelines in a small feasibility study. Due to time limitations these first versions were evaluated in a straightforward way.

\subsection{Designing guidelines on usability and accessibility of toys and technologies for play for children with disabilities for different stakeholders}

\subsubsection{Objectives of guidelines on usability and accessibility of toys and technologies}

More than 20 experts in the field of toys and technologies for children with disabilities have discussed the objectives for different stakeholders. They are based on the research and clinical practice experiences with them. The objectives should answer the questions described below, in part different for main types of possible users of the guidelines.

\section{A. Parents, relatives, informal caregivers.}

How to evaluate whether a toy, game, robot or app is usable and accessible for a specific child with disabilities? What features are important when choosing an appropriate toy? Where to look at for sustainability of a toy which will be 
interesting for a child over time? Which toys or technological products can be interesting to play with siblings, peers, or the whole family? What kind of toys or technological products are normative?

Objective: The main objective of a guideline on usability and accessibility of toys and technologies for play for children with disabilities for parents is to support in choosing a suitable toy, in getting ideas for variation in play objects, being inspired for new toys and technologies, possibly exploring the possibility to have different play experiences with the available toys.

B. Professionals, working with children e.g., teachers, occupational therapists, physiotherapist, speech language therapists, pedagogues, psychologists.

How to evaluate usability and accessibility of toys and technologies for play for children with disabilities? Which toy is suitable to enable a variation of play activities? Can the toy stimulate the child(ren) to take control and direct the play situation? How can a toy or technology enable inclusive play with siblings or peers?

Objective: The objective for a guideline on usability and accessibility of toys and technologies for play for children with disabilities for professionals is to support them in evaluating the usability and accessibility of toy or technological product in the perspective of the intended objectives for given child(ren), in selecting an appropriate play object, in critical analyzing the play situation in the preparation phase, in having arguments for shared decision making process with parents, possibly in inter-professional meetings.

\section{Designers, makers, engineers, technicians.}

How can issues about usability and accessibility be taken into consideration for designing and constructing toys, games, robots and apps for play for children with disabilities? What does it mean for children to have a disability? What kind of play does a group of children like? How can the toy elicit their strengths rather than focusing on limitations? How can a play object enable inclusive play with peers? How can a toy or technological product be interesting for playing over time?

Objective: The objective for a guideline on usability and accessibility of toys and technologies for play for children with disabilities for designers is to stimulate them to apply aspects of usability and accessibility in the design and producing process of a play object and experiences for given children, to support the realization of user-centred design process, the inter-professional cooperation with users or their representatives, the importance of qualitative and quantitative user experiences' evaluations in different phases. 
D. Researchers investigating the usability and accessibility of toys and technologies for children with disabilities.

How can research be done about usability and accessibility for toys and technologies for play for children with disabilities? What kind of tools are available to measure usability and accessibility aspects?

Objective: The objective for a guideline on usability and accessibility of toys and technologies for play for children with disabilities for researchers is to stimulate them to investigate (aspects) of usability and accessibility of toys and technologies for given children, to support them in finding the right research question, to stimulate to connect to former research, to use suitable tools in investigating usability and accessibility of toys and technologies.

E. Policy makers or persons in charge of taking decisions about innovations in society, in educational or health care organizations.

What is necessary to know about children with disabilities, what is necessary to know about play, what does it mean creating play opportunities which are accessible and usable by children with disabilities, what are the possible benefits about creating inclusive play opportunities for children themselves and for others?

Objective: The objective for a guideline on usability and accessibility of toys and technologies for play for children with disabilities for policy makers is to stimulate them to incorporate usability and accessibility of toys and technologies for play for children with disabilities in their policy about creating inclusive play opportunities for all children.

\subsubsection{Features of guidelines on usability and accessibility of toys and technologies}

The results of the discussion among the LUDI Working Group members are listed according to different stakeholders, first starting with some general characteristics:

- The guidelines should reflect that play for the sake of play is the overall aim.

- Educational, therapeutic aspects should be able to be embedded as well.

- The guidelines should address characteristics of stakeholder groups e.g. parents are concerned about safety, cleaning and sustainability besides the play aspects.

- The guidelines should have clear aims. These objectives should be leading the guidelines.

- Clear description of target group should be added, with respect to both the users of the guidelines and the children with disabilities.

- The guidelines should be described to the point and as short as possible.

- Evidence to support the content of the guidelines should be incorporated.

- The validation of the guidelines is important.

- In the guidelines the context of play should be taken into consideration. 
- The guidelines should address also the aspects about how to make changes in the application, how to adapt the toy.

A. Features of guideline for parents, relatives, informal caregivers:

- Is easy to read and to follow.

- Is activity oriented, not focusing on underlying components e.g. cognitive, motor skills.

- Supports to select the use of a toy and/or a technology.

- Has clear information, is short.

- Has a selection matrix for child's play $\rightarrow$ how to use toys, technologies, different kind of use depending on goals, ....

- Has practical information.

- Incorporates icons on the boxes of toys.

- Mentions also the icon or symbol indicating single and multi-player gamer.

B. Features of guideline for designers:

- Is product oriented.

- Contains background information for the developmental process e.g., characteristics of impairments and the possible impact of play, of ageappropriateness.

- Fits to the known design process.

- Addresses evaluation topics e.g., of the concept, of the prototype.

- Addresses also detailed physical characteristics related to specific target.

- Guideline has to follow the safety and ethic procedures.

C. Features of guideline for professionals:

- Focus on play situation, not only on the child, not only on the product (toytechnology), not only on the activity.

- Considers consequences of choices.

- Is activity oriented, not focusing on underlying components like motor, cognitive, social skills.

- Guideline should support the selection process of an appropriate toy or technological product as well as how to use the toy/technology.

- Should incorporate also the preparation of the setup of the play situation.

- Stimulates to take a short course if technology is new/high tech.

- Emphasizes to test the toy or technology out before playing with children.

D. Features for a guideline for researchers:

- Contains detailed and specific information regarding research about usability and accessibility of toys and technologies.

- Emphasizes that background information, gap of knowledge and the added value of the research should be mentioned. 
- Stimulates for looking for possible improvements for the child and others involved regarding play.

- Stimulates to describe a kind of theory.

- It should be clear which are the goals of playing with the toy or technology.

- Stimulates to carry out a validation process.

\section{E. Features of guideline for policy makers}

- Should be short and described to the point.

- Can be a standard with icons or symbols.

The features for a guideline for policy makers are limited as the expertise in this area was lacking among Working Group 2 members. Neither the review emerged a guideline for this stakeholders group (see Table 6.2). Therefore, developing a guideline to support policy makers in their work of pleading and realizing inclusive play opportunities with toys and technologies for children with disabilities, was not taking forward.

Children with disabilities often cannot rely on commercially available (technological) toys or (digital) games. Creative parents and relatives, and sometimes also therapists and teachers, tend to make or adapt an existing toy or technological product, possibly adding an input or output device to create an accessible and tailored-sized play object. These groups of persons could be considered as bricoleurs or makers and can be very important in realizing play opportunities. Therefore, it was decided to develop a guideline for this group of stakeholders as well. The aim is to support them in analysing the features of the toys or technology, in discovering play opportunities, transforming play wishes of children into features of a toy or technology.

\subsubsection{Structure of the newly developed LUDI guidelines}

The general objective of a guideline on usability and accessibility of toys and technologies for play for children with disabilities is to support a particular group when encountering questions, dilemmas for making choices regarding choosing, developing, adapting and/or applying toys and technologies. Bearing this in mind, the structure of a LUDI guideline is outlined in two parts:

1. Reflective questions related to different themes for creating play opportunities for children with disabilities. Existing guidelines, definitions about concepts, tools and classifications, developed by LUDI and related to usability and accessibility of toys and technologies could be added to support clarification and application.

2. Decision tree with different steps to be considered, resulting in a usable and accessible toy or technological product for a given child(ren). 
An important feature of the LUDI guidelines is to be clear, concise and having a good flow so easy to be used by different stakeholders. Therefore, extra information about concepts, classifications, existing tools and guidelines will be added via links to the original sources. It is up to the user to go deeper into it.

\subsubsection{Evaluation of the first version of the guidelines on usability and accessibility of toys and technologies for play for children with disabilities}

This evaluation was carried out with a small-scale qualitative approach by answering the following questions:

- Are the questions/comments clear?

- Is the flow of the guideline working for you.

- Can you imagine using this guideline? When, how.... describe the possible occasion.

- Other comments.

Participants were recruited via the LUDI network: participants of the network as well as colleagues, acquaintances were involved. Data were summarized and a straightforward content analysis was carried out.

The evaluation was given by 31 persons from 11 countries: 10 professionals working with children with disabilities, 13 designers or engineers, 6 researchers, 1 parent and 1 maker.

We obtained feedback from different points of view:

- Feedback regarding clarity was about clarification of some terms e.g. hygienic rules, the need to add the safety aspect, the wish to emphasize play for the sake of play.

- Feedback regarding the flow of the guideline concerned practical aspects, such as the fact that not all hyperlinks in the presentation were working, about the fact that the document is inspiring, but it is not a real guideline in the sense of a standard, about the length of the guideline, generally considered as too long.

- Feedback regarding seeing possibilities for use gave mixed answers some yes, some doubts, some no as there was nothing new in it. Several persons emphasized the potential for using the guideline with students. Comments referred to the common knowledge about user centred design, the importance to incorporate European Standard EN 301549.

The feedback was processed into the version of guidelines for different stakeholders presented in the next section. 


\subsection{Guidelines on usability and accessibility of toys and technology for play for children with disabilities for different stakeholders; parents, professionals, designers, makers and researchers}

This paragraph presents the adapted guidelines for each group of stakeholders. The reviewed guidelines on usability and accessibility as found in the literature review were incorporated in the LUDI guidelines on accessibility and usability of toys and technologies for play for children with disabilities. A critical approach was taken into considerations about the added value as the current developed guidelines aim to support the reasoning and considerations process in a pragmatic and inviting way tailored to the specific stakeholder.

The guidelines on usability and accessibility of toys and technologies for play for children with disabilities for different stakeholders: parent, professional, designer, maker, researcher are as well available via https://www.dropbox.com/sh/ hwf0pw96cqu3ecn/AAAy9wATfGO9uBt3SSuxodLna?dl=0 


\section{Guideline for parents, relatives, caregivers How to evaluate whether a play tool is usable and accessible for your child with disabilities?}

\section{Introduction}

This guideline aims to support a parent or relative in evaluating the usability and accessibility of a play tool. The findings of this evaluation facilitate the choice for an appropriate toy, game, robot, app or other play tool for the child. This guideline starts with reflective questions eliciting the reasoning, followed by a checklist and an advice for choosing a play tool for a child with disabilities. Extra information about concepts, classifications with the number of document, can be consulted at this link: https:// www.dropbox.com/sh/wii2si50apcgglu/AAAQCBfS1UQ2KGbKOEW8Kr2Ha?dl=0

[Check out this Dropbox link for document: 1) definitions guideline, usability, accessibility]

\section{Reflective questions}

CHILDREN WITH DISABILITIES [Check out the Dropbox link above for document: 2) definition children with disabilities, and document 4) challenges in play of children with different disabilities]

- What is appealing for your child when playing? (discovering an object, getting a reward, getting the attention of a playmate, the (sensory/motor) experience itself, the result of playing, etc.)

- What is motivating your child? (try to look at his/her personal motivation, when and with what does s/he show autonomous initiative, when do you recognize his/ her personal motivation, what is the possible influence of playmates?)

- How can your child be in charge, what are his/her possibilities for directing the play situation?

- With what kind and to what extent of self-direction do you feel comfortable with as a parent/relative?

- What are important aspects for a safe play situation?

\section{FAMILY LIFE}

- Does the playing take place on a certain time during the day? Or does it start spontaneously? 
- $\quad$ Do you want the play situation fit in your family routines? If yes, what does this mean for the play situation? (with others, kind of play, choice of play tool, timing, play space, etc.)

- Do you want the play situation to reflect some family values? If yes, which?

PLAY TOOL [Check out the Dropbox link above for document: 3) definition of play and play tool]

- Do you prefer a toy, board game, computer game, TV game, app on tablet/phone or a robot? Or isn't it that important?

- Is the toys, game, robot or app accessible for your child? Can the child reach it, can the child reach from different positions? Can the child push, pull, grasp, release, manipulate it? Can the child change position of the play tool? Can the child use buttons or switches to cause an action?

- If it is needed, is it possible to connect the play tool to other input/output devices?

- Can the play tool be used when using other assistive devices?

- Does the play tool fit your child's motivation, interest for play?

- Does the play tool give your child opportunity to self-direct?

- Is it easy to understand how to play? Can the child understand different elements, steps of the play tool?

- Is it comfortable, usable to play?

- Is the play tool easy to control, to interact with? Are there variations in the interaction?

- Does the play tool enables/exploits interactions with playmates?

- Can the play tool be customized or personalized?

- Can the play tool evolve with the player?

- How much the play tool can engage the player? In the beginning? Over time?

- Does the play tool provide enough clear and motivating feedback and reward?

- How easy is it to learn how to use the play tool?

- Does the play tool exploit multimodal interaction and stimulate different senses (e.g., sounds, lights and vibration)?

- How the behaviour of the play tool is predictable (clear cause-effect relationships)?

- How the play tool has the ability to repeat its behaviour?

- Is the play tool safe?

- Is the play tool sustainable, if important for you?

- Can the play tool be cleaned easily?

PLAY [Check out the Dropbox link above for document: 3) definition of play and play tool]

- Do you have an objective for creating the play situation? (e.g., stimulate the child playing alone, stimulate playing together with siblings, therapeutic/educational goals, stimulating your child to take initiatives/being in charge, stimulating play 
development, etc.) [Check out the Dropbox link above for document: 3 definition of play and play tool, and document: 5) classification of play]

- Are there possibilities to have some variation in the play situation (e.g., play itself can be varied, the play situation can be changed)

- Is the play very structured or rather unstructured, what is fitting best to your child?

- Is it possible to perform free play with the play tool?

ENVIRONMENT [Check out the Dropbox link above for document: 7) definition environment and environmental factors]

- Should the play situation be indoors or outdoors?

- Is the physical environment suitable for using the play tool?

- Can your child have a comfortable appropriate (seating, lying, standing) position?

- Is the room suitable for the play activity, for your child? (e.g., distraction, space wise, etc.)

- Who should be involved in the play situation?

- What should be the role of the involved person? As a play mate, an assistant for the child, as a controller?

\section{Checklist for parents, relatives, caregivers to evaluate whether a play tool is usable and accessible for your child with disabilities}

Your child's interest in playing is mostly related to:

o discovering an object or environment

o getting a reward

o getting the attention of a playmate

o experiencing the play experience itself

o the result of playing, the final product

o other

You want to address the following abilities of your child:

- curiosity

- social interaction

○ running, walking, jumping, crawling, grasping, manipulating, seeing, smelling, hearing

- storytelling, imagination, fantasy

- learning new skills or knowledge

other

You want your child or your child wants him/herself to play

- alone

$\circ$ with peers 
- with a sibling

- with a playmate (age doesn't matter)

- with an adult who can assist in the play situation

o other

What is your child's or yours goal when playing?

$\circ$ having fun

- possibility to take initiatives, to be in control

○ playing alone playing together with siblings

- achieving results (improving his own abilities, result of the game, winning from playmates)

- curiosity, wish to discover new play tools, new activities

$\circ$ other

What is the context of play?

- spontaneous play everywhere

- structured play in a predetermined place

- fitting in family routines

$\circ$ indoors in a room

o outdoors: in garden, in parc,

- Safety rules to be taken into account:

- Hygienic rules to be taken into account:

\section{Advice for choosing a play tool for your child with disabilities.}

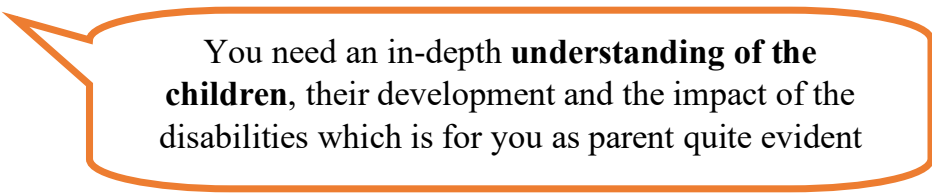

1. You can consult websites from toyshops, assistive technology, libraries where you lend toys, etc. You can talk to other children/parents, to teachers, therapists, etc. to get inspiration for a toy, game, robot or app.

Assessing usability and accessibility of play tools must be user-centred! Children with disabilities, no matter what age or disabilities, should be involved!

2. If it's important for you, choose whether it has to be a toy, board game, computer/ videogame, robot or app. 
3. Select possible a specific play tool.

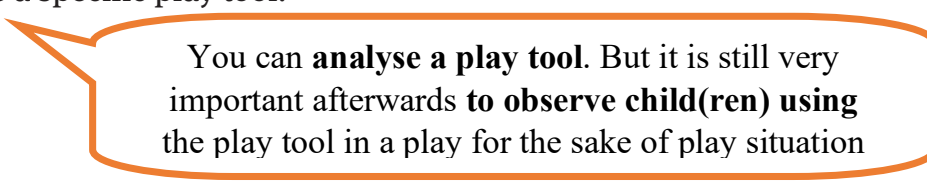

Toys, games and disabilities. The importance of a universal design (2007) https://www. dropbox.com/s/4h60tom16buxx0f/Nr\%205\%20Toys\%2C\%20games\%20and\%20 disabilities.pdf? $\mathrm{dl}=0$ is a guideline for selecting and adapting toys for children with (physical and sensory) disabilities

4. Check if the selected play tool meets the items you have marked at the checklist above. The information at the box of the play tool are important as they address usability and accessibility. Try out the toy yourself to get a better understanding of the play tool

5. Try out: give your child and yourself opportunities to try the toy, board, videogame, robot or app several times. Observe your child responses, personal initiatives.

Be aware of the elements of play for the sake

of play (self-direction - intrinsic motivation - fun)

Guidelines to promote play opportunities for children with disabilities (n.d.) https://www.dropbox.com/s/ncmc185bfnktxa6/Nr\%209\%20Guidelines\%20to\%20 Promote $\% 20$ Play $\% 20$ Opportunities $\% 20$ for $\% 20 \% 20$ Children $\% 20$ with $\% 20$ Disabilities. pdf? $\mathrm{dl}=0$ provides in layman language questions and suggestions for positioning, communication and social supports, adapting toys and play strategies.

6. Consider the play situation: where does the child want/can play? Who is involved? What are important environmental factors to take into consideration?

Environmental factors are complex, consider all aspects, as they can influence the play situation 
The following chapters can be useful as well (Encarnação, Ray-Kaeser, \& Bianquin, 2018):

Chapter 5: How can I, as an adult facilitate play?

Chapter 6: What assistive technologies exist to enable participation in play?

Chapter 7: Which toys and games are appropriate for our children?

Chapter 8: Which digital games are appropriate for our children?

Encarnação, P., Ray-Kaeser, S., \& Bianquin, N. (Eds.). (2018). Guidelines for supporting children with disabilities' play. Methodologies, tools, and contexts. Warsaw: De Gruyter Poland. Retrievable at https://www.degruyter.com/viewbooktoc/product/507228 


\section{Guideline for professionals \\ How to evaluate usability and \\ accessibility of toys and technologies \\ for play for children with disabilities?}

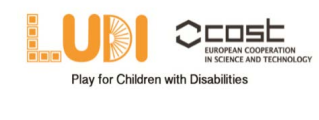

\section{Introduction}

This guideline aims to support the professional (therapist, teacher, pedagogue, etc.) in his/her professional reasoning and in the decision making process about whether a play tool is usable and accessible for given child(ren) with disabilities.

This guideline starts with reflective questions eliciting the reasoning. Followed by a decision tree. Extra information about concepts, classifications with the number of document, can be consulted at this link: https://www.dropbox.com/sh/ wii2si50apcgglu/AAAQCBfS1UQ2KGbKOEW8Kr2Ha?dl=0

[Check out this Dropbox link for document for: 1) definitions guideline, usability, accessibility]

\section{Reflective questions}

PLAY [Check out the Dropbox link above for document: 3) definition of play and play tool, and document: 5) classification of play, and document: 6) Possible goals of play]

- What is the intended goal for the child(ren) for playing with the play tool?

- Is it play for the sake of play?

- Is the focus on achieving rehabilitation or educational goals?

- What kind of play is intended to enable?

\section{PLAY TOOL}

- Is the play tool safe for the given child(ren)?

- How can a play tool be accessed? Can the child reach the play tool from different positions? Can the child push, pull, grasp, release, manipulate it? Can the child change position of the play tool? Can the child use buttons to cause an action?

- Is it possible to connect the play tool to interfaces or input devices? [Check out the Dropbox link above for document: 10) definition input and output devices, interface]

- What can you do with the play tool (functionalities)?

- Can the child(ren) interact with the play tool, i.e. can the play tool react or propose activities to the child(ren)?

- Is it possible to connect the play tool to output devices, to make it usable? 
- What kind of physical adaptations can be made on the play tool to make it usable for the given child(ren)?

- Is it possible to create different ways of playing? Can you create new challenges in play with the play tool so that it becomes more usable, or it can engage the child(ren) for a longer time?

- What are the materials of the play tool and supported device? (texture, looks, smell, sound, etc.)

- What are the costs?

- Are you satisfied with the hygienic rules for the play tool and connected devices? E.g. cleaning, maintenance.

- Is the play tool reliable? Does it work when and how you need it? Can it be repaired when broken?

- Is the play tool sustainable, is it robust?

CHILDREN [Check out the Dropbox link above for document: 2) definition children with disabilities, and document: 4) challenges in play of children with different disabilities]

- What are the disabilities of the child(ren)?

- What aspects of the disabilities might influence the child(ren)'s play?

- What are strengths of the child(ren) which can be used to help or to compensate the limitations?

- How much time have the child(ren) available for playing? How often?

- Which subjective dimensions are important for the child(ren) when playing? [Check out the Dropbox link above for document: 9) definition of subjective dimensions of occupational performance]

- What will appeal the child(ren)?

- Can the child(ren) be challenged now as well as in the long term?

ENVIRONMENTAL FACTORS [Check out the Dropbox link above for document: 7) definition environment and environmental factors]

- Can the play tool be used at home, in school, in a playground, in a built and/or natural environment?

- Which characteristics of the physical environment are important for playing with the play tool?

- $\quad$ Could the child play alone with the play tool?

- What kind of persons [peers, adult, sibling, etc.] is needed to play with the play tool?

- What should be key features of the play mate?

- Are any cultural influences relevant for playing with the play tool?

- Are there organizational, service-related or attitude like aspects to be considered? 


\section{Decision tree to decide whether the play tool is usable and accessible for given child(ren) in the available environment}

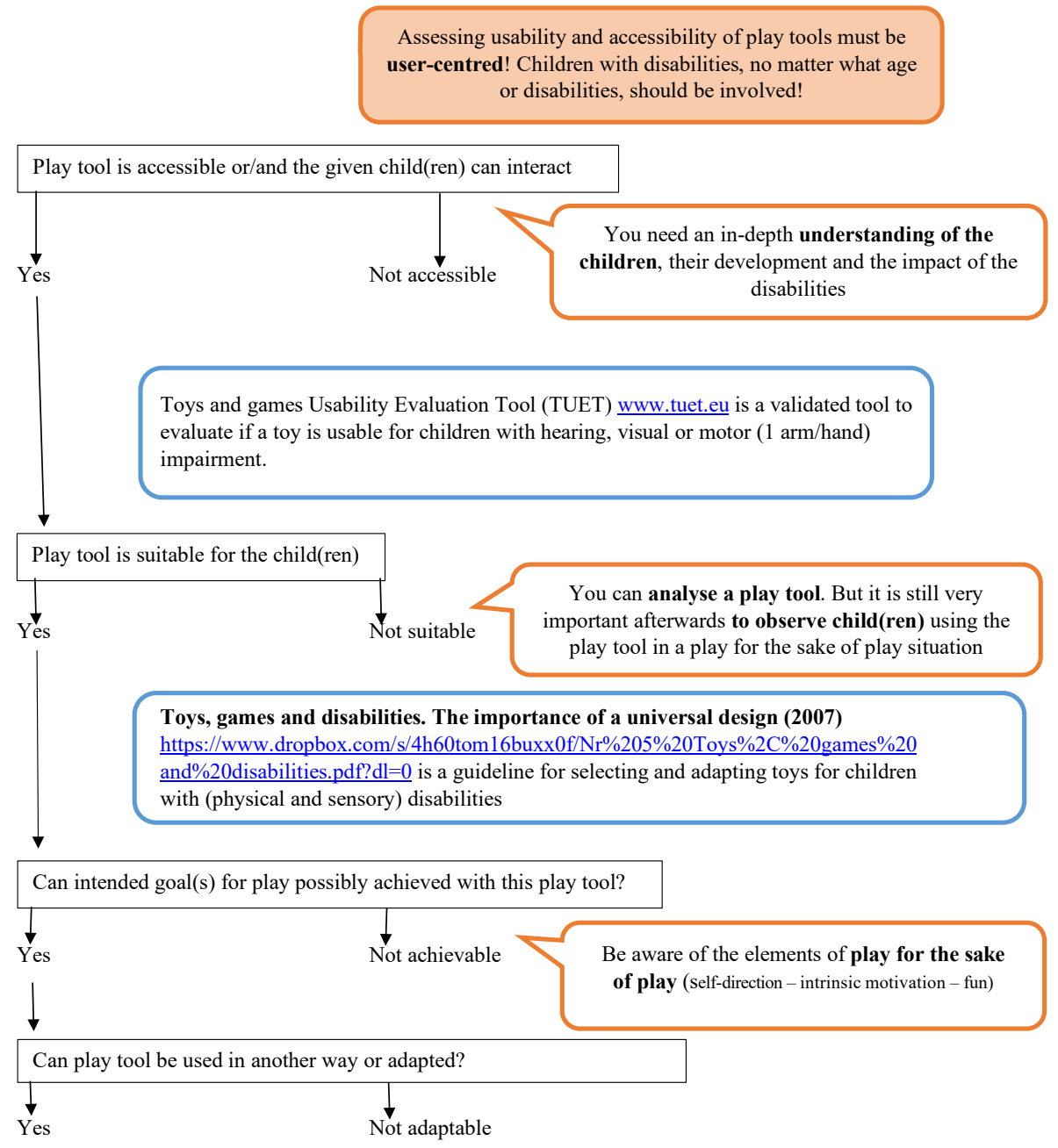

Includification. A practical guide to game accessibility Drumgoole, A., \& Mason, T.J. (2012) Retrieved from

https://accessible.games/includification/gives advices for persons with mobility, visual, hearing and cognitive disabilities 


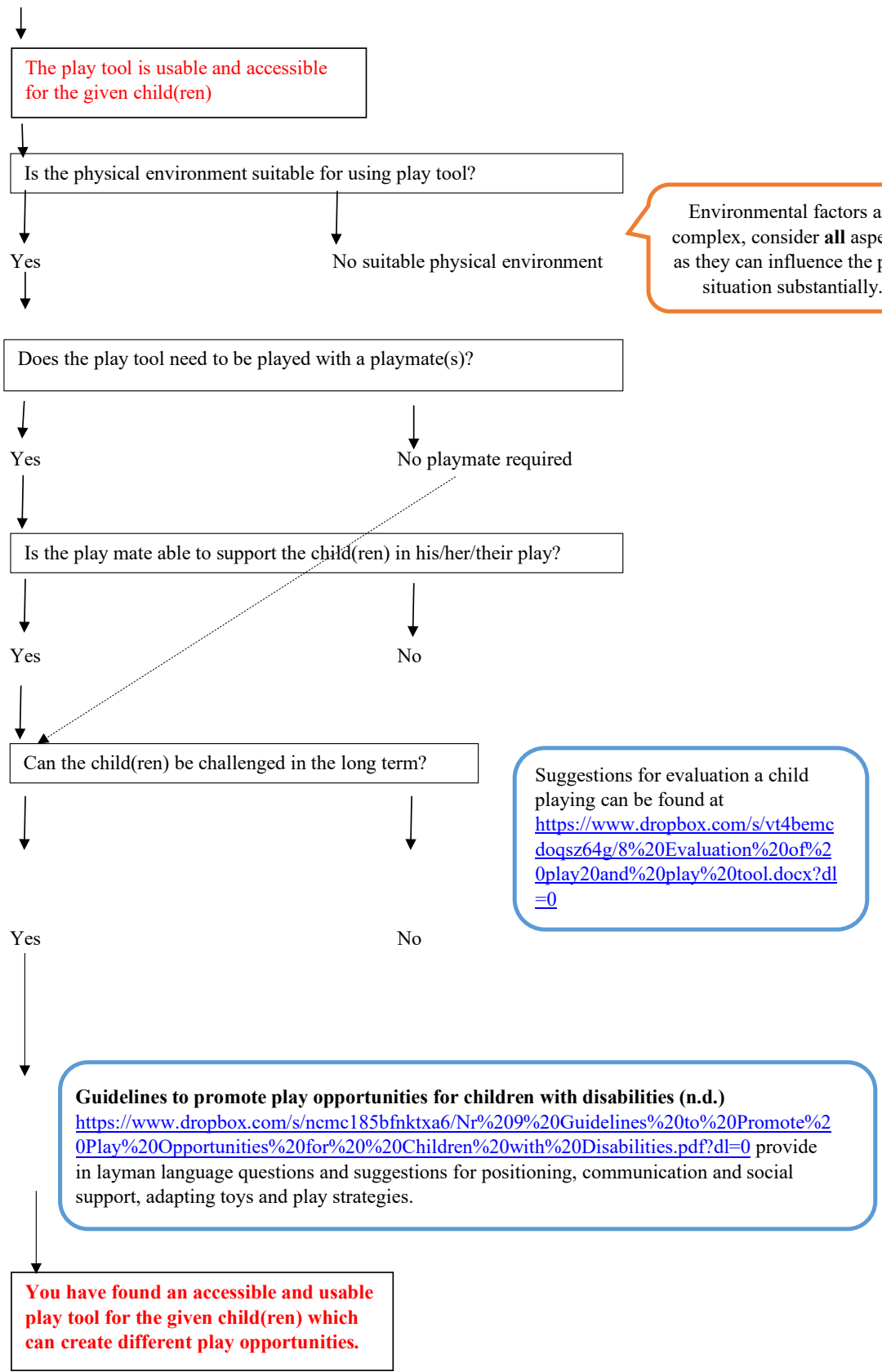


The following chapters can be useful as well (Encarnação, Ray-Kaeser, \& Bianquin, 2018):

Chapter 4: Are our children playing?

Chapter 5: How can I, as an adult facilitate play?

Chapter 6: What assistive technologies exist to enable participation in play?

Chapter 7: Which toys and games are appropriate for our children?

Chapter 8: Which digital games are appropriate for our children?

Encarnação, P., Ray-Kaeser, S., \& Bianquin, N. (Eds.). (2018). Guidelines for supporting children with disabilities' play. Methodologies, tools, and contexts. Warsaw: De Gruyter Poland. Retrievable at https://www.degruyter.com/viewbooktoc/product/507228 


\section{Guideline for makers How making or adapting a play tool to be usable and accessible for play for child(ren) with disabilities?}

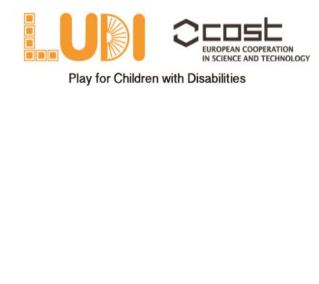

\section{Introduction}

This guideline has to support technicians, makers, retired engineers, skillful parent or relative who wants to make a play tool or wants to adapt an existing toy, game, robot or app so it will be accessible and usable for specific child(ren) for play. Usually these makers or so called bricoleurs face specific problems related to a specific child with disabilities.

This guideline starts with reflective questions, followed by a decision tree based on the User Centred Design Process. Extra information about concepts, classifications with the document's number, can be consulted at this link: https://www.dropbox. com/sh/wii2si50apcgglu/AAAQCBfS1UQ2KGbKOEW8Kr2Ha?dl=0

[Check out this Dropbox link for document: 1) definitions guideline, usability, accessibility]

\section{Reflective questions}

PLAYING USERS [Check out the Dropbox link above for document: 2) definition children with disabilities, and document: 4) challenges in play of children with different disabilities]

- Who is the child playing? Chronological and developmental age, disability related features, abilities and strengths, motivation and attention span, etc.

- What is the kind of play the user and/or play mate wants to play? (Note: sometimes, there may be more than one kind of play) [Check out the Dropbox link above for document: 5) classification of play, and document: 6) Possible goals of play]

- Does the child and/or a playmate has specific goals in mind for playing with the play tool?

PLAY TOOL (TOY, GAME, ROBOT OR APP) [Check out the Dropbox link above for document: 3) definition of play and play tool]

- Are there requirements on material? (Unbreakable, resisting to humidity, liquids, washable, etc.)

- Are there requirements on basic appearance? (to match specific disabilities or design for all like weight, grasping, sound, colors, movement of parts, etc.) 
- What are the safety requirements to be satisfied for the specific toy, game, robot or app? (See Toy Safety Directive 2009/48/EC https://eur-lex.europa.eu/LexUriServ/ LexUriServ.do?uri=OJ:L:2009:170:0001:0037:en:PDF)

- How is the play tool accessible? Can it be connected to (input-output) devices if needed? Can the child reach, push, pull, manipulate it? Can an assistive product support the accessibility of the play tool? [Check out the Dropbox link above for document: 10) definition input and output devices, interface]

- How can the user interact with the toy, game, robot or app?

PHYSICAL ENVIRONMENT [Check out the Dropbox link above for document: 7 definition environment and environmental factors]

- Are there requirements regarding the physical environment for playing? (indoors, outdoors, features of the room, furniture, light, etc.)?

\section{Decision tree to support the maker in the decision making process for making or adapting a play tool for children with disabilities}

Based on General phases of the UCD process retrieved from https://www.usability. gov/what-and-why/user-centered-design.html:

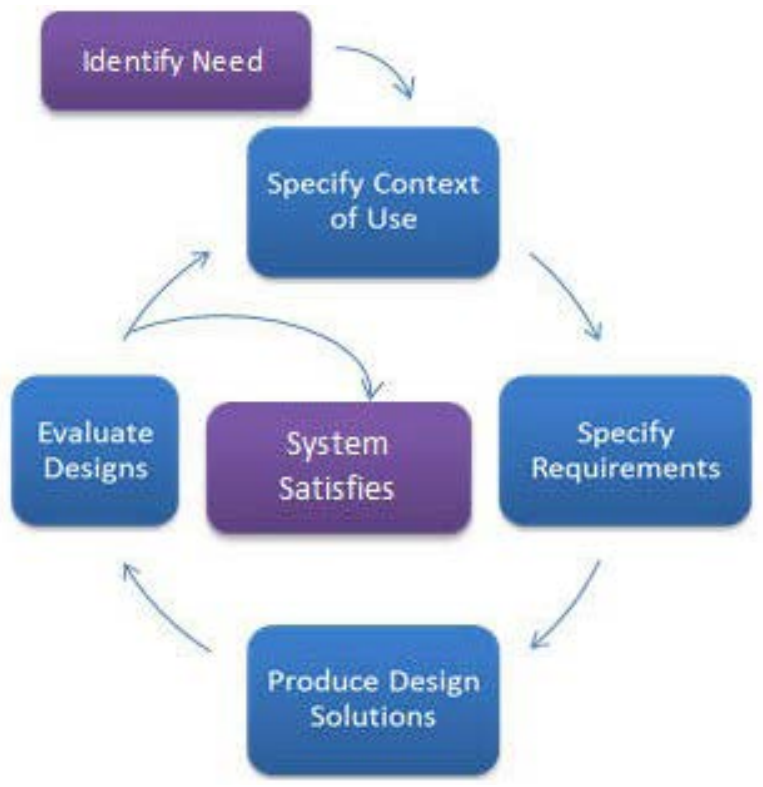

Figure 6.1: User centred design. 


\subsection{Identify need}

What are the issues to be solved? Does the child play alone with the play tool or together with a play mate? What is the role of the play mate (player, assistance, observer)?

Is there a problem in accessibility (reaching the play tool, interacting with the play tool)?

Is there a problem in usability? (Is there an effective and efficient interaction with the play tool? Is the user satisfied? Can the user play in the desired context?)

What is the problem, when does it appear, how often does it appear, where does it appear?

Assessing usability and accessibility of play tools must be user-centred! Children with disabilities, no matter what age or disabilities, should be involved!

\subsection{Specify context of use (describe in your own words)}

. [the user] should be able to play with .[toy, computer game, video game, robot or app] during/when [time framework] with. [playmate, siblings] at [physical context of use]

Environmental factors are complex, consider all aspects, as they can influence the play situation

\subsection{Specify requirements}

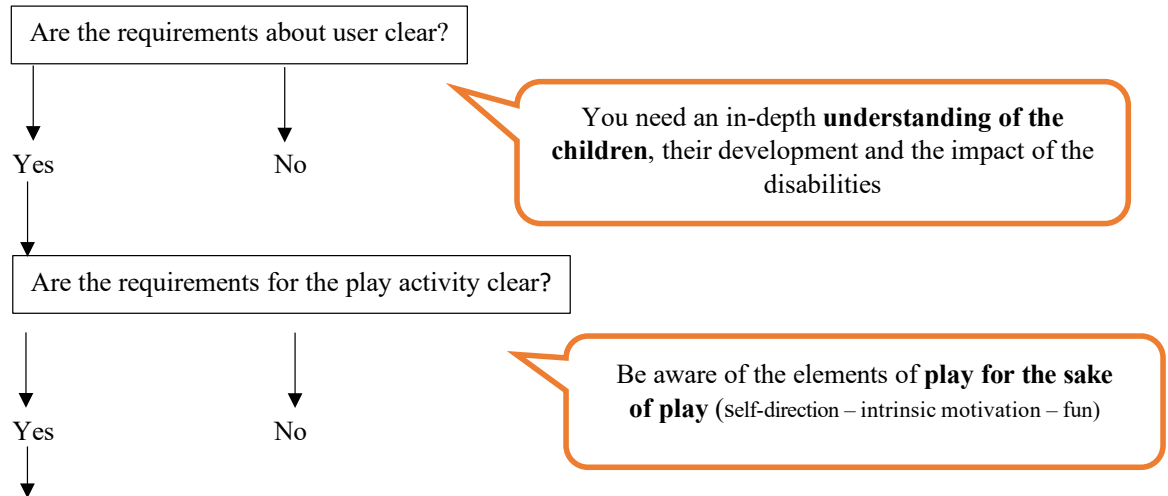




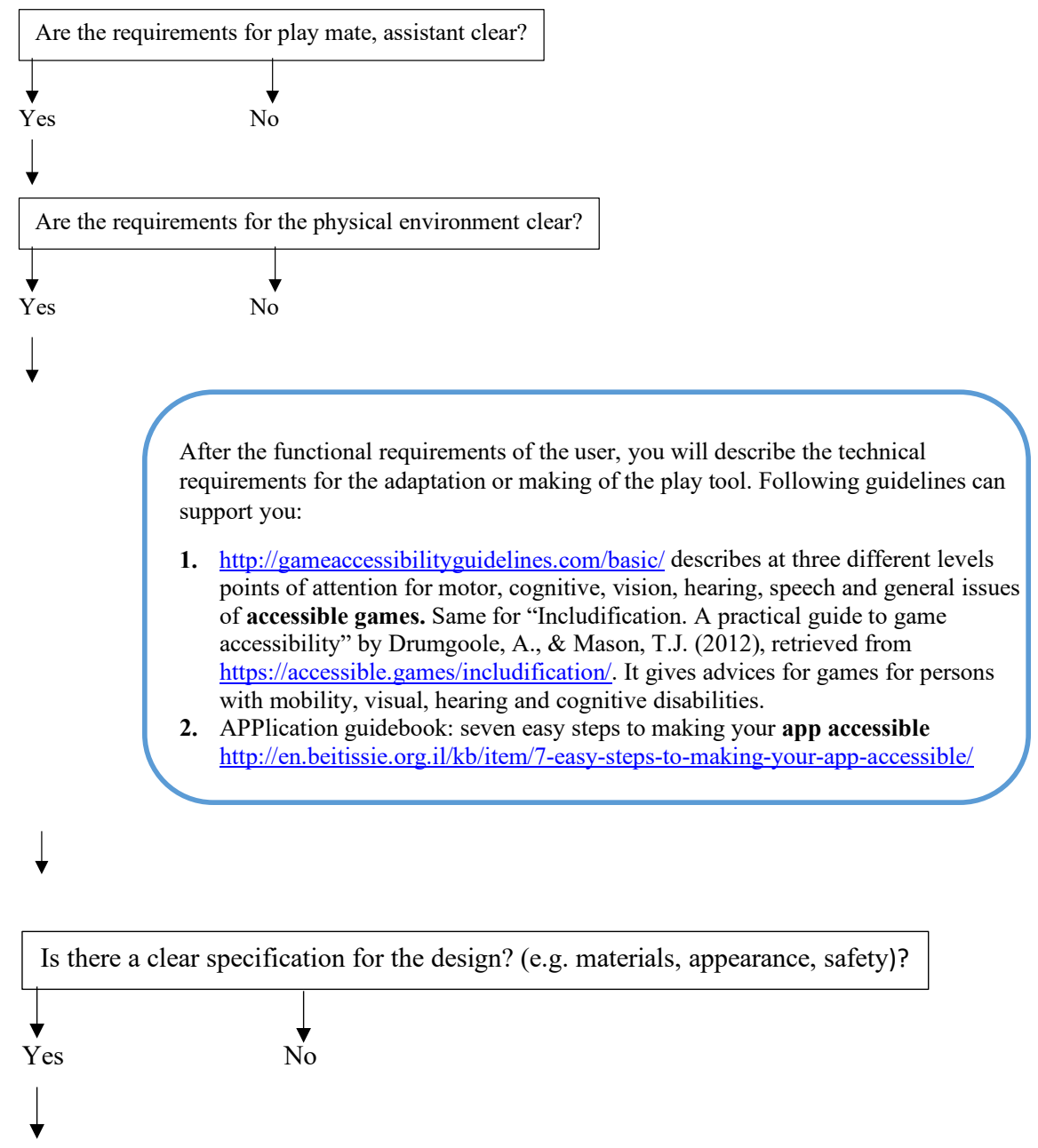

\title{
3.4 Produce design solutions
}

\author{
Design several prototypes \\ You can analyse a play tool. But it is still very \\ important afterwards to observe child(ren) using \\ the play tool in a play for the sake of play situation
}




\subsection{Evaluate design solutions}

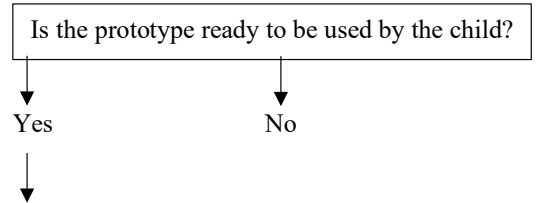

Be aware that play experience of the child can differ very much from play experience of play mates (peer, sibling, adult). Adapt the prototype till it can be used by the child in a satisfying way

Think about how you will evaluate the new or adapted) play tool? Think about the identified need, the requirements of the users, play activity, accompanying persons, physical environment, the design
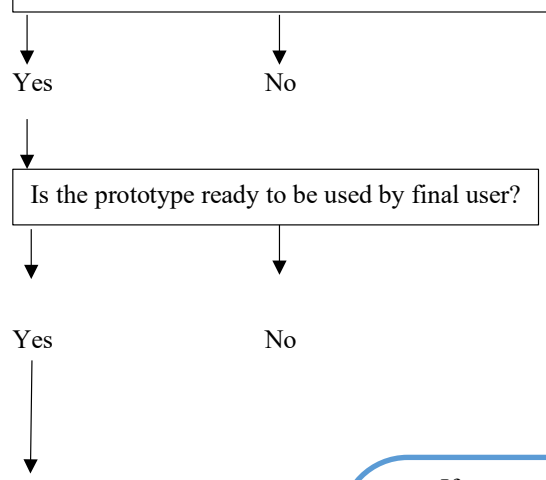

If you want to play with the child yourself or to observe the play situation yourself (instead of/besides getting information from the child, parent, professional) you can use Guidelines to promote play opportunities for children with disabilities (n.d.)

https://www.dropbox.com/s/ncmc185bfnktxa6/Nr\%209\%20

Guidelines $\% 20$ to $\% 20$ Promote $\% 20$ Play $\% 20$ Opportunities $\% 2$ 0for $\% 20 \% 20$ Children $\% 20$ with $\% 20$ Disabilities.pdf?dl $=0$ provide in layman language questions and suggestions for positioning, communication and social supports, adapting toys and play strategies.

\subsection{User satisfaction}

Check if the user (= child with disabilities and eventually play mate) is satisfied.

The following chapters can be useful as well (Encarnação, Ray-Kaeser, \& Bianquin, 2018): Chapter 5: How can I, as an adult facilitate play?

Chapter 6: What assistive technologies exist to enable participation in play?

Chapter 7: Which toys and games are appropriate for our children?

Chapter 8: Which digital games are appropriate for our children?

Encarnação, P., Ray-Kaeser, S., \& Bianquin, N. (Eds.). (2018). Guidelines for supporting children with disabilities' play. Methodologies, tools, and contexts. Warsaw: De Gruyter Poland. Retrievable at https://www.degruyter.com/viewbooktoc/product/507228 


\section{Guideline for a designers, engineers How can issues about usability and accessibility taken into consideration for designing and making toys, computer/video games, robots and apps for play for children with disabilities?}

\section{Introduction}

This guideline aims to support designers and engineers in their professional reasoning and decision making process when (re)designing and making a play tool usable and accessible for children with disabilities.

It is assumed a scenario where the designer/engineer has to develop a play tool for a category of potential users, not a specific individual which is the case considered in the section guideline for a maker.

This guideline starts with questions eliciting professional reasoning, followed by a decision tree based on User Centred Design Process. Extra information about concepts, classifications with the document's number to be consulted, can be consulted at this link: https://www.dropbox.com/sh/wii2si50apcgglu/ AAAQCBfS1UQ2KGbKOEW8Kr2Ha?dl=0

[Check out this Dropbox link for document: 1) definitions guideline, usability, accessibility]

\section{Reflective questions}

\section{THE USERS}

- Who are the intended users? Chronological and developmental age, disability related features, abilities and strengths, motivation and attention span [Check out the Dropbox link above for document: 2) definition children with disabilities]

- What is the kind of play that the toy is expected to be used to? Kind of play: functional play, symbolic play, etc. [Check out the Dropbox link above for document: 5) classification of play)]

(Note: sometimes, there may be more than one kind of play)

- Are there specific goals for the play activity or is the play tool designed for play for the sake of play [Check out the Dropbox link above for document: 3) definition of play and play tool, and document: 6) possible goals for play]

- Where the play activity is expected to be performed? What are characteristics of the room, of the place? (floor or underground, furniture, walls, etc.) [Check out 
the Dropbox link above for document: 7) definition environment and environmental factors]

- Will the play activity be performed autonomously or with playmates, or with assistants? [Check out the Dropbox link above for document: 4) challenges in play of children with different disabilities]

- How much time the play activity is expected to require? How often can the user play?

- Has the play activity to be adaptable, does it need different (motor skills, cognitive, multitasking) levels?

PLAY TOOL [Check out the Dropbox link above for document: 3) definition of play and play tool]

- $\quad$ Try to apply the The Principles of Universal Design https://projects.ncsu.edu/design/cud/about_ud/udprinciplestext.htm

- Are you designing a toy, video game, computer game, robot or app?

\section{Guidelines for game developers:}

Game accessibility guidelines http://gameaccessibilityguidelines.com/

Includification. A practical guide to game accessibility. Drumgoole, A., \& Mason, T.J. (2012) Retrieved from https://accessible.games/includification/

Grammenos, D., Savidis, A., \& Stephanidis, C. (2009). Designing universally accessible games. ACM Computers in Entertainment, 7(1), 8:3-8:27.

Yuan, B., Folmer, E., \& Harris, F. C. J. (2011). Game accessibility: A survey. Universal Access in the Information Society, 10(2011), 120.

\section{Guidelines for app developers:}

Highlights of Inclusive Design for App Development

https://tech.beitissie.org.il/en/highlights-of-inclusive-design-for-appdevelopment/

APPlication guidebook: 7 easy steps to making your app accessible http://en.beitissie.org.il/kb/item/7-easy-steps-to-making-your-app-accessible/

\section{Guideline for toy developers:}

Costa, M., Romero, M., Mallebrera, C., Fabregat, M., Torres, E., Martinez, M., . . . Martinez, P. (2007). Toys, games and disabilities. The importance of a universal design.

\section{Guideline for developers of play things and environment}

Mullick, A. (2013). Inclusive indoor play: An approach to developing inclusive design guidelines. Work, 44(2013), S5-S17.

- Are there requirements on material? (Unbreakable, resisting to humidity, liquids, washable, etc.) 
- Are there requirements on basic appearance? (to match specific disabilities or design for all like weight, grasping, sound, colors, movement of parts, etc.)

- What are the safety requirements to be satisfied for the specific toy, game, robot or app ? See European guidelines on toy safety https://eur-lex.europa.eu/ LexUriServ/LexUriServ.do?uri=0J:L:2009:170:0001:0037:en:PDF

Are there guidelines to be followed related to the products used? (ISO, CE?)

- How is the play tool accessible? Motor skills wise, cognitively, visually or auditory? Can it be connected to (input-output) devices if needed? [Check out the Dropbox link above for document:10) Definition of input, output devices and interface]

- How can the user interact with the play tool?

- Does the play tool sufficiently meet the following criteria [Check out the Dropbox link above for document: 11) categories of design guidelines]

o Clarity, readability, understandability

o Comfortability

o Controllability, affordability

o Cooperability

o Customizability, personalisability

o Evolvability

o Feedback, rewarding

o Inclusiveness

o Learnability, generisability

o Multimodality

o Multisensoriality

o Predictability

o Repeatability

o Safety

o Serendipity, motivation, engagement

\section{Decision tree to support the designers/engineers in the decision making process for designing and making toy, game, robot or app for play for children with disabilities}

General phases of the UCD process retrieved from https://www.usability.gov/whatand-why/user-centered-design.html: 


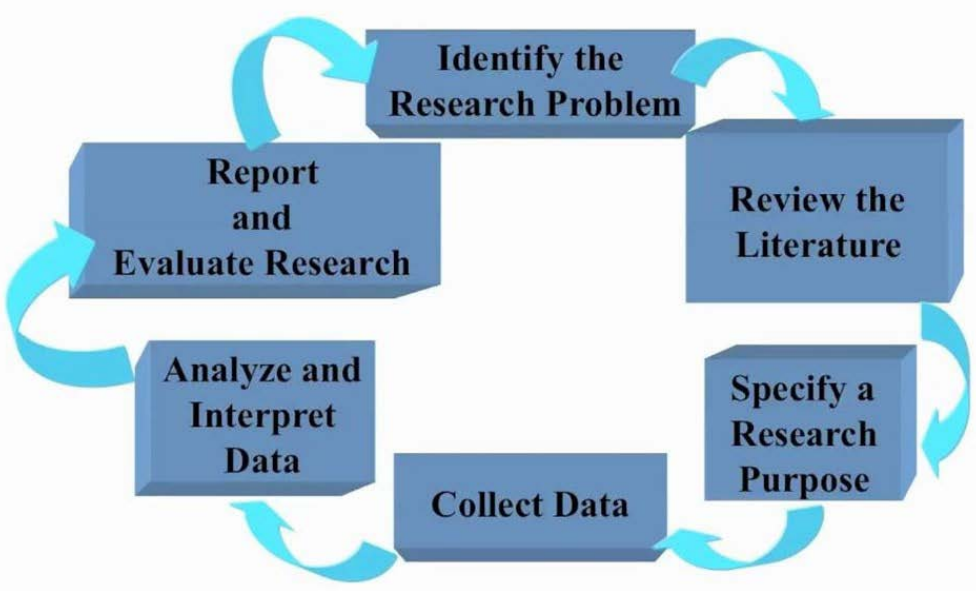

Figure 6.2: The process of research.

\subsection{Identify need}

Assessing usability and accessibility of play tools must be user-centred! Children with disabilities, no matter what age or disabilities, should be involved!

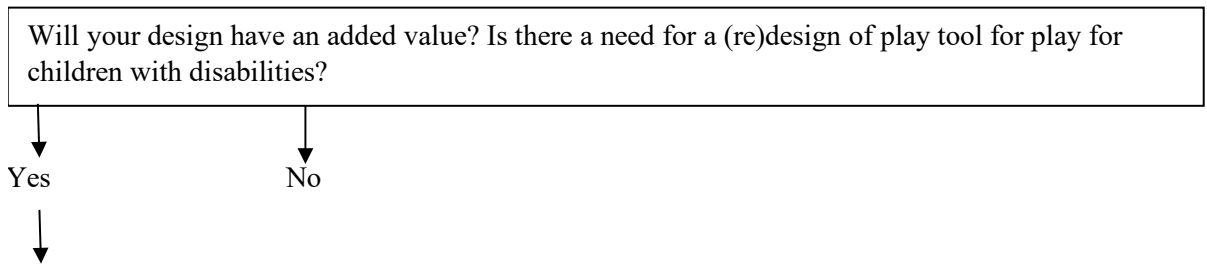

\subsection{Specify context of use (describe in your own words)}

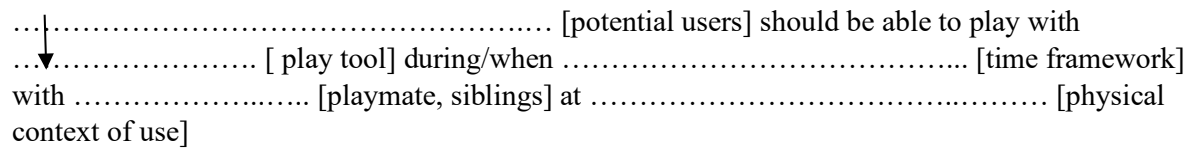




\subsection{Specify requirements}

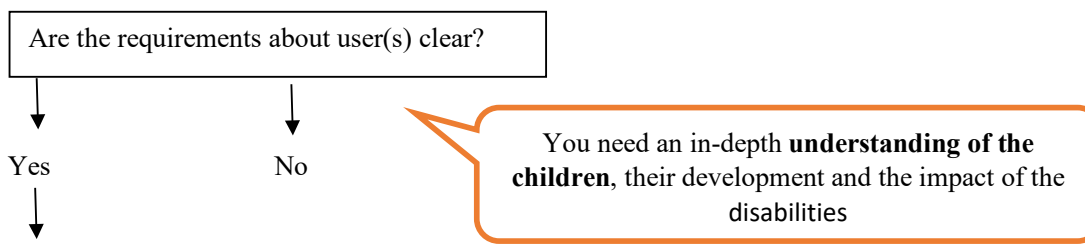

Are the requirements for the play activity clear?
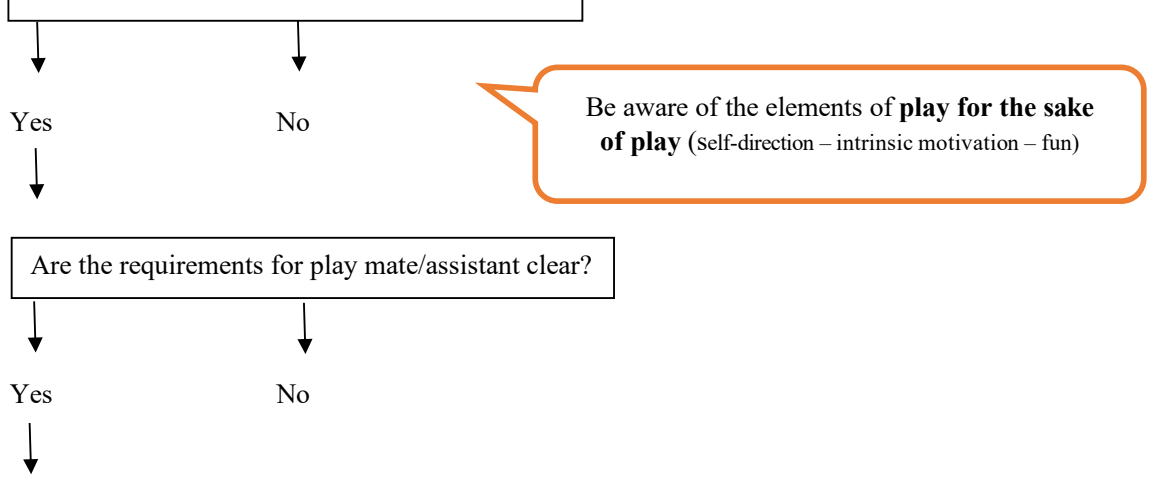

Are the requirements for the physical environment clear?

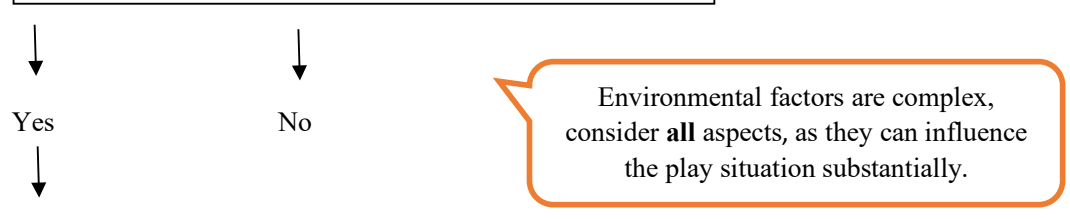

Is there a clear specification for the design? (e.g., materials, appearance an safety)?

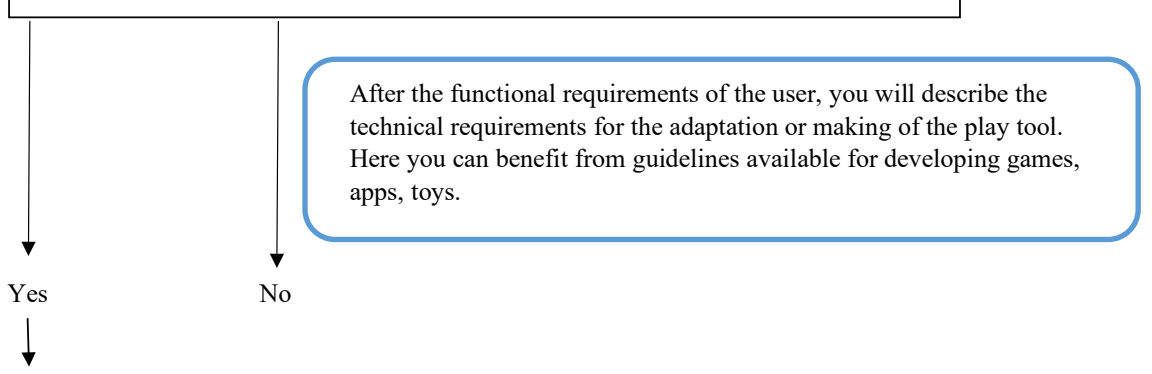




\subsection{Produce design solutions}

Will the play tool be made with technology? (or from wood, paper, glass, plastic, etc.)?

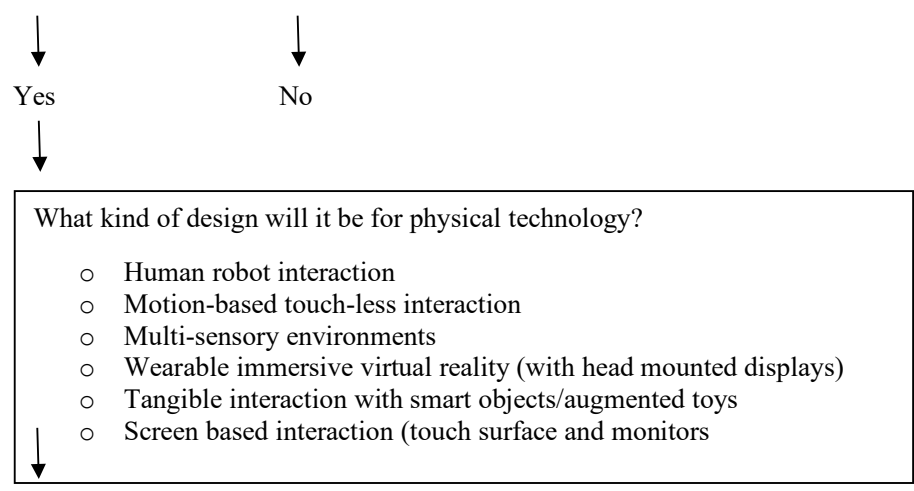

Develop different prototypes

You can analyse a play tool. But it is still very important afterwards to observe child(ren) using the play tool in a play for the sake of play situation

\subsection{Evaluate design solutions}

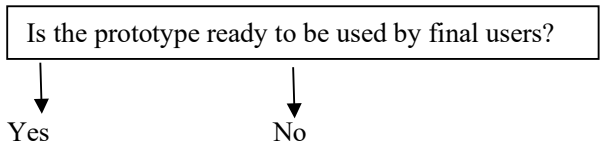

Is there a plan for evaluating the prototype? (usability test: who will evaluate, who's involved, what will be the try out situation, what kind of measurements are used, etc.)? [Check out the Dropbox link above for document: 8) Evaluation of play and play tool]

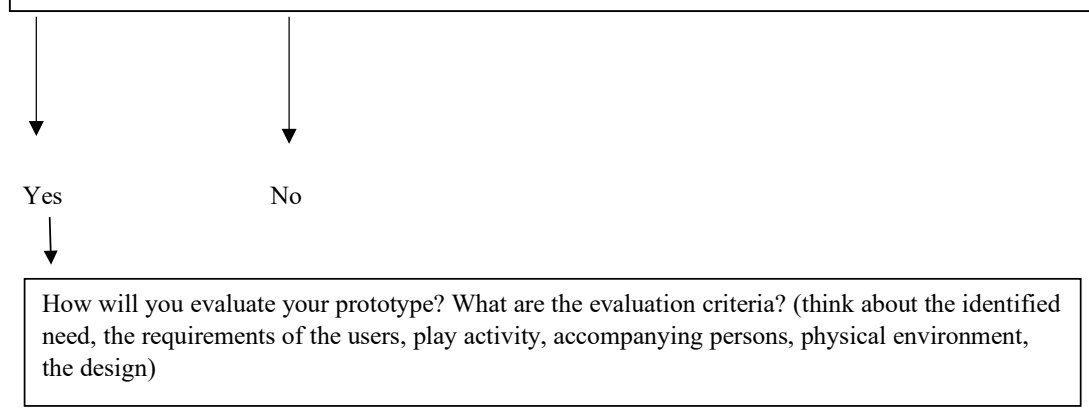



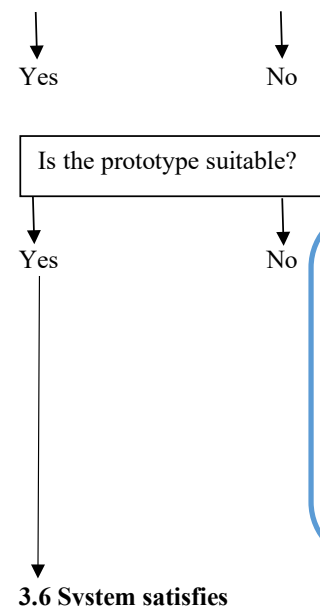

3.6 System satisfies
Be aware that play experience of the child can differ very much from play experience of play mates (peer, sibling, adult). Adapt the prototype till it can be used by the child in a satisfying way.

If you want to play with the child yourself or to observe the play situation yourself (instead of/besides getting information from the child, parent, professional) you can use Guidelines to promote play opportunities for children with disabilities (n.d.)

https://www.dropbox.com/s/ncmc185bfnktxa6/ $\mathrm{Nr} \% 209 \% 20$ Guideline s\%20to\%20Promote $\% 20$ Play $\% 20$ Opportunities $\% 20$ for $\% 20 \% 20$ Child ren $\% 20$ with $\% 20$ Disabilities.pdf? $\mathrm{dl}=0$ provide in layman language questions and suggestions for positioning, communication and social supports, adapting toys and play strategies.

\subsection{User satisfaction}

If the prototype supports the play situation of the child(ren) as planned, consider to bring your prototype to an engineering production phase.

The following chapters can be useful as well (Encarnação, Ray-Kaeser, \& Bianquin, 2018):

Chapter 4: Are our children playing?

Chapter 5: How can I, as an adult facilitate play?

Chapter 6: What assistive technologies exist to enable participation in play?

Chapter 7: Which toys and games are appropriate for our children?

Chapter 8: Which digital games are appropriate for our children?

Encarnação, P., Ray-Kaeser, S., \& Bianquin, N. (Eds.). (2018). Guidelines for supporting children with disabilities' play. Methodologies, tools, and contexts. Warsaw: De Gruyter Poland. Retrievable at https://www.degruyter.com/viewbooktoc/product/507228 


\section{Guideline for researchers \\ How to investigate usability and accessibility of toys and technologies for play for children with disabilities?}

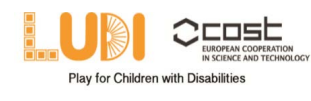

\section{Introduction}

This guideline aims to support researchers when considering studying the usability and accessibility of toys and technologies for play for children with disabilities?

This guideline starts with reflective questions followed by some considerations. Extra information about concepts, classifications with the document's number, can be consulted at this link https:/www.dropbox.com/sh/wii2si50apcgglu/ AAAQCBfS1UQ2KGbKOEW8Kr2Ha?dl=0

[Check out this Dropbox link for document see link for: 1) definitions guideline, usability, accessibility]

\section{Reflective questions}

\section{PLAY OF CHILDREN WITH DISABILITIES}

- There are different definitions about play. Consider which definition suits your study LUDI has described these and adopted the definition of Garvey. [Check out the Dropbox link above for document: 3) definition of play and play tool]

- There are different kinds of play. Think about them. [Check out the Dropbox link above for document: 5) classification of play]

- LUDI distinguish play for the sake of play and play like activities. [Check out the Dropbox link above for document: 3) definition of play and play tool]. It's important to get clear which will be the focus of your research.

- Children with disabilities are challenged in play: try to get a clear picture of the group of children and their challenges in playing. [Check out the Dropbox link above for document: 2) definition children with disabilities, and document: 4) challenges in play of children with different disabilities]

- Consider the whole play situation: children - playmates - toys and technologies used for play - environmental factors [Check out the Dropbox link above for document: 7) definition environment and environmental factors] 
PLAY TOOL [Check out the Dropbox link above for document: 3) definition of play and play tool]

- Is the play tool to be used in research safe for the given child(ren)? Is it considered to be safe according to the EU Toy Safety Directive? https://eur-lex.europa.eu/ LexUriServ/LexUriServ.do?uri=0J:L:2009:170:0001:0037:en:PDF

- How can the play tool be accessed? (reaching, grasping, letting go, manipulating, etc.)

- Is it possible to connect the play tool to interfaces or input devices? [Check out the Dropbox link above for document: 10) definition input and output devices, interface]

- What can you do with the play tool (functionalities)?

- Can the child(ren) interact with the play tool, i.e. can the play tool react or propose activities to the child(ren)?

- Is it possible to connect the play tool to output devices, to make it usable?

- What kind of physical adaptations can be made on the play tool to make it more usable for the given child(ren) when evaluating data proves this necessity?

- Is it possible to create different ways of playing? Can you create new challenges in play with the play tool so that it becomes more usable, or it can engage the child(ren) for a longer time?

- What kind of play situations can be created with this play tool? (think about environments, play mates, scenarios, etc.) [Check out the Dropbox link above for document: 7) definition environment and environmental factors]

\section{RESEARCHABOUTUSABILITY AND ACCESSIBILITY OFTOYSANDTECHNOLOGIES}

- Analyse former research with the specific play tool, for the targeted group of children. Here for you can consult LUDI database http://ludi.utad.pt/

- Have a clear picture of the concepts of usability and accessibility and its meaning in relation to toys and technologies

See also Chapter 5 in this publication: Usability and accessibility of toys and technologies for play for children with disabilities: Scoping review of guidelines and tools.

- Examples of research about accessibility of usability of toy, board or videogame, robot or app are limited. The review, carried out by LUDI Working Group 2 and presented in Chapter 5, showed this research about game accessibility:

Yuan, B., Folmer, E., \& Harris, F. C. J. (2011). Game accessibility: A survey. Universal Access in the Information Society, 10(2011), 1-20. 


\section{Considerations for carrying out research about usability and accessibility of toys and technologies about toys and technologies for play for children with disabilities}

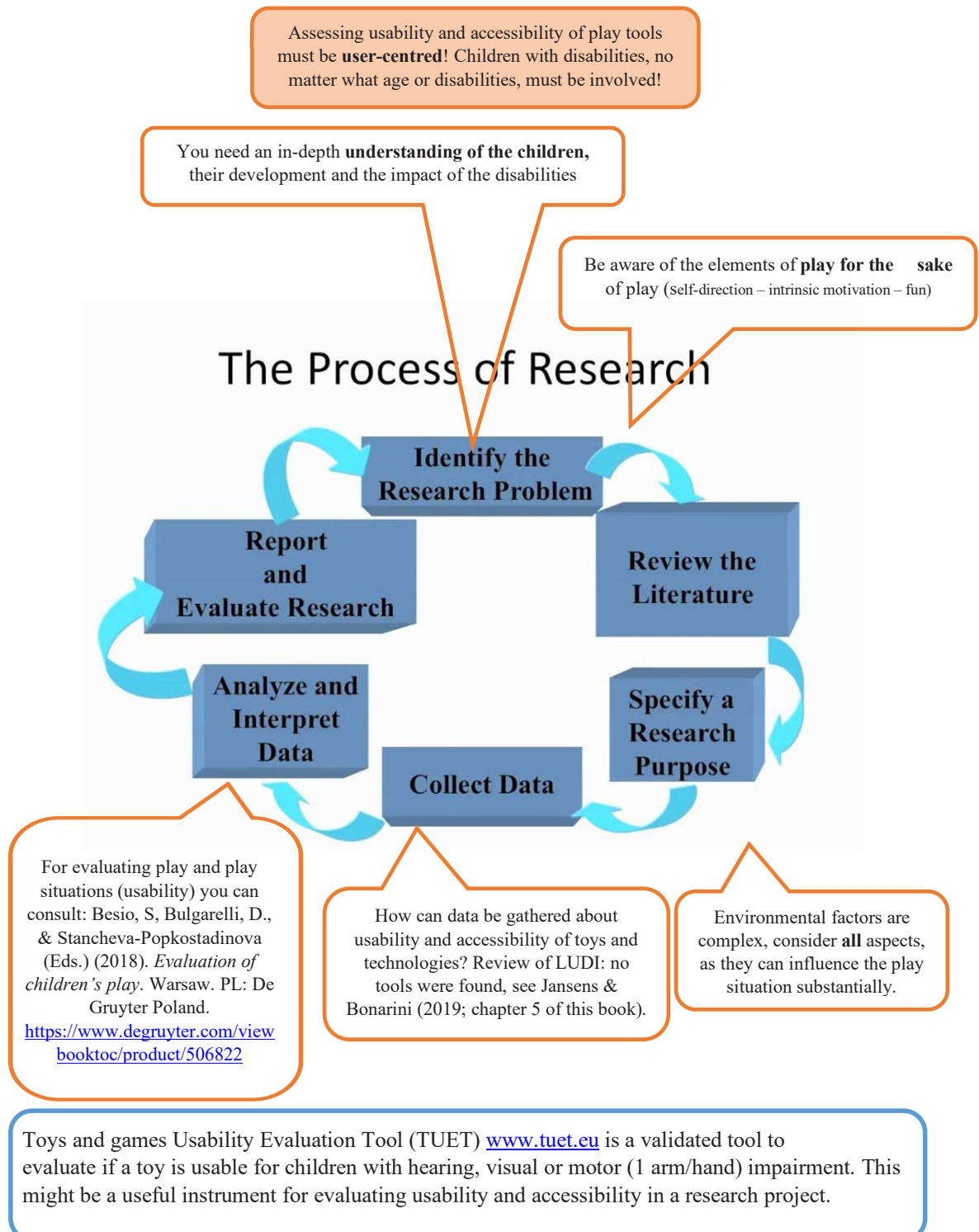




\subsection{Discussion}

Although efforts were made to have a transparent and scientifically sound process, this research was challenged in different ways. Cooperation with experts from different countries, with different languages and cultures, with expertise in different professional and scientific fields demanded time for understanding, a common mindset and a methodological thorough work preferably in face to face meetings, whose availability was very limited.

The objective of developing guidelines for different stakeholders on usability and accessibility of toys and technologies for play for children with disabilities was huge and maybe even not feasible within the framework of LUDI. However, we believe that the current guidelines are an interesting first attempt that could be applied in daily practice and scientifically evaluated in the near future.

Incorporating clarification of concepts, classifications, existing (and reviewed) tools and guidelines while bearing the desired flow and feasibility of the guideline in mind was challenging. On the other hand, the authors were depending on the availability and the quality of different sources.

In the perspective of the fast technological developments and the challenges with implementation of innovations in practice there is an enormous need for further research in this field to support makers, designers, engineers and in making inclusive toys and technologies as well as to support parents and professionals in using these toys and technologies and to strengthen transparent professional reasoning and, if possible, evidence based practice. There is still a lot of work to be done by researchers, innovation managers and policy makers to support these processes, to cooperate and exchange expertise. As the last ones have an important role to support creating and using accessible and useable toys and technological products for play for children with disabilities, it's recommended to develop a guideline for the stakeholder group of policy makers.

\subsection{Conclusion}

This paper presents guidelines on usability and accessibility of toys and technologies for different stakeholders: parents, professionals, designers, makers and researchers. These guidelines support the reasoning and decision-making process for the play objects. Commercially available toys, adapted toys, board games, computer games, apps, robots, and other technological products are very important in play situations involving every child. They can enable intrinsic motivation, being in control and pleasure, components of play for the sake of play (Besio et al., 2017 p. 45-46). Above this, technology is promising in creating inclusive play (Jansens \& Bonarini, 2019). Although the appropriate choice and usability of play objects will always be 
important, there are still the impairment of the given child(ren), the role of the adults, the suitability of the environment to consider and shape it to an optimal match.

\subsection{Acknowledgements}

We would like to thank LUDI Working Group 2 members for their support in different phases of the development of the guidelines: (in alphabetic order) Ms Natalia Amelina UNESCO Institute for Information Technologies in Education in Russia, Ms Nan Cannon Jones Independant Consultant in UK, Ms Dana Cappel Beit Issie Shapiro in Israel, Ms Maria Costa AIJU - Technological Institute for Children's Products and Leisure Alicante in Spain, Ms Tânia de Jesus Vilela da Rocha University of Trás-osMontes and Alto Douro and INESCT/ UTAD in Portugal, Mr Pedro Encarnação Católica Lisbon School of Business and Economics Universidade Católica Portuguesa, in Portugal, Ms Silvia Giordano Institute for Informatics and Networking Systems Univ. of Applied Science and Arts of Southern Switzerland, Mr Raymond Holt University of Leeds in UK, Ms Iolanda Iacono Glitch Factory in Italy, Mr Antoni Jaume-i-Capó Universitat de les Illes Balears in Spain, Ms Malgorzata Jedrzejewska-Szczerska Gdansk University of Technology in Poland, Mr Jari Jessen Jari Due Jessen Digiplay in Denmark, Mr Vygaudas Juozaitis Lithuanian College of Democracy in Lithuania, Ms Hatice Kose Istanbul Technical University in Turkey, Ms Agnieszka Landowska Gdansk University of Technology ETI Faculty in Poland, Ms Patrizia Marti University of Siena in Italy, Ms Veronica Montanaro University of Malta \& TAASC in Malta, Ms Lourdes Moreno Universidad Carlos III de Madrid in Spain, Mr Mati Mõttus Tallinn University in Estonia, Ms Noa Nitzan Beit Issie Shapiro in Israel, Ms Selda Ozdemir Gazi University in Turkey, Mr Suat Ozdemir Gazi University in Turkey, Ms Lucía PérezCastilla Alvarez Ceapat (Imserso). National Reference Centre for Personal Autonomy and Assistive Technology in Spain, Ms Odile Perino FM2J, Play training centre, Lyon in France, Ms Noemí Rando AIJU, Technological Institute for Children's Products and Leisure Alicante in Spain, Mr Ben Robins University of Hertfordshire in UK, Ms Evelyne Thommen University of Applied Sciences and Arts, Western Switzerland, Mr Tim Vanden Hende Arteveldehogeschool in Belgium, Ms Renée van den Heuvel Zuyd University of Applied Sciences in the Netherlands, Mr Robin van Kampen NYOYN international in the Netherlands.

Special thanks to Mr Mirko Gelsomini, former PhD student at Politecnico di Milano in Italy, and Ms Manon van der Hoef, former student occupational therapy Zuyd University of Applied Sciences in the Netherlands for their significant contributions. 


\subsection{References}

Besio, S., Bulgarelli, S., \& Stancheva-Popkostadinova, V. (Eds.). (2017). Play development in children with disabilities. Tools and methods. Warsaw, PL: De Gruyter Poland.

Besio, S, Bulgarelli, D., \& Stancheva-Popkostadinova (Eds.) (2018). Evaluation of children's play. Warsaw. PL: De Gruyter Poland.

Costa, M., Romero, M., Mallebrera, C., Fabregat, M., Torres, E., Martínez, M., ... Martínez, P. (2007). Juego, juguetes y discapacidad. La importancia del diseño universal. Alicante, E: AlJU. Retrieved from http://www.guiaaiju.com/2015/docs/juego-juguete-y-discapacidad.pdf

Drumgoole, A., \& Mason, T. J. (2012). Includification. A practical guide to game accessibility. Retrieved from https://accessible.games/includification/

Encarnação, P., Ray-Kaeser, S., \& Bianquin, N. (Eds.). (2018). Guidelines for supporting children with disabilities' play. Methodologies, tools, and contexts. Warsaw, PL: De Gruyter Poland.

Gelsomini, M. (2018). Empowering Interactive Technologies for Children with Neuro-Developmental Disorders and their Caregivers (Doctoral thesis). Milan, I: Politecnico di Milano.

Grammenos, D., Savidis, A., \& Stephanidis, C. (2009). Designing universally accessible games. ACM Computers in Entertainment, 7(1), 8:3-8:27.

Jansens, R., \& Bonarini, A. (2019). Usability and accessibility of toys and technologies for play for children with disabilities: Systematic review of guidelines and tools. In D. Bulgarelli (Ed.), Perspectives and research on children with disabilities and play. Collected papers. Warsaw: De Gruyter.

Mullick, A. (2013). Inclusive indoor play: An approach to developing inclusive design guidelines. Work, 44(2013), S5-S17.

Van der Hoef, M. (2018). Reviewing guidelines on usability and accessibility of toys and technologies for play for children with disabilities and possible implication for OT services (Bachelor thesis). Heerlen, NL: Zuyd University of Applied Sciences.

Yuan, B., Folmer, E., \& Harris, F. C. J. (2011). Game accessibility: A survey. Universal Acces in the Information Society, 10(2011), 1-20. 


\section{Parents' perspectives on the play of children with sensory disabilities: a comparative study}

Abstract. This research is based on a questionnaire distributed to 20 families of children with sensory disabilities - 10 families of children with visual impairments and 10 families of children with hearing impairments. The main aim is to compare the parents' perspectives and understanding of play, as well as their involvement, and to establish whether families of different groups of SEN children (with sensory disabilities) have different attitudes.

Key-words: play; visually impaired; hearing impaired; parents; comparison.

\subsection{Introduction}

«Play is a range of voluntary, intrinsically motivated activities normally associated with recreational pleasure and enjoyment» (Garvey, 1990, p. 5). The COST Action TD1309 "LUDI- Play for Children with Disabilities" adopted this definition, as it accurately and in details shows the three main and most important areas of play in the infant: 1) pleasure, 2) self-direction, 3) intrinsic drive.

In addition LUDI came up with the following classification of play (Bianquin \& Bulgarelli, 2017):

Table 1: LUDI Classification of play.

\begin{tabular}{|c|c|}
\hline Dimensions of Play & Types of Play \\
\hline Cognitive dimension & $\begin{array}{ll}\text { - } & \text { Practice } \\
\text { - } & \text { Symbolic } \\
\text { - } & \text { Constructive } \\
\text { - } & \text { Play with rules (including videogames) }\end{array}$ \\
\hline Social dimension & $\begin{array}{ll}\text { - } & \text { Solitary } \\
\text { - } & \text { Parallel } \\
\text { - } & \text { Associative } \\
\text { - } & \text { Cooperative } \\
\end{array}$ \\
\hline
\end{tabular}


It is well known in special education that the different groups of children with special educational needs (SEN) face various problems when engaging in play. Often they need guidance, support or supervision in order to play.

It is documented by research that children with visual impairments may face the following difficulties in their play (Tzvetkova-Arsova \& Zappaterra, 2017):

- less interactions with sighted peers and tendency to play alone;

- difficulties in imitation and thus problems to follow play and games;

- $\quad$ poor and rare engagement in symbolic, pretend and fantasy plays;

- $\quad$ preferences to tactile-auditory games and toys;

- tendency for repetitive and stereotyped play;

- manual and bimanual coordination difficulties;

- difficulties in coordination and orientation.

Children with hearing impairments may also face difficulties in their play, such as (Andreeva, Celo \& Vian, 2017):

- language and communication issues;

- less interactions with hearing peers;

- less engagement in associative or cooperative play;

- less involvement in pretend play;

- problems in joint attention.

These features can be positively influenced by in-play training and playing with more experienced partners, such as older children, typically developing children (TroshevaAsenova, 2018), parents and teachers. Play is a social activity and its development is related to communication with other people. This development can be stimulated by appropriate support and training (Wood, Bruner \& Ross, 1976; Vigotskij, 1978). In preschool age, parents are the ones who can influence to a great deal the child's progress and opportunities for social development.

Parents play a crucial role in the process of play as they often are the primary play-companions of their children. How they will play with their own child, what toys and games would be used and introduced to the child, the frequency of the play are all significant factors that will have important impact on the children's abilities and desires to get involved into play activities. Parents' involvement will also influence the children's preferences to different toys and games, their whole attitude towards and understanding for play as an activity, and will thus have a cultural, social and learning impact and value (Childress, 2010; Bianquin, 2018). Often parents play with their children consciously - with the clear intention to teach them something new, in other cases they play with them just for the sake of play, with the only intention to have fun together. In many occasions play may have both goals -to have learning, cognitive and social impact on the child, and to achieve joint pleasure and fun. Of course, the parents' personal visions, understanding and perspectives on play will influence themselves and their involvement in their child's play. In addition, the 
type of disability of the child will also have influence on the parents and will tailor their play activities with the child, the choices of toys and games, and will probably increase their intent and aim to incorporate teaching elements in the play.

The adult can assume three different main roles in facilitating and supporting play for children with disabilities (Bianquin, 2018):

- observer (to gather information about the child itself and about the child's play, identify the child play skills),

- activator (should identify the best promising conditions from which play can spring, exist and evolve),

- companion (play partner, allow the child to express full potential).

For parents of young children with disabilities, the definitive role of parent as play partner and companion often shifts to that of a medical overseer/coordinator. Spontaneous interactions become inhibited by the parent's anxiety over the medical condition of their child as well as by the reduced level of responsiveness that many children with disabilities exhibit (Jackson, Robey, Watjus \& Chadwick, 1991). Researchers conducting laboratory studies of mother-child play have often concluded that mothers of children with disabilities are more controlling and directing in their play with their children than mothers of more typically developing children (Hanzlik, 1989; Hanzlik \& Stevenson, 1986; Kogan \& Tyler, 1973 as cited in Mistrett, Lane \& Goetz, 2000). But there are also contrary findings (Buchanan \& Johnson, 2009), when mothers were observed responding to their children's play initiations, following their children's leads in play, and intentionally scaffolding play to support their children's own play goals. In the play of parents with their disabled children, it is important to maintain the balance between educational games and fun games. In children (especially children with disabilities) it is also important to teaching them to play. The reason of this is, because play "(a) is flexible and can be used in multiple settings, (b) sets the occasion for having social and communicative interactions with peers, (c) increases the likelihood of learning in natural settings, and (d) may offer a foundation for developing leisure skills. Furthermore, play is a context in which intervention strategies for other goals (social, communicative, cognitive) are embedded [...] Additionally, play is an activity that can have reinforcing properties for other skills" (Barton \& Wolery, 2008, p.109).

Parents' attitudes towards playing with their children are important for the quality of play. It is crucial for parents to realize their role and significance. In a research carried by Buchanan \& Johnson (2009), mothers talked about play and emphasized that their children were not "just playing, but learning" and how play provided "a window" into their children's minds or worlds.

It is known that children with disabilities often face challenges in their daily routines and lives which can cause physical and emotional discomfort and stress. Everyday activities such as eating, dressing, bathing, moving from one setting to another, and communicating wants and needs can be especially difficult. The 
programs in early intervention, which often include various therapies, can also cause stress. Play provided pleasure in these children's daily lives and thus decreased the stress in a way. Mothers found a great deal of enjoyment in playing with their children, and also in seeing them enjoy play. They valued both the cognitive complexity in play, but also the emotional intensity of the mutual experiences. They reported that they liked to see their children have fun, get excited, laugh, and be happy (Buchanan \& Johnson, 2009). In addition, we have not to forget that play is a fundamental right of the child, as reported in Article 31 of the UNCRC.

\subsection{Method}

This study aimed to collect information regarding the play of children with sensory disabilities - visual and hearing impairments, through a parent-report questionnaire.

\subsubsection{Sample}

Twenty Bulgarian families of children with sensory disabilities were involved - 10 families of children with visual impairments, attending special school for visually impaired (with preparatory class) and 10 families of children with hearing impairments, attending special kindergarten and having special classes of speechhearing therapy. The 20 children were aged between 2,5 and 7 .

Four of the hearing impaired children were boys and 6 were girls. Among the visually impaired children 7 were girls and 3 were boys. In total 13 of all the 20 children were girls and 7 were boys.

Regarding the degree of disability 8 children (80\%) of the visually impaired were with total blindness (100\% visual loss), one was with $73 \%$ of visual loss and for one child there was no information provided. All the hearing impaired were deaf, 3 children among them had a Cochlear implant.

None of the parents included in the survey had any visual or hearing impairment.

Three of the visually impaired children had mild additional disabilities - two had mild form of $\mathrm{CP}$ and one had a boarder intellect. Another child with visual impairment was with suspicions for eventual boarder intellect. One of the hearing impaired children also had additional disability - ADHD.

Regarding the attendance of a kindergarten, 9 of the visually impaired children (90\%) attended such and for one no answer was provided. All of the hearing impaired children attended a kindergarten (100\%). Table 2 provides all the demographic information. 
Table 2: Demographic data.

\begin{tabular}{llll}
\hline Demographic data & Visually impaired & Hearing Impaired & Total \\
\hline $\mathrm{N}$ & 10 & 10 & 20 \\
Girls & 7 & 6 & 13 \\
Boys & 3 & 4 & 7 \\
Average age & 6,15 & 4,5 & 5,3 \\
Degree of disability & total blindness, visual & Deafness & \\
Additional disabilities & loss & 1 & 4 \\
\hline
\end{tabular}

\subsubsection{Procedure}

A parent-report questionnaire was developed, which consisted of 18 questions in total. In addition, 5 demographic questions were asked regarding the age and the gender of the child, his/her degree of disability, presence of any additional disabilities and the visual/hearing status of the parents. The questionnaire is provided in Appendix 1.

The open-ended questions were interpreted by the authors according to the answers provided to them. There were no answers ignored. In the cases where similar answers were given, they were unified, and in the cases where very different answers were provided, they were interpreted according to their frequency and according to the LUDI classification of play.

The questionnaire was fully anonymous, voluntarily done, and was distributed as hard copy to the parents.

\subsection{Results and discussion}

The results below will be presented question by question in order to provide a full picture of the data collected through the Questionnaire.

Question 1: Does your child play independently? If yes, please describe briefly how and on what games.

The answers to Question 1 showed that all children, except one child with visual impairment, played independently, according to their parents. Graph 1 presents the types of games and types of play the children got involved into independently. We used such a mixed classification of both types of games and types of play in order to interpret in a most correct and natural way the answers provided. 


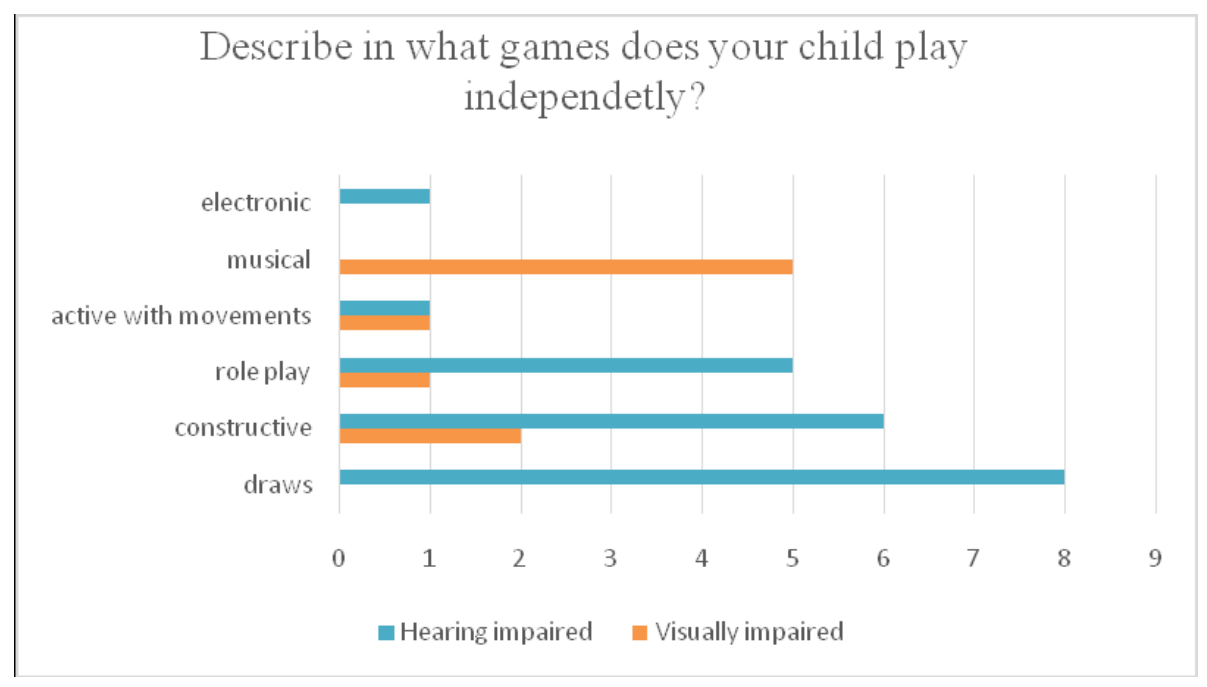

Graph 1: Independent involvement in games.

It is interesting to notice that children with hearing impairments got involved mostly in drawing, constructive games and role play, which was almost not applicable for the children with visual impairments. They, as expected, got engaged mostly in musical games, but some of them also into constructive games ( 2 children) and in role play (only one child). Again, as expected, children with hearing impairments were not involved at all in musical games and play. The constructive games in the visually impaired, however, were quite simple as for instance: playing with rings and cones, and the same types of games were more complicates in the hearing impaired puzzles, building blocks, Lego and constructors.

Question 2: Does your child start playing by himself/herself?

All parents reported that their children do start playing by themselves, which is very positive.

Question 3: What is his/her favourite toy?

As Graph 2 shows, $40 \%$ of the visually impaired children had a sound toy as a favourite one (e.g. musical car or another musical item), and $40 \%$ of the hearing impaired children had no preferred toy, which may be indication of a larger interest in many toys or the parents simply had not identified the child's favourite toy. The verbal games included electronic question-answers games and others. Under the fitness equipment category parents included running path, simulators etc. Graph 2 presents the answers to this question. 


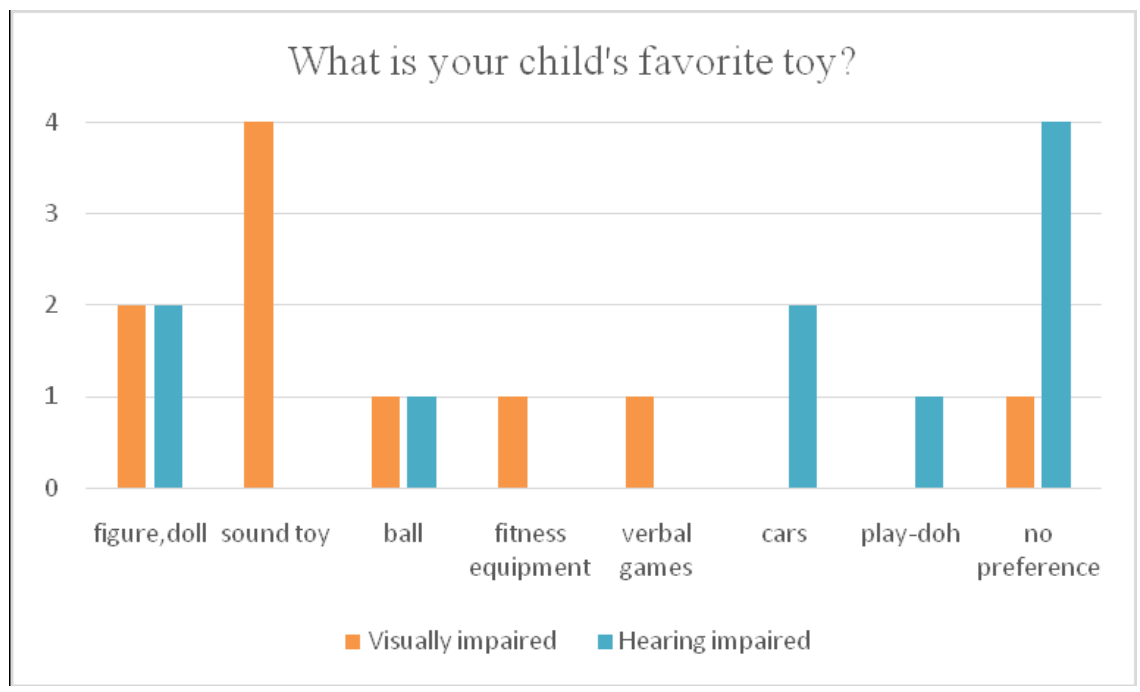

Graph 2: Child's favourite toy.

Question 4: How many toys does your child have at home?

On this question parents of hearing impaired children reported having more toys than the visually impaired $-70 \%$ of the hearing impaired had over 30 toys compared to $40 \%$ of the visually impaired with the same amount. It is noticeable that $40 \%$ of the visually impaired children had only between 5 and 10 toys. Graph 3 presents all answers given to this question.

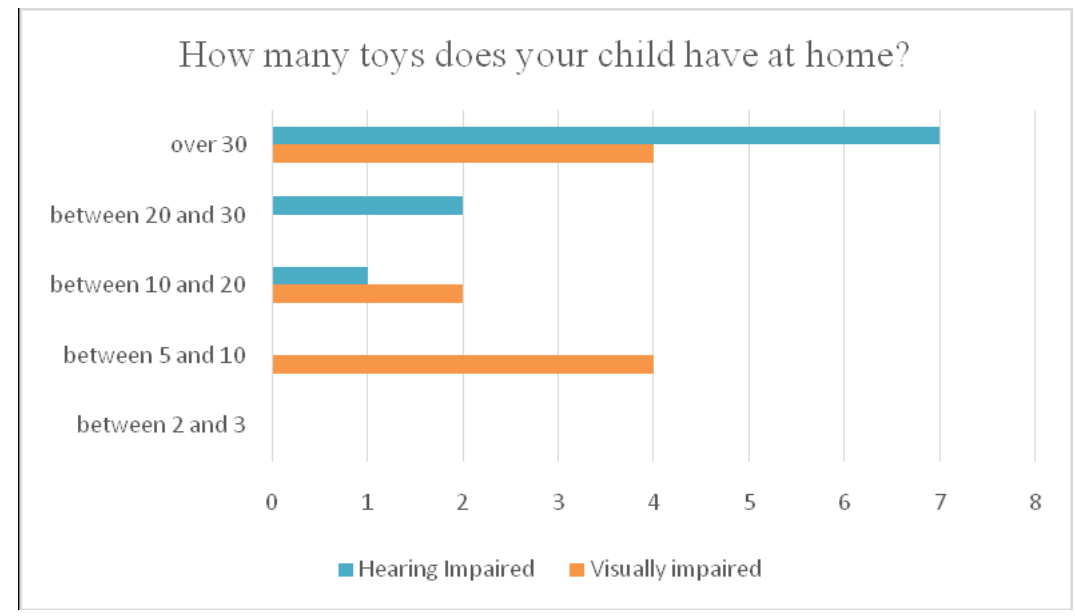

Graph 3: Number of toys at home. 
Question 5: How many games does your child have at home? (e.g, board games - cards, dominoes, etc.)

The answers to this question were very diverse. $60 \%$ of the hearing impaired children had between 10 and 20 games. Visually impaired children possessed much lower number of games $-40 \%$ of them between 5 and 10 games. One parent of a visually impaired child indicated her child had no games at all and one did not give any answer.

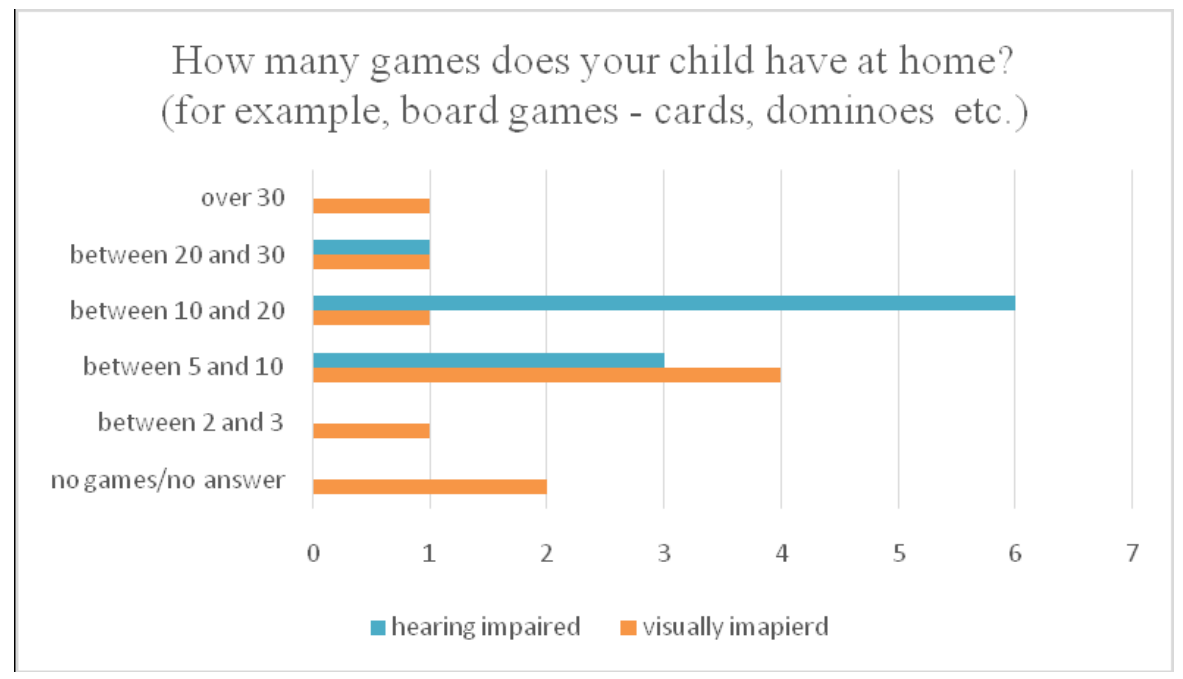

Graph. 4: Number of games at home.

Question 6: Does your child play with his/her toys using them according to their purpose (in an appropriate way)?

The answers to this question were equal and identical for the visually and for the hearing impaired children. In the perception of the parents, $90 \%$ in both groups were using toys accordingly and $10 \%$ are not. Graph 5 presents the answers. 


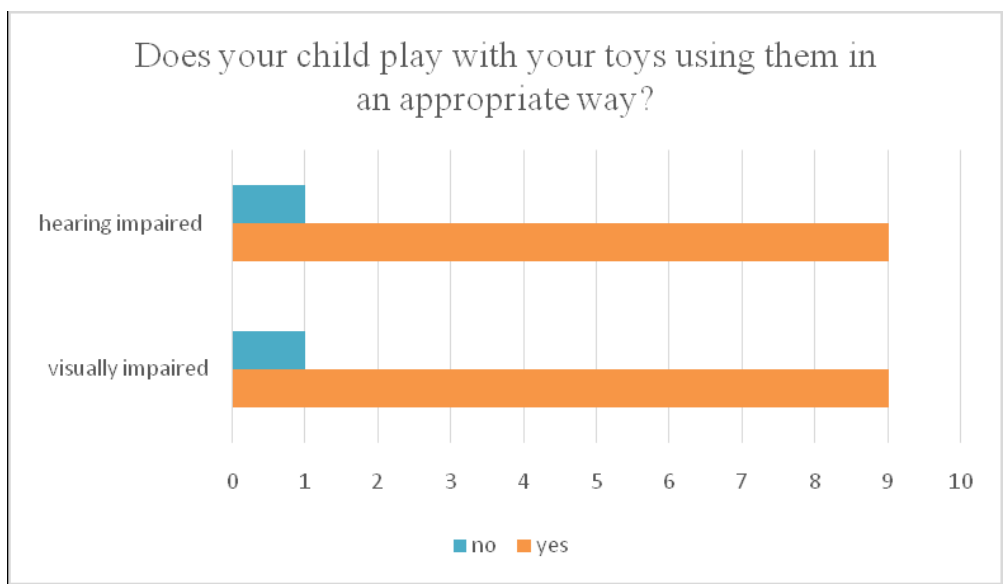

Graph 5: Way of playing with toys.

Question 7: How does your child prefer to play?

This question had multiple-choice answers. 50\% of the hearing impaired children played with other children, while only one visually impaired child got involved in such play. Most of them played with adults, which was no option for any of the hearing impaired children. It is important to notice that $30 \%$ of the hearing impaired children could engage in all possible forms of play, while $20 \%$ of the visually impaired could do so. The answers showed that on a contrary to our expectations, hearing impaired children managed to get involved in play activities with peers, while the visually impaired children were not so successful in such play. The importance of play with peers is well known both in general and in special education for its social, communicative and cognitive values. The answers are presented on Graph 6.

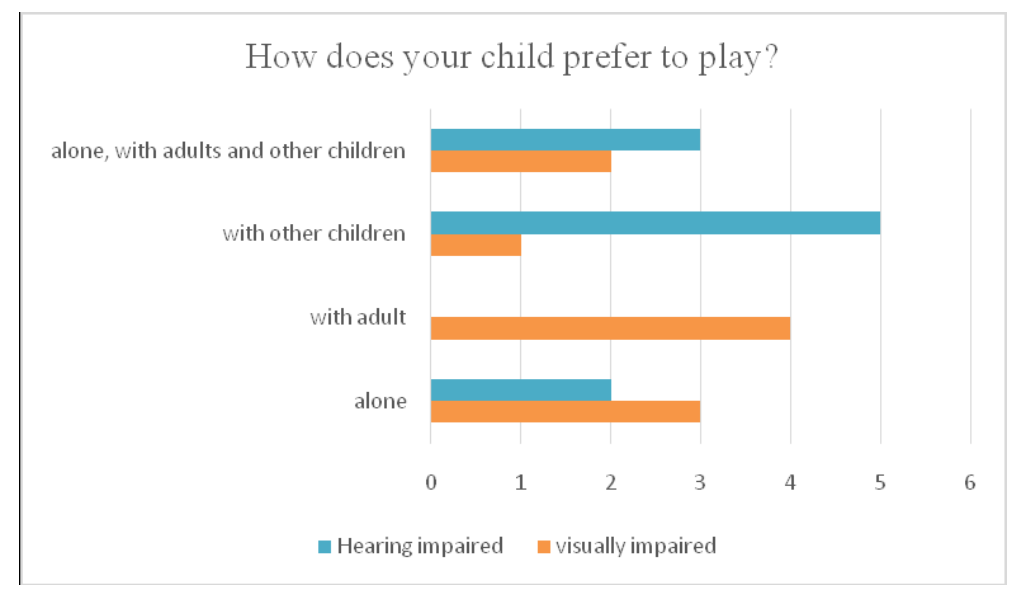

Graph 6: Preference for play. 
Question 8. Do you think the games your child plays match his age?

As shown on Graph 7, all parents of hearing impaired children reported that the games used by their children matched their age. Only parents of two visually impaired children reported the same for their children, while six thought there was no match and two provided no answer. This can be explained with the mild additional disabilities some of the visually impaired children have, although two parents of children with visual impairment only, also indicated lack of correspondence between the age if the children and the games used by them.

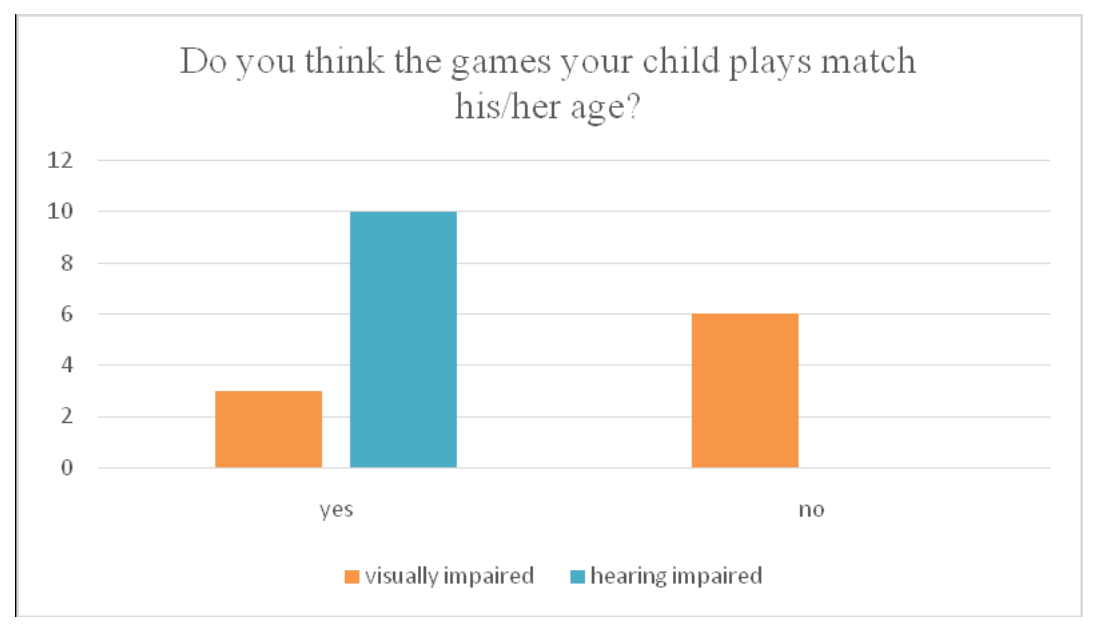

Graph 7: Match between games and age.

Question 9: Do you play with your child? How often?

The answers to this question, like in Question 6, were equal and identical for the visually and for the hearing impaired children. $80 \%$ of the parents in both groups played with their children on every-day basis, which is an excellent tendency. $50 \%$ in both groups played many times per day and 30\% of parents in both groups play with their children once a day. Only one parent of hearing impaired child did not played with her child, indicating that the older brother plays enough with the child. Parents who answered that they played less with their children, explained it with a lack of time. Graph 8 presents the answers. 


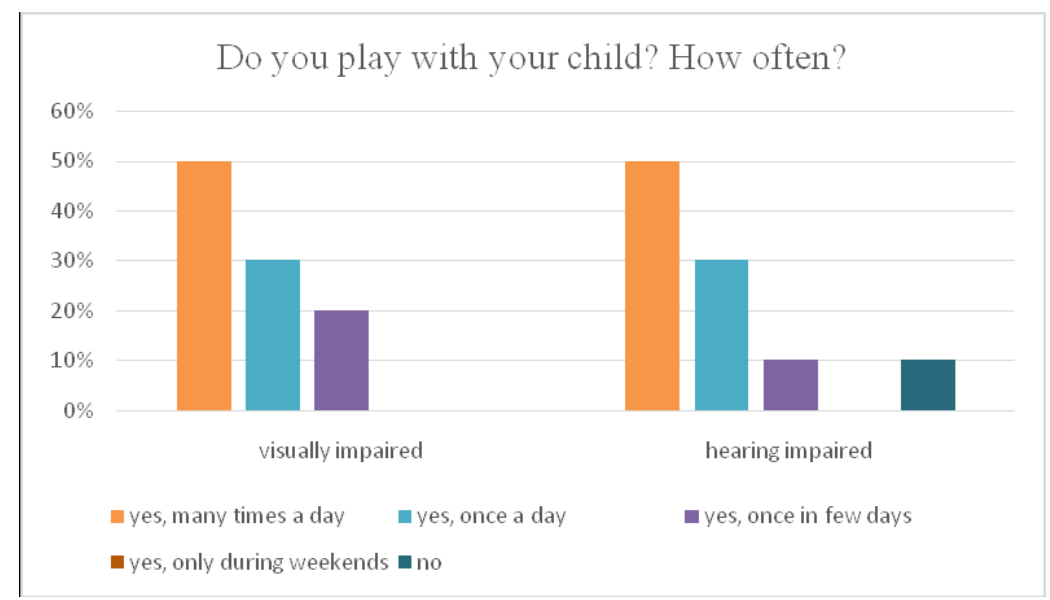

Graph 8: Frequency of adult-child play.

Question 10: What are your favourite joint play activities/games with your child?

When answering this question, some of the parents of hearing impaired children listed joint activities, which cannot be defined exactly as play (play-like activities) - e.g. book reading, writing letters engaging in household activities. In this group of children, the constructive and board-games were reported as favourites - in $60 \%$ and respectively in $50 \%$. There was no clear tendency of favourite play activities in the group of visually impaired children - they played all sorts of games except of movement games, which can be expected. The hearing impaired children, on a contrary, played all sorts of games, except of verbal and musical ones, which again is an expected tendency. Graph 9 shows the answers.

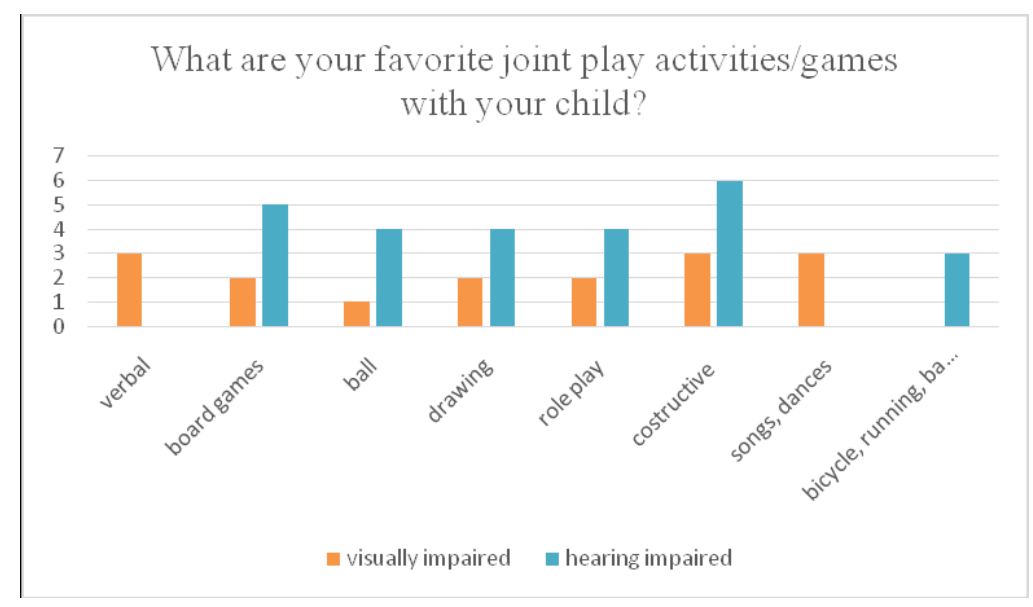

Graph 9: Favourite joint play activities between parent and child. 
Question 11: Do you create new joint play activities/games? If so, who invents them - you or the child?

In both groups there was one parent who gave a negative reply to this question, indicating they were not creating new joint play activities. There was huge difference in the other answers between the two groups. The majority of the parents of hearing impaired children $-80 \%$, created new play activities together with their children, while only $30 \%$ of the families with visually impaired were doing so. Probably the visual impairment turns to be more challenging for the parents to find spontaneous ways to interact with their children and they may need more support and guidance by therapists, educators and other professionals to learn how and what new joint activities and games to invent. In 50\% of the families with visually impaired children, the parents were initiating and developing new plays and games. All answers are presented in Graph 10.

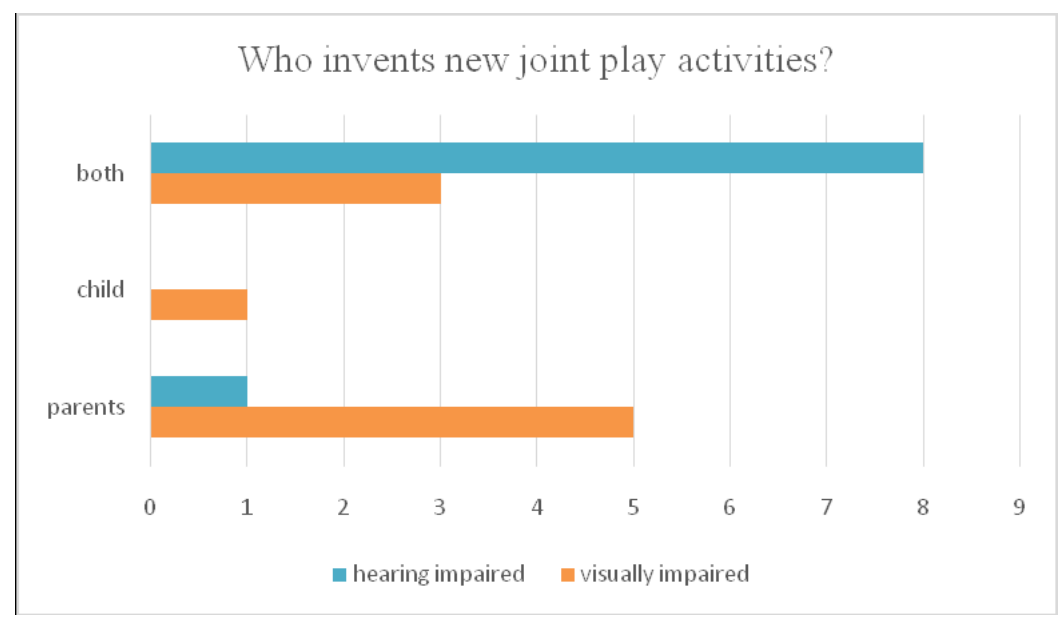

Graph 10: Invention of new play.

Question 12: Who offers first to play together - you or the child?

As shown in Graph 11, there was a huge difference in the initiation of play in the two groups - most of the hearing impaired children initiated it - $80 \%$, while in $60 \%$ of the cases with visually impaired children, the parents offered to play with their children. 


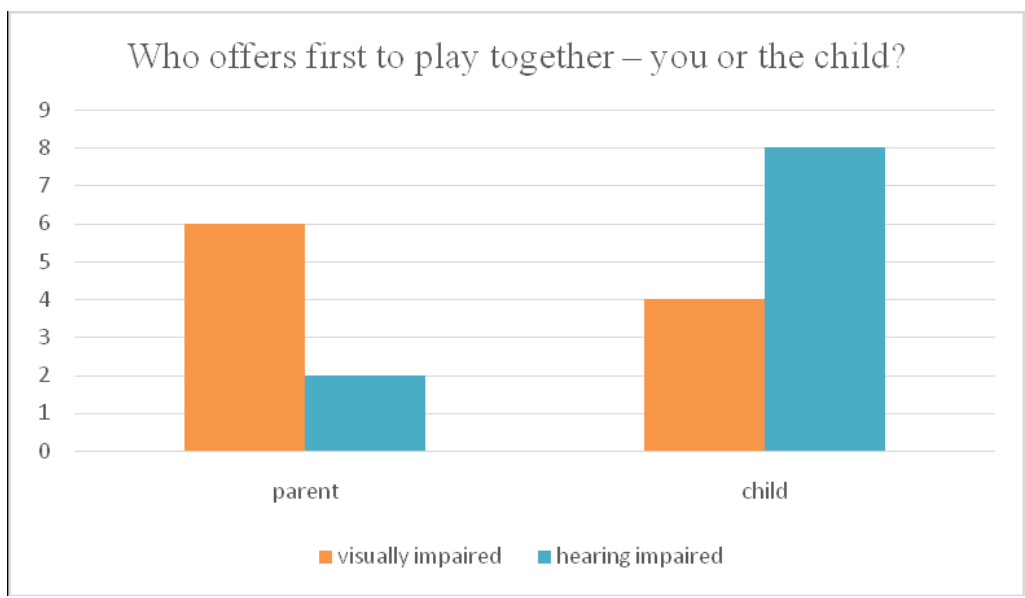

Graph 11: Initiative for adult-child play.

Question 13: Do you try to teach your child something new during the play/game? What?

It is remarkable and in the same time expected, as Graph 12 presents, that all parents in both groups replied positively, namely they tried to teach the child something new during the play activities. There were equal number of answers in both groups - 40\%, indicating the importance of daily living skills. Expectedly, parents of hearing impaired children gave some priority to verbal skills, and also to new play skills, both of which were not prioritized by parents of the visually impaired. The latest tried to teach motor skills to their children, which was not indicated by any parent of hearing impaired children.

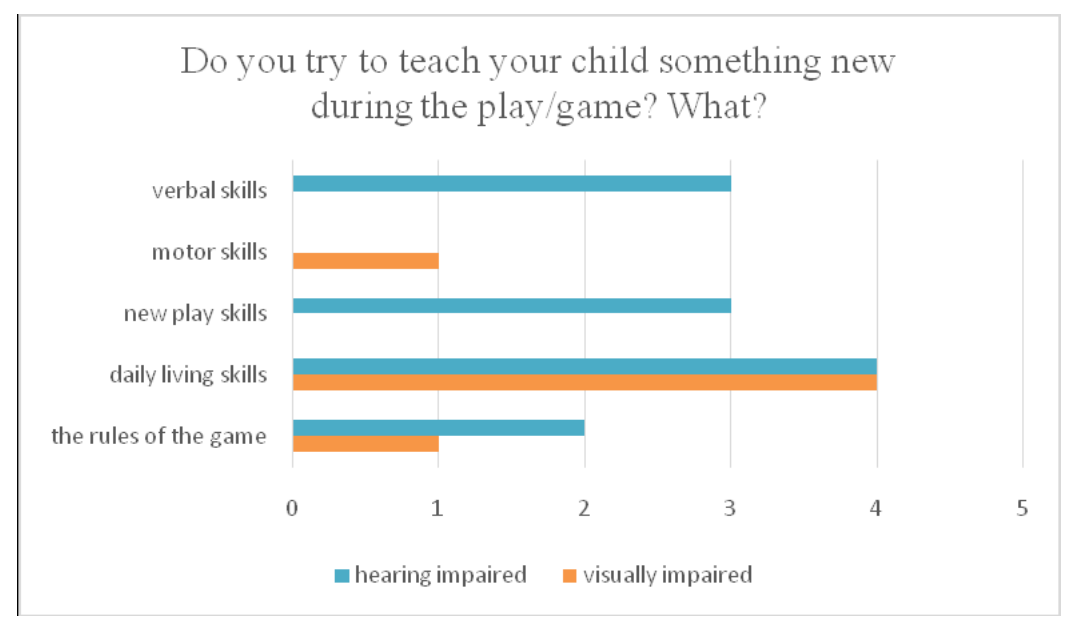

Graph 12: Teaching elements in play. 
Question 14: Do you feel a need and desire to play with the child? Why?

In both groups most of the parents $-90 \%$, gave positive answers. However, there were two parents - one in each groups, who gave negative replies (one explained that this is due to lack of enough time). Asked to explain further why parents played with their children, most of the parents gave multiple answers, the most common among them in both groups were: to be close with the child, to have mutual positive emotions or to have teaching opportunities. Graph 13 shows the answers to this question.

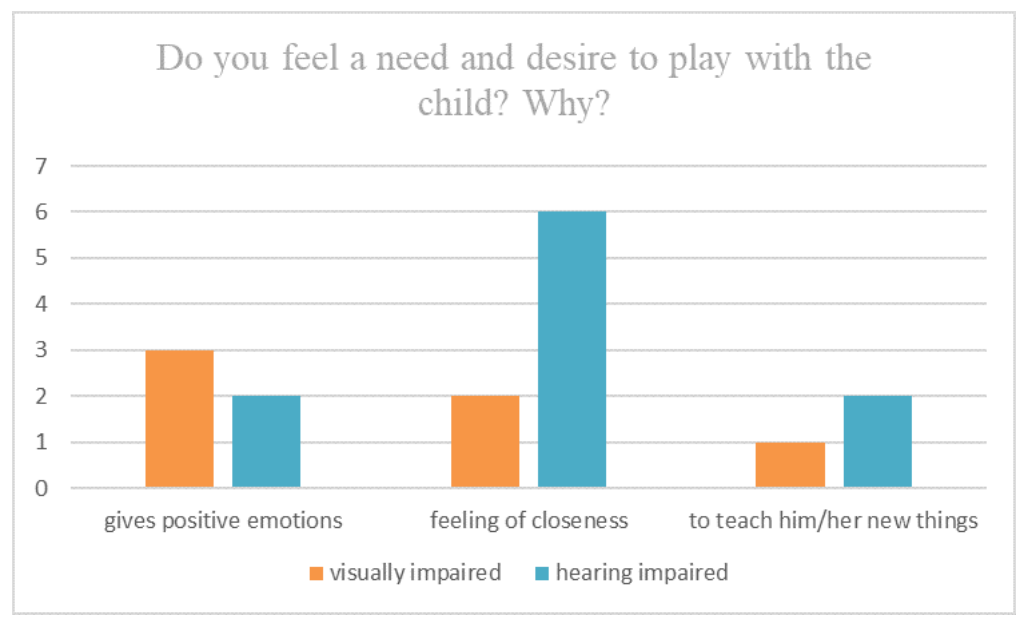

Graph 13: Reasons for parent-child play.

Question 15: Does your child play with other children? With whom?

Two parents of visually impaired children gave quite specific answers - one that the child did not play with other children at all (not shown on Graph 14) and another parent specified that the child played only with a sibling. All other parents gave multiple replies. Almost the same number of children $-80 \%$ for the hearing impaired and $70 \%$ for the visually impaired-played with various groups of children (of neighbours, of parents' friends). Some parents specified that their children played only with children with the same disability ( 2 of the hearing impaired and one of the visually impaired), while others did not circle this reply at all. The answers are shown on Graph 14. 


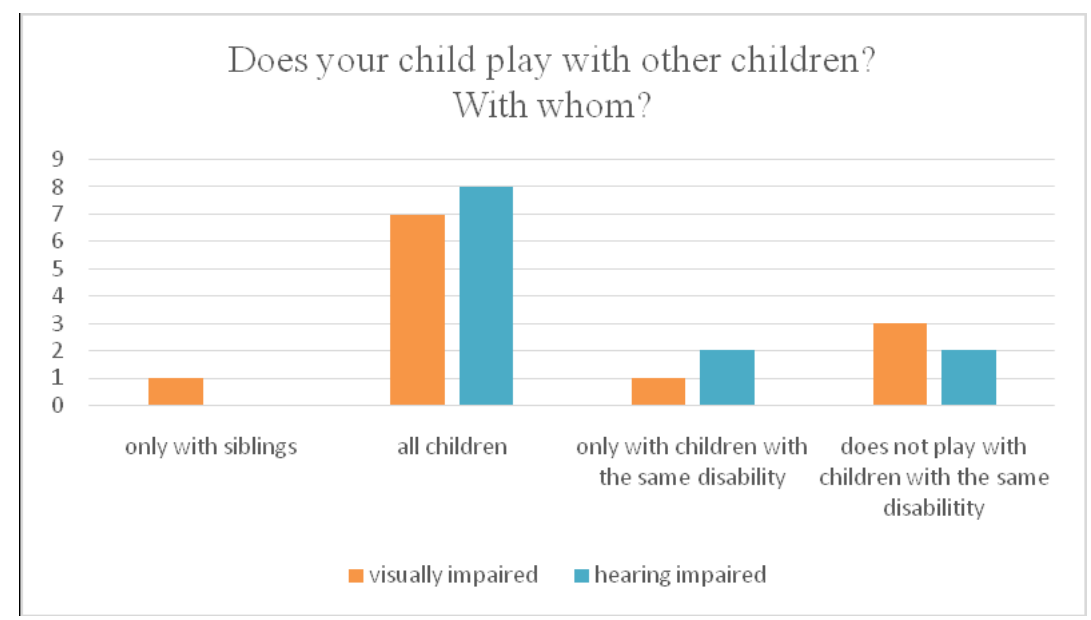

Graph 14: Play with other children.

Question 16: Who usually initiates a play with other children - your child or other children?

As Graph 15 presents, visually impaired children initiated play with other children less than the hearing impaired children with a ratio $2: 8$. In $50 \%$ of the hearing impaired, parents indicated that both their child and other children may initiate play, which was applicable for $20 \%$ of the visually impaired. However, for 5 of the visually impaired children there was no answer given to that question, and one answer for a hearing impaired child was "I do not know".

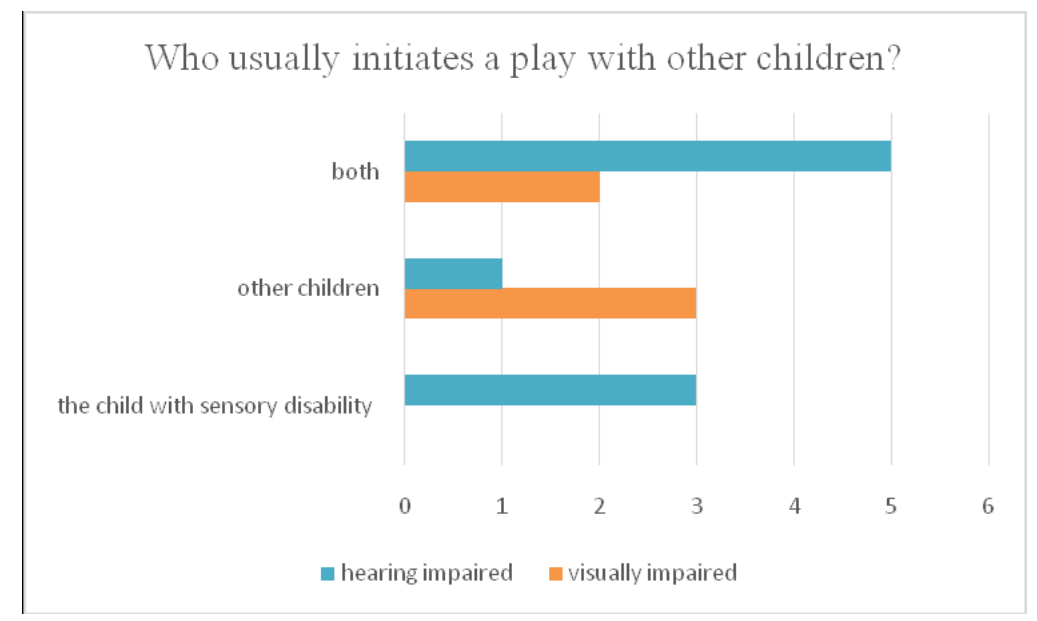

Graph 15: Initiative for child to child play. 
Question 17. Do you encourage your child to play with other children? Why?

Two parents of hearing impaired children gave a negative answer, namely they did not encourage their child to play with other children, explaining that their children were active enough to play with others and did not need any encouragement. All other parents replied positively. The explanations why they did so, included answers as improving their socialization skills, more inclusion, just for fun or to encourage their development. Graph 16 presents the answers.

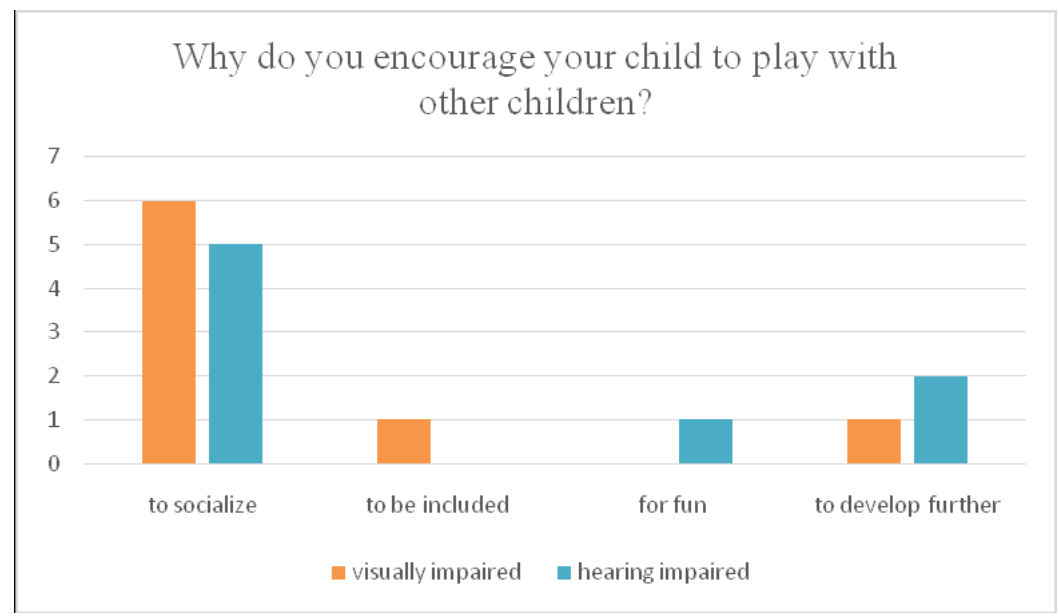

Graph 16: Reasons for encouragement child to child play.

Question 18. What games does your child play with other children?

This was an open-ended question and parents could give more than one answer. Some trends here showed play and games that were typical for one of the groups of children, as for instance only hearing impaired played more games involving movements like bicycling, running or badminton (with the only exclusion of football, which was pointed out also for few of the visually impaired). On a contrary, only the visually impaired ( 2 children) got engaged in verbal games and none of the hearing impaired. It is interesting that no parents gave "board games" as example. 


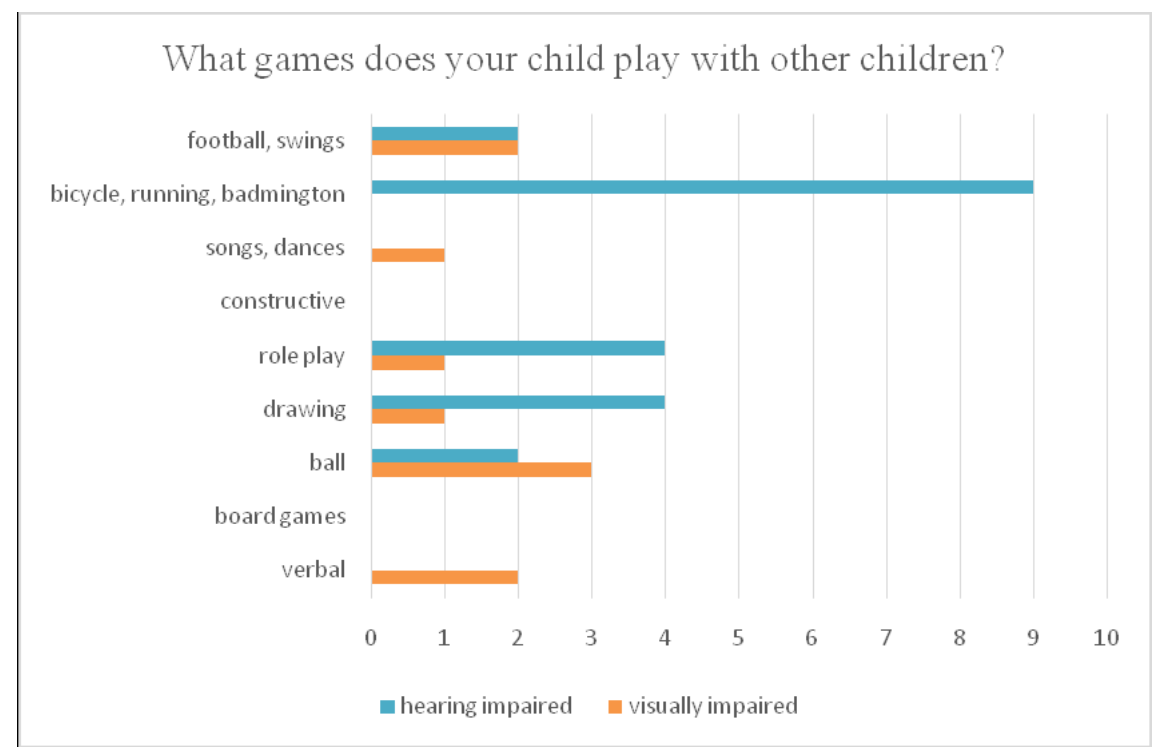

Graph 17: Games played with other children.

\subsubsection{Comparison between visually impaired and hearing impaired children}

This survey showed close and identical results between the visually impaired and hearing impaired children in some areas, and differences in others. What we found common for all children was that they did play, which means they were given the opportunities, partners, toys and games to do so. Parents of almost all children reported to have fun, pleasure, joy and the sense of closeness with their children during play times and activities. However, all of the parents also reported that they were trying to implement teaching elements during play, including socialization skills (Question 17).

All children in our survey did have toys and games at home, however, the hearing impaired had higher number of both, which number seems closer to the typically developing children. All children from both groups had more toys than games, which can be somehow explained with their age: 2.5 - 7 years. This result actually shows that not so many toys and games are suitable for children with visual impairment, and this may be considered as a contextual barrier due to a lack of Design for All with respect to toys. On one hand, the right to play is not supported, but on the other, LUDI tried to work on this issue through the Training School "Play and Toys for All" and a special chapter "Training model to support play of children with disabilities in inclusive contexts and on strategies of intervention (methods and tools): final version” by Besio and Jansens will be dedicated to this matter. 
Expectedly differences were found between the two groups in pointing out a favourite toy. Visually impaired children played more with sound-making and musical toys, either when playing alone or in joint play with adults, while hearing impaired children preferred constructive and board games both during independent play and in joint play situations and did not get involved in any verbal games (even the children with cochlear implants). On a contrary, however, parents of latter reported tried to teach verbal skills during play situations (Question 13), which does not well corresponds with the answers provided to question 10 of not playing verbal games with their children. In independent play, hearing impaired children also got more involved in drawing, while two parents of visually impaired children reported drawing activities during adult-child play, which was surprising as both of these children were with total blindness. Probably parents tried to introduce play activities, not so typical for their children, in order to increase their awareness of such play options.

Another big difference between the two groups of children was established in taking the initiative for play, both with adults and with other children - hearing impaired children were much more active than the visually impaired, who did not take often such initiative. The hearing impaired children got engaged in many cases in movement plays and games with other children. They were also much more involved in inventing and creating new joint play activities with their parents, while the visually impaired were less creative. Hearing impaired children showed a preference to play more with other children, according to their parents, while visually impaired played more with adults.

\subsection{Conclusion}

It was very positive to discover through this small survey that parents both of visually and of hearing impaired children understand play as a very important activity for their children. They get involved in play quite often and try to teach their children new skills and to support their whole development through games and play, as well as to increase their socialization. They also provide games and toys for their children, taking into account their sensory disability, although our results showed that visually impaired had less number of toys and games. It is very much expected that parents think it is important to teach new skills, to get new knowledge and concepts through play, but professionals should also support the importance of play "as play" and "for the sake of play", especially in children with disabilities. Those answers show that the LUDI commitment to spread the idea of "play for the sake of play" is highly needed.

There was no difference in the attitude towards play in parents of both groups. Most parents also realized the significance of play for their children with other children, and did efforts to encourage them to get engaged in play situations. Even though visually impaired children were less creative and less initiating play with others, a positive attitude was shown by their parents to compensate for this lack, 
getting involved in more play activities by themselves. This comparison showed more identities, than differences in the parents' understanding, attitudes, involvement and encouragement for play in children with two sensory disabilities - hearing impairment and visual impairment.

\subsection{References}

Andreeva, A., Celo, P., \& Vian, N. (2017). Play in children with hearing impairments. In: V. StanchevaPopkostadinova \& S. Besio (Eds.), Play development in children with disabilities (pp.94-101), Warsaw, P: De Gruyter Poland.

Barton, E., \& Wolery, M. (2008). Teaching pretend play to children with disabilities: A review of the literature, Topics in Early Childhood Special Education, 28(2), 109-125.

Bianquin, N. (January, 2018). Increasing and Improving the Play Abilities. The Adults as Expert Play Companions. Presentation on the $2^{\text {nd }}$ LUDI Training School, Bergamo, Italy.

Bianquin, N., \& Bulgarelli, D. (2017). Conceptual review of disabilities. In: V. StanchevaPopkostadinova \& S. Besio (Eds.), Play development in children with disabilities (pp. 71-87), Warsaw, P: De Gruyter Poland.

Bianquin, N. (2018). How can I, as an adult, facilitate play? In: P. Encarnação, S. Ray-Kaeser \& N. Bianquin (Eds.), Guidelines for supporting children with disabilities' play. Methodologies, tools, and contexts (pp. 50-58), Warsaw, P: De Gruyter Poland.

Buchanan, M., \& Johnson, T. G. (2009). A second Look at the Play of Young Children with Disabilities. American Journal of Play, Summer, 41-59.

Childress, D. C. (2010). Play Behaviors of Parents and Their Young Children With Disabilities, Topicas in Early Childhood Special Education, Hammil Institute on Disabilities, Available at: https://doi. org/10.1177/0271121410390526

Jacson, S.C., Robey, L., Warjus, M., \& Chadwick, E. (1991). Play for all children: The toy library solution. Childhood Education,18(1),27-31, doi:10.1080/00094056.1991.10520841

Garvey, C. (1990). Play. Cambridge, MA: Harvard University Press.

Mistrett, S., Lane, Sh., \& Goetz, A. (2000). Professionals Guide to: Assisting Families in Creating Play Environments for Children with Disabilities. http://letsplay.buffalo.edu/products/Play Manual. pdf

Trosheva-Asenova, A. (2018). Play development and symbolic play in children with hearing impairment Today's Children Tomorrow's Parents, 47/48, 131-143.

Tzvetkova-Arsova, M., \&Zappaterra, T. (2017). Play in children with visual impairments. In: V. Stancheva-Popkostadinova \& S. Besio (Eds.), Play development in children with disabilities (pp. 102-110). Warsaw, P: De Gruyter Poland.

Vigotskij, L. S. (1978). Mind in Society: Development of Higher Psychological Process. Cambridge, MA: Harvard University Press.

Wood, D., Bruner, J., \& Ross, G. (1976). The role of tutoring in problem solving. Journal of Child Psychology and Psychiatry, 17, 89-100. 


\section{Appendix 1}

\section{Questionnaire for parents of children with visual/hearing impairments}

\section{Dear parents,}

This questionnaire is fully anonymous. Its goal is to compare play in children with visual and hearing impairments in order to get information about its peculiarities. The results from the questionnaire will be useful for specialists working with your child, but also for other parents.

Please write your answers in the free spaces if the question is open-ended. Please select (circle or underline) an answer if there are multiple choices or yes/no answers.

- $\quad$ Age of your child:

- Your child is a boy - Your child is a girl

- $\quad$ Degree of visual/hearing impairment:

- Is the mother or father a person with impaired vision/hearing?

- $\quad$ Additional disabilities of your child, except of the visual/hearing one.

- Is your child attending a kindergarten / nursery:

1) Does your child play independently?

If yes, please describe briefly how and on what games:

2) Does your child start playing by himself/herself?

- Yes • No

3) What is his/her favourite toy?

4) How many toys does your child have at home?

- 2-3 $\quad$ between 5-10 • between 10-20 • between 20-30 over 30

5) How many games does your child have at home? (for example, board games - cards, dominoes, etc.)

- 2-3 - between 5-10 - between 10-20 • between 20-30 over 30

6) Does your child play with his/her toys using them according to their purpose (in an appropriate way)?

- Yes - No

7) How does your child prefer to play:

- most often alone •always with an

adult

- always together - something else:

with other

children 


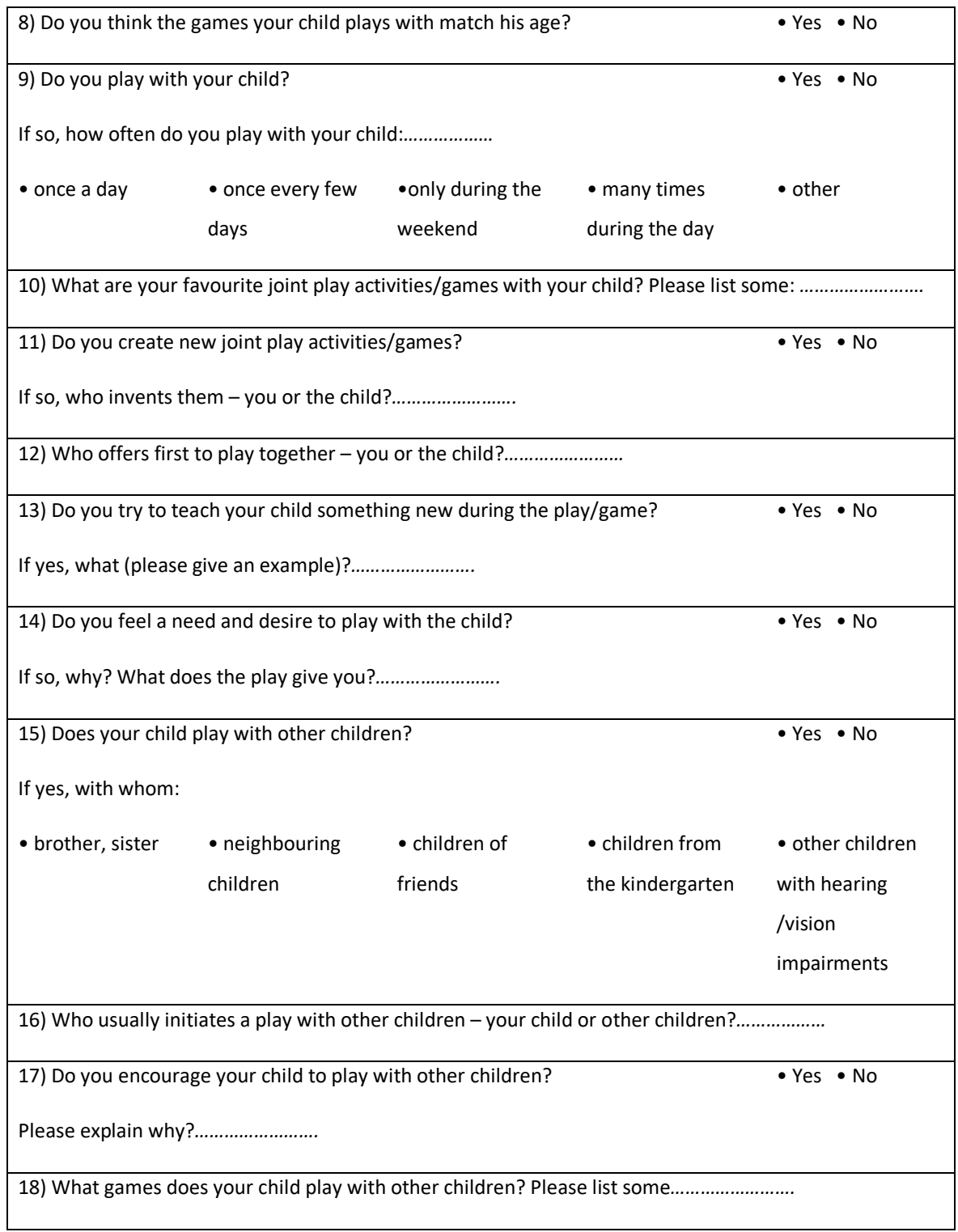




\title{
8 Inclusive Play and Disability in Early Childhood Education and Care Services. The Experiences of Italian Practitioners
}

\begin{abstract}
Italian mainstream Early Childhood Education and Care (ECEC) services are characterized by their inclusive approach. The current study aimed at collecting the educators' experiences in promoting inclusion in everyday activities with children with disabilities in nursery schools, using a questionnaire specifically designed for this purpose. The main goal was describing the strategies practitioners used to foster inclusive play and the difficulties they faced in preventing or overthrowing the barriers to participation in play. A deductive content analysis was performed on the answers to two open questions, to investigate the themes of types of play, adult's role in supporting play and didactic strategies to promote inclusive play. The role of toys as barriers or facilitators to play and the perceived need for training about the theme of play for children with disabilities were also reported.
\end{abstract}

\subsection{Italian inclusive child care services: education for all}

In Italy, since their birth, children with disabilities can enter mainstream Early Childhood Education and Care (ECEC) services. The nursery school (called nido d'infanzia) for children from 0 to 3 years of age was established in 1971 by the Law n. 1044: it was a municipal facility, supported also by national funding. The law explicitly stated that the nursery school was meant to take care of the children, to support the families and to facilitate the labour market entry of mothers; moreover, it aimed at involving qualified professionals, and at fostering children's harmonious development.

In 1992, the Law n. 104 aimed at regulating the school integration of persons with disabilities; in this document, the nursery school was part of the educational system in which persons with disabilities could be included since their birth. Thus, the nursery school was mainly conceived as a crucial means to guarantee every child's full cognitive, affective, social and relational development. Compared to the situations in other European countries, the Italian legislation about inclusive education for very young children with disabilities was ground-breaking and anticipated similar trends that emerged later in other countries..$^{31}$

31 Interesting sources of information about legislation and policy regarding young children with disabilities in Europe are retrievable on the website of the European Agency for Special Needs and 
Recently, in 2015, the Law n. 107 reformed the structure of educational services and established an integrated system for children from 0 to 6 years, that aimed to guarantee equal opportunities of education, relationships and care for all children and to conciliate parents' life and work duties. Nevertheless, currently, the facilities in Italy are still split into services for children up to 3 years of age and children between 3 and 6 years. Three types of service are available for children up to 3 years (Bulgarelli, 2018a; Fortunati \& Parente, 2018).

- Nursery school (nido d'infanzia): in 2016, 10,559 nursery schools were present in Italy. The $61 \%$ were private and the $39 \%$ were public. About the $11 \%$ of the public services were given in entrusted management, i.e. the public organization gave a budget to a private company (mainly in the third sector) to manage the facility.

- Integrative service (Servizio integrativo) was established in 1997, by the Law n. $285 / 1997$. This kind of facility was meant to better reach a vast majority of children, thanks to differentiated services as play spaces, centres for children and families and home-based small facilities, where a trained adult takes care of 3-5 children. In 2016, the integrative services were $2,551,81.3 \%$ private and $18.7 \%$ public.

- Spring class (Sezione primavera) was established by the Law n. 296/2006. It was a special class for children between 24 and 36 months within the kindergarten that usually are attended by children between 3 and 6 years.

The receptiveness of the facilities for children up to 3 years strongly varied across the country (Fortunati \& Parente, 2018): the North of Italy is divided into 9 regions and the enrolment rate varied between $43.5 \%$ and $24.3 \%$; the Centre of Italy is composed by 4 regions, with rates varying between $44.4 \%$ to $28.1 \%$; the South is made of 6 regions and 2 islands and the enrolment rate varied between $25.0 \%$ to $6.8 \%$. In Europe, the average rate of school enrolment at age two is 40\% (OECD, 2017): three Italian regions are close to this percentage, while many of them are far below. In 2015, the Law $n$. 107 established that, compatibly with the economical and structural resources of the country, the integrated system should aim at involving the totality of children in ECEC; at the moment, the Legislative Decree n. 65/2017 aimed at enrolling at least the $33 \%$ of children under 3 years of age, and to set ECEC services on the $75 \%$ of the Italian cities.

In line with international standards of quality monitoring (OECD, 2015), each ECEC service needs a national accreditation to become operative, that certifies the quality according to a series of criteria, also addressing some indicators of inclusion, as the users' satisfaction, the families' participation in the educational project of the

Inclusive Education (https://www.european-agency.org/country-information) and on the website of the Disability Rights Education and Defense Fund (https://dredf.org/legal-advocacy/internationaldisability-rights/international-laws/). 
service and the availability to host children with disabilities (Centro Nazionale di Documentazione e Analisi per l'Infanzia e l'Adolescenza, 2013).

Summarizing, as regulated by law and accordingly to the UN Convention on the Rights of the Child, Italian educational system fosters inclusion. Educators are trained to assume a child-centred approach, this means that they accompany the children along their development and learning, respecting their individuality. On the other side, participation in activities and relationships is a key point in ECEC services and, as children with disabilities are included in mainstream facilities, the staff is challenged to find customized ways to meet each child's special needs.

\subsection{Organizational aspects of ECEC services in Italy}

In terms of organization of the space, the nursery schools are made of several rooms and area that are set up according to their function: entrance with one cupboard per child, classrooms (children play and do activities there, and also have lunch if a refectory is not included in the service), toilets for children and toilets for adults, rooms for the nap (that can also be used as laboratory for specific activities), kitchen and storage area, spaces for staff, outdoor spaces with green areas, administrative office.

Each group of children has a personal class; both the group of children and the room they mainly live in are called sezione (i.e. section). Children in the first year belong to a class where the ratio between educators and children is $1 / 6$. For children between 12 and 36 months, two types of organization are possible: the class can be horizontal (children in the second year and in the third year of life belong to two different groups), or vertical (the class is attended by children between 13 and 36 months). Usually, one service encompasses at least three classes. The ratio between educators and children varies from 1/8 for children from 13 to 24 months and 1/10 for children from 25 to 36 months (ISPESL, 2005). Thus, work groups in the nursery school are made by 2-3 educators, up to 4-5 colleagues in the same class, depending on the number of children.

By law, the coordinator and the staff have to prepare a public document to describe the educational objectives and the practices and procedures to achieve them. At the beginning of the year, the staff plans the activities, and realizes them throughout the year. The educational planning is renewed every year, and each service usually choses a common theme to link all the activities. Surveillance, play, education and caring are all tasks of the educators.

The ordinary opening hours in the services is 7.30-17.30. The organization of the day is quite similar across the services and quite stable throughout the educational year (September-July). The organization of the service is based on the alternation between daily routines (eating, cleaning, sleeping) and activities (play and creative ateliers): the underlying educational idea is that children develop their motor, 
communicative, social, emotional and cognitive competences by getting involved in relationships with adults and peers and by experiencing the environment (materials, spaces, etc.). As an example, during lunch, children practice fine motor abilities (using the cutlery or helping with setting the table). Educators and children sit at the table together; chatting about food allows to practice language and, also, to discuss about personal preference ("what I like and what I don't like"), physical properties of food (colour, consistency, taste), culture ("the food we eat at home is the same we eat in the service?"), etc. Then, eating together solves the task of learning social rules as 'staying together at the table'.

The typical day is organized in several phases:

- 7.30-9.30: children arrive, educators shortly talk with the parents; the room for welcoming is usually organized in structured corners (books, Lego bricks, little house with dolls, etc.) where children freely get involved in different activities.

- 9.30-10.00: song to welcome the group and snack with fruits and/or bread.

- 10.00-11.00: structured activities directly managed by the educators (manipulation, drawings, taking care of the vegetable garden, playing with water, sand, etc.).

- 11.00-11.30: routine in the toilet.

- 11.30-12.30: lunch.

- 13.00-15.00: nap; children who get up first, are then involved in free activities in the class.

- 15.00-15.30: routine in the toilet.

- 15.30-16.00: afternoon snack (merenda).

- 16.00-17.30: children leave; educators shortly talk with the parents; children leaving later can be involved in structured activities or can freely play and interact with others in the class.

The daily organization is stable and changes when children and educators go on class trips. In the frame of this quite strict agenda of the day, the educators pursue an inclusive educational approach. On one side, all children should have the possibility to participate in the routines and activities together with the peers. On the other side, the educators dedicate some time to each specific child: the time devoted to the routines (lunch, cleaning and nap) could be the occasion for individualized interactions while, during the group activities and the free play time, the educators could specifically focus on a child to observe his/her participation and inclusion in the group of peers.

\subsubsection{The role of play in Italian ECEC services}

Play is a range of voluntary activities that are internally motivated and are associated with enjoyment and pleasure (Garvey, 1990). Currently, several classifications of 
play activities are available; they are mainly derived from Piaget (1962) and Parten's proposals (1932) yet the literature is cofusing: in some cases, different terminologies refer to similar types of play while, in others, same labels are attributed to different concepts of play (Bulgarelli \& Bianquin, 2017). To create a common language, the COST Action "LUDI-Play for Children with Disabilities"32 proposed a classification of types of play, with respect to the cognitive and social dimension (Bulgarelli \& Bianquin, 2017). The cognitive dimension, derived from Piaget and Smilansky (1990), includes:

- Practice play: it refers to body actions or experimentation and to visual and tactile experimentation of objects.

- Symbolic play: it happens when new signification are given to objects, persons, actions or events: children symbolically use objects as they were something else, they produce pretend play and make-believe activities.

- Constructive play: it consists in gathering, combining, arranging and fitting more elements to form a whole, and achieve a specific goal.

- Rule play: it consists in games with a specific code and rules accepted and followed by the players.

The social dimension, derived from Parten includes:

- Solitary play: The child plays alone and independently even if surrounded by other children

- Parallel play: The children play independently at the same activity, at the same time, and in the same place.

- Associative play: The child is still focused on a separate activity but there is a considerable amount of sharing, lending, taking turns, and attending to the activities of the peers.

- Cooperative play: Children can organize their play and/or activity cooperatively with a common goal and are able differentiate and assign roles.

Play, in both the cognitive and social dimensions, has a crucial role in Italian nursery schools (Bondioli, 1987; Borghi, 2015), because it is conceived as the main drive for motor, cognitive, affective and social development (Piaget, 1962; Vygotskij, 1976). Part of the structured activities are focused on play proposals made by the practitioners, who suggest play scenarios and help the children getting involved in the situation and interacting with each other. Besides, during the day, children can spontaneously play by themselves or with peers.

32 The Action TD1309 "LUDI-Play for Children with Disabilities" was a European network of researchers and practitioners involved in the study of play of children with disabilities from multidisciplinary point of views. The network was financed by the COST Association between 2014 and 2018. For more detailed information, please check the introduction to this book and the websites http://www.cost.eu/COST_Actions/tdp/TD1309 and http://ludi-network.eu. 
As discussed elsewhere (Bianquin, 2018), the adult can support play assuming three different roles: observer of play, in order to better know the child's behaviour, skills and preferences; activator of play, in order to organize space, materials and conditions to let play exist and evolve; partner in play activities. All these roles refer to the scaffolding process, where a temporary support is provided to learners to help them completing a challenging task; effective scaffolding is tuned to the learners' needs, is adjusted in response to their achievements, and gradually fades (Wood, Bruner, \& Ross, 1976). Thus, to better support play in spontaneous and structured activities, educators are invited to observe the children to better know them and to better plan their play proposals. Professionals are invited to assume the role of activators, by specifically setting up the play spaces in each class (the little house, the costume corner, the construction corner, etc.) and in the outdoors. Moreover, toys and play materials need to be specifically selected: different toys better suite different types of play; educators are also invited to regularly change the toys and materials in the class, to keep the children interested in play and to renew the possible activities (Bondioli, 1987; Bulgarelli, 2018a; Perino, 2014). Last but not least, educators often become play partners both during the structured activities and the spontaneous play moments, and provide explicit and implicit feedbacks also based on their evaluation of children's play ability and preferences.

\subsubsection{Ongoing training for the ECEC service staff}

The training of the nursery school staff is mandatory and should be ongoing (Legislative Decree n. 65/2017). Regional laws regulate the organization of the training and the service coordinator is responsible for the contents that are proposed to the staff (Bulgarelli, 2018a). Usually, coordinators vary the training programme over the years, to cover the needs of the service and/or the staff's perceived needs.

The ongoing training for educators usually focuses on helping them to build on and become aware of the specificity of their professional skills: deep knowledge about child development, evidence-based practice to interact with children, expertise in organizational issues, expertise in interacting with the children and the parents, etc. The most effective training paths very often allow to develop a reflective approach towards the educational practice: educators become aware of the motivations, beliefs and theoretical approach underlying and guiding their intervention (Bobbio \& Traverso, 2016; Schön, 1983). 


\subsection{Play and disabilities in Italian early child care services: an explorative study}

The current study aimed at collecting the educators' work experiences with children with disabilities in nursery schools, using a questionnaire specifically designed for this purpose, given that no such tool was already available in Italy. The main goal was describing the strategies educators used to foster inclusion and the difficulties they faced in preventing or overthrowing the barriers to participation and inclusion.

As previously discussed, play is one of the most important activity in the ECEC services and it is conceived as the main drive for child development. For these reasons, play has to be at the centre of an inclusive educational approach, which is fully in line with the LUDI perspective of the need to support play for the sake of play in children with disabilities (Besio, 2017). Thus, part of the data collected in the study refer to play: they are the focus of the analyses reported in the current paper.

\subsubsection{Participants}

Ninety-three female workers (91 educators and 2 coordinators ${ }^{33}$ ) from 10 services participated in the study (see Table 1). Nine facilities were placed in a big town (more than 500.000 inhabitants) and one service in a small town (less of 30.000 inhabitants) in the North of Italy.

In terms of education, $46.2 \%$ of educators held a high-school diploma $(\mathrm{N}=43)$, $48.4 \%$ were graduates $(\mathrm{N}=45)$ and $5.4 \%$ held a post lauream degree (specialization or Ph.D., $\mathrm{N}=5$ ). One of the two coordinators was 41, was graduated and has been working since 5 years; the other coordinator was 56, held a high-school degree and her length of service was 32 years.

The workers filled out 100 questionnaires: five educators completed two questionnaires each, because they reported their experiences with two different children with disability. Seventy-four out of 100 questionnaires were referred to 55

33 In the Italian system, every service includes a coordinator, who is responsible for the administrative and educational aspects of the service; s/he supports the staff in taking decisions about the educational and organizational aspects of the activities. The team of educators plans and realizes the organization of spaces and materials, and the everyday activities (routines linked to food, diapers and sleep, educational ateliers, day trips in the neighbourhood or special places, etc.). The educators take care of the children: greet them in the morning, play with them, clean them and change diapers, put them in bed for the nap, comfort them when crying, etc. They take care of the group of peers, facilitating the relationships and interactions among the children. They also take care of the relationship and communication with the families, thanks to everyday short talks and programmed meetings. Auxiliary personnel are in charge of cleaning the spaces and supporting the educators during the routines, when needed. 
Table 1: Characteristics of the service and participants.

\begin{tabular}{|c|c|c|c|c|c|c|}
\hline \multirow{3}{*}{$\begin{array}{l}\text { Service } \\
\begin{array}{l}\text { On-site service in } \\
\text { company }\end{array}\end{array}$} & \multirow{3}{*}{$\begin{array}{l}\text { Town } \\
\text { Big Town }\end{array}$} & \multicolumn{5}{|c|}{ Workers filling the questionnaire } \\
\hline & & \multirow{2}{*}{$\begin{array}{l}\mathbf{N} \\
12\end{array}$} & \multicolumn{2}{|c|}{$\begin{array}{l}\text { Mean age in years } \\
\text { (SD) }\end{array}$} & \multicolumn{2}{|c|}{$\begin{array}{l}\text { Mean length of service } \\
\text { in years (SD) }\end{array}$} \\
\hline & & & 33,33 & $(5,82)$ & 10,68 & $(6,25)$ \\
\hline Municipal & Small Town & 16 & 41,13 & $(10,81)$ & 14,19 & $(10,13)$ \\
\hline $\begin{array}{l}\text { Entrusted } \\
\text { management_1 }\end{array}$ & Big Town & 19 & 37,42 & $(9,20)$ & 11,45 & $(6,78)$ \\
\hline $\begin{array}{l}\text { Entrusted } \\
\text { management_2 }\end{array}$ & Big Town & 10 & 33,40 & $(7,29)$ & 8,25 & $(4,71)$ \\
\hline $\begin{array}{l}\text { Entrusted } \\
\text { management_3 }\end{array}$ & Big Town & 3 & 36,33 & $(1,53)$ & 10,67 & $(1,15)$ \\
\hline $\begin{array}{l}\text { Entrusted } \\
\text { management_4 }\end{array}$ & Big Town & 13 & 37,69 & $(8,51)$ & 11,00 & $(6,48)$ \\
\hline $\begin{array}{l}\text { Entrusted } \\
\text { management_5 }\end{array}$ & Big Town & 8 & 34,38 & $(7,41)$ & 8,69 & $(5,09)$ \\
\hline $\begin{array}{l}\text { Entrusted } \\
\text { management_6 }\end{array}$ & Big Town & 8 & 35,88 & $(4,67)$ & 10,50 & $(4,11)$ \\
\hline Private_1 & Big Town & 1 & 26,00 & -- & 6,00 & -- \\
\hline Private_2 & Big Town & 3 & 27,33 & $(2,52)$ & 4,33 & $(2,08)$ \\
\hline Total & & 93 & 36,26 & $(8,43)$ & 10,78 & $(6,80)$ \\
\hline
\end{tabular}

children with disabilities. In fact, 15 children were the focus of at least two different questionnaires: two or more educators answered reporting their experience with the same child. Twenty-six questionnaires were completed exclusively in the sections about the personal data and the training perceived needs, because the educators had never been working with children with disabilities. These 26 educators worked in the big town involved in the study, and their average length of service was 8.3 years (SD = 5.9; $\min =1, \max =19$ ).

\subsubsection{The Questionnaire "The Child with Disability in ECEC Service"}

The questionnaire "The Child with Disability in ECEC Service” was designed in 2017, to collect educators' work experiences about inclusion (Bulgarelli, 2018a; 2019). The 
fillers were asked to report their experiences about a specific child with disability they were working with in the current year or in the past.

The tool consisted of six open questions and 24 multiple choice questions, organized into seven sections.

a) Respondent's personal data.

b) Characteristics of the service attended by the child.

c) Characteristics of the child and his/her disability.

d) Information about the activities attended by the child in the service.

e) Barriers and facilitators to the child's inclusion.

f) Relationship with the child's parents.

g) Respondent's perceived needs with respect to training on the theme of disabilities.

Six questions directly refer to play and their responses are analysed and discussed in the current paper:

1. Think about the moments of spontaneous play in the service: did you and the colleagues of yours use specific strategies for the child's play? Which ones? (open question).

2. Think about the moments of structured activities in the service: did you and the colleagues of yours use specific strategies for the child's activity? Which ones? (open question).

3. Which kind of difficulties you had to face with the child with disabilities? (multiple choice question)

a. Toys and materials for play were not adequate for the child's needs.

4. Was the type of toys a barrier or a facilitator?

5. Have you ever participated in a specific training on children with disabilities? If yes, on which topic?

6. If you could participate in a training focused on the theme of children with disabilities, which topic would you like to be addressed? (multiple choice question).

a. Strategies to adapt materials and toys to the child's needs.

Data were collected between June and July 2017.

\subsubsection{Data analyses}

A deductive content analysis was performed on the answers to the two open questions (Elo \& Kyngäs, 2007), which consists in subjectively interpreting the content of texts through the coding of the underlying themes (Hsieh \& Shannon, 2005). The answers were divided into units of meaning, later called "sentences", that were categorised using the system reported in Table 2: cognitive types of play, presence of social play, role of the adult in supporting play (observer, activator, partner) and didactic 
strategies. Two independent observers ${ }^{34}$ coded the sentences. The percentage of agreement was $68 \%$. The disagreements were discussed and solved to reach a full consensus.

\subsection{Results and discussion}

\subsubsection{Strategies to support play in structured and spontaneous situations}

Sixty-nine persons answered to Question 1: “Think about the moments of spontaneous play in the service: did you and the colleagues of yours use specific strategies for the child's play? Which ones? (open question)." The "moments of spontaneous play" referred to that part of the day when children are free to organize their games and play activities. The 69 answers were divided into 96 sentences, that were analysed to reveal the presence of common contents; more than one topic could be present in each sentence (see Table 2).

Seventy-two persons answered to Question 2: “Think about the moments of structured activities in the service: did you and the colleagues of yours use specific strategies for the child's activity? Which ones? (open question)." Play is one of the most usual structured activity in the services. The 72 answers were divided into 134 sentences, that were analysed to reveal the presence of common contents; more than one topic could be present in each sentence (see Table 2).

The content analysis showed that cognitive types of play were mentioned in 60 sentences (26.1\%) and practice play was the most common type the respondents referred to. As an example, the sentences P46_3 shows items of three types of play (practice, symbolic, constructive):

Sentence P46_3: "The child started [...] having an interest in [...] Lego bricks, wooden bricks, cubes, eggs in their box, mosaic sticking game, drawings, books, kitchen boxes, shoes in the costume corner, modelling clay, play corn."

Symbolic and constructive play were poorly mentioned, respectively 3 and 7 times each. From a developmental point of view, practice play is common in the first and second years of life; symbolic play structures in the second year and first types of constructive play emerges in the third year (for a brief review, see Bulgarelli, 2018b). Thus, this result is expected, also taking into account that children with disabilities may show a delayed development. Nevertheless, it is worth noticing that the respondents were more likely to write about toys and games, and rarely described

34 The author would like to thank dr. Nicole Bianquin for her contribution to the content analysis. 
Table 2: Main topics addressed in the answers to Question 1: "During spontaneous play, did you use specific strategies for the child's play? Which ones?" and Question 2: "During structured activities, did you use specific strategies for the child's activity? Which ones?”.

\begin{tabular}{|c|c|c|c|c|}
\hline Categories & Subcategories & $\begin{array}{l}\text { Question } 1 \\
\text { Spontaneous play } \\
\text { (96 sentences) }\end{array}$ & $\begin{array}{l}\text { Question } 2 \\
\text { Structured activities } \\
\text { (134 sentences) }\end{array}$ & Total \\
\hline \multirow{3}{*}{$\begin{array}{l}\text { Cognitive types } \\
\text { of play }\end{array}$} & Practice play & 21 & 29 & 50 \\
\hline & Symbolic play & 1 & 2 & 3 \\
\hline & Constructive play & 4 & 3 & 7 \\
\hline Social play & Child plays with peers & 7 & 9 & 16 \\
\hline $\begin{array}{l}\text { Role of play } \\
\text { observer }\end{array}$ & Adult observes play & 2 & 5 & 7 \\
\hline \multirow[t]{8}{*}{$\begin{array}{l}\text { Role of play } \\
\text { activator }\end{array}$} & $\begin{array}{l}\text { Adult follows child's } \\
\text { preferences }\end{array}$ & 11 & 15 & 26 \\
\hline & Adult as physical support & 0 & 1 & 1 \\
\hline & Adult supports attention & 16 & 13 & 29 \\
\hline & Adult enlarges activity & 8 & 2 & 10 \\
\hline & Adult explains & 5 & 5 & 10 \\
\hline & Adult selects environment & 13 & 11 & 24 \\
\hline & Adult selects toys & 6 & 12 & 18 \\
\hline & Adult facilitates interaction & 5 & 0 & 5 \\
\hline $\begin{array}{l}\text { Role of play } \\
\text { partner }\end{array}$ & Adult as play partner & 3 & 0 & 3 \\
\hline \multirow{4}{*}{$\begin{array}{l}\text { Didactic } \\
\text { strategies }\end{array}$} & Ratio 1 adult / 1 child & 5 & 13 & 18 \\
\hline & Small group & 8 & 32 & 40 \\
\hline & Rehabilitation activities & 1 & 6 & 7 \\
\hline & No strategies & 11 & 4 & 15 \\
\hline
\end{tabular}

which kind of play children were used to make with those materials: thus, it is not possible to know for sure if Lego bricks were used to just stick pieces together (practice play), to purposely build an object (constructive play), or to use the built object in a pretend play scenario (symbolic play). For these reasons, the coders decided that reference to Lego or wooden bricks was coded as "constructive play" and the reference to costume or theatre figures was coded as symbolic play. 
It was not possible to precisely determine which kind of social play the children with disabilities were usually involved in, thus a general category was used (social play-the child plays with peers) that emerged in 16 sentences (7.0\%):

Sentence A02_1: "The child was really well integrated, he loved staying with the others and making things together with the peers."

One-hundred and thirty-three sentences reported about the adult assuming the role of play observer $(\mathrm{N}=7,3.0 \%)$, play activator $(\mathrm{N}=123,53.5 \%)$ or play partner $(\mathrm{N}=3,1.3 \%)$. Observing children's play is a crucial step in the process of supporting play: in fact, observation allows a deeper knowledge about the child's activities and preferences; it allows to act as play activator by addressing the child's needs; and, last but not least, it is the baseline to start from to enlarge the child's play and make it more complex and rich. Yet, the role of play observer was only mentioned in 7 sentences and the practitioners could lack awareness about its importance:

Sentence A71_2: "In various observations, the team noticed that the child prefers activities such as: sand, pouring game at the table, painting."

The majority of sentences reported about the adult assuming the role of play activator $(\mathrm{N}=123 ; 53.5 \%)$. In this role, the practitioners supported the child's attention and explained the activity:

Sentence A19_0: “The practitioner placed side by side to the child, showing him how to do, and trying to sustain/capture his attention."

As a play activator, the adult selected the environment and the types of toys:

Sentence A54_1: "We set the environment and the space to let the child explore."

Sentence P34_2: "We gave him toys to stimulate him at a cognitive level, such as bricks, books, little cars."

As a play activator, the adult also enlarged the activity:

Sentence P03_0: "Given that, during free play, he tended to search only for strings and small chains, and he tended to play with them for hours, [...] we guided him to choose other toys.”

As a play activator, the adult facilitated the communication and interaction among peers:

Sentence A99_0: "We encourage her to share her things with the others. We teach her [...] to touch or call the peers to catch their attention." 
The physical support was almost never mentioned $(\mathrm{N}=1)$, but such strategy is crucial for children with physical and motor disabilities. The type of strategies used by the adult partly varied according to the situation: during spontaneous play, the educators were more likely to enlarge the activity, facilitate peer interaction and become a play partner; during the structured activities, the practitioners were more likely to observe play and select toys and materials.

The role of play partner was rarely mentioned as well (3 sentences); this was also the case of the role of peers, as social play was marginally reported. Three reasons for this result could be hypothesized: children with disabilities actually played mainly alone; the respondents took for granted that children usually played with somebody else (adult or peer); play was intended as being mainly a cognitive skill. More research is needed to solve this issue.

With respect to the didactic strategies, the respondents' writings were coded according to four contents (Table 2). Selecting a small group of peers $(\mathrm{N}=40,17.4 \%)$ and being side by side to the child with disability (ratio 1 adult per 1 child; $\mathrm{N}=$ $18,7.8 \%$ ) were the most reported strategies to allow a higher participation in play activities. Small groups of children were selected to facilitate the interaction, and to contain the noise:

Sentence P44_0: "We always tried to split into small groups, to keep the girl within a group of younger peers, who were calmer and less noisy."

In 7 sentences, the educators reported that the child was involved in activities that were proposed by the therapists.

Sentence A33_2: "Sometimes, [we proposed] individualized and specialized activities as suggested by the health service that took the child in charge."

It is worth noticing that this mainly happened during the time devoted to structured activities; it seems that the time for spontaneous and free play was preserved in the services, and this condition is crucial to let play for the sake of play happen. Nevertheless, during the time devoted to structured activities, usually a special needs educator is present in the service and s/he can individually help the child. In one sentence, the respondent reported that the whole group of peers was involved in the special activities for the child with disability, showing a nice example of participation. In another sentence, the respondent wrote that the child was individually involved in specific activities in a separate room. In inclusive contexts, educators have to find an adequate balance between the time the child with disability spends with the peers and the time s/he spends alone with adults. In fact, those moments "outside the classroom" can be useful to support the development of skills that the child needs to better engage with peers. Such debate, in Italy, usually concerns primary and secondary school context (Cottini \& Vivanti, 2013) but it can also be applied to ECEC context. 
The respondents usually reported to use no strategies to promote inclusion ( $\mathrm{N}=$ 15). This answer was more frequent with respect to the spontaneous play time. On one side, some educators stated that they used no strategies because they observed that the child with disability was nicely participating in the activities with the peers. On the other side, often this aspect was not specified and the lack of strategies to facilitate participation and inclusion could be alarming. It is possible that practitioners did use strategies they were not aware of; or that they did not use strategies at all. To address such issue, training specifically devoted to reflecting on the way practitioners are used to foster inclusion and participation of children with disabilities could be helpful.

\subsubsection{Toys: barriers or facilitators?}

Multiple choice question 3 was: "Which kind of difficulties you had to face with the child with disabilities?”. Option 2 (out of 7) was: “Toys and materials for play were not adequate for the child's needs."

Seventy-four persons filled this question and only 7 practitioners chose the option 2. They belonged to four different nursery schools and filled the questionnaire referring to six different children: three of them had an Autistic Spectrum Disorder (ASD), two a motor disability and one an intellectual disability.

Both those types of disability pose challenges to the choice of the toy. Objects suitable for children with ASD should be interesting but should avoid triggering stereotyped and repetitive behaviours; moreover, children who are highly sensitive to noise or lights, could face personal difficulties with specific toys that typicallydeveloping children find nice and funny. Children with motor disability usually need accessible toys, adapted to the child's muscle tension, abilities in grasping, pinching, holding, or coordination ability. Thus, the types of toys that are already available in the services could not meet the child's needs, and the practitioners should be ready to buy new objects or to adapt them, if possible.

Question 4: "Was the available type of toys a barrier or a facilitator to inclusion?". Seventy-four persons filled this question: four people left the box empty; 41 declared that the toys were a facilitator, nine that they were mainly a barrier, and 19 crossed the option "neither a barrier nor a facilitator" (see Table 3).

Thus, the practitioners considered the toys and play materials useful to support the children's participation in everyday activities in the service. Obviously, a toy could not be defined as a barrier or as a facilitator in the absolute sense: it depends on the features of the object, of the environment and on the characteristics of the playerstheir preferences, playfulness and cognitive, motor and social skills. When choosing the toys to better support the children's play and, consequently, their participation and inclusion, the practitioners should also take into consideration some advices specifically linked to each type of disability, as reported in Perino \& Besio (2017). 
Table 3: Answers to question 4 "Was the available type of toys a barrier or a facilitator to inclusion?" per type of child's impairment.

\begin{tabular}{lllll}
\hline Type of disability35 & \multicolumn{2}{l}{ Toy evaluated as } & N of answers \\
\cline { 2 - 4 } & Facilitator & Neither/nor & Barrier & \\
\hline Visual impairment & 3 & 1 & 0 & 4 \\
Hearing impairment & 2 & 2 & 0 & 4 \\
Physical impairment & 5 & 4 & 1 & 10 \\
Intellectual disability & 13 & 2 & 2 & 17 \\
Autism Spectrum Disorder & 13 & 9 & 5 & 27 \\
Other disabilities & 5 & 1 & 1 & 7 \\
& 41 & 19 & 9 & 69 \\
\hline
\end{tabular}

\subsubsection{Training on disabilities and toys}

One-hundred practitioners filled the questionnaire section dedicated to the training activities. Answering to Question 5, 33 declared to have been involved in trainings about disabilities in the past and the specific topics of those courses are reported in Table 4. Forty-three practitioners out of the 74 who stated to have been working with children with disabilities, had never attended a specific training. On one side, the professional skills of the educators should be sufficient to meet the children with disabilities' special needs. In fact, a child centred approach, by definition, is focused on adapting contexts, materials, activities and relational approach to each person's necessities. On the other side, some conditions of severe disability pose great challenges to the educational staff. Thus, it is likely that those who had attended specific training about the theme of disability needed to further build skills to better support the child's inclusion in the service.

The multiple choice Question 6 investigated the perceived training needs: "If you could participate in a training focused on the theme of children with disabilities, which topic would you like to be addressed? Ninety-nine answered to this question and 68 chose the option 5 (out of 10): "Strategies to adapt materials and toys to the child's needs." Thus, the practitioners felt they need more support and time to reflect on the use of objects to build on children's play skills.

35 The LUDI classification of type of disabilities is used here (Bianquin \& Bulgarelli, 2017). 
Table 4: Topics of the training about the theme of disability attended by the practitioners in the past.

\begin{tabular}{|c|c|c|c|}
\hline $\begin{array}{l}\text { Topic of the training about the theme of } \\
\text { disability }\end{array}$ & $\mathbf{N}$ & & \\
\hline $\begin{array}{l}\text { General presentation about atypical } \\
\text { development }\end{array}$ & 13 & & \\
\hline Characteristics of some disabilities & 20 & Autism Spectrum Disorder & 14 \\
\hline $\begin{array}{l}\text { How to adapt environment/objects to } \\
\text { children's special needs }\end{array}$ & 13 & Intellectual disability & 5 \\
\hline $\begin{array}{l}\text { How to adapt routines to children's } \\
\text { special needs }\end{array}$ & 12 & Visual impairment & 4 \\
\hline $\begin{array}{l}\text { How to adapt interaction to children's } \\
\text { special needs }\end{array}$ & 9 & Physical impairment & 2 \\
\hline Relationship with children's parents & 10 & Hearing impairment & 2 \\
\hline $\begin{array}{l}\text { Presentation of institutions taking } \\
\text { care of children with disabilities }\end{array}$ & 8 & & \\
\hline $\begin{array}{l}\text { Supervision and support about } \\
\text { specific cases }\end{array}$ & 10 & & \\
\hline Special education & 2 & & \\
\hline
\end{tabular}

NB: the respondents could choose more than one option

\subsection{Conclusion}

The current study focused on an explorative research about the inclusion of children with disabilities in Italian nursery schools and the practice educators used to foster inclusive play. Strategies to support play were investigated, through a self-report questionnaire administered to the educators and coordinators of the services.

Selecting a small group of peers and being side by side to the child with disability were the most reported strategies to allow a higher participation in play activities. The adult could assume three different roles: play observer, play activator or play partner; most of the answers focused on the role of play activator, who mainly supported the child's attention and explained the activity, selected the environment and the types of toys, enlarged the activity, facilitated the communication and interaction among the peers. Moreover, the educators reported that toys and play materials were useful to support the children's participation in everyday activities. The pattern of answers differed between two conditions: when the respondent referred to the time devoted to spontaneous play and to the time devoted to structured activities. It seems that free play was preserved and this condition is crucial to let children explore play possibilities and express play preferences. 
The results allowed to make some reflections about the practice to foster inclusion, participation and play in nursery schools. Yet, the questionnaire cannot allow to deepen the reasons for some respondents' critical answers, that potentially addressed a lack of self-awareness and reflective approach. Future research is needed to better investigate such critical aspects. The current results also showed that specific training about children with disabilities is needed to better support educators in their inclusive practices.

\subsection{References}

Besio, S. (2017). The need for play for the sake of play. In S. Besio, D. Bulgarelli \& V. StanchevaPopkostadinova (Eds.), Play development in children with disabilities (pp. 9-52). Warsaw, PL: De Gruyter Open.

Bianquin, N. (2018). 5 How can I, as an adult, facilitate play?. In P. Encarnação, S. Ray-Kaeser \& N. Bianquin (Eds.), Guidelines for supporting children with disabilities' play: Methodologies, tools, and contexts (pp. 50-58). Warsaw, PL: De Gruyter Open.

Bianquin, N., \& Bulgarelli, D. (2017). Conceptual review of disabilities. In: S. Besio, D. Bulgarelli, \& V. Stancheva-Popkostadinova (Eds.), Play Development in Children with Disabilities (pp. 71-87). Warsaw, PL: De Gruyter Open.

Bobbio, A. \& Traverso, A. (2016). Contributi per una pedagogia dell'infanzia. Teorie, modelli, ricerche [Contributions for an infancy education. Theories, models, research]. Firenze, I: Edizioni ETS.

Bondioli, A. (1987). La dimensione ludica nel bambino da zero a tre anni e nell'asilo nido [Play dimension in the child from zero to three years and in the nursery school]. In A. Bondioli \& S. Mantovani (Eds.), Manuale Critico dell'Asilo Nido, Milano, I: Franco Angeli.

Borghi, B. Q. (2015). Nido d'infanzia. Buone prassi per promuovere il benessere e la qualità della vita dei bambini [Nursery school. Good practice to promote children's wellbeing and quality of life]. Trento, I: Erickson.

Bulgarelli, D. (2018a). Nido inclusive e bambini con disabilità [Inclusive nursery school and children with disabilities]. Trento, I: Erickson.

Bulgarelli, D. (2018b). Tipologie di gioco: una tassonomia condivisa per lo sviluppo della ricerca [Types of play: a shared taxonomy to develop research]. In: S. Besio \& T. Zappaterra (Eds.), Children's Play. Multifaceted Aspects. Firenze, I: ETS.

Bulgarelli, D. (2019). Il nido d'infanzia come servizio educativo inclusivo. Esperienze dal Piemonte [Inclusive nursery school. Experiences from Piedmont]. L'integrazione scolastica e sociale, 18(3), 286-300.

Bulgarelli, D. \& Bianquin, N. (2017). Conceptual review of play. In S. Besio, D. Bulgarelli \& V. Stancheva-Popkostadinova (Eds.), Play development in children with disabilities (pp. 58-70). Warsaw, PL: De Gruyter Open.

Centro Nazionale di Documentazione e Analisi per l'Infanzia e l'Adolescenza (2013). Verso linee guida per il sistema integrato dei servizi educativi. Un documento di riflessione sulla qualità. [Towards guidelines for an integrative system of childcare services. Reflections on quality]. Retrieved on May 2018: https://www.minori.it/it/verso-linee-guida-per-il-sistema-integratodei-servizi-educativi

Cottini, L. \& Vivanti, G. (2013, Eds.). Autismo. Come e cosa fare con i bambini e ragazzi a scuola [Autism. What to do with children at school]. Firenze, I: Giunti.

Fortunati, A. \& Parente, M. (Eds.) (2018). Monitoraggio del piano di sviluppo dei servizi socioeducativi per la prima infanzia. Rapporto al 31/12/2016 [Monitoring of development plan of 
childcare services for early infancy. Report at December 2016]. Dipartimento delle Politiche per la Famiglia. Retrieved on April 2018: https://www.minori.gov.it/sites/default/files/allegati/ Rapporto_servizi_educativi_al_31_12_16.pdf

Garvey, C. (1990). Play. Cambridge, USA: Harvard University Press.

Hsieh, H. F., \& Shannon, S. E. (2005). Three approaches to qualitative content analysis. Qualitative Health Research, 15(9), 1277-1288.

ISPESL - Istituto Superiore per la Prevenzione e la Sicurezza del Lavoro (2005). Servizi educativi da 0 a 3 anni. Quaderni per la salute e la sicurezza [Childcare services from 0 to 3 years. Booklet on health and security]. Retrieved on April 2018: http://www.salute.gov.it/imgs/C_17_ opuscoliPoster_159_ulterioriallegati_ulterioreallegato_0_alleg.pdf

OECD (2015). Starting Strong IV: Monitoring Quality in Early Childhood Education and Care. Paris (F): OECD Publishing. doi: https://dx.doi.org/10.1787/9789264233515-en

OECD (2017). Education at a glance 2017. OECD indicators. Paris (F): OECD Publishing. doi: http:// dx.doi.org/10.1787/eag-2017-en

Parten, M. B. (1932). Social play among preschool children. Journal of Abnormal and Social Psychology, 27, 243-69.

Perino, O. (2014). Des espaces pour jouer [Spaces for playing]. Toulouse, F: Erés.

Perino, O., \& Besio, S. (2017). Mainstream toys for play. In S. Besio, D. Bulgarelli \& V. StanchevaPopkostadinova (Eds.), Play Development in Children with Disabilities (pp. 181-200). Warsaw, PL: De Gruyter Open.

Piaget, J. (1962). Play, dreams and imitation in childhood. New York, USA: Norton.

Schön, D. A. (1983). The reflexive practitioner. New York, USA: Basic Books.

Smilansky, S. (1990). Sociodramatic play: Its relevance to behavior and achievement in school. In E. Klugman \& S. Smilansky (Eds.), Children's play and learning (pp. 18-42) New York, NY: Teachers College Press.

Vygotskij, L. S. (1976). Play and its role in the mental development of the child. In J. S. Bruner, A. Jolly \& K. Silva (Eds.), Play. Its Role in Development and Evolution, (pp. 537-554). New York, USA: Basic Books.

Wood, D., Bruner, J., \& Ross, G. (1976). The role of tutoring in problem solving. Journal of Child Psychology and Psychiatry and Allied Disciplines, 17, 89-100. 


\section{Contributors}

Dr Carol Barron is an Assistant Professor at Dublin City University, Dublin (IE). Academically, Dr Barron holds a Ph.D in Anthropology, an MSc in Social Anthropology in Child Development and a BSc in Education. Professionally, Dr Barron holds nursing qualifications in General, Children's and Neonatal nursing. She was the Chairperson of Súgradh, a registered Irish charity promoting the child's right to play in Ireland. Dr Barron is an elected member of the board for The Association for the Study of Play (TASP). Dr Barron has over 20 years' experience researching children and young people's play and recreation; her specific play interests include research methodologies with children and young people, inclusive play, folklore of children's games. In the last three years Dr Barron has consulted with nearly 900 children and young people (3 - 18 Years) on their play and recreation experiences and needs to help inform Play and Recreation Policies.

Serenella Besio is psychologist and speech therapist, and full Professor in Special Education at the Università degli Studi di Bergamo (I). Her research interests have been related to the disability field of studies, in particular to the educational and assistive technologies and their role to support the independence of persons with disabilities. She was the Chair of the EU COST Action TD1309 "LUDI-Play for Children with Disabilities".

Nicole Bianquin is a pedagogist. She accomplished her Ph.D studies in "Quality of education: development of knowledge and differences" at the University of Florence (I) in 2012. She is currently Research Fellow in Didactics and Special Education at the Department of Human and Social Sciences of the University of Bergamo (I). Her main research interests concern the inclusive processes within the school system, and in particular, the methods of evaluation and self-evaluation of the school inclusion quality, and play for children with disabilities, with a specific focus on the adults' role and play materials.

Andrea Bonarini accplished his Ph.D in Computer Engineering in 1989. He is full professor at the Politecnico di Milano (Italy) and, since 1990, coordinator of the AI and Robotics Lab (AIRLab). He has participated and leaded several EU, national, and industrial projects. He is among the founders of the Italian Association for Artificial Intelligence (AI^IA) and the Italian Chapter of the IEEE Computational Intelligence Society (chair 2008-2010). His research interests include: Machine Learning (deep Learning, reinforcement learning, mostly for classification and dta interpretation), Fuzzy Systems, Affective Computing, and development of interactive autonomous robots (more than 50), for service, entertainment, and edutainment also for people with disabilities. He has published more than 200 papers on international journals, books, and proceedings of peer reviewed congresses. In the last years, he is focusing 
on assistive robotics and robotic games, where autonomous robots should manage complex interaction situations.

Daniela Bulgarelli, Ph.D., is assistant professor in developmental psychology at the Department of Psychology, Università degli Studi di Torino, Torino (I). She is member of the CHILD research unit at the Collegio Carlo Alberto (I). Her main research interests concern the development of play and communication in typical and atypical populations; the use of observation for practitioners as a means to act on educational contexts; the effect of early childcare on children's cognitive and linguistic development. She took part to several projects; among them: the COST Action TD1309 "LUDI-Play for Children with Disabilities (years 2014-2018)"; the European Project "Changing Families and sustainable societies: Policy contexts and diversity over the life course and across generation (call CP_FP7-SSH-2012.3.2-1; years 2013-2017)”; the Fondazione CRT "GioDi-Gioco per la Disabilità" focused on the supportiveness of environmental factors on play of children with disabilities (Vivomeglio calls 2014 and 2017; years 2015-2016 and 2018-2019).

Karen De Maesschalck is lecturer in higher education in the bachelor primary education at the Artevelde University College, Ghent (BE). Her experience is in the educational settings for primary education as she used to teach for ten years (including teaching children with special needs) and was a school-leader of a (pre)primary school. She also has a master in educational studies with a special interest for learning problems. She is now focused on 'the motivation to learn' and finding inclusive ways of learning, especially in the field of mathematics.

Nan Cannon Jones has a master's degree in Special Education, she worked in various educational settings, as a mainstream infant/junior teacher, as an early-years specialist teacher in a setting for children (0-5) with moderate to severe learning difficulties, and as an advisory teacher for children in mainstream schools with physical and neurological impairments. In mainstream schools she worked with parents in conjunction with educational and medical professionals, to enable the best outcomes for every child, adapting the curriculum to meet individual need whilst supporting the use of specialist equipment to encourage physical access to everyday life. She supported a research project at Hertfordshire University developing the use of KASPAR, a humanoid robot, encouraging social interaction and social communication for children with autism, through collaborative play. She designed an assessment document to fit with the Early Years Foundation Stage and the World Health Organisation International Classification of Functioning, Disability and Health.

Marieke Coussens received a master's degree in occupational therapy at the University of Alberta (Canada) and is working more than 15 years part-time at Artevelde University 
College, Department of Occupational Therapy, Ghent (BE). She combines this job with a Ph.D position at the Faculty of Medicine, Department of Rehabilitation Sciences at Ghent University (BE). She is involved both in teaching as in research. In her research she focuses on participation, of young children with Attention Deficit Hyperactive Disorder (ADHD) and / or Developmental Coordination Disorder (DCD) and/or Autism Spectrum Disorder (ASD). She has a private practice where she mainly supervises and coaches young children and their families. This gives her the possibilities to combine both theory and practice.

Annemie Desoete (Prof. Dr.) is Full Professor at Ghent University and at the Artevelde University College, Ghent (BE). She has extensive experience in research in characteristics of learning disabilities (dyscalculia, dyslexia). In addition she is conducting research on comorbidity (with DCD, ASD), opportunities and propensities, number sense/numeracity, motivation, metacognition/ executive functions, comprehensive reading and spelling, time related problems and fractions, serious games, M-decree. She was promoter or co-promoter of 14 successfully defended Ph.D studies. She has published a wide variety of international journals and international books. She is involved in a number of journals. For more information see: https:// www.ugent.be/pp/ekgp/en/about-us/staff/ads-pagina

Mabel Giraldo is Ph.D and Fellow Researcher at the Department of Human and Social Sciences, University of Bergamo (I). From 2012 to present, she has worked as Teaching and Research Assistant in Didactics and Special Education by the same University for Bachelor Degree in Education Sciences and Master Degree in Pedagogical Sciences. Her main research interests concern: theatre and its use within educational contexts, including youth and children with disabilities; the historical, cultural, social and pedagogical debate on disability (at school and in the society) at Italian and international level; the construct of self-determination and related design and evaluation models to promote and support it for adults and elderly with intellectual disabilities.

Rianne Jansens, MSc. OT completed her training as an occupational therapist in Ghent (BE) in 1987 and the European Master in Science of Occupational Therapy in 2011. She has been working with children and youngsters with disabilities at Koninklijke Kentalis, St. Michielsgestel in the Netherlands till 2000. Since this time she has been working at Zuyd University of Applied Sciences in Heerlen (NL) as lecturer at the School of Occupational Therapy and as researcher at the Research Centre for Assistive Technology in Care. Her work is related to inclusion (at school, in the community) of children and youngster with disabilities and the interventions of occupational therapy or assistive technology to support this. 
Dr Helen Lynch is Senior Lecturer in the Department of Occupational Science and Occupational Therapy, UCC (IE) and a Research Associate of the Institute for Social Sciences in the Twenty First Century. She has been engaged for many years in research programme concerning play environments, and the rights of children to play, in particular play for children with disabilities. She has authored papers and book chapters on these topics. She has been involved in several projects exploring these issues through the European COST Action TD1309 "LUDI-Play for Children with Disabilities" and other grants at home and in Europe. She is a member of the International Play Association and the Children's Rights Alliance (IE), and is a member of Occupational Science and Therapy organisations including ENOTHE and the Society for the Study of Occupation (USA). Dr Lynch practised as an occupational therapist for 20 years with children and young adults, with disabilities in schools, training centres, homes and communities.

Hólmdís Freyja Methúsalemsdóttir, received her BSc. in Occupational Therapy from University of Akureyri (IS) in 2004 and her master in Public Health Science (MPH) from University of Iceland in 2011. Since 2013 she has been an adjunct lecturer at the Faculty of Occupational Therapy at the University of Akureyri, teaching in bachelor's degree programme of Occupational Therapy particularly on the subject of Pediatrics and Fieldwork Practice. In addition to her position at the University of Akureyri, she has been working for 14 years with children and their families who face participation challenges and activity limitations. Her work and research aims to improve their everyday life situations.

Fabio Sacchi, graduated in Pedagogical Sciences, is a Ph.D student (XXXIV cycle) of the Doctoral School in Development of the Person and Labour Market, at the University of Bergamo (I). He has worked for several years on the training of future primary school teachers, creating workshops aimed at developing the acquisition of skills for the inclusion of students with disabilities in Italian school. Currently his research interests consist mainly of assistive technologies for persons with visual disabilities and processes to facilitate the employment of persons with disabilities. Regarding the latter aspect, his research is moving towards the training of the disability manager and case manager professions.

Christina Schulze, Ph.D, completed her training as an occupational therapist at the School of Occupational Therapy in Osnabrück in 2001. Since 2003 she has been working at the Centre for Children with Sensory and Physical Impairment (ZKSK) in Solothurn (CH) and completed her doctorate at the Karolinska Institutet Stockholm in Sweden in 2015. She has been working at the School of Health Profession at the ZHAW University of Applied Sciences (CH) since 2008. In this function, she is active in research projects such as overcoming the barriers of outdoor play, supporting children from a migrant background and she is teaching in bachelors and master's 
degree programmes, particularly on the subject of assessments, paediatrics and research methods.

Anna Trosheva-Asenova, Ph.D, is Associate Professor in SDepartment of Special Education and Speech Therapy at Sofia University "St. Kliment Ohridski", Sofia (BG). She began her professional career as a speech therapist, then worked and defended her dissertation on the topic of Developing graphical handwriting skills in children with cerebral palsy. She has co-authored the books "How to Help a Child with Learning Disabilities" (2006) and "Including a hearing impaired child in an educational setting” (2014). As a scientist and lecturer, her interests lie within the field of therapeutic interventions in children with autism, hearing impairment, communicative disorders, childhood cerebral palsy. Her views on the free play of children with disabilities are found in the minds of LUDI members. Her experience on the subject is reflected in her book, The Play and Children with SEN (2018).

Mira Tzvetkova-Arsova is full-time Professor at Dsc. Department of Special Education and Speech Therapy, Sofia University "Saint Kliment Ohridski" (BG). She is lecturer in Special Education - Education of Visually Impaired, Education of multidisabled students etc. She is working for Sofia University since 1992. Her specializations are: 1) Paimio-Finland (Work with children, youths and adults with diverse disabilities, incl. multiply disabled); 2) The Educational Leadership Program of Perkins school for the Blind, Watertown, (MA, USA); 3) Fulbright scholarship in Boston college(USA) on Education of Deafblind. She worked on many national projects coordinated by the Ministry of Education, and on numerous international projects under TEMPUS, Erasmus, Erasmus+, Pharos and other programs. She published 12 books, textbooks, handbooks/manuals in Bulgarian language; over 90 articles in Bulgarian scientific Journals and conference proceedings; over 40 publications in English language.

Ursula Winklhofer, holder of an M.A. in Communication Studies, Education and Psychology and a graduate diploma in Social Education, is a senior researcher at the German Youth Institute in Munich (Children and Childcare Unit). She was responsible for the project "Scientific Support of the Implementation of the National Action Plan for a Germany Fit for Children 2005-2010”. From 2011 to 2013 she has been in charge of the EU-funded project "Re-play-Raising awareness of the value of play". From 2014 to 2018, she was engaged in the COST Action "LUDI-Play for Children with Disabilities" as a member of the Management Committee. Her research interests are in the area of childhood research, children's living conditions and children's rights. Since 2012 she is affiliated to a group of experts concerned with children's rights in the context of educational relations, and is one of the editors of the "Reckahner Reflections on the Ethics of Educational Relations”. 